\title{
Investigação de Técnicas Fotônicas de Chaveamento Aplicadas em Arquiteturas
}

\section{Paralelas}

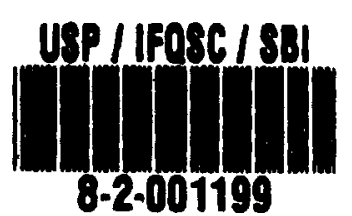

João Eduardo Machado Perea Martins

\begin{abstract}
Tese apresentada ao Instituto de Física de São Carlos, da Universidade de São Paulo, para obtenção do título de Doutor em

Ciências: Física Aplicada
\end{abstract}

Orientador: Prof. Dr. Álvaro Garcia Neto

São Carlos/SP

1998

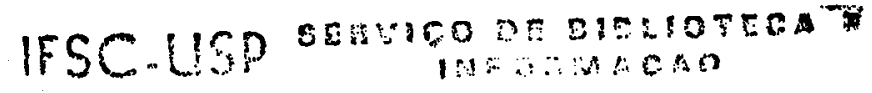


Martins, João Eduardo Machado Perea

Investigação de Técnicas Fotônicas de Chaveamento Aplicadas em Arquiteturas Paralelas / João Eduardo Machado Perea Martins - São Carlos - SP, 1998.

$214 \mathrm{p}$.

Tese (Doutorado) - Instituto de Física de São Carlos, 1998.

Orientador: Prof. Dr. Álvaro Garcia Neto

1. Arquiteturas Paralelas de Computadores 2. Redes Ópticas de Interconexão 3. Fotônica 
MEMBROS DA COMISSÃO JULGADORA DA TESE DE DOUTORADO DE JOÃO EDUARDO MACHADO PEREA MARTINS APRESENTADA AO INSTITUTO DE FÍSICA DE SÃO CARLOS, DA UNIVERSIDADE DE SÃO PAULO, EM 20 DE MARÇO DE 1998.

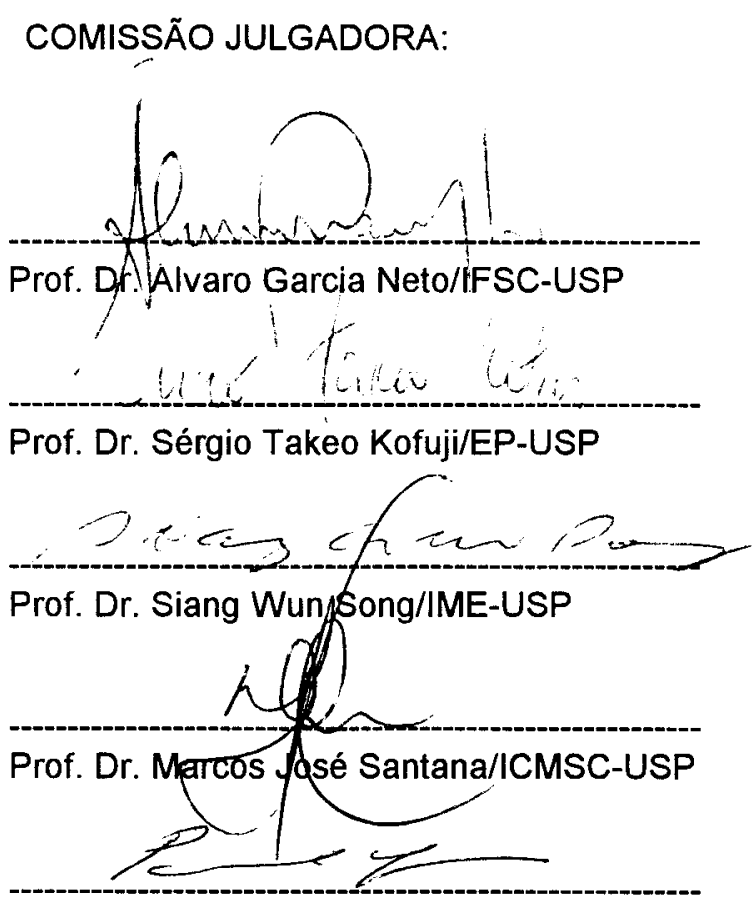

Prof. Dr. Paulo Lício de Geus/UNICAMP 


\section{Agradecimentos}

Ao meu orientador, Prof. Dr. Álvaro Garcia Neto, pela orientação, por ter confiado no meu trabalho e pelo fato de ter contribuido significativamente para o meu desenvolvimento profissional.

Aos meus pais, José Perea Martins e Ercilia Machado Perea Martins, pelo incentivo ao desenvolvimento do meu trabalho.

Ao amigo Marcos Antônio Cavenaghi, pela colaboração e pelas importantes discussões a respeito de arquiteturas a fluxo de dados.

À amiga Roberta Spolon Ulson, pela amizade e pela colaboração no desenvolvimento desse trabalho.

Aos amigos João Angelo Martini e Patrícia Magna, pelo apoio que me foi dado.

À Wladerez Aparecida G. Caiado, do setor de pós-graduação do IFSC-USP, pelo profissionalismo e pela constante atenção dispensada.

À secretária Leonilda Lopes, do Departamento de Computação da UNESP-Bauru, e à secretária Cláudia Tofaneli, do IFSC-USP, pela atenção que sempre me dispensaram. 


\section{Sumário}

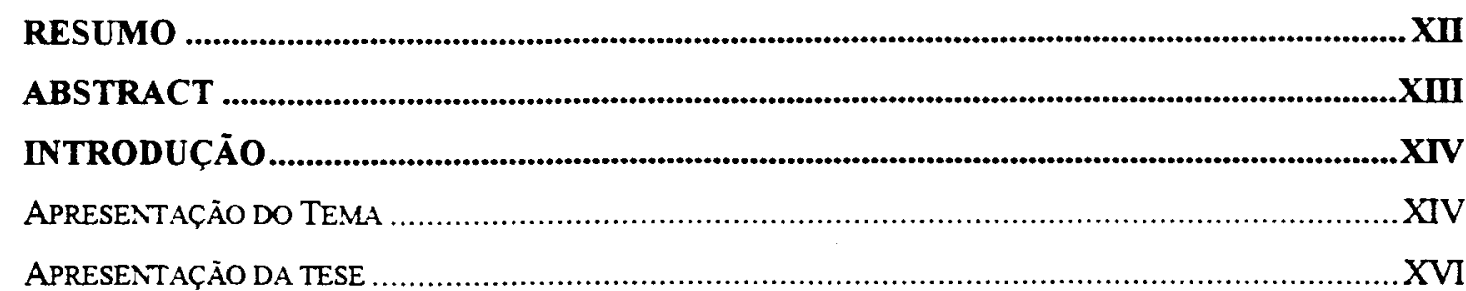

CAPÍTULO 1

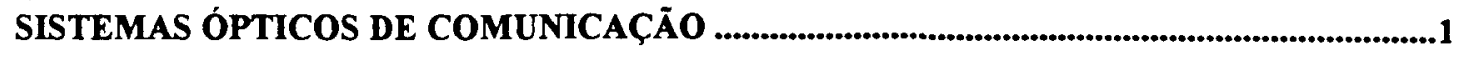

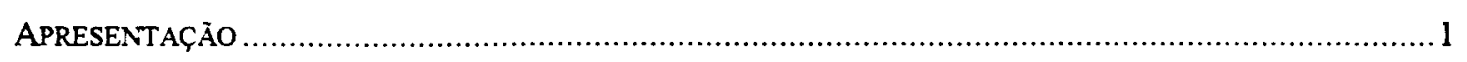

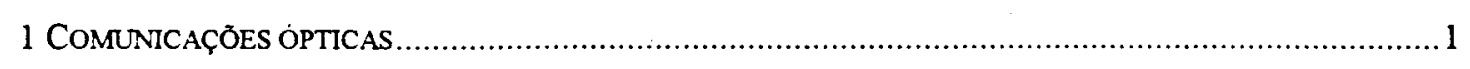

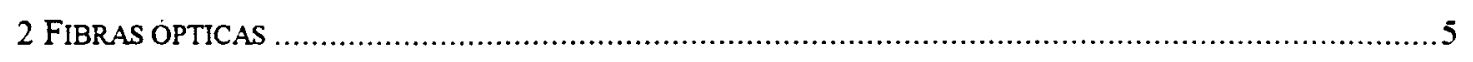

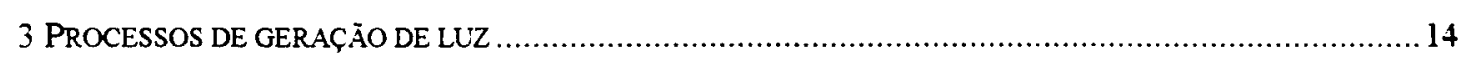

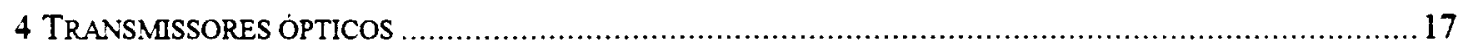

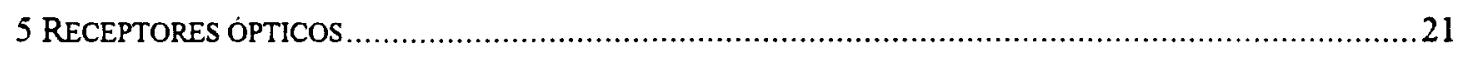

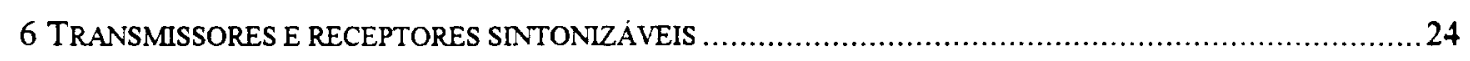

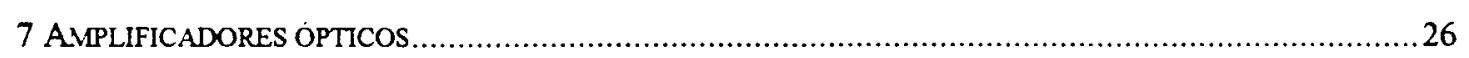

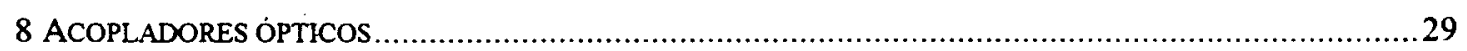

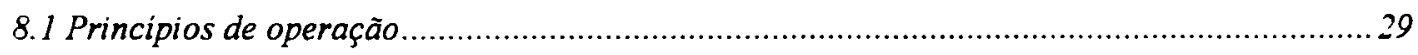

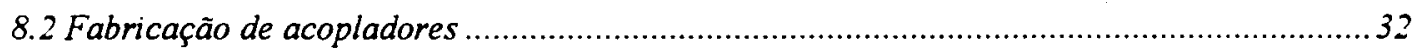

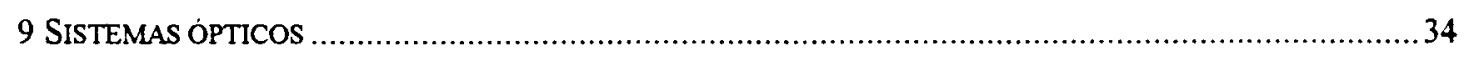

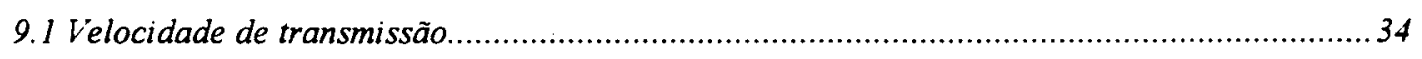

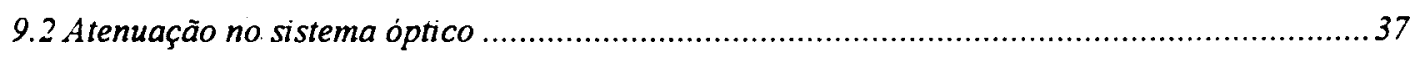

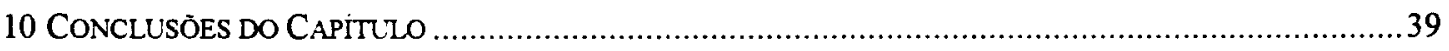

CAPÍTULO 2

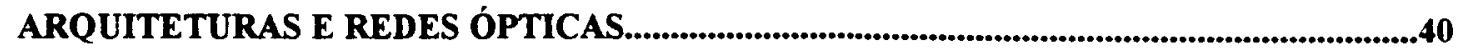

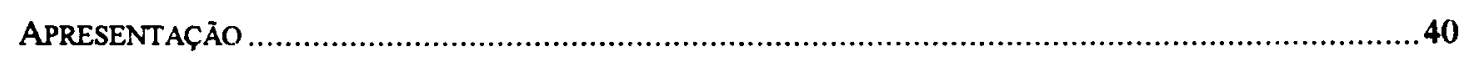

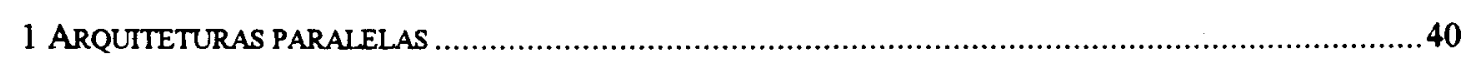

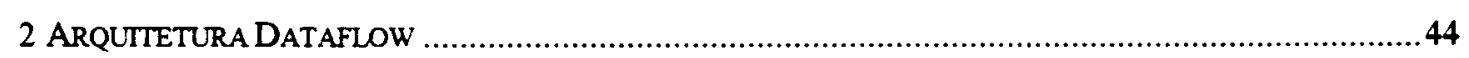

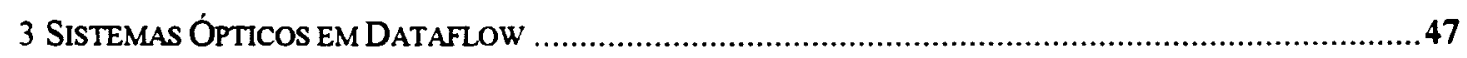

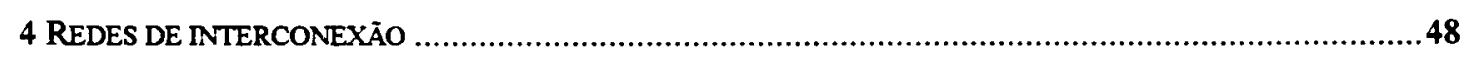

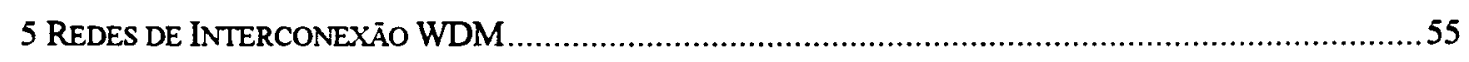

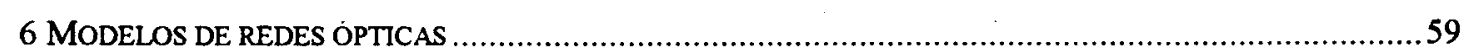

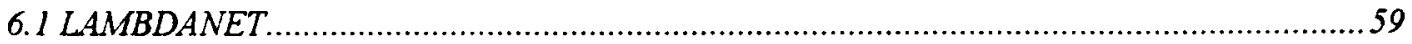

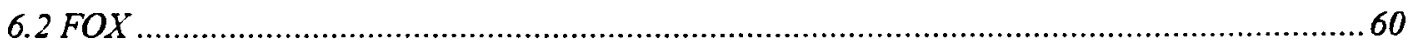

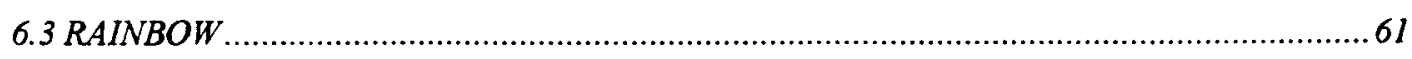




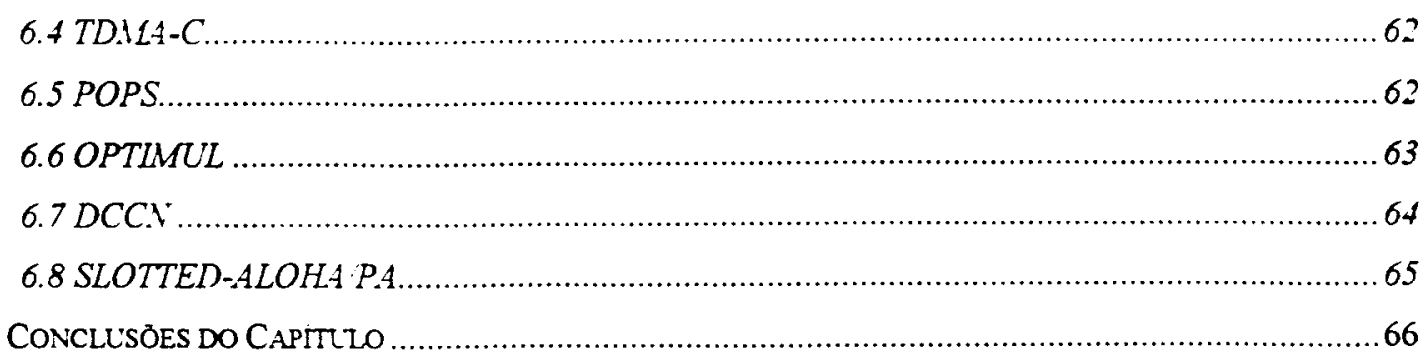

\section{CAPÍTULO 3}

SIMULAÇÃO E DESEMPENHO DE REDES.............................................................................67

1 SLMULAÇÃO

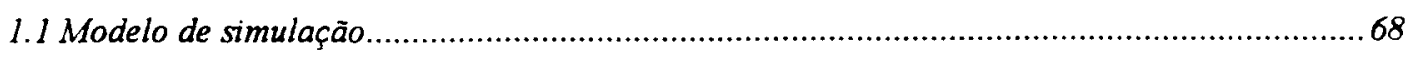

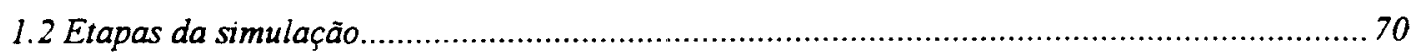

1.2.1 A análise e modelagem do sistema real ...................................................................... 71

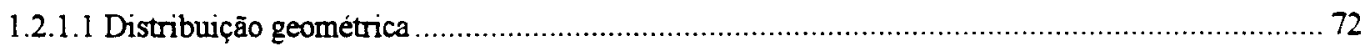

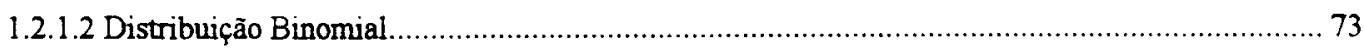

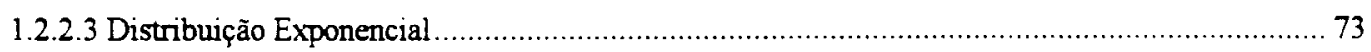

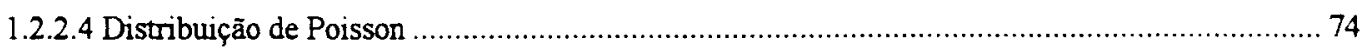

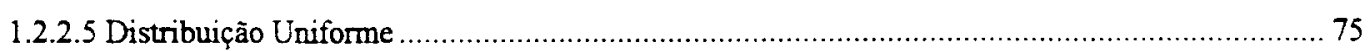

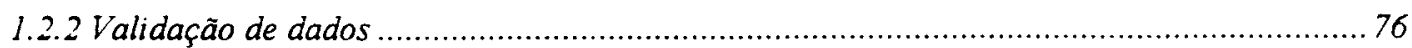

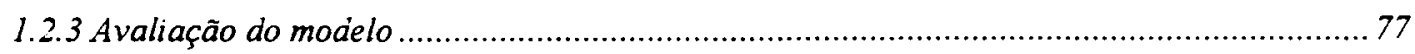

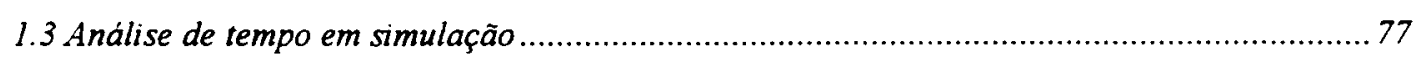

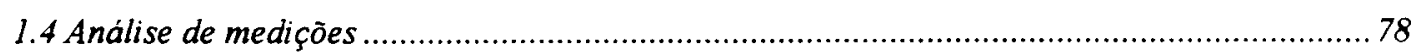

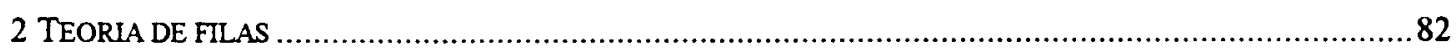

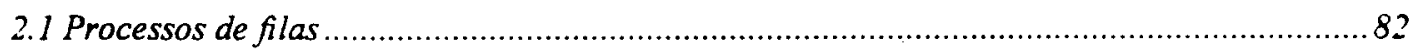

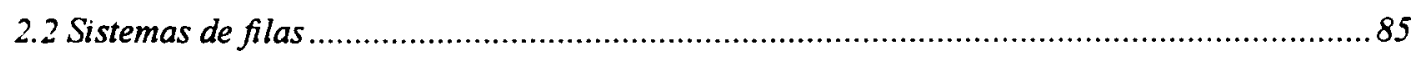

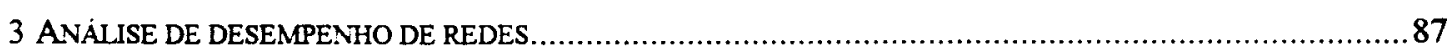

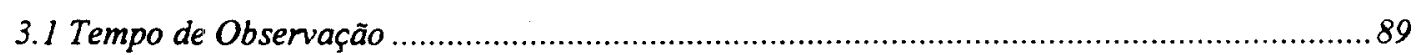

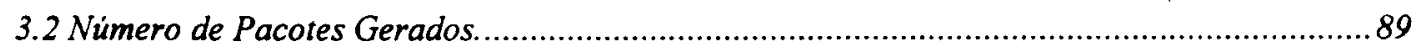

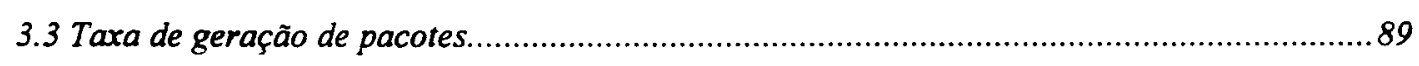

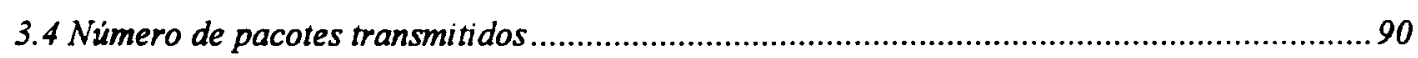

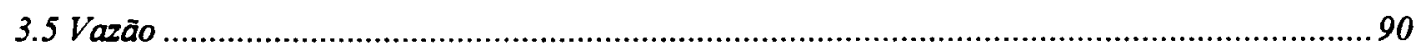

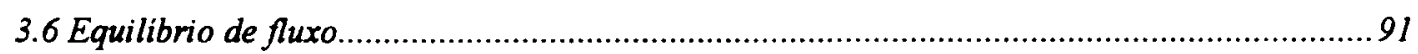

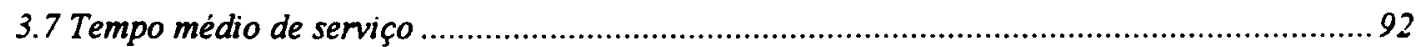

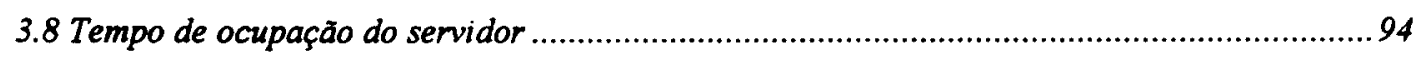

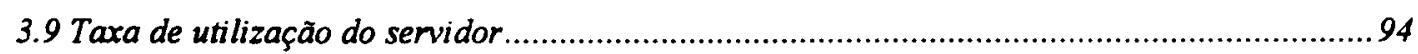

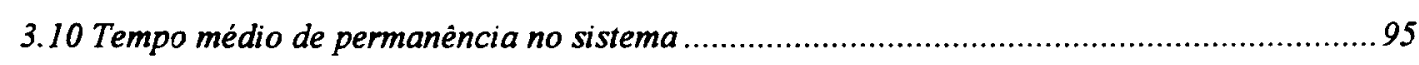

3.11 Tempo médio de permanência em fila ................................................................................96

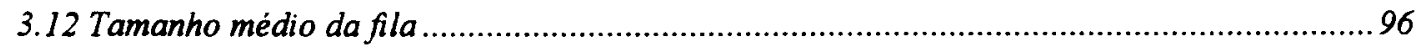

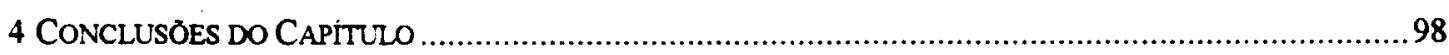




\section{CAPÍTULO 4}

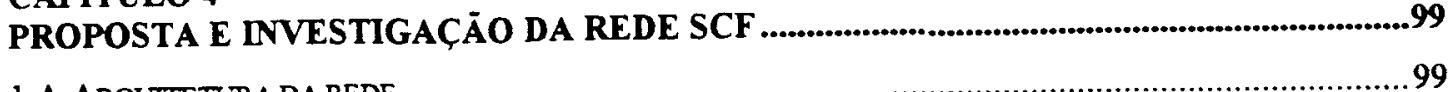

1 A ARQUTTETURA DA REDE

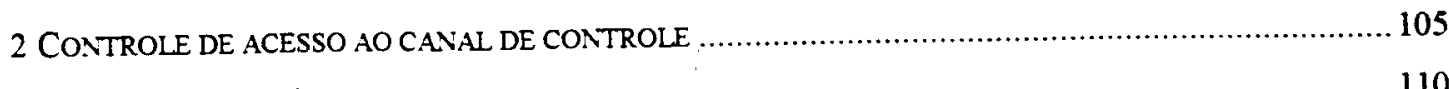

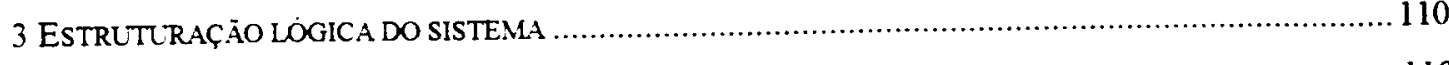

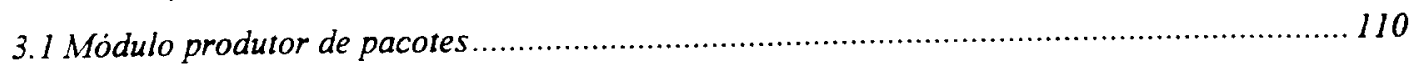

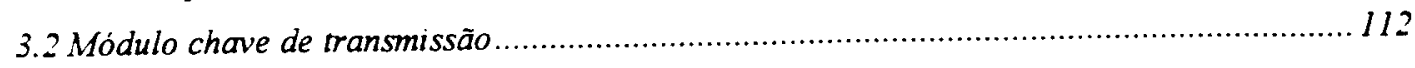

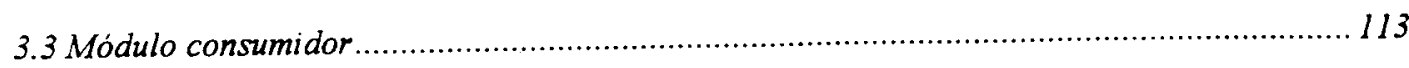

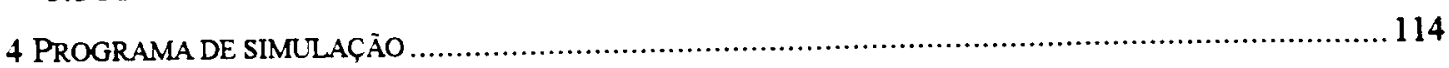

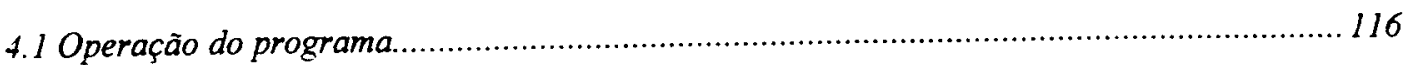

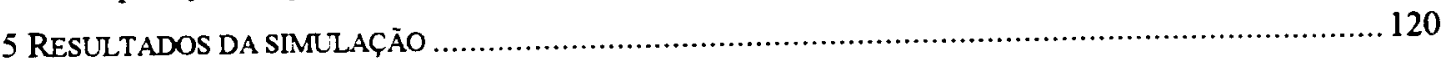

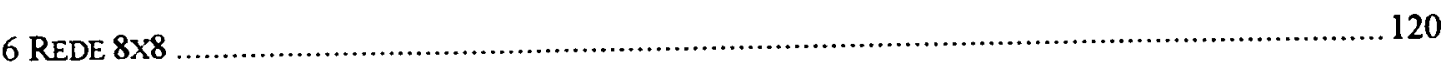

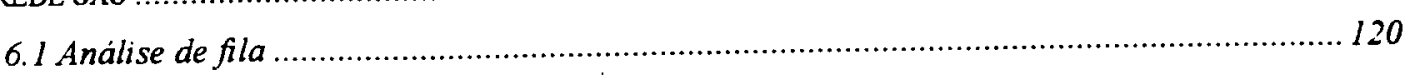

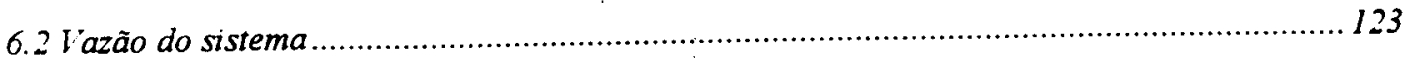

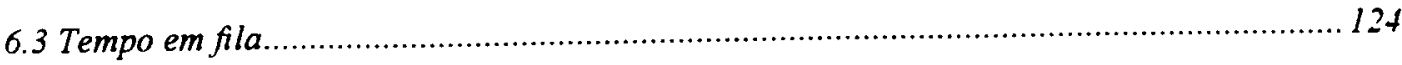

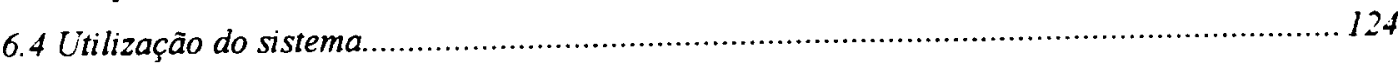

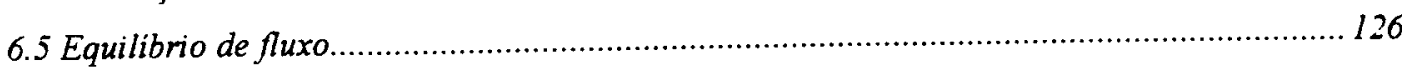

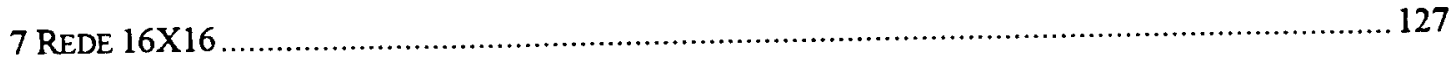

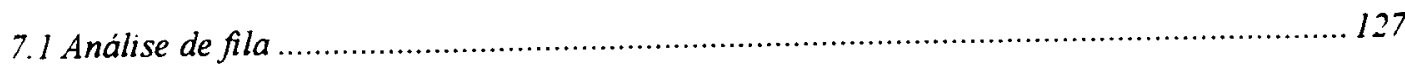

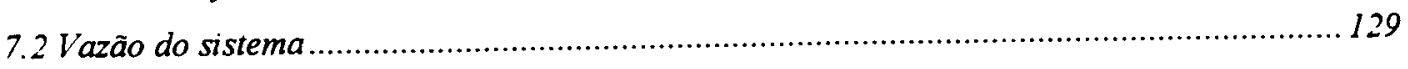

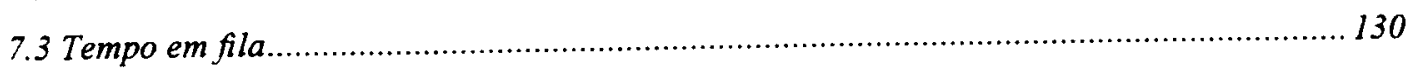

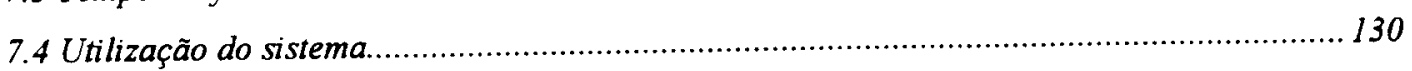

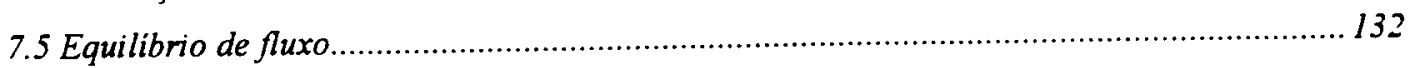

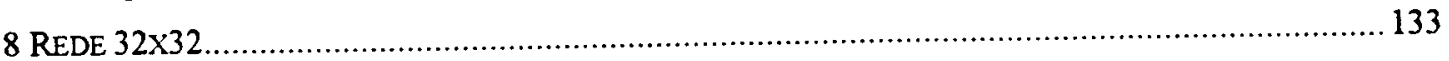

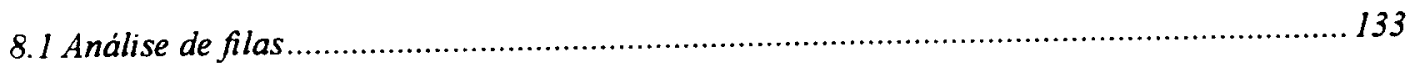

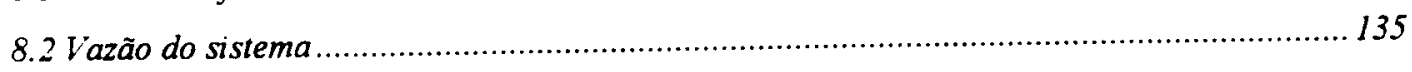

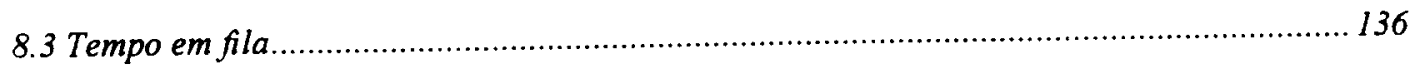

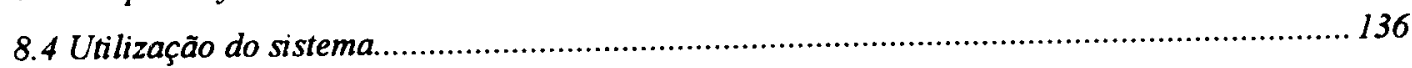

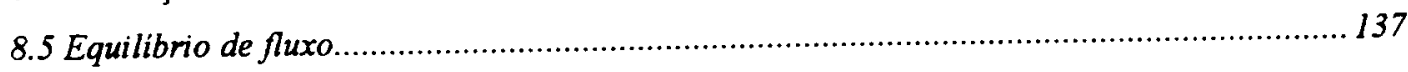

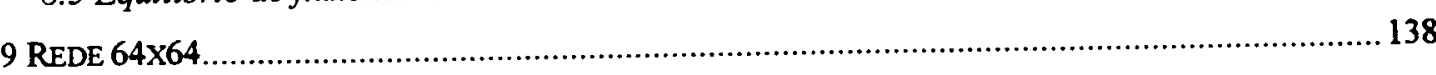

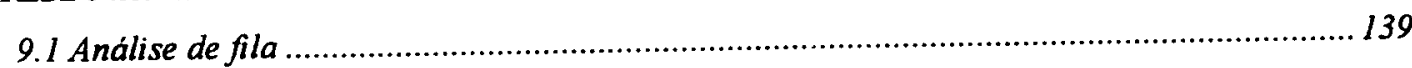

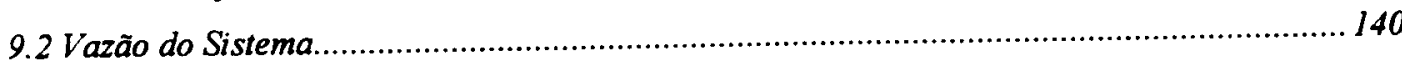

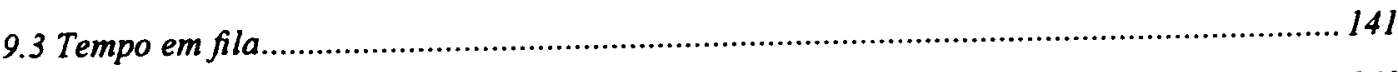

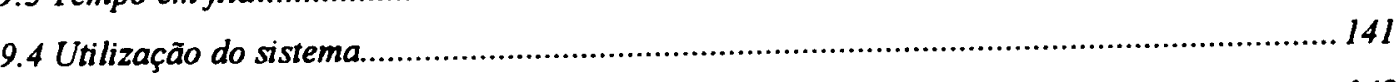

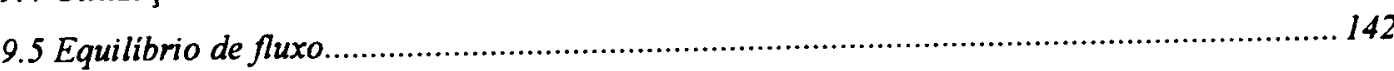

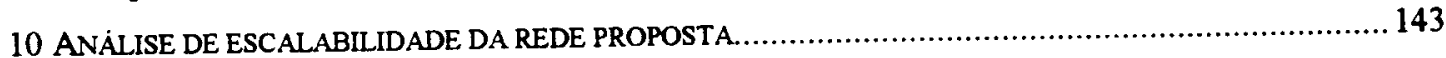

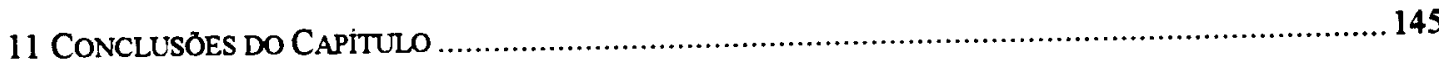




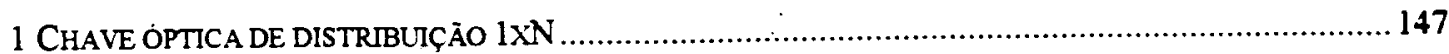

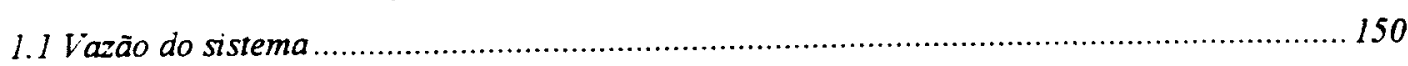

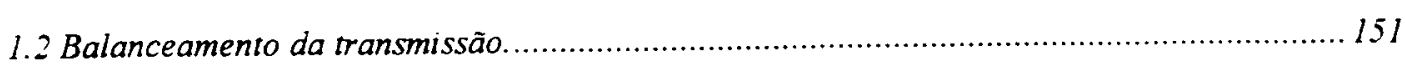

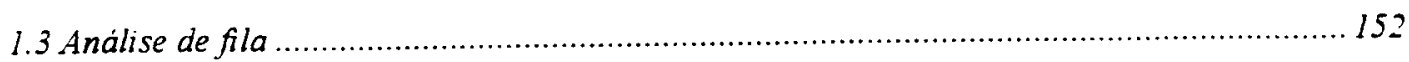

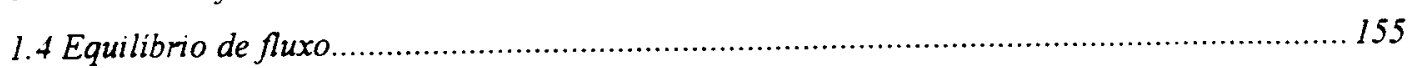

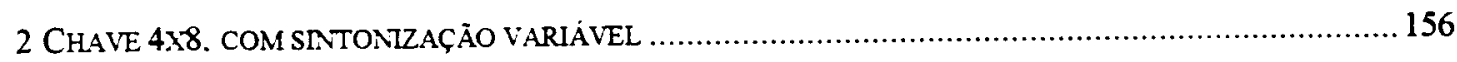

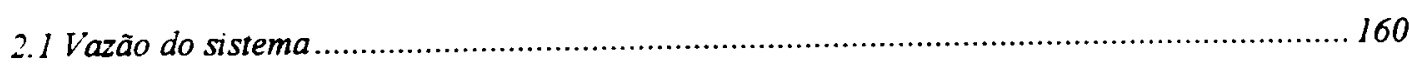

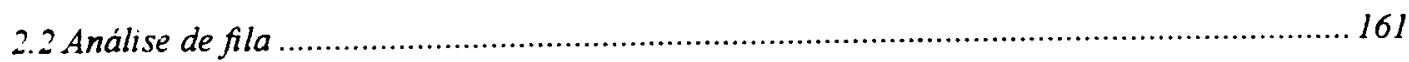

2.3 Balanceamento de transmissão .......................................................................... 163

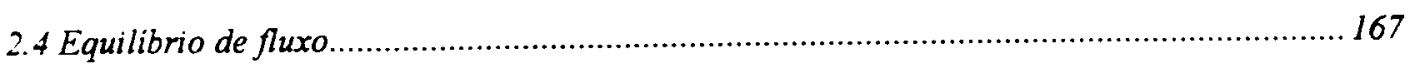

3 CHAVE ÓPTICA DE DISTRIBUIÇÃo 8X8. COM SINTONZZAÇÃO FLXA ....................................... 167

3.1 Vazão do sistema ........................................................................................ 170

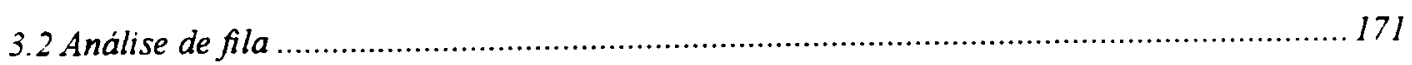

3.3 Balanceamento da Transmissão......................................................................... 173

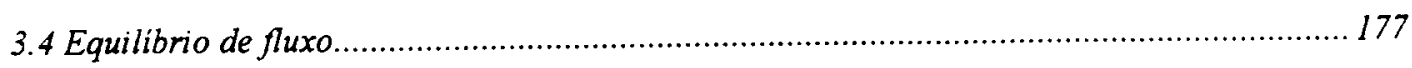

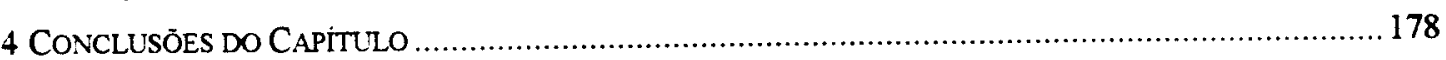

CAPÍTULO 6

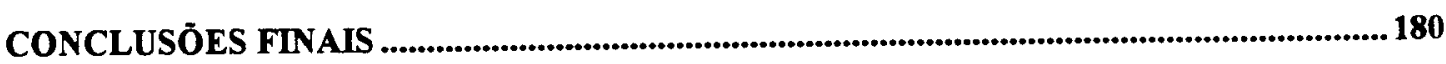

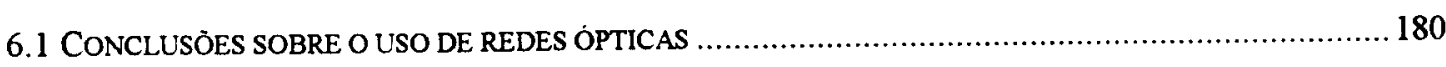

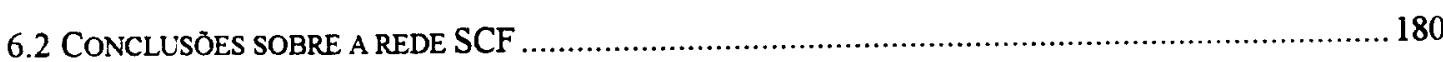

6.3 CONCLUSÕES SOBRE A CHAVE OPTICA DE DISTRIBUIÇĀO PARA DATAFLOW ................................ 181

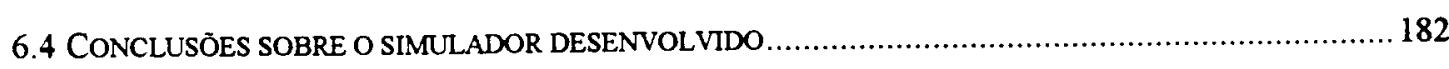

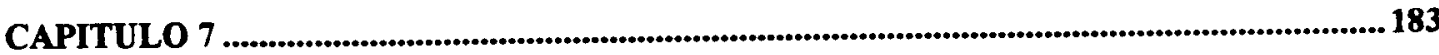

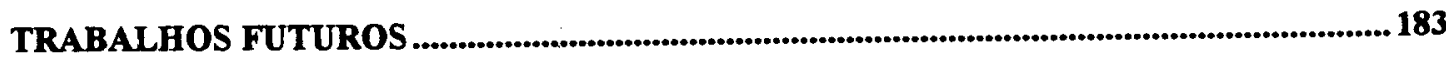

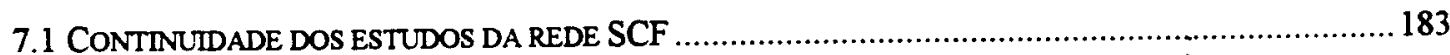

7.1.1 Análise da rede SCF com diferentes modelos de geração de pacotes .............................. 183

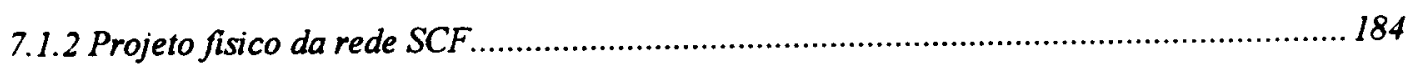

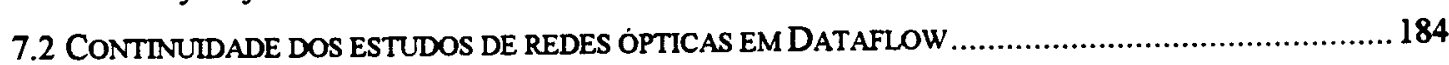

7.2.1 Incorporação das chaves ópticas de distribuição aos sistemas SAW e SEED .................... 184

7.2.2 Desenvolvimento de uma chave óptica de coleta para a arquitetura Dataflow.................. 185

7.2.3 Incorporação da chave óptica de coleta aos sistemas SAW e SEED................................ 185

7.2.4 Projeto fisico das chaves ópticas para Dataflow........................................................... 185

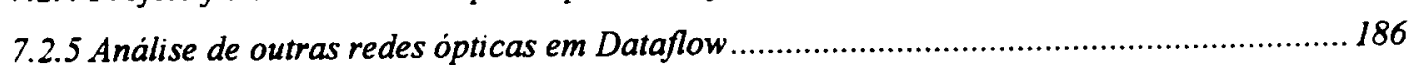


7.3 SIMULAÇÃO DE REDES ÓPTICAS

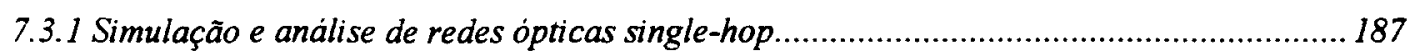

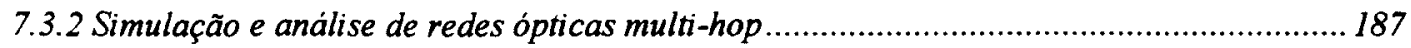

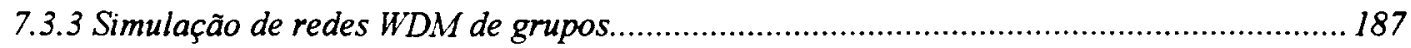

BIBLIOGRAFIA 


\section{Lista de Figuras}

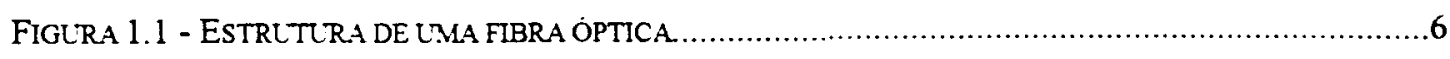

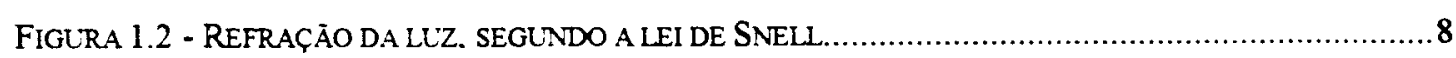

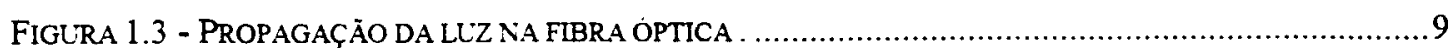

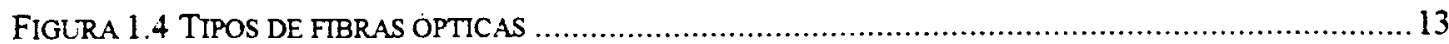

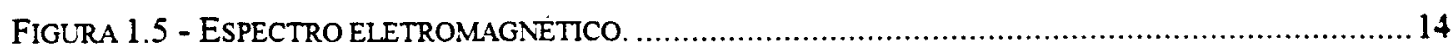

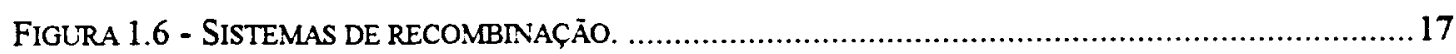

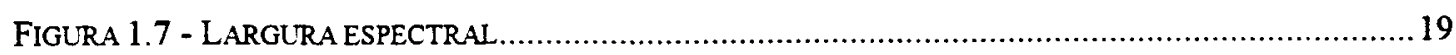

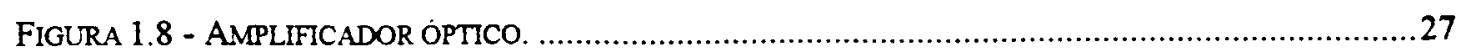

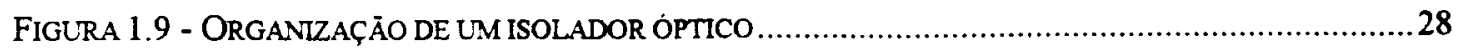

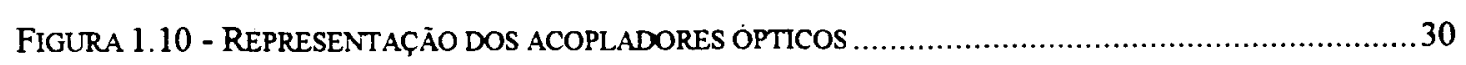

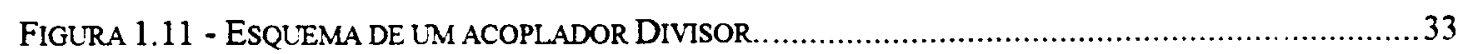

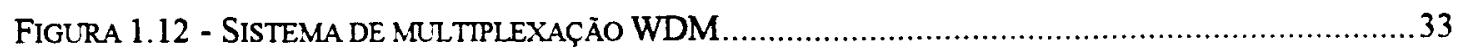

FIGLRA 1.13 - SISTEMA DE MLLTIPLEXAÇÃO ÓPTICA (WDM) DE 2 CANAIS ........................................ 34

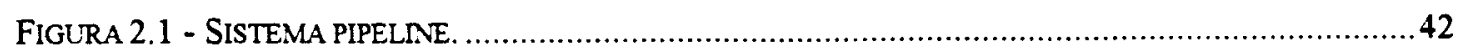

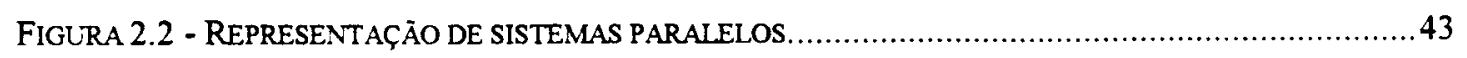

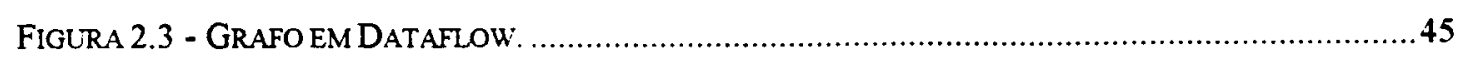

FIGURA 2.4 - ORGANTZAÇÃo BASICA DA ARQUTIETURA MANCHESTER DATAFLOW MACHINE................46

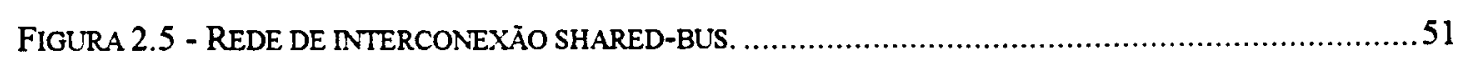

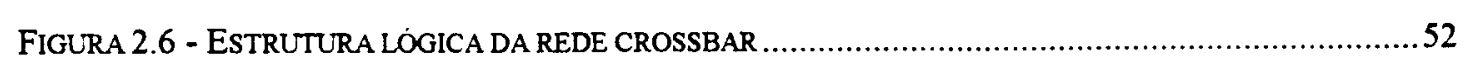

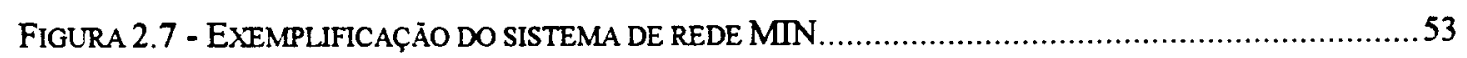

FIGURA 2.8 - UM SISTEMA DE MUTIPLEXAÇÃO ÓPTICA WDM SINGLE-HOP $3 \times 3$.................................57

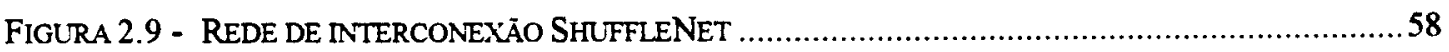

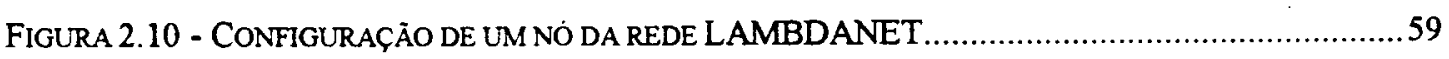

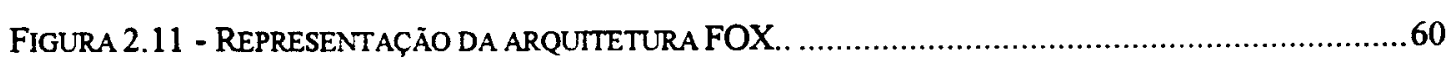

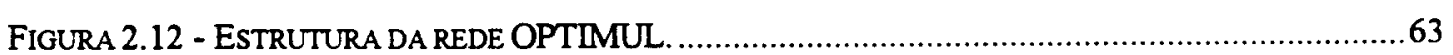

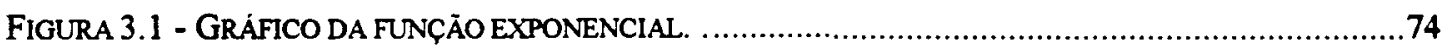

FIGURA 3.2 - GRÁFICO DE REPRESENTAÇĀO DA DISTRIBUÇÇÃO UNIFORME.........................................76

FIGURA 3.3 - REPRESENTAÇÃO DE UM SISTEMA COM DISTRIBUIÇÃO "NORMAL" .................................80

FIGURA 3.4 - DISTRIBUIÇÃo DE PROBABILIDADES DAS AMOSTRAS MEDIDAS EM UM SISTEMA .................80

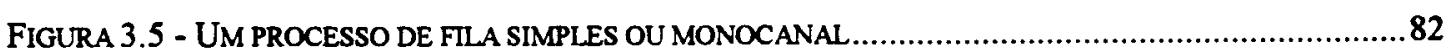

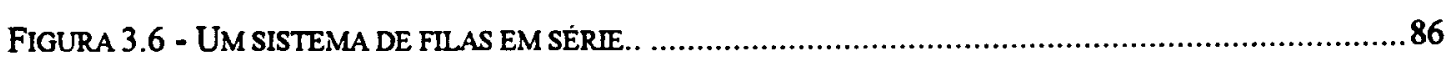

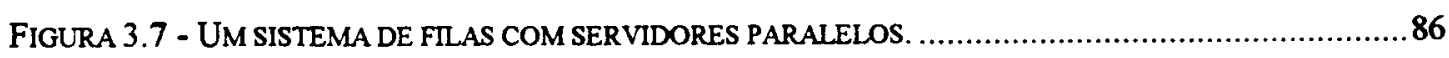

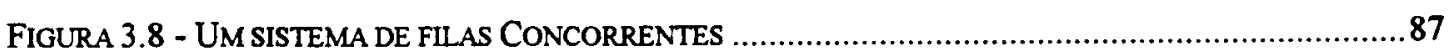

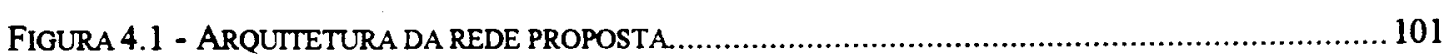

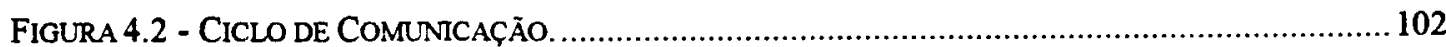

FIGURA 4.3 - ALGORTMO DE GERENCIAMENTO DO CICLO DE CONTROLE........................................ 103 


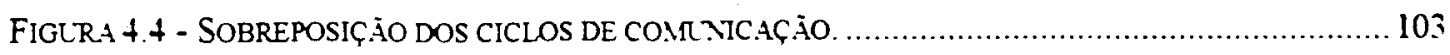

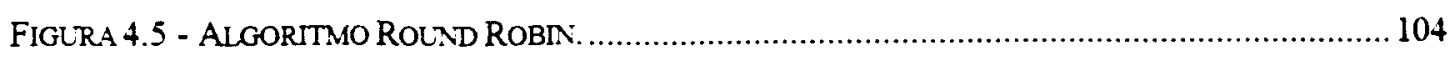

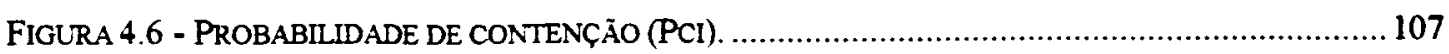

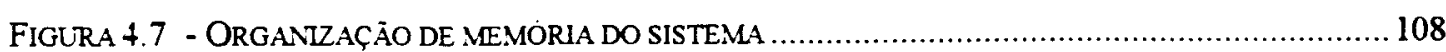

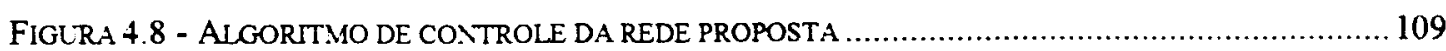

FIGLRA 4.9 - ESTRLTLRA DO MODLZO PRODLTOR DE PACOTES.............................................. 111

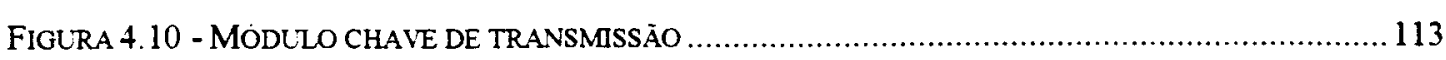

FIGURA 4.11 - ESTRUTIRA LOGICA DO SISTEMA PRODUTOR-CHAVE-CONSUMIDO ...............................115

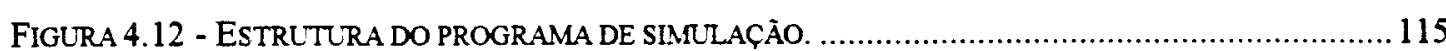

FIGLRA 4.13 - VALORES DE LQE LA PARA REDE 8X8, COM PP DE 25\% ....................................... 121

FIGURA 4.14 - VARIAÇÃO DE LA EM UMA REDE 8X8, EM FUNÇÃO DE PP............................................. 122

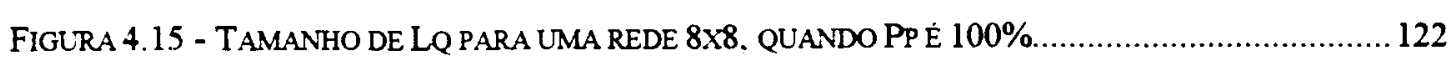

FIGLRA 4.16 - VAZÃo DO SISTEMA (X) PARA UMA REDE 8X8. EM FUNÇÃo DE PP. ............................... 123

FIGURA 4.17 - TEMPO MÉdIO EM FILA PARA UMA REDE 8X8, EM FUNÇÃO DA VARIAÇÃO DE PP.............. 124

Figlra 4.18 - UtillzaÇÃo dos CANAIS DA REDE 8X8, QUANDO A PP É DE 25\%............................... 125

FIGLRA 4.19 - EQLILIBRIO DE FLLXO DO SISTEMA (FB) COM PP DE 25\% E 100\%............................ 126

FIGURA 4.20 - VALORES DE LQE LA PARA OS N NÓS DE UMA REDE 16×16, COM PP DE 25\% ............... 127

FIGURA 4.21 - VALORES DE LA EM FUNÇÃo DE PP. PARA UMA REDE 16X16 .................................. 127

FIGURA 4.22 - TAMANHO MÉDIO DE FILA DOS N NÓS DE REDE 16X16. QUANDO PPÉ100\% …............. 129

FIGURA 4.24 - TEMPO MÉDIO EM FILA NA REDE 16X16, EM FUNÇÃO DE PP........................................ 131

FIGURA 4.26 - EQUILIBRIO DE FLUXO DO SISTEMA (FB) COM PP DE 25\% E 100\%.............................. 132

FIGURA 4.27 - VALORES DE LQ E LA PARA OS N NÓS DE UMA REDE 32X32, COM PP DE 25\% ............... 133

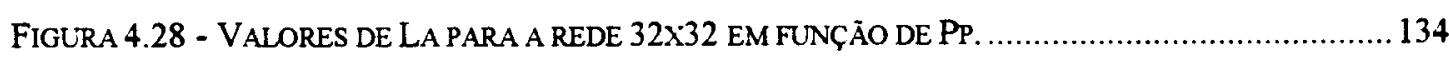

FIGURA 4.29 - VALOR DE LQ PARA OS N NÓS DA REDE 32X32, QUANDO PPÉ 100\% …......................135

FIGURA 4.31 - TEMPO EM FILA ANTES DA TRANSMISSÃo, EM UMA REDE 32X32, EM FUNÇÃO DOS

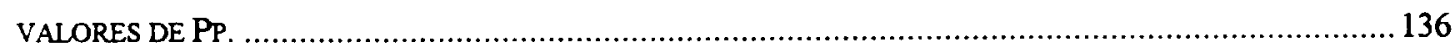

FIGURA 4.32 - UTILIZAÇÃo MÉDIA DE CADA UM DOS N CANAIS WDM DE UMA REDE 32X32, QUANDO O

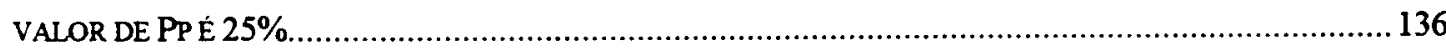

FIGURA 4.33 - EQUILIBRIO DE FLUXO DO SISTEMA (FB) EM UMA REDE 32X32 ............................... 138

FIGURA 4.34 - VALORES DE LQ E LA PARA CADA NÓ DE UMA REDE 64X64, COM PP DE 25\% ............... 138

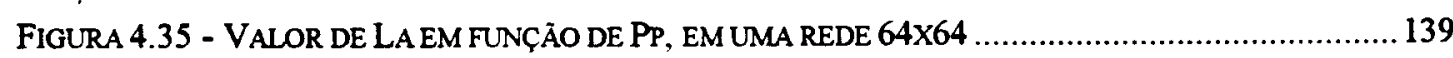

FIGURA 4.36 - VALOR DE LQ PARA CADA UM DOS N NOS DA REDE 64X64, COM DE 100\%................. 140

FIGURA 4.37 - VAZÃO DO SISTEMA EM UMA REDE 64X64, EM FUNÇÃO DO VALOR DE PP. ..................... 140

FIGURA 4.38 - TEMPO MÉDIO EM FLLA, EM FUNÇÃO DA VARIAÇÃO DO VALOR DE PP............................ 141

FIGURA 4.39 - VALORES DE FB, COM PP DE 25\% E 100\%, EM UMA REDE 32X32 ........................... 142

FIGURA 4.40 - TAMANHO MÉdIO DA FILA (LQ) EM FUNÇÃo DO TAMANHO DA REDE NXN, QUANDO O

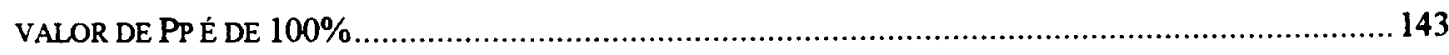

FIGURA 4.41 - MAIOR VALOR ABSOLUTO DE FILA (LA) EM FUNÇÃO DA VARIAÇÃO DO TAMANHO DA REDE,

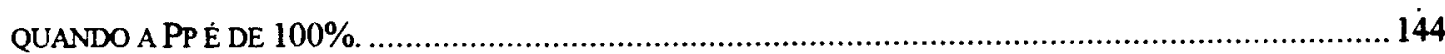


FIGLRA 4.42 - VAZİO DO SISTEMA (X) EM FTXÇÃO DA VARIAÇÃO DO TAMANHO DA REDE NXN. QLANDO

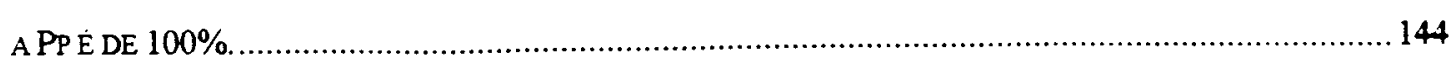

FIGLRA 5.1 - MODELO DO SISTEMA DATAFLOW COM UMA CHAVE OPTICA DE DISTRRUIÇĀO ….............148

FIGLRA 5.2 - REPRESE.NTAÇÃO DO PROCESSO DE COMUNCAÇÃO .............................................. 149

FIGLRA 5.3 - NUMERO DE PACOTES GERADOS (R) E NÚMERO DE PACOTES TRANSMITIDOS (C) ............ 150

FIGLRA 5.4 - NUMERO DE FICHAS (NF) QUE AS UNIDADES-PROCESSADORAS 1 E 2 RECEBERAM .......... 151

FIGLRA 5.5 - TAMANHO MÉDIO DA FILA DE FICHAS (LQ). EM FUNÇÃO DA VARIAÇÃO DA AR.................. 153

FIGLRA 5.6 - MAIOR VALOR ABSOLUTO DA FILA DE FICHAS (LA), EM FUNÇÃO DA AR …...................... 154

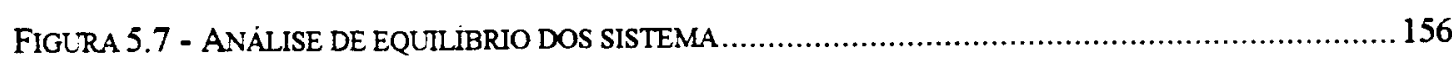

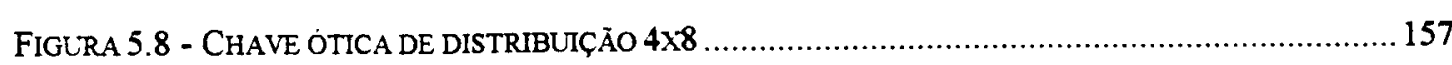

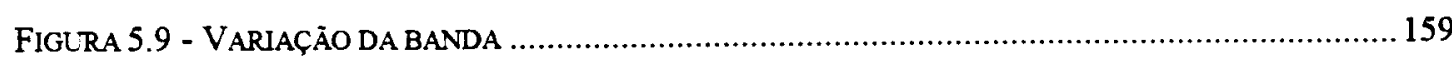

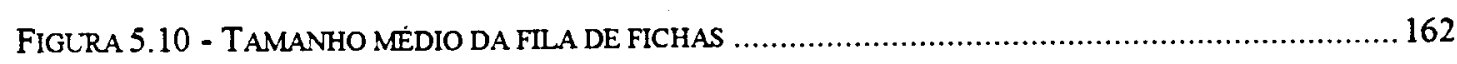

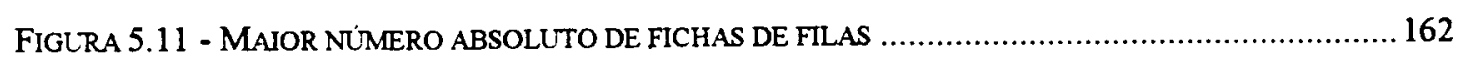

FIGLRA 5.12 - NUMMERO DE FICHAS PROCESSADAS (NF) POR UNDADE-PROCESSADORA (UP), COM UM

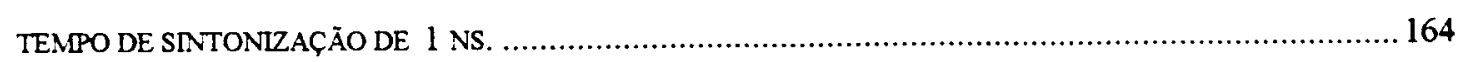

FIGLRA 5.13 - NÚMERO DE FICHAS PROCESSADAS (NF) POR UNDADE-PROCESSADORA (UP). COM UM

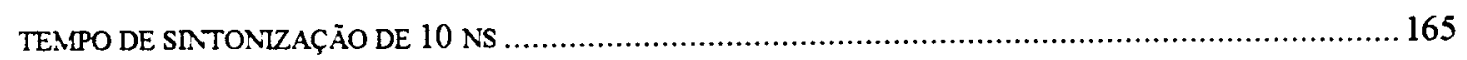

FIGLRA 5.14 - NÚMERO DE FICHAS PROCESSADAS (NF) POR UNIDADE-PROCESSADORA (UP), COM UM

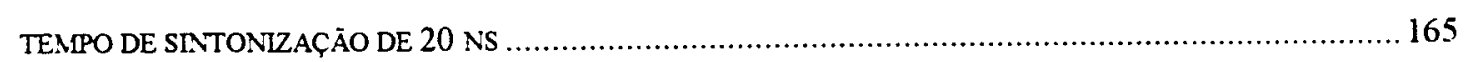

FIGLRA 5.15 - NÚMERO DE FICHAS PROCESSADAS (NF) POR UNIDADE-PROCESSADORA (UP). COM UM TEMPO DE SINTONZZAÇĀO DE 50 NS.

165

FIGLRA 5.16 - NÚMERO DE FICHAS PROCESSADAS (NF) POR UNIDADE-PROCESSADORA (UP), COM UM

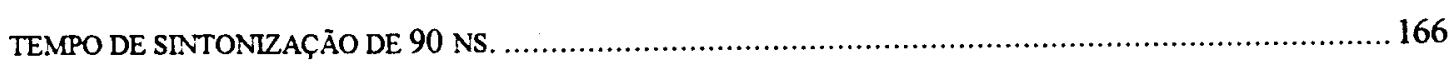
FIGLRA 5.17 - NÚMERO DE FICHAS PROCESSADAS (NF) POR UNIDADE-PROCESSADORA (UP), COM UM TEMPO DE SINTONIZAÇÃO DE 95 NS. .166 FIGURA 5.18 - NÚMERO DE FICHAS PROCESSADAS (NF) POR UNIDADE-PROCESSADORA (UP), COM UM

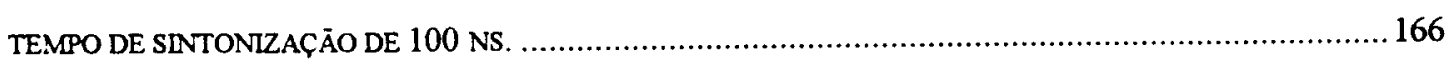

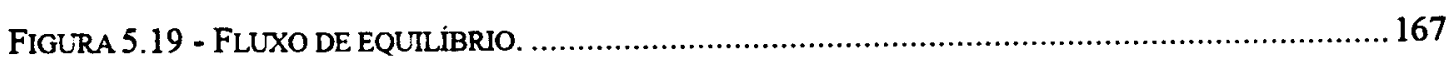

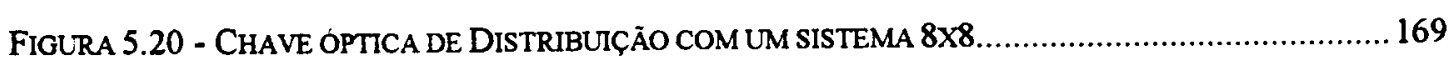

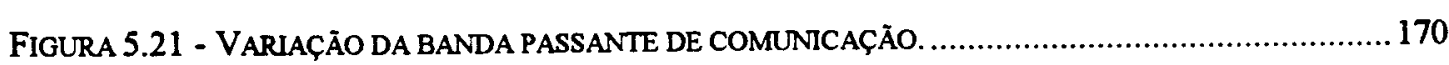

FIGURA 5.22 - TAMANHO MEDIO DA FILA DE FICHAS (LQ) EM FUNÇÃO DE AR. .................................. 172

FIGURA 5.23 - MAIOR VALOR ABSOLUTO DO TAMANHO DE FILA (LA) EM FUNÇÃO DE AR.....................172

FIGURA 5.24 - NÚMERO DE FICHAS RECEBIDAS (NF) POR UNDDADE-PROCESSADORA (UP), COM UMA AR DE $5.3 \mathrm{~GB} / \mathrm{s}$

FIGURA 5.25 - NÜMERO DE FICHAS RECEBIDAS (NF) POR UNIDADE-PROCESSADORA (UP), COM UMA AR

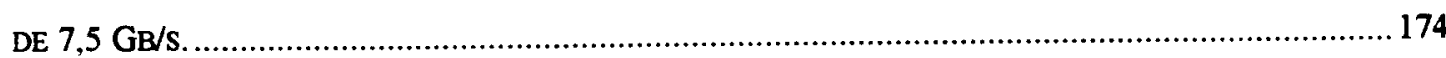

FIGURA 5.26 - NÚMERO DE FICHAS RECEBIDAS (NF) POR UNDDADE-PROCESSADORA (UP), COM UMA AR DE $8,0 \mathrm{~GB} / \mathrm{s}$. 
FIGLRA 5.27 - NLMERO DE FICH.AS RECEBIDAS (NF) POR UNIDADE-PROCESSADORA (UP). COM LMA AR DE $10.0 \mathrm{~GB} / \mathrm{s}$.

FIGURA 5.28 - NÚMERO DE FICHAS RECEBIDAS (NF) POR UNDADE-PROCESSADORA (UP), COM UMA AR DE $10.66 \mathrm{~GB} / \mathrm{s}$.

175

FIGLRA 5.29 - DIFERENÇA ENTRE O NUMMERO DE FICHAS RECEBIDAS ............................................. 176

FIGLRA 5.30 - VARIAÇÃo da VAZÃo do SISTEMA (X) 


\section{Lista de Tabelas}

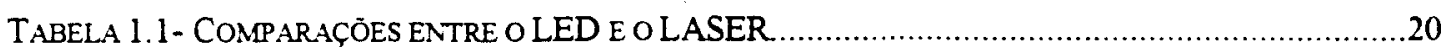

TABELA 1.2 - TERMINOLOGIA WDM EM RELAÇÃO AO ESPAÇAMENTO DO C.ANAL …….......................... 31

TABELA 2.1 - CARACTERISTICAS IDEAIS DE UMA REDE DE INTERCONEXÃO ........................................49

TABELA 4.1 - VARIAÇÃO DE LQ EM FUNÇÃO DE PP. EM UMA REDE 8X8 .......................................... 121

TABELA 4.2 - VALORES MĖDIOS DE UI E UW EM FUNÇÄO DE PP........................................................ 125

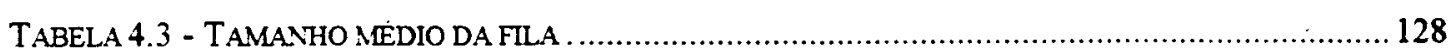

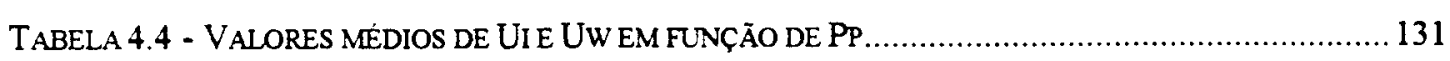

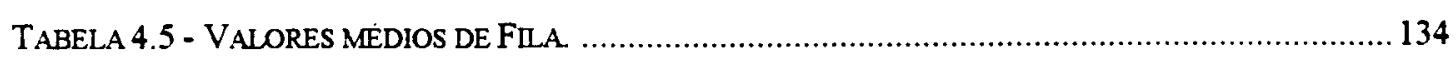

TABELA 4.6 - VALORES MĖDIOS DE UI E UW EM FUNÇÃO DE PP........................................................ 137

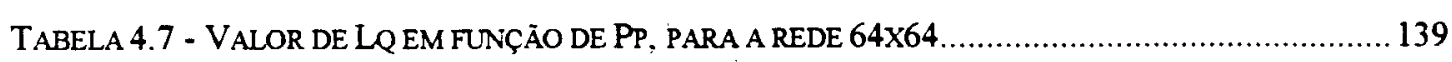

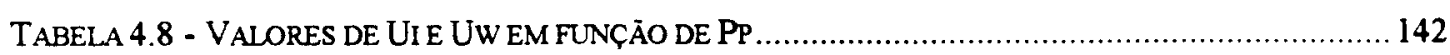

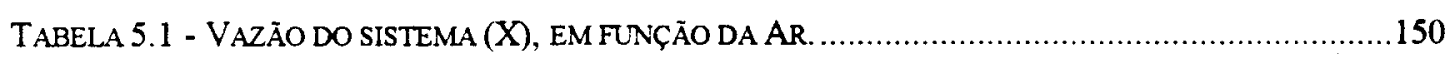

TABELA 5.2 - COEFICIENTE DE VARIAÇÃO (CV) DO TAMANHO MÉDIO DE FILA …............................. 153

TABELA 5.3 - VAZÃO DO SISTEMA (X) EM FUNÇÃO DO TEMPO DE SINTONZZAÇÃO (TT) ........................ 161

TABELA 5.4 - VAZÃO DO SISTEMA (X) EM FUNÇÃO DA VARIAÇÃO DE AR ...................................... 171

TABELA 5.5 - TAMANHO MÉDIO DE FILA (LQ) E MAIOR TAMANHO ABSOLUTO DE FILA. ......................... 173 


\section{Resumo}

Este trabalho apresenta um estudo sobre redes ópticas de interconexão aplicadas em arquiteturas paralelas, onde são propostos, simulados e analisados alguns modelos de redes. Essa é uma importante pesquisa, pois, as redes de interconexão influenciam diretamente o custo e desempenho das arquiteturas paralelas de computadores

O primeiro modelo de rede óptica proposto é chamado de SCF (Sistema Circular com Filas). Esse é um sistema sem colisões, onde há um canal exclusivo para controle de comunicação e cada nó possui um canal exclusivo para recepção de dados. Esse sistema tem um desempenho com alta taxa de vazão, alto nível de utilização e pequenas filas.

Para a simulação da rede SCF foi desenvolvido um simulador dedicado, cuja adaptação para a simulação de outros modelos de redes, propostos nesse trabalho, foi facilmente realizada.

Neste trabalho também foram propostos, simulados e analisados três modelos diferentes de chaves ópticas de distribuição para arquitetura paralela do tipo Dataflow. Os resultados dessas simulações mostram que componentes ópticos relativamente simples podem ser utilizados no desenvolvimento de sistemas de alto desempenho. 


\section{Abstract}

This work presents a study about optical interconnection network applied to parallel computer architectures, where is proposed, simulated and analyzed some models of optical interconnection networks. It is an important research because the interconnection networks influence directly the cost and performance of parallel computer architectures

The first optical interconnection network model proposed in this work is called SCF (Sistema Circular com Filas). It is a system without collisions, where there is a dedicated channel for communication control and each node has a fixed channel for data reception. The system has a performance with high throughput, high utilization level and small queue size.

For the SCF simulation was developed a dedicated simulator, whose adjust to simulate others optical interconnection network, proposed in this work, was easily performed.

In this work also was proposed, simulated and analyzed three different models of optical distributing network for Dataflow computer architecture, whose results shows that single optical devises can ensure the development of high performance systems 


\section{Introdução}

\section{Apresentação do tema}

A fotônica é a tecnologia que visa o desenvolvimento de sistemas que utilizam fotóns em áreas como as telecomunicações ou a computação [Loural 1994-b]. Uma das principais aplicações da fotônica é relativa ao desenvolvimento das redes ópticas de comunicações, pois, o uso de sistemas ópticos apresenta várias vantagens em relação aos sistemas elétricos. Entre essas vantagens pode-se mencionar a alta banda passante, a integração de sinais de voz, dados e imagens no mesmo meio fisico, a imunidade à interferência eletromagnética e a possibilidade de transmissão de diversos sinais com diferentes taxas de transmissão pelo mesmo meio fisico [Partridge 1994].

As fibras ópticas apresentam uma banda passante na ordem de até $30 \mathrm{THz}$, no entanto, os sistemas eletrônicos comerciais processam sinais com uma taxa em torno de $2,5 \mathrm{GHz}$. Há uma perspectiva para que os sistemas eletrônicos atinjam uma taxa operacional em torno de $10 \mathrm{GHz}$, o que ainda é um valor muito inferior ao potencial de banda passante das fibras ópticas. A limitação eletrônica de velocidade levou ao surgimento de um esforço para o desenvolvimento das chamadas "redes transparentes", onde a informação deve ser enviada do transmissor para o receptor sem qualquer processamento eletrônico intermediário [Miki 1994].

Os fatores fundamentais para o desenvolvimento dos sistemas ópticos de comunicações foram a criação do laser e de fibras ópticas com baixo nivel de atenuação, porém, diversos novos dispositivos têm contribuído significativamente 
para o aprimoramento desses sistemas. Entre esses dispositivos, podem-se mencionar os amplificadores ópticos, os lasers sintonizáveis e os multiplexadores ópticos.

Os multiplexadores ópticos são chamados de WDM Wavelength Division Multiplexing) e permitem que diversos sinais ópticos, cada um com um comprimento de onda especifico, sejam opticamente multiplexados e transmitidos por uma única fibra, possibilitando o desenvolvimento de sistemas com alta banda passante. $O$ desenvolvimento de sistemas, que usam de modo conjunto a tecnologia WDM e a tecnologia TDM (Time Division Multiplexing), tem permitido a transmissão na faixa de Tera bits por segundo [Willer 1997]

Os multiplexadores ópticos WDM foram utilizados na interconexão de diversos modelos de redes ópticas, como, por exemplo, a FOX, a LAMBDANET, a POPS e a OPTIMUL. Além desses e diversos outros modelos de redes, um WDM permite que diversos modelos de redes de interconexão, como a ShuffleNet ou a Manhattan, sejam implementados como topologias virtuais, utilizando-se a mesma base fisica [Mukerjee 1992-a, Mukerjee 1992-b].

Existe toda uma classificação teórica já desenvolvida para as redes WDM, que são classificadas em função dos transmissores e receptores serem sintonizáveis ou fixos e em função do sistema de comunicação, que pode exigir ou não a utilização de nós intermediários durante a transmissão.

O desempenho das redes ópticas já implementadas e todo o formalismo teórico já desenvolvido permitem concluir que esses sistemas já estão amadurecidos e são uma solução eficiente para a comunicação de dados em arquiteturas paralelas de computadores.

Os. sistemas ópticos de comunicações têm um grande potencial de uso, porém, é necessário que se desenvolvam técnicas adequadas em relação aos programas de 
controle e aos sistemas fisicos de engenharia. Essas novas técnicas visam o aproveitamento máximo de todo o potencial óptico e permitem supor o surgimento de inúmeras novas pesquisas

\section{Apresentação da tese}

O objetivo desta tese de doutorado é a investigação do uso de redes ópticas de interconexão em arquiteturas paralelas. Assim, nos três primeiros capitulos, é feita uma revisão a respeito desse assunto, e nos capítulos quatro e cinco são apresentados projetos e resultados dos sistemas ópticos propostos.

O capítulo 1 mostra conceitos fundamentais a respeito de comunicações ópticas, abordando temas como fibras ópticas, transmissores, receptores, acopladores e considerações sobre projetos de sistemas ópticos.

O capítulo 2 faz uma análise sobre arquiteturas paralelas de computadores e redes ópticas de interconexão. Nesse capitulo, são abordados assuntos como os conceitos fundamentais sobre arquiteturas paralelas, arquitetura Dataflow, aplicações de sistemas ópticos em Dataflow, redes de interconexão, arquiteturas WDM e, finalmente, são mostrados alguns modelos de redes ópticas.

O capítulo 3 apresenta os conceitos relacionados às técnicas de simulação, como modelos de simulação, modelagem de sistemas, teoria de filas e análise de desempenho de redes. Esses conceitos foram utilizados no trabalho de doutorado para o desenvolvimento de um simulador que permitisse a simulação das redes propostas e a conseqüente análise do seu desempenho.

XVI

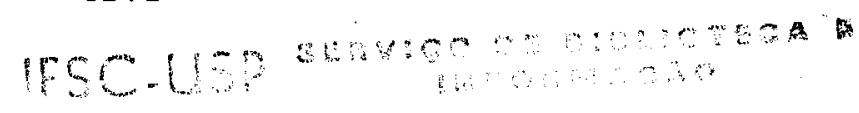


O capitulo 4 mostra o projeto, simulação e análise da rede SCF (Sistema Circular com Filas). Essa rede foi proposta neste trabalho e apresentou um desempenho altamente satisfatório.

O capitulo 5 apresenta os projetos de três chaves ópticas de distribuição utilizadas na arquitetura paralela do tipo Dataflow. Dois desses projetos apresentaram resultados altamente satisfatórios, sem a necessidade de componentes ópticos sofisticados.

Nos capitulos 2, 4 e 5 desta tese são apresentadas conclusões especificas para cada um deles, e, no capítulo 6 , é apresentada uma conclusão final, onde se confirma a vantagem de utilização de sistemas ópticos no desenvolvimento de redes de interconexão.

O capítulo 7 mostra uma relação de trabalhos que poderão ser futuramente desenvolvidos com base na presente tese. A diversidade de trabalhos futuros permite concluir que essa área tem um grande potencial para o desenvolvimento de novos trabalhos científicos. 


\section{Capítulo 1}

\section{Sistemas Ópticos de Comunicação}

\section{Apresentação}

Este capitulo descreve os princípios dos sistemas ópticos atualmente utilizados em comunicações de dados. Para isso, é feita uma abordagem sobre fibras ópticas, fontes luminosas, transmissores e receptores ópticos e sobre acopladores ópticos.

\section{Comunicações ópticas}

A implementação de redes ópticas de comunicação apresenta diversas vantagens em relação às redes eletrônicas convencionais, como por exemplo [Giozza 1991, Mukerjee 1992-a, Partridge 1994, ]:

- Alta banda passante. A banda passante nas fibras ópticas é na ordem de $30 \mathrm{THz}$, sendo que existem sistemas comerciais de transmissão de dados operando na ordem de $\mathrm{Gb} / \mathrm{s}$ e sistemas experimentais na ordem de $\mathrm{Tb} / \mathrm{s}$;

- Baixo nível de perdas. Atualmente, existem fibras com um nível de atenuação muito baixo, que é na ordem de décimos de $\mathrm{dB} / \mathrm{Km}$; 
- Ligações a longas distâncias. Existem sistemas ópticos de comunicação transmitindo dados em distâncias de algumas de centenas de $\mathrm{Km}$, sem nenhuma forma intermediária de amplificação;

- Transparência em relação ao formato de dados. Isto permite sinais de voz, dados e imagens sejam transmitidos pela mesma fibra;

- Transparência em relação à taxa de serviço. Isto permite que o mesmo meio físico suporte diversos serviços com velocidades diferentes;

- Baixa taxa de erros. Os sistemas ópticos normalmente operam na faixa de um bit errado para cada bilhão ou trilhão de bits transmitidos;

- Possibilidade de multiplexação óptica de dados. Isto permite que diversos sinais, independentemente do seu formato e taxa de transmissão, sejam opticamente multiplexados e transmitidos simultaneamente por uma única fibra óptica.

Como a eletrônica não permite a implementação de redes com o mesmo desempenho das redes ópticas, existe uma concentração tecnológica no desenvolvimento das chamadas redes transparentes, onde o sinal se propaga entre o transmissor e o receptor, totalmente no domínio óptico, sem conversões eletro/ópticas intermediárias. Isto tem exigido pesquisas no desenvolvimento de novos dispositivos ópticos, novas arquiteturas de redes e novos protocolos de comunicação, que permitam $o$ uso efetivo de todas as vantagens das redes transparentes [Miki 1994, Nelson et al 1994].

Essa crescente evolução tecnológica pode ser observada em diversos dispositivos ópticos usados em comunicações, como as fibras ópticas, os transmissores ópticos, os receptores ópticos, os acopladores, os amplificadores, etc. 
Isto tem gerado sistemas com óptica integrada, onde funções tipicamente eletrônicas, como a comutação, podem ser realizadas no domínio óptico.

Todo esse desenvolvimento acabou criando uma nova área tecnológica, chamada fotônica, que visa o uso de fótons na substituição de elétrons em diversas aplicações, como telecomunicações, automação, medicina ou computação. A fotônica engloba o desenvolvimento de dispositivos ópticos e eletro/ópticos, como fontes de luz, fibras ópticas ou visores, e entre suas principais caracteristicas está o fato de ser considerada uma tecnologia "habilitadora", pois, serve como uma indispensável base para o desenvolvimento de outras áreas tecnológicas [Loural 1994-b]

A idéia de utilização de sistemas ópticos de comunicação é antiga e vem se acelerando desde a década de 70 , quando se conseguiu a fabricação de fibras ópticas com uma considerável diminuição do nivel de atenuação do sinal transmitido [Giozza 1991]. Além da evolução das fibras ópticas, o outro impulso inicial dos sistemas ópticos de comunicações foi o desenvolvimento do laser, a partir dos anos 60 , que permitiu a implementação de uma eficiente fonte de luz para os sistemas de comunicações.

Em função desse impulso, atualmente existem fibras ópticas com uma atenuação inferior a $0,2 \mathrm{~dB} / \mathrm{Km}$ e os diodos laser estão comercialmente disponíveis desde o meio da década de 80. Apesar do desenvolvimento ocorrido nos últimos anos, ainda existe um grande número de pesquisas visando uma evolução ainda maior no desempenho desses e de outros dispositivos ópticos, que de certa forma ainda são considerados como partes de uma tecnologia emergente.

Além da evolução das fibras ópticas e dos transmissores laser, dois outros dispositivos que causaram um aumento da expectativa em relação às comunicações ópticas, são os multiplexadores ópticos (WDM) e os amplificadores ópticos. 
Os multiplexadores ópticos permitem que vários sinais, em diferentes comprimentos de onda, sejam opticamente multiplexados e transmitidos por uma única fibra, o que tem permitido a implementação de sistemas de comunicação com uma alta taxa de transmissão de sinais, na ordem de $\mathrm{Tb} / \mathrm{s}$ [Morioka 1994]. Os amplificadores ópticos permitem que um sinal óptico seja amplificado totalmente no domínio óptico, sem conversões eletro/ópticas, permitindo que seja mantido o conceito de rede transparente e que não haja prejuízos da velocidade de comunicação. Atualmente existem sistemas de fibras ópticas, operando em algumas centenas de Km, sem amplificadores, assim, o seu uso pode possibilitar ligações entre distâncias consideravelmente longas.

A transparência em relação à taxa de operação permite que uma rede óptica transporte sinais com diferentes taxas de transmissão, como sinais de um modem de baixa velocidade ou sinais de TV com alta definição, que pode operar na faixa de $\mathrm{Mb} / \mathrm{s}$ [Partridge 1994]. Além disto, possíveis aumentos na velocidade de transmissão de um determinado serviço não exigem alterações dos cabos ópticos [Loural 1994-b]

A transparência ao formato de dados permite que a mesma rede transporte sinais de voz, dados e imagens, o que viabiliza a implementação de diversos serviços integrados em multimidia, como a videoconferência ou projetos de realidade virtual [Partridge 1994].

Uma outra aplicação dos sistemas ópticos de comunicações é relativa ao desenvolvimento de redes de interconexão em arquiteturas paralelas de computadores. O processamento de determinados problemas, em áreas como a dinâmica molecular ou a meteorologia, exigem a manipulação de um volume muito 
grande e de informações, tornando-se inviável para um sistema com um único processador.

O desenvolvimento de arquiteturas paralelas tem esbarrado em um problema, que é a interconexão fisica entre os diversos processadores e memórias, que fazem parte do sistema. Embora tenham sido desenvolvidos eficientes modelos teóricos, como a rede de interconexão crossbar [Youn 1993], a sua implementação com conexões elétricas fica limitada em função de restrições como a banda passante, a interferência eletromagnética e o número de conexões exigidas. As redes ópticas podem ser uma solução para esse problema, pois, têm uma alta banda passante, não sofrem interferência eletromagnética e, através da multiplexação óptica, permitem que diversos sinais sejam simultaneamente transmitidos por uma única fibra e enviados a diversos receptores.

\section{Fibras ópticas}

A fibra ótica é definida como um dispositivo normalmente cilíndrico e transparente, feito de material dielétrico como a sílica ou plástico e que normalmente absorve pouca luz, podendo transmiti-la por um caminho não retilíneo. Sua estrutura fisica é composta por um núcleo interno (core) e uma capa externa (cladding) [Personick 1983, Giozza 1991], conforme mostra a figura 1.1, e o seu principio de funcionamento está na sua capacidade de fazer a luz se propagar dentro do núcleo, através de múltiplas reflexões. 


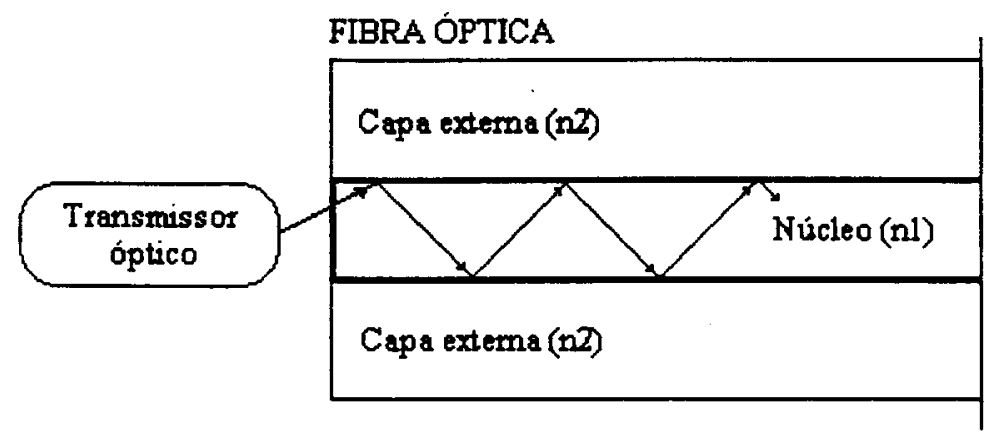

Figura 1.1 - Estrutura de uma fibra óptica. O dispositivo é composto por uma capa externa e um núcleo, onde a luz fica confinada e se propaga através de reflexões múltiplas.

Uma fibra óptica apresenta significativas vantagens sobre os condutores elétricos, como o baixo nivel de perdas, imunidade à interferência eletromagnética, isolação elétrica e banda passante na ordem de $30 \mathrm{THz}$. Outra vantagem é a resposta do nível de perdas em função da freqüência do sinal transmitido, pois, nos cabos metálicos, as perdas aumentam sensivelmente em função do aumento da frequêencia do sinal, enquanto que isto não ocorre nas fibras ópticas [Hecht 1993]. Existem algumas desvantagens das fibras ópticas em relação aos condutores metálicos, como a fragilidade fisica das fibras não encapsuladas e dificuldade de conexões fisicas [Giozza 1991].

Em 1910 foi apresentada a primeira análise sobre a propagação eletromagnética em cilindros dielétricos, que seriam posteriormente utilizados no desenvolvimento das fibras óticas. Um dos problemas era o alto nível de perdas do sinal transmitido, que, na década de 60 , atingia grandezas na ordem de $1000 \mathrm{~dB} / \mathrm{Km}$ [LI 1983].

Somente em 1970, conseguiu-se uma fibra óptica com atenuação inferior a 20 $\mathrm{dB} / \mathrm{Km}$, o que veio a viabilizar a utilização de sistemas ópticos de comunicação, que já estavam sendo propostos desde o desenvolvimento do laser, na década de 60 . 
Atualmente existem fibras com atenuações na ordem de $0,2 \mathrm{~dB} / \mathrm{Km}$, usadas em sistemas de comunicação com $200 \mathrm{Km}$ de comprimento, e sem repetidores [Giozza 1991].

O sinal é transmitido na fibra óptica com uma velocidade aproximadamente igual à do sinal elétrico em um fio condutor, que é aproximadamente 0,69 da velocidade da luz no vácuo. No entanto, o sinal transmitido na fibra tem um menor comprimento fisico, permitindo uma maior densidade de informações [Partridge 1994]. Enquanto a banda passante na fibra óptica é na ordem de $30 \mathrm{THz}$, nos cabos coaxiais esse valor gira em torno de $400 \mathrm{MHz}$ e, nos sistemas de microondas, esse valor é na ordem de $700 \mathrm{MHz}$ [Giozza 1991]

As sucessivas reflexões que a luz sofre no núcleo da fibra óptica, dependem do índice de refração do núcleo do índice da capa externa. O índice de refração de um determinado material (n) é um valor dependente da velocidade com que a luz se propaga no mesmo $(\mathrm{Cm})$ e, em termos práticos, essa medida é feita em relação à velocidade da luz no ar $(C v)$, sendo expressa por:

$$
\mathrm{n}=\mathrm{Cv} / \mathrm{Cm}
$$

Quando a luz se propagar entre dois meios, com indices de refração diferentes, ocorrerá uma alteração no ângulo de sua trajetória, devido à diferença de velocidade da luz, nos diferentes meios. Esse ângulo é determinado pela lei de Snell, que é dada pela equação 1.2 e representada pela figura 1.2 [Halliday; Resnick 1980]:

$$
\mathrm{n} 1 \sin (\theta)=\mathrm{n} 2 \sin (\alpha)
$$




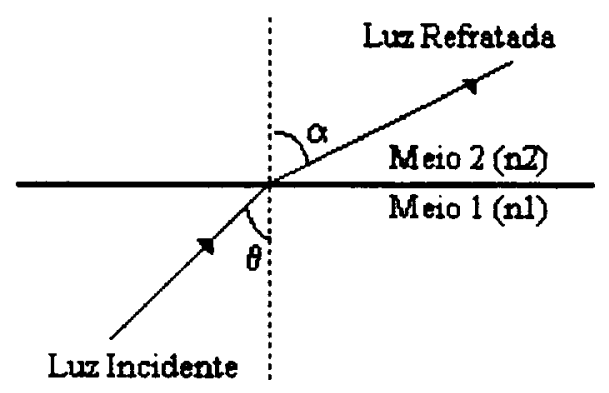

Figura 1.2 - Refração da luz, segundo a lei de Snell. Os ângulos $\theta$ e $\alpha$ são relativos à reta Normal formada entre dois meios fisicos, com indices diferentes de refração, denominados de nl e n2.

Se a luz incidente se propaga para um outro material, com índice de refração menor, poderá ocorrer uma reflexão total do sinal, ou seja, a luz poderá ser totalmente refletida de volta ao material com maior indice de refração. Esse é o princípio de funcionamento da fibra óptica onde o indice de refração do núcleo é um pouco maior que o índice de refração da capa externa [Hecht 1993].

$\mathrm{O}$ ângulo $\theta$, mostrado na figura 1.2 , pode ser aumentado até que se atinja um valor chamado ângulo critico, onde a luz refratada se propaga na divisa entre os dois meios. A luz incidente, com um ângulo maior ao ângulo crítico, não sofrerá refração e será totalmente refletida para o meio 1. Assim, pode ser determinado um ângulo chamando ângulo de aceitação ( $\theta x)$, onde a luz incidente, com ângulo menor que o mesmo, será refletida, enquanto que a luz incidente, com um ângulo maior que o mesmo, será inteiramente refratada para o meio 2 . A figura 1.3 mostra a aplicação desse conceito em uma fibra óptica, onde a luz refletida dentro do núcleo será efetivamente utilizada na transmissão de dados. 


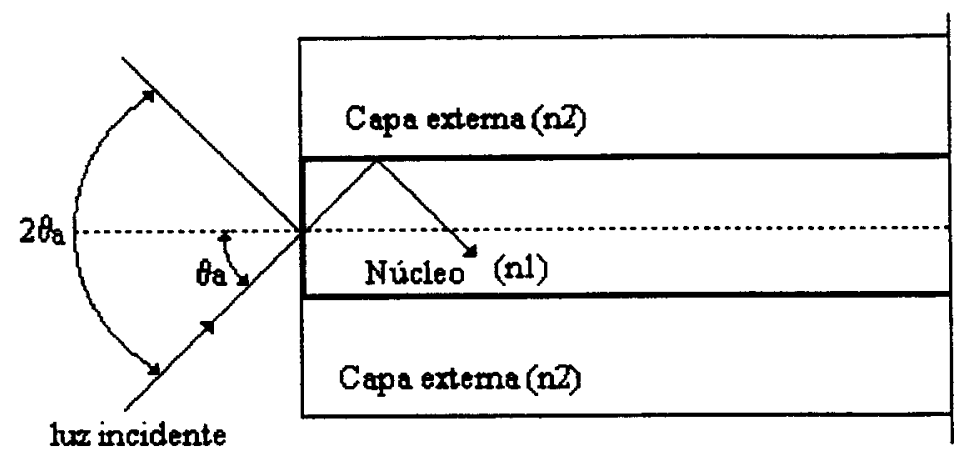

Figura 1.3 - Propagação da luz na fibra óptica. $O$ indice de refração da Capa externa (n2) é menor que o do núcleo (n1), assim, somente a luz incidente com um ângulo menor que o ângulo de aceitação (Ba) sofrerá reflexão total.

O ângulo de aceitação $\theta$ a pode ser determinado a partir da lei de Snell e é expresso por:

$$
\theta \mathrm{a}=\operatorname{arcsen} \sqrt{\mathrm{n} 1^{2}-\mathrm{n} 2^{2}}
$$

As principais características críticas de uma fibra ótica são relativas à sua atenuação e à sua dispersão. A atenuação representa o nível de perdas da potência óptica durante a transmissão do sinal e é expressa em $\mathrm{dB} / \mathrm{Km}$. Ela pode ser causada por falhas de fabricação, como impurezas de material ou ondulações entre o núcleo e a capa externa (microcurvas). As impurezas podem dissipar energia na forma de calor e as microcurvas podem alterar o ângulo de reflexão dentro da fibra e fazer com que uma parte do sinal se refrate e não reflita [Tabini 1990, Giozza 1991].

A atenuação está intrinsecamente relacionada com o comprimento de onda do sinal transmitido e pode ser contornada com o uso de repetidores eletro-ópticos ou amplificadores ópticos . Na prática, existem comprimentos de onda menos suscetiveis ao efeito da atenuação. Esses comprimentos de onda estão em 3 regiões do espectro, 
chamadas de "janelas", que têm cerca de $200 \mathrm{~nm}$ e estão centradas em $0,85 \mu \mathrm{m}$, 1,3 $\mu \mathrm{m}$ e 1,5 $\mu \mathrm{m}$ [Li 1983, Tabini 1990, Giozza 1991, Willner 1997].

A dispersão é uma distorção na forma de onda do sinal transmitido, que provoca um "alongamento" do mesmo e, conseqüentemente, diminui a capacidade do volume de informações transmitidas na fibra. A dispersão está associada à pureza do material de fabricação da fibra e ao comprimento de onda do sinal transmitido. Existem quatro tipos básicos de dispersão, que são a dispersão cromática, a dispersão material, a dispersão por guia de onda e a dispersão modal.

A dispersão cromática é causada pela largura espectral ou por pequenas variações no comprimento de onda do sinal que está sendo transmitido. A largura espectral é uma característica do transmissor, verificada quando ele emite um sinal com diversas frequêencias próximas ao valor desejado. Cada uma destas frequeências se propaga com características diferentes, provocando a dispersão.

Essa forma de dispersão apresenta menores valores na faixa de $1,3 \mu \mathrm{m}$ [Refi 1994] e é medida em $p s$ de espalhamento por $n m$ de largura do sinal de origem e $\mathrm{Km}$ de fibra (ps/nm-Km). Assim, o espalhamento do pulso aumenta com a largura espectral e com a distância percorrida.

A dispersão material é causada por impurezas no material de fabricação da fibra e a dispersão por guia de onda é causada por alterações ocorridas no índice de refração do núcleo ou da capa externa, ou ainda, por variações no diâmetro do núcleo ao longo da fibra.

A dispersão modal é causada pela diferença de percurso que os componentes do sinal transmitido percorrem no interior do núcleo da fibra, o que provoca um atraso entre os mesmos. 
A dispersão modal é normalmente expressa em ns/Km e divide as fibras em fibras multimodo, que têm maior dispersão modal, e em fibras monomodo, onde essa forma de dispersão é muito pequena. Quando maior for o diâmetro do núcleo da fibra, maior será o efeito da dispersão modal.

A partir do ângulo de aceitação, pode-se determinar a chamada abertura numérica (AN), que é usada na análise da capacidade da fibra óptica de captar a luz. $\mathrm{O}$ valor de $\mathrm{AN}$ não depende do diâmetro da fibra e, quando a mesma estiver envolvida no ar, ele será expresso pela equação 1.4 .

$$
\mathrm{AN}=\operatorname{sen} \theta=\sqrt{\mathrm{n} 1^{2}-\mathrm{n} 2^{2}}
$$

Dependendo do ângulo com que a luz incide na fibra, ela irá percorrer uma determinada distância. A luz incidente na fibra óptica pode formar diversos ângulos de propagação e cada um deles percorrerá um caminho diferente na fibra. Isto faz com que os componentes de um sinal cheguem a um determinado ponto em instantes diferentes de tempo, provocando a dispersão modal. As fibras, onde ocorre esse comportamento recebem o nome de fibras multimodo ou fibras multimodo degrau.

Pode-se obter uma sensivel diminuição nessa forma de dispersão, fazendo com que todos os componentes de propagação da luz transmitida, cheguem a um determinado ponto, sem atrasos entre si.

Uma forma de se evitar atrasos na propagação é através de uma diminuição do número de modos de propagação da luz incidente. Se a luz se propagar através de um único modo, não haverá caminhos diferentes e, conseqüentemente, não haverá dispersão modal. As fibras, que permitem esse comportamento no modo de 
propagação da luz, são chamadas de fibras monomodo e o seu número de modos de propagação (Nm) depende do diâmetro do núcleo (d), da abertura numérica (AN) e do comprimento de onda $(\lambda)$, conforme mostra a equação 1.5 .

$$
\mathrm{Nm}=\left(\mathrm{d}^{*} \mathrm{AN} * \pi / \lambda\right)^{2} / 2
$$

Baseando-se na equação 1.5 , pode-se concluir que é possivel reduzir o número de modos de propagação na fibra monomodo, diminuindo-se o diâmetro do núcleo ou a abertura numérica ou ainda aumentando o comprimento de onda da luz incidente [Hecht 1993].

A diminuição do diâmetro da fibra pode exigir uma maior complexidade no acoplamento entre a fibra óptica e a fonte de luz, enquanto que o aumento indiscriminado do comprimento de onda pode levar a faixas operacionais com maior nível de atenuação, ou pode até mesmo influenciar alterações em relação ao índice de refração.

Uma outra maneira de diminuir a dispersão modal, de um modo tecnologicamente mais simples que as fibras monomodos, é através da utilização da fibra multimodo gradual. Nessa fibra, o índice de refração do núcleo diminui continuamente à medida que se afasta do centro em direção à capa externa. Desta forma, à medida que o sinal se afasta do centro do núcleo, a sua velocidade aumenta $e$ as diferenças de percursos dos diferentes modos de propagação sofrem uma compensação que diminui a dispersão modal.

A figura 1.4 mostra o sistema de variações do índice de refração em relação ao centro do núcleo da fibra óptica. Na fibra multimodo degrau, o diâmetro do núcleo 
pode variar de 100 a $200 \mu$ m e o diâmetro da capa externa pode variar de 140 a $280 \mu \mathrm{m}$, enquanto que, na fibra multimodo gradual, o diâmetro do núcleo varia de 50 a $85 \mu \mathrm{m}$ e o diâmetro da capa é em torno de $125 \mu \mathrm{m}$. Nas fibras monomodo, o diâmetro do núcleo varia de 10 a $17 \mu \mathrm{m}$ e o da capa gira em torno de $125 \mu \mathrm{m}$.

A dispersão cromática, na fibra monomodo, pode ser considerada desprezivel na faixa de $1,3 \mu \mathrm{m}$, enquanto que, na faixa de $1,5 \mu \mathrm{m}$, ela normalmente gira em torno de $15 \mathrm{ps} / \mathrm{nm}-\mathrm{Km}$. Assim, à nível de dispersão, é preferível utilizar uma fibra monomodo e transmitir na faixa de $1,3 \mu \mathrm{m}$. A janela de $1,5 \mu \mathrm{m}$ tem a vantagem de maior banda espectral e uma melhor resposta nos sistemas de amplificação óptica.

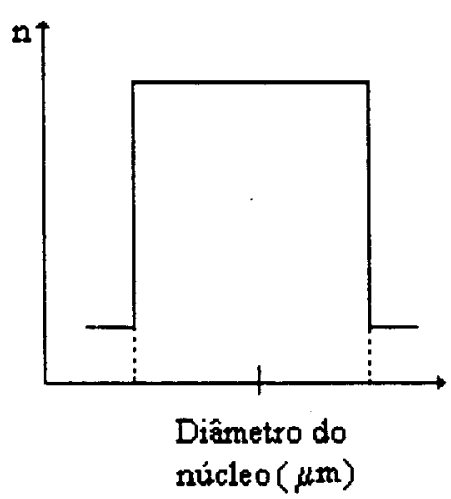

(A)

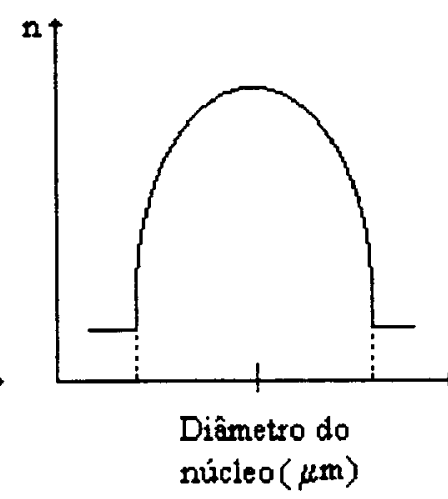

(B)

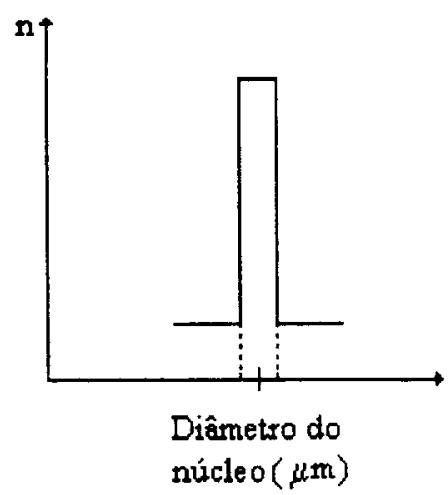

(C)

Figura 1.4 Tipos de fibras ópticas. A figura (A) mostra uma fibra multimodo degrau, a figura (B) mostra uma fibra multimodo gradual e a figura (C) mostra uma fibra monomodo. A marca, no centro do eixo horizontal, representa o centro do núcleo da fibra óptica. 


\section{Processos de geração de luz}

Um sistema de comunicação óptica depende fortemente do sistema de geração de luz, que fornecerá sinais ópticos à fibra óptica. A luz tem um comportamento dual e pode ser analisada como uma onda eletromagnética ou como uma partícula.

A luz está associada a grandezas medidas na forma de freqüência, comprimento de onda, energia de fótons, amplitude e velocidade de propagação, conforme mostra a figura 1.5. Dentro dessa faixa espectral, o olho humano é sensivel a apenas uma faixa que varia entre $0,38 \mu \mathrm{m}$ e $0,76 \mu \mathrm{m}$ [Isaacs 1979] e os sistemas de comunicação operam em uma faixa que varia de $0,2 \mu \mathrm{m}$ a $20 \mu \mathrm{m}$ [Hecht 1993]

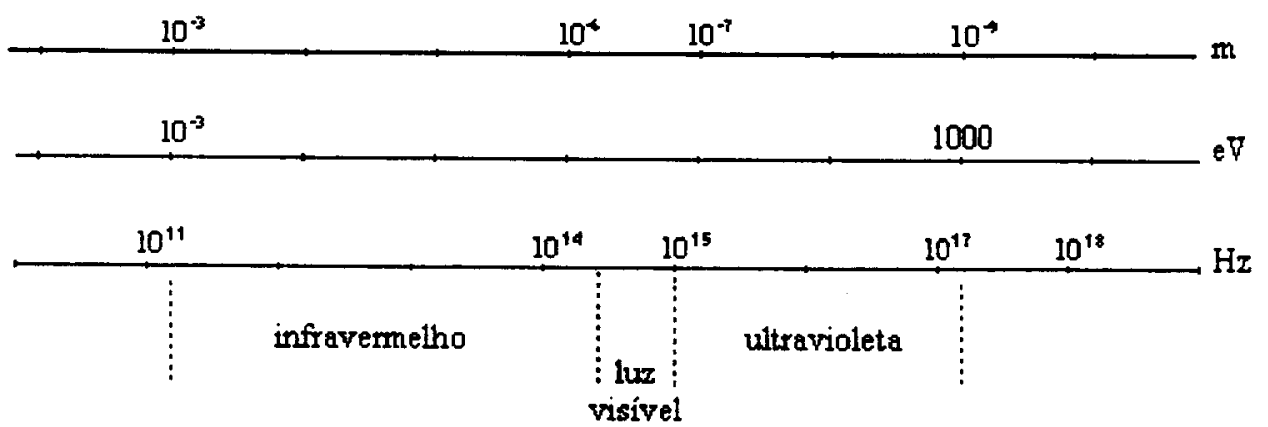

Figura 1.5 - Espectro eletromagnético. Representação através do comprimento de onda $(\mathrm{m})$, da energia ( $\mathrm{eV}$ ) e da freqüência $(\mathrm{Hz})$.

O comprimento de onda $(\lambda)$ pode ser determinado em função da freqüência do sinal (v) e da velocidade da luz no vácuo (C), conforme mostra a equação 1.6 .

$\lambda=\mathrm{C} / v$ 
O nível de energia do fóton (E) é medido em $\mathrm{eV}$ (eletron-Volts) e representa a energia absorvida por um elétron, quando atravessa um campo elétrico de $1 \mathrm{~V}$ [Hecht 1993]. Esse valor também é determinado em função da frequência (f ) do sinal, conforme mostra a equação 1.7, onde $h$ é a constante de Plank e equivale a $6,63 * 10^{-34} \mathrm{~J} / \mathrm{s}$ ou $4,14 \mathrm{eV} / \mathrm{s}$.

$$
E=h f
$$

Os transmissores e receptores ópticos são freqüentemente desenvolvidos a partir de materiais semicondutores. Em um material semicondutor, os átomos podem completar a sua última camada orbital com os elétrons dos átomos vizinhos, formando uma ligação covalente, ocupando todos os niveis da banda de valência. Acima da banda de valência existe uma banda proibida (gap), onde não há estados energéticos permitidos, e logo acima da banda proibida há a banda de condução. A largura da banda proibida (Eg) é esquematizada em função da quantidade de energia necessária para que um elétron possa ultrapassá-la.

Um elétron pode passar da camada de valência para a camada de condução, em função de fatores, como a agitação térmica, absorção de fótons ou injeção de elétrons. Quando isto ocorre, passa a existir uma ligação covalente incompleta ou lacuna e o elétron tende a voltar para a banda de valência, em um processo chamado recombinação espontânea, e acaba liberando energia que pode ser na forma de fóton, formando um sistema de fotogeração.

Para facilitar a recombinação espontânea, são usados materiais onde elétrons e lacunas têm momentum parecidos, permitindo a chamada recombinação direta, sem a exigência fonons para a recombinação. Entre os materiais com recombinação direta, 
está o arseniato de gálio (GaAs) e, entre os materiais sem recombinação direta, estão elementos simples, como o silício ou germânio.

Além da recombinação espontânea, existe a chamada recombinação estimulada, onde o processo de recombinação sofre a influência de um fóton estimulante. Isto faz com que o fóton, liberado na recombinação, tenha a mesma fase do fóton estimulante, criando um mecanismo de ganho óptico. Esse processo de realimentação forma o LASER, que gera uma luz monocromática e coerente.

Um sistema de realimentação muito comum é o Fabry-Perot, que é formado por dois espelhos, cuja distância permite a realimentação para um comprimento de onda específico. Como um dos espelhos não é totalmente refletivo, uma parte do sinal é emitida para fora do sistema [Higgins 1994].

No laser semicondutor, deve se evitar que os fótons sejam absorvidos pelo material, sendo necessário que haja a produção de muitas combinações em espaços limitados e que haja uma condução do fótons para o exterior do dispositivo, antes da recombinação [Kao 1986]. Essa alta produção de recombinações é feita por um processo de realimentação com uma cavidade óptica. Nesse caso, alguns fótons saem da cavidade e formam o feixe de luz, porém, alguns fótons ficam retidos na cavidade e estimulam novas recombinações, formando a realimentação [Tabini 1990].

A figura 1.6 mostra o processo de recombinação espontânea e o processo de recombinação estimulada. 


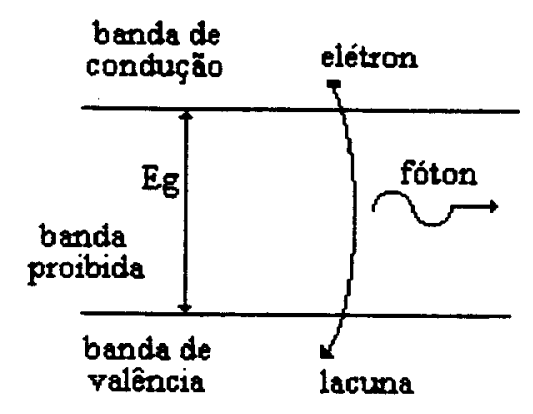

(A)

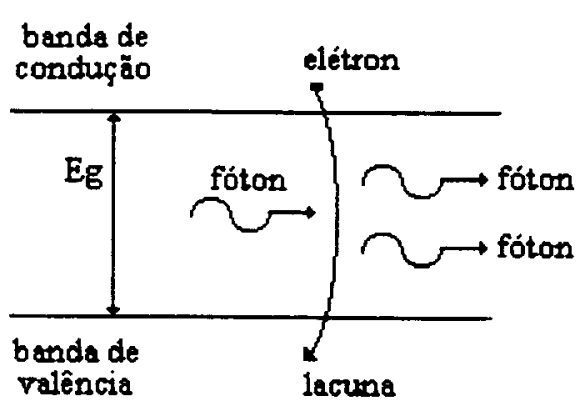

(B)

Figura 1.6 - Sistemas de recombinação. Na figura (A) ocorre uma recombinação espontânea e na figura (B) ocorre uma recombinação estimulada.

\section{Transmissores ópticos}

Os transmissores ópticos geram os sinais que serão transmitidos pela fibra óptica, fazendo uma conversão eletro/óptica. Esses dispositivos são basicamente classificados em dispositivos LED (Light-Emitting Diode) ou LASER (Light Amplification by Stimulated Emission of Radiation) e o seu desempenho pode ser medido em função de algumas características fundamentais como [Kao 1986]:

- Potência óptica de saída;

- Faixa espectral de operação;

- Largura espectral do sinal emitido;

- Faixa térmica de operação;

- Tempo de resposta.

Em sistemas de comunicações, a potência dos transmissores opera na faixa de centenas de miliwatts ou dezenas de microwatts. A especificação desse valor é 
fibra óptica. No interfaceamento, entre o transmissor e a fibra, ocorrem perdas que farão com que a potência, entregue à fibra, seja menor que a potência emitida pelo transmissor [Hecht 1993]

A potência óptica pode influenciar o próprio comportamento da fibra, como no efeito chamado de Four Wave Mixing, onde a elevação exagerada da potência óptica pode provocar alterações no índice de refração da fibra, podendo provocar a mistura de dois sinais diferentes, produzindo um novo comprimento de onda [Refi 1994]. Outro problema seria a diminuição da potência, o que pode aumentar a taxa de erros do sinal transmitido ou mesmo inviabilizar a recepção.

A faixa espectral de operação determina a faixa de comprimentos de onda, em que o transmissor consegue gerar sinais. Alguns transmissores são fixos e geram sinais em um único comprimento de onda, porém, existem transmissores que podem ser sintonizados para gerarem sinais em diversos comprimentos de onda.

A largura espectral do sinal emitido representa uma caracteristica indesejada do transmissor, que é projetado para emitir sinais em um comprimento de onda específico, mas, acaba emitindo o sinal com diversos comprimentos de onda. Essa característica é mostrada na figura 1.7 e o ideal é que ela seja a menor possível, pois, irá influenciar a dispersão e, conseqüentemente, a banda passante do sistema.

Um laser pode operar com uma largura espectral de 1 a $3 \mathrm{~nm}$ [Hecht 1993], enquanto que o LED opera na faixa de 25 a $100 \mathrm{~nm}$, dependendo da janela de transmissão [Giozza 1991]. 


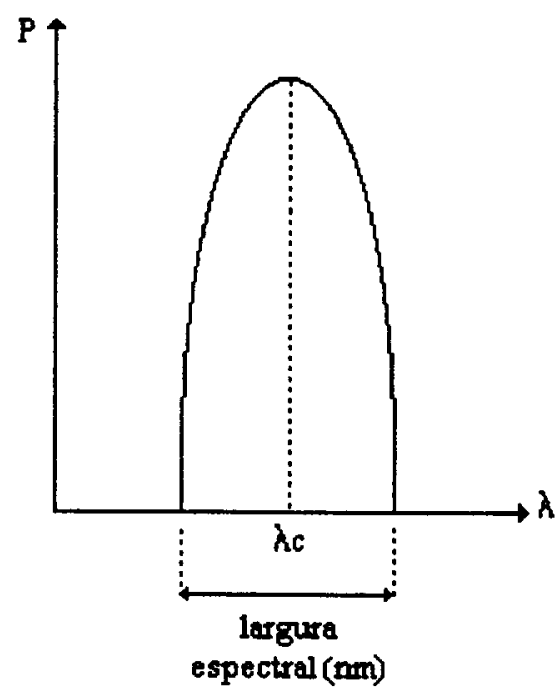

Figura 1.7 - Largura espectral. O transmissor é projetado para emitir um sinal em um comprimento de onda especifico ( $\lambda c)$, porém emite o sinal com mais de um comprimento de onda.

A faixa térmica de operação representa a influência que as variações térmicas ocasionam em determinadas características do transmissor óptico, como a potência de saída e precisão do comprimento de onda do sinal emitido. Essas alterações podem ser compensadas por variações na corrente de controle do transmissor, o que pode comprometer sua vida útil, ou através de um sistema de controle térmico específico.

O tempo de resposta representa a chamada velocidade de transição e determina o tempo gasto para que o sinal óptico de saída suba até um determinado nivel ou desça do mesmo. No laser, esse valor é medido na ordem de fração de nanosegundos, enquanto que, no LED, ele pode atingir centenas de nanosegundos [Hecht 1993]. Assim, a velocidade máxima de operação $(B)$ depende do tempo de resposta do transmissor (Tr) e pode ser calculada conforme a equação 1.8 .

$$
\mathrm{B}=0,35 / \mathrm{Tr}
$$


Embora o laser apresente diversas vantagens em relação ao LED, conforme é mostrado na tabela 1.1, o LED apresenta a vantagem de um baixo custo operacional.

Tabela 1.1- Comparações entre o LED e o LASER

\begin{tabular}{|c|c|}
\hline LED & LASER \\
\hline Custo menor & Custo maior \\
\hline Baixa Potência & Alta potência \\
\hline Sinal de saída largo & Sinal de saída estreito \\
\hline Feixe espalhado & feixe direcional \\
\hline Espectro operacional menor & Espectro operacional maior \\
\hline Mais lento na subida do sinal & Mais rápido na subida do sinal \\
\hline Tempo de subida maior & Tempo de subida menor \\
\hline Vida útil maior & Vida útil menor \\
\hline
\end{tabular}

Dois diodos laser, que são comercialmente usados para comunicações na faixa de 1,3 e $1,5 \mathrm{~nm}$, e emitem luz lateralmente, são o DFB (distributed-feedback) e o DBR (distributed-Bragg-Reflection). Ambos são baseados no uso de uma estrutura de grade de difração, que é colocada junto da região ativa, onde se produz o laser. O DFB tem a grade colocada ao longo da região ativa do laser e apresenta alta estabilidade por longos períodos de tempo. O DFR tem a grade de difração colocada atrás da camada ativa e apresenta melhor exatidão no espaçamento do sinal emitido [Soole; Zah 1994, Higgins 1995]. 


\section{Receptores ópticos}

Os receptores ópticos são dispositivos cuja finalidade é captar a luz e convertê-la em um sinal elétrico para ser processado, formando um sistema conversor óptico/elétrico. Esses dispositivos normalmente são formados por um fotodetector, que faz a deteç̧ão do sinal óptico, e por dispositivos auxiliares como amplificadores e filtros. O princípio de funcionamento de um fotodetector pode ser baseado em materiais semicondutores com junção $\mathrm{PN}$, reversamente polarizada.

A polarização reversa aumenta a zona de depleção da junção PN e a luz incidente, nessa região, pode fazer com que os elétrons saltem da banda de valência para a banda de condução, criando portadores elétron-lacuna. A tensão de polarização reversa faz com que esses portadores de corrente se movimentem rapidamente para longe da junção, evitando a sua recombinação e formando uma corrente elétrica.

A eficiência de um receptor pode ser medida em função de alguns fatores básicos, como:

- Sensibilidade;

- Relação sinal/ruído (S/N);

- Faixa espectral de sensibilidade;

- Reprodutibilidade;

- Eficiência Quântica;

- Tempo de resposta.

A sensibilidade determina o menor sinal óptico de entrada, capaz de gerar um sinal elétrico de saída, com determinadas características. Esse parâmetro depende 
diretamente do comprimento de onda da luz incidente e é importante para a determinação da potência óptica necessária no sistema de transmissão. A potência óptica que chega ao receptor também deve ser analisada com critério, pois, existe um limite chamado de faixa dinâmica, a partir do qual, um aumento da potência provocaria distorções no sinal de saída.

A relação sinal/ruído $(\mathrm{S} / \mathrm{N})$ é expressa em decibéis $(\mathrm{dB})$ e determinada pela razão entre a intensidade do sinal de operação dividida pela intensidade do ruído. Essa relação deve ser a maior possível e, em comunicações ópticas, valores na ordem de 40 a 50 dB são considerados satisfatórios [Hecht 1994].

Essa relação afeta diretamente a BER (Bit Error Rate) do sistema, que é uma taxa de erros na transmissão de bits, cujo valor em transmissão de dados é normalmente usado na ordem de $10^{-12}$, ou seja, 1 bit errado para cada 1 trilhão de bits transmitidos.

O ruído pode ser causado pelas partes eletrônicas do receptor, como os amplificadores, porém, existe uma espécie de ruído que é inerente ao fotodetector e que é chamado de corrente escura (dark current). Essa corrente é causada pela agitação térmica da rede cristalina e ocorre mesmo quando o fotodetector não está exposto à luz, assim, ela determina que deve haver um nivel mínimo de sinal de entrada para que seja produzida uma corrente de saida maior que a corrente escura. Os valores da corrente escura podem ser críticos para o desenvolvimento de um projeto e normalmente estão na faixa de fração até centenas de nanoamperes [Hecht 1994].

A faixa espectral de sensibilidade determina a faixa de comprimentos de onda que podem sensibilizar um determinado receptor e fazer com que o mesmo opere satisfatoriamente. Nesse caso, existe um comprimento de onda mínimo e um 
máximo, onde um receptor pode operar. Para cada comprimento de onda, dentro desse intervalo, o receptor pode ter diferentes níveis de sensibilidade e fora desse intervalo pode ficar totalmente inoperante. Para os receptores a base de silício, essa faixa está entre 0,4 e $1 \mu \mathrm{m}$, enquanto que, para o germânio, a faixa é de 0,6 a $1,6 \mu \mathrm{m}$.

A reprodutibilidade é a razão entre o sinal de saída elétrica do receptor e o sinal óptico de sua entrada, sendo dado em Amperes por Watts (A/W) ou Volts por Watts (V/W). Essa grandeza é importante para se determinar o nível do sinal elétrico que será entregue ao processamento e da possível necessidade de amplificação do mesmo.

A eficiência quântica $(\eta)$ é uma grandeza relacional entre os fótons incidentes no receptor e os elétrons gerados na saida do mesmo. Esse valor não pode ser maior que 1 e está diretamente relacionado com o comprimento de onda, pois, 0 nível de energia de um fóton depende diretamente do comprimento de onda originário.

O tempo de resposta determina o tempo que o sinal elétrico de saída leva para passar do nível baixo para o nível alto e vice-versa, podendo haver uma histerese nessa transição. Esse tempo limita a banda passante do sistema e gira na ordem de fração ou unidade de nanosegundos para os dispositivos PN, embora existam sistemas que operam na ordem de dezenas de picosegundos [Hecht 1994].

Dois fotodetectores populares são baseados em tecnologia PIN e APD. Os fotodetectores PIN possuem uma camada intrínseca (I), que fica entre as camadas P e $N$, o que aumenta a zona de depleção e, conseqüentemente, a sensibilidade do receptor. Apesar do aumento da sensibilidade, o aumento da zona de depleção 
aumenta a distância a ser percorrida pelos portadores, provocando uma diminuição do tempo de resposta.

O fotodetector do tipo APD (Avalanche PhotoDiode) tem um sistema de junções NPIP e a baixa tensão funciona como um fotodetector PIN, porém, à medida que o campo elétrico aumenta, ocorre uma aceleração dos portadores que, através do impacto com átomos neutros, geram novos portadores. Isto cria uma espécie de "avalanche" e permite um aumento da sensibilidade, sem prejuizos da velocidade de operação [Tabini 1990]. Apesar das vantagens, o fotodetector APD necessita de um sistema mais eficiente de alimentação elétrica, pois, é ela que determina o seu fator de multiplicação.

\section{Transmissores e receptores sintonizáveis}

O uso de dispositivos transmissores e receptores sintonizáveis pode permitir o desenvolvimento de sistemas mais eficientes de comunicação. Uma análise desses dispositivos deve levar em conta o número de canais sintonizáveis e a velocidade de sintonização. Normalmente, essas características são opostas e o projetista deve optar por um dispositivo que seja rápido, ou por um dispositivo que possa manipular diversos canais [Borella et al 1994].

Brackett classifica os lasers em função do modo de sintonização e os divide em quatro categorias: sintonia térmica, sintonia mecânica, sintonia elétrica e sintonia acústico-óptica [Brackett 1990].

Existem diodos laser, com controle por injeção de corrente, cujo tempo de sintonização é menor que $8 \mathrm{~ns}$ e operam na faixa de $1,5 \mu \mathrm{m}$ com 24 freqüências 
diferentes [Kazovsky et al 1994]. Sistemas transmissores, cujo controle da freqüência de transmissão são feitos mecanicamente, podem sintonizar centenas de canais, mas, o tempo de sintonia é na ordem de milisegundos [Borella et al 1994].

Os sistemas sintonizáveis de recepção podem ser divididos em filtros sintonizáveis e receptores sintonizáveis. Os filtros sintonizáveis podem ser passivos, como os interferômetros, ou ativos, como os sistemas acústico-ópticos. Os receptores sintonizáveis selecionam um determinado comprimento de onda em função da injeção de uma corrente elétrica. Nesse caso, um laser sintonizável é utilizado para formar um oscilador local, que seleciona um comprimento de onda específico, formando um sistema coerente de recepção [Brackett 1990, Kazovsky et al 1994].

O sistema de recepção óptica, apresentado por lida e Asakura em 1995, usa um processo baseado em uma grade de difração com uma única entrada e uma única saída. Nesse caso, o ângulo da grade de difração determina o comprimento de onda que irá para a saída. A alteração do ângulo da grade de difração é feita com um motor de passo, e o sistema é capaz de selecionar mais de 100 canais WDM, com espaçamento de $2 \mathrm{~nm}$. O tempo para sintonizar um determinado comprimento de onda é, na ordem de unidades, de milisegundos, o que pode ser muito grande para redes computacionais, mas, pode ser eficiente na recepção de serviços como o vídeo [Iida; Asakura 1995]

Uma outra proposta de sistema de recepção sintonizada foi apresentada por Hirabayashi et al 1993, onde a sintonização é feita em função de um cristal líquido. Os cristais líquidos são compostos orgânicos, cujo alinhamento das moléculas pode ser diretamente influenciado por um campo elétrico [Ondris-Crafort et al 1992]. Assim, variando a tensão sobre o receptor com cristal liquido, haverá um alinhamento de suas moléculas e a conseqüente variação do seu indice de refração, permitindo a seleção 
de um canal específico. O sistema apresentado por Hirabayashi opera em uma faixa de $50 \mathrm{~nm}$, com um espaçamento de $0,3 \mathrm{~nm}$, e tempo de sintonia de algumas dezenas de milisegundos.

\section{Amplificadores ópticos}

A atenuação do sinal na fibra óptica é um problema que pode comprometer o usos de fibras em sistemas de comunicações a longas distâncias. A partir de uma determinada distância, a intensidade do sinal cai para níveis inaceitáveis, exigindo alguma forma de amplificação que pode ser feita por repetidores elétricos ou amplificadores ópticos.

Os repetidores são sistemas eletrônicos, onde o sinal óptico é convertido para eletricidade e então é amplificado, para, posteriormente, ser reconvertido para um sinal óptico e seguir o percurso na fibra. Uma desvantagem desse sistema são as conversões óptico/elétricas e elétro/ópticas, que exigem um tempo de conversão e limitam o desempenho do sistema. Outra desvantagem é que os repetidores são normalmente projetados para operarem com sinais em formatos e velocidades específicas, o que não os torna transparentes ao formato dos dados e à taxa de transmissão. A vantagem desse sistema é que ele pode eliminar deformações no sinal óptico, como a dispersão.

Os amplificadores ópticos não podem eliminar a dispersão do sinal, mas, não necessitam de conversões eletro/ópticas e são totalmente transparentes ao formato do dado e à taxa de transmissão, tornando-se, assim, uma ferramenta importante no 
desenvolvimento das redes transparentes. Além disso, um único amplificador óptico pode amplificar simultaneamente sinais de mais de uma fonte.

Os amplificadores ópticos com fibras são baseados em fibras dopadas com determinados elementos do tipo terras raras, como o érbio, e permitem a amplificação de sinais. Esses amplificadores, chamados de EDFA (Erbium-Doped Fiber Amplifiers), têm um melhor desempenho quando o comprimento de onda do sinal amplificado está na janela de $1,5 \mu \mathrm{m}$, atingindo um ganho típico na ordem de 30 a $40 \mathrm{~dB}$ [Kazovsky et al 1994].

A fibra dopada com érbio recebe o sinal de um laser de amplificação, chamado laser de "bombeamento", que opera com 0,98 ou $1,48 \mu \mathrm{m}$, excitando os átomos do érbio e elevando-os a niveis mais altos de energia. O sinal a ser amplificado entra na fibra dopada e estimula os átomos de érbio a liberarem a energia excedente. Isto causa uma amplificação do sinal de entrada, pois, a energia liberada pelos átomos de érbio tem o mesmo padrão do sinal de entrada, somando-se ao mesmo [Lacroix; Vella 1995]. A figura 1.8 mostra esse sistema.

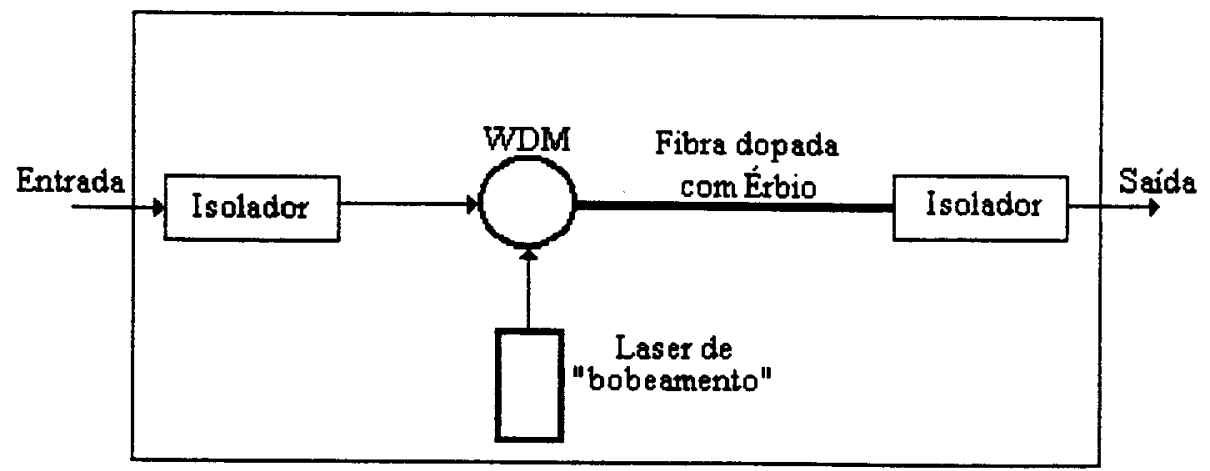

Figura 1.8 - Amplificador óptico. O laser de bombeamento excita os átomos de érbio que fornecem energia para a amplificação do sinal de entrada. 
No esquema da figura 1.8, o WDM faz a multiplexação do sinal de entrada e do sinal de bombeamento, que serão propagados na fibra dopada com érbio, e os isoladores impedem a propagação de resíduos de potência óptica do laser de bombeamento.

O isolador é um dispositivo que oferece uma baixa atenuação para a luz que se propaga em um sentido e uma alta atenuação para a luz que se propaga reversamente, podendo operar em uma grande faixa espectral. O princípio de funcionamento é formado por um polarizador de entrada, um rotacionador e um polarizador de saida, conforme mostra a figura 1.9 .

A luz de entrada é polarizada e, posteriormente, sob efeito de um campo magnético, é rotacionada em um determinado ângulo. Esse sinal é então entregue a um polarizador de saida que permite a sua passagem. Desta forma, a luz incidente na saída do isolador não pode se propagar em direção à sua entrada, formando um sistema isolador [Borgo; Celaschi 1996].

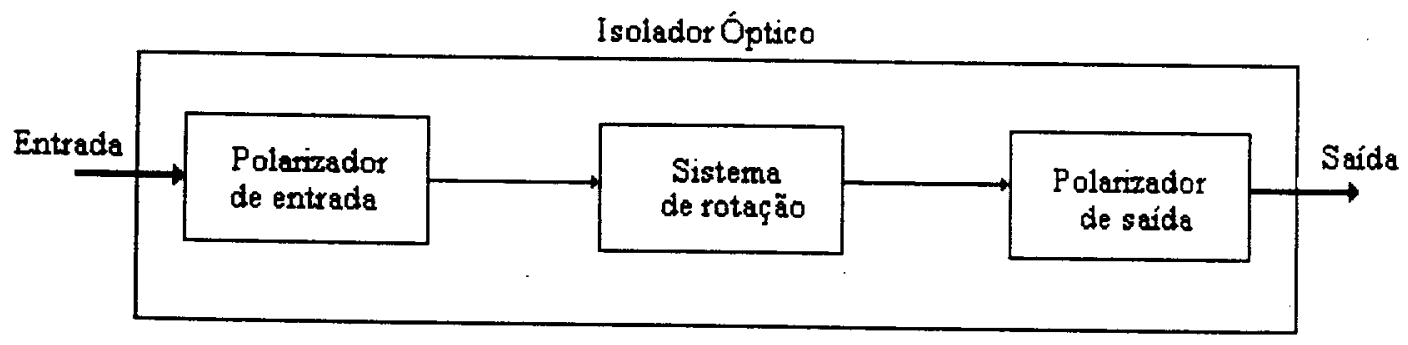

Figura 1.9 - Organização de um isolador óptico. A passagem de luz só é permitida em um único sentido. 


\section{Acopladores ópticos}

\subsection{Princípios de operação}

Os acopladores ópticos são dispositivos que permitem a interconexão entre diversas fibras ópticas [Scholl 1988] e podem ser analisados em função do número de portas, sensibilidade à direção de condução da luz, seletividade do comprimento de onda, tipo de fibra e níveis de atenuação [Hecht 1994].

Os acopladores também podem ser classificados em passivos, que operam sem a necessidade de fontes de alimentação, e em ativos, que necessitam de uma fonte de alimentação elétrica pelo fato de estarem diretamente associados a dispositivos eletrônicos, como repetidores [Husbands; Metclaf 1985].

Em relação à terminologia usada para a classificação dos acopladores, pode-se dividi-los nos seguintes tipos básicos [Giozza 1991, Hecht 1994, Robinson; Spandinger 1994]:

- Divisor (Splitter): É um sistema que divide um sinal de entrada entre várias saidas. Freqüentemente esses acopladores são chamados de $Y, T$ ou Árvore, dependendo do seu formato. Esse sistema funciona como se as saidas estivessem ligadas em paralelo e cada uma receberá um sinal menor que o sinal de entrada. Isto se deve ao fato do sinal óptico ser formado por fluxo de portadoras (fótons) e não por um potencial como a tensão, tendo sua potência dividida entre os receptores;

- Acoplador estrela (Star Coupler): É um sistema formado por um conjunto de entradas e um conjunto de saidas $(\mathrm{MxN})$, onde o sinal de qualquer 
entrada pode ser enviado para todas as saídas. Alguns acopladores do tipo estrela são direcionais e a luz deve ser transmitida em uma direção especifica (transmissivos), enquanto que outros são bidirecionais (reflexivos) e o sinal pode ser transmitido em qualquer direção;

- WDM (Wavelength Division Multiplexing): Este tipo de acoplador combina (multiplexa) diversas entradas, com diferentes comprimentos de onda, em uma única fibra. $\mathrm{O}$ mesmo acoplador pode realizar a demultiplexação do sinal oriundo de uma única fibra para diversas saídas.

A figura 1.10 mostra a representação dos acopladores ópticos descritos acima.

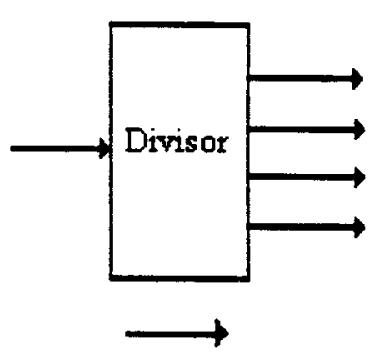

(A)

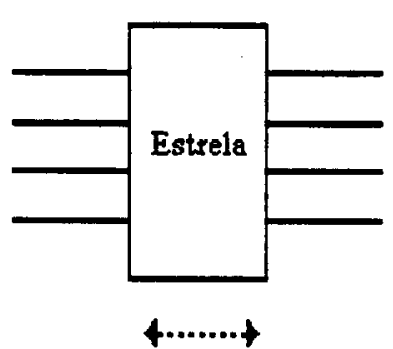

(B)

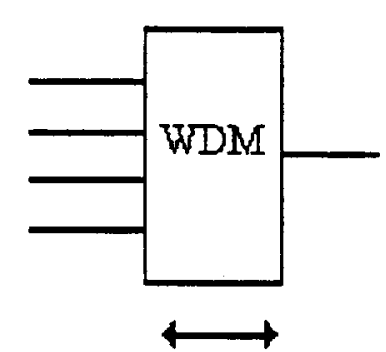

(C)

Figura 1.10 - Representação dos acopladores ópticos. Acoplador divisor (A), acoplador estrela (B) e WDM (C).

A operação do acoplador WDM é baseada na divisão do espectro de transmissão entre diversos canais, visando maximizar a performance do tempo de transmissão e minimizar o tempo de chaveamento entre os diversos nós do sistema de comunicação [Partridge 1994].

Essas características tornam o sistema WDM uma possivel solução para a interconexão de redes e para a interconexão entre processadores e memórias em arquiteturas paralelas de computadores, que tem tido, na interconexão elétrica, um grave problema para o seu desenvolvimento. 
A performance do sistema WDM pode ser medida em função do espaçamento de cada canal, do número de canais, das perdas no sistema. Entre suas vantagens, podem-se destacar:

- Passividade, pois, não necessitam de alimentação elétrica;

- Versatilidade do mesmo dispositivo poder multiplexar e demultiplexar sinais ópticos;

- Baixo nível de perdas;

- Os canais são independentes entre si;

- O sistema é transparente ao formato dos dados.

Uma análise a respeito da degradação do sinal, em sistemas de comunicação com WDM, foi feita por Blumenthal et al 1997, onde são mostrados fatores críticos, como o Crosstalk, a atenuação, a distorção e o ruído gerado por etapas de amplificação ou por fotodetectores.

Existe um esforço constante no sentido de se ampliar o número de canais possiveis de serem transmitidos, criando-se um sistema chamado WDM-denso, onde o espaço relativo a um determinado comprimento de onda é na ordem de $1 \mathrm{~nm}$ [Brackett 1990, Pan; Liang 1994].

Existe uma classificação da terminologia do sistema WDM, em função do espaçamento do canal, que é mostrada na tabela 1.2 [Wagner; Kobrinsk 1989].

Tabela 1.2 - Terminologia WDM em relação ao espaçamento do canal

\begin{tabular}{|c|c|c|c|}
\hline Terminologia & WDM & WDM Denso & FDM Óptico \\
\hline Espaçamento do conal (nm) & 100 & $10 \ldots 1$ & 0,1 \\
\hline Tecnologia de multiplexação & Acopladores & Grade de difração & Interferômetro \\
\hline
\end{tabular}


Nas faixas de 1,3 nm e 1,5 nm, existem espectros de baixas perdas, com cerca de $200 \mathrm{~nm}$ cada, que poderiam acomodar de 100 a 200 canais pelo sistema WDM-denso. No entanto, na prática, existem fatores como a dispersão, que limitam esse número a uma faixa de algumas dezenas de canais [Brackett 1990]. Uma análise da tecnologia sobre sistemas com muitos canais é feita por Nosu et al, onde é apresentado um sistema com FDM óptico, operando com 100 canais de dados e com um espaçamento de 0,1 nm [Nosu et al 1993].

\subsection{Fabricação de acopladores}

Existem acopladores de fibras fundidas (bicônicos), onde as fibras têm seus núcleos fundidos, permitindo a transferência de luz de uma para a outra. Na prática, não é necessário que haja um fusão completa, pois, se os núcleos forem colocados a uma distância de apenas alguns micrometros, ocorrerá um acoplamento por onda evanescente, que é uma parte da onda que se propaga pela capa da fibra e, em função da proximidade, poderá passar entre os dois núcleos [Hecht 1994]. Essa técnica pode ser utilizada na fabricação de acopladores divisores e estrela.

Outra maneira de se fazer um acoplador é através do uso da chamada microóptica, onde, uma lente com índice gradual e pequena distância focal, pode ser utilizada para a formação de um acoplador árvore, conforme mostra a figura 1.11 [Giozza 1991]. As lentes de índice gradual e os prismas podem ser implementados com diâmetros de uma fração de milimetro [Guha et al 1990] 


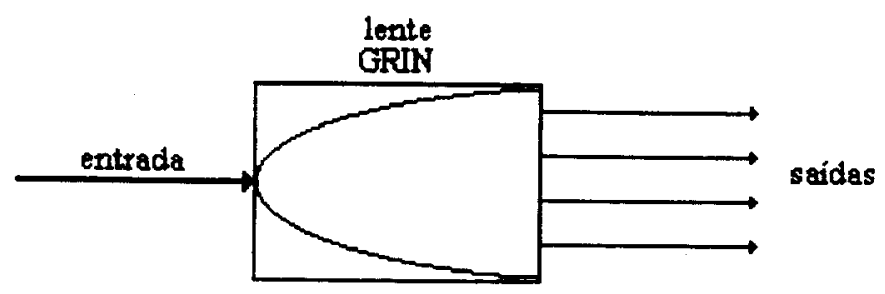

Figura 1.11 - Esquema de um acoplador Divisor. Esse sistema é desenvolvido com uma lente de indice gradual e tem uma entrada e $N$ saidas.

O uso de microóptica também permite o desenvolvimento de acopladores WDM, utilizando-se lentes e filtros de interferência, conforme mostra a figura 1.11. [Giozza 1991]. O multiplexador e o demultiplexador, mostrados na figura 1.12, são de 2 canais e podem ser associados em um arranjo de diversas unidades, para formarem sistemas WDM com mais canais.

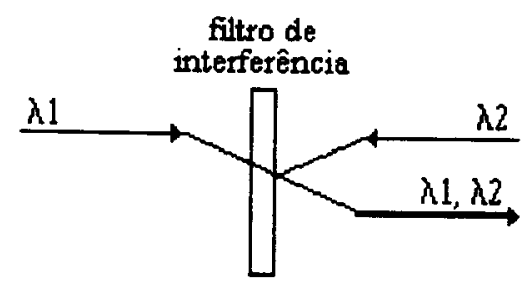

(A)

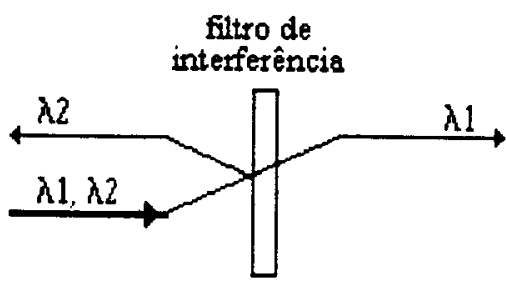

(B)

Figura 1.12 - Sistema de multiplexação WDM. A figura (A) mostra um sistema multiplexador e a figura (B) mostra o mesmo dispositivo sendo usado como demultiplexador.

Os dispositivos WDM também podem ser construídos a partir de grades de difração que espalham a luz em ângulos diferentes, conforme o comprimento de onda. Isto pode ser comparado a um prisma que refrata a luz em um ângulo dependente do comprimento de onda, decompondo o sinal de entrada. A figura 1.13 mostra esse conceito [Edwards 1989]. 


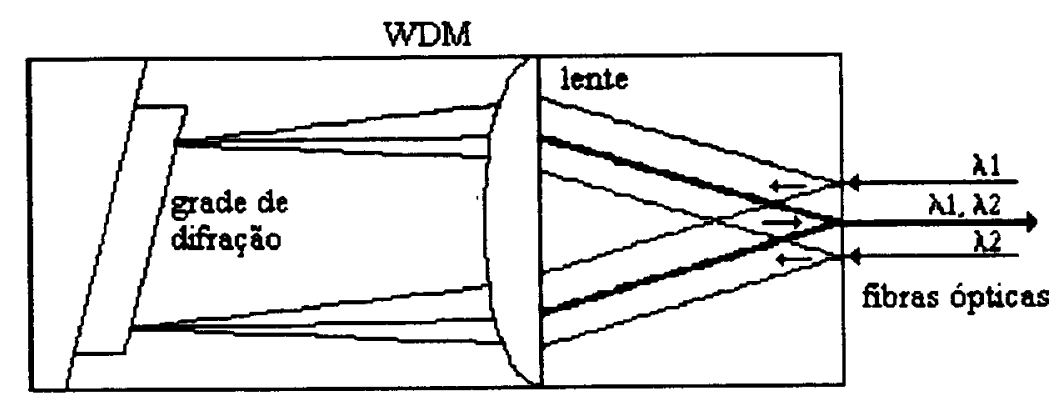

Figura 1.13 - Sistema de multiplexação óptica (WDM) de 2 canais. O sistema usa uma grade de difração para fazer a multiplexação dos sinais de entrada, $\lambda 1$ e $\lambda 2$, em uma única saida $(\lambda 1, \lambda 2)$ [Edwards 1989].

\section{Sistemas ópticos}

\subsection{Velocidade de transmissão}

Embora os sistemas ópticos tenham uma banda passante na ordem de $30 \mathrm{~Tb} / \mathrm{s}$ [Partridge 1994], os sistemas eletrônicos atuais operam na faixa de $2,5 \mathrm{~Gb} / \mathrm{s}$, sendo que o processamento desses sinais, a partir de $10 \mathrm{~Gb} / \mathrm{s}$, torna-se muito dificil. Isto coloca a eletrônica como um fator limitante para o uso do potencial oferecido pelos sistemas ópticos [Miki 1994, Saruwatori, 1994, Spirit et al 1994].

Uma técnica utilizada para aumentar o aproveitamento de um sistema WDM, é através da subdivisão de cada canal, em um processo TDM [Willner 1997]. Um exemplo de utilização desse princípio foi mostrado por Morioka [1994], onde cada um dos 40 canais de um acoplador WDM foi utilizado com TDM, permitindo um sistema final com taxa de transmissão de $1 \mathrm{~Tb} / \mathrm{s}$ em um única fibra monomodo com $4,9 \mathrm{Km}$. 
O cálculo da banda passante de um sistema determina a velocidade máxima de operação e depende do tempo de resposta da fibra óptica utilizada, do tempo de resposta do transmissor e do tempo de resposta do receptor em uso.

O tempo de resposta do sistema (Ts) pode ser calculado pela equação 1.1 .

$$
\mathrm{Ts}=\left(\mathrm{Tt}^{2}+\mathrm{Tr}^{2}+\mathrm{Tf}^{2}\right)^{1 / 2}
$$

Onde: Tt é tempo de resposta do transmissor

Tr é o tempo de resposta do receptor

Tf é o tempo de resposta da fibra utilizada

Os tempos de respostas dos transmissores e receptores são tabelados pelos fabricantes e dependem da velocidade de transição do dispositivo. O tempo de resposta, na fibra, depende do tempo de resposta ocasionado pelas dispersões modal e cromática e é dado pela equação 1.2 .

$$
\mathrm{Tf}=\left(\mathrm{Tdm}^{2}+\mathrm{Tdc}^{2}\right)^{1 / 2}
$$

Onde: Tdm é tempo de resposta devido à dispersão modal

Tdc é o tempo de resposta devido à dispersão cromática

O tempo de resposta devido à dispersão modal (Tdm) depende do valor da dispersão modal (D), dado pelo fabricante, e do comprimento da fibra (L) e pode ser expresso pela equação 1.3 .

$$
\mathrm{Tdm}=\mathrm{D} * \mathrm{~L}
$$


O tempo de resposta devido à dispersão cromática (Tdc) depende do valor da dispersão cromática da fibra (dc), que é dado pelo fabricante, da largura espectral da fonte de luz $(\Delta)$ e do comprimento da fibra (L). O seu valor é expresso pela equação 1.4 .

$$
\mathrm{Tdc}=\mathrm{dc} * \Delta * \mathrm{~L}
$$

O tempo de reposta dos transmissores e receptores ópticos provoca um limite máximo da velocidade de comunicação. Além do tempo de resposta, existe o chamado tempo de atraso ou tempo de propagação, que é um atraso entre a chegada do sinal em um dispositivo e a produção de um sinal de saida. O tempo de propagação não afeta a velocidade de operação do sistema, mas, causa um deslocamento no tempo [Hecht 1994]. Em um sistema de comunicação óptica, haverá um tempo de propagação no transmissor, na fibra e no receptor, que, somados, irão causar uma latência intrínseca do sistema.

Em sistemas onde as distâncias entre os transmissores e os receptores são pequenas, a velocidade máxima de transmissão fica dependente, quase que exclusivamente, do tempo de resposta do transmissor e do receptor. Assim, supondo um sistema de curta distância com $\mathrm{Tt}=7 \mathrm{~ns}$ e $\mathrm{Tr}=12 \mathrm{~ns}$, teremos uma banda passante máxima de $\left(6 \mathrm{~ns}^{2}+10 \mathrm{~ns}^{2}\right)^{1 / 2}=11,7 \mathrm{~ns}$, o que equivale a $85,5 \mathrm{MHz}$.

O tempo de resposta determina a velocidade com que um dado pode ser transmitido em um determinado sistema óptico. Desta forma, a tentativa de se 
transmitir informações, com velocidades superiores a essa, provocaria uma sobreposição de dados (overlap).

\subsection{Atenuação no sistema óptico}

A atenuação óptica mede o nivel de redução da potência óptica de um sinal que se propaga por uma fibra óptica. O seu valor depende basicamente das características intrínsecas da fibra, do comprimento de onda do sinal transmitido, do comprimento da fibra e das ligações com dispositivos ópticos, como transmissores, receptores e acopladores.

A atenuação em um sistema $(\mathrm{P})$ pode ser genericamente medida pela relação entre a potência de saída $(\mathrm{Ps})$ e a potência de entrada $(\mathrm{Pe})$, conforme mostra a equação 1.5 .

$$
\mathrm{P}=-10 \log _{10}(\mathrm{Ps} / \mathrm{Pe})
$$

Em um sistema de multiplexação óptica WDM, o cálculo do nivel de perdas do sistema depende de diversos fatores, como as características intrínsecas do acoplador, o seu número de saídas e a distância entre os nós e o acoplador. Esse cálculo é expresso pela equação 1.6 e é fundamental para que possa determinar a potência da fonte de luz e a sensibilidade mínima do receptor óptico.

$$
\mathrm{Lt}=\mathrm{Lw}+\mathrm{La}+\mathrm{Lo}+\mathrm{Lf}+\mathrm{Lm}
$$


A variável $\boldsymbol{L w}$ representa a atenuação intrínseca do próprio WDM, cujo valor é dado pelo fabricante e normalmente é menor que $2 \mathrm{~dB}$. A variável $L a$ é a atenuação no acoplamento do multiplexador e normalmente varia de 2 a $3 \mathrm{~dB}$. A variável $L o$ é um fator de perdas relativo ao fanout óptico do sistema, ou seja, depende do número de saídas $(N)$ do acoplador e é expresso pela equação 1.7 .

$$
\text { Lo }=1,5+10 \log _{10} \mathrm{~N}
$$

A variável $L f$ representa o nivel de atenuação na fibra de ligação entre os nós do sistema óptico e o acoplador WDM. O seu valor gira na faixa de 1 a $2 \mathrm{~dB} / \mathrm{Km}$. A variável $\boldsymbol{L} \boldsymbol{m}$ representa um valor adicional de margem de segurança e normalmente é em torno de $5 \mathrm{~dB}$.

Para exemplificação do cálculo da atenuação $(L t)$ em um sistema com WDM, podemos usar um WDM com 8 canais, com atenuação intrínseca de $2 \mathrm{~dB}$ e atenuação de acoplamento de 2,5 dB. A distância entre os nós e o acoplador será de 5 metros e a perda nessa fibra de ligação é de $1 \mathrm{~dB} / \mathrm{Km}$. A margem de segurança escolhida é de $5 \mathrm{~dB}$.

Usando um valor de $L f$ de $1 \mathrm{~dB} / \mathrm{Km}$, será feito um cálculo em relação a 10 metros, que é a distância entre dois nós quaisquer do sistema. Assim teremos um valor de Lf igual a $0,01 \mathrm{~dB}$.

O valor de Lo é calculado por:

Lo $=1,5+10 \log 8=10,53 \mathrm{~dB}$

Com base nesses valores pode-se calcular a atenuação do sistema, que será:

$L t=2+2,5+10,53+0,01+5=20,04 \mathrm{~dB}$ 
Calculando-se o total de perdas no sistema $(\mathrm{Lt})$, pode-se determinar a potência óptica necessária para os transmissores e a sensibilidade mínima necessária para os receptores. Suponha um transmissor que coloque na fibra uma potência óptica de $16 \mathrm{~dB}$ (valor dado pelo fabricante) e um sistema de comunicação com um nível de atenuação (Lt) de 15,2 dB (valor calculado). Somando-se os dois valores, teremos um valor de $31,2 \mathrm{~dB}$, que é a relação de potência que atinge o receptor e, portanto, é a relação de sensibilidade mínima exigida do mesmo.

A sensibilidade do receptor é um valor dado pelo fabricante e expresso em $\mathrm{dB}$, com base na potência óptica incidente e da relação sinal/ruído. Conforme mencionado, uma relação sinal/ruído na faixa de 40 a $50 \mathrm{~dB}$ é considerada boa e o sinal que incide sobre o receptor, normalmente está na faixa de 1 a $10 \mu \mathrm{W}$.

\section{Conclusões do Capítulo}

Como conclusões do capitulo podem-se mencionar:

- Os sistemas ópticos de comunicações apresentam vantagens como a transparência ao formato de dados a uma alta banda passante;

- O desenvolvimento do LASER e das fibras ópticas com baixo nível de atenuação foram a base de desenvolvimento das comunicações ópticas;

- Os multiplexadores ópticos WDM permitem a multiplexação de diversos sinais ópticos e a sua transmissão em uma única fibra;

- Atualmente existem sistemas ópticos operando na faixa de $\mathrm{Gb} / \mathrm{s}$ e $\mathrm{Tb} / \mathrm{s}$. 


\section{Capítulo 2}

\section{Arquiteturas e Redes Ópticas}

\section{Apresentação}

O objetivo deste capítulo é descrever alguns modelos de redes ópticas já desenvolvidos. Inicialmente é feita uma revisão a respeito dos fundamentos de arquiteturas paralelas e de redes de interconexão, sendo que, posteriormente, é feita uma descrição sobre o formalismo de classificação de redes WDM e é feita a descrição de alguns modelos de redes ópticas.

\section{Arquiteturas paralelas}

Uma arquitetura paralela permite a utilização de diversos processadores e unidades de memória, permitindo um aumento da capacidade de processamento. Essa característica é importante, no processamento de alguns sistemas, que seria inviável em sistemas convencionais de processamento.

O desenvolvimento de um sistema paralelo de processamento envolve problemas de dispositivos físicos, arquiteturas, programação e de redes de interconexão. A rede de interconexão é a maneira como é feita a ligação entre os processadores e memórias do sistema e pode ser considerada uma das questões 
básicas no desenvolvimento de arquiteturas paralelas, pois, o seu desempenho afeta sensivelmente o funcionamento de todas as demais partes da arquitetura.

Os dispositivos eletrônicos têm tido um avanço significativo em relação ao aumento da escala de integração, aumento da velocidade de operação, e diminuição do custo. Apesar desse avanço tecnológico, as redes de interconexão mais eficientes, como a crossbar, têm uma implementação elétrica muito complexa, e, em alguns casos, pode ser até inviável.

Existem diversas formas de se classificar uma arquitetura paralela, e a maioria delas não pode ser considerada de forma mutuamente exclusiva. Em relação à sua estrutura, uma arquitetura pode ser classificada de três formas básicas, que são: [Hwang; Briggs 1985]

- Arquitetura Pipeline;

- Arquitetura vetorial;

- Arquitetura com sistema multiprocessador.

Em uma máquina seqüencial, a execução de uma instrução envolve a busca da instrução na memória, a sua decodificação na CPU e finalmente a sua execução, formando um ciclo de instrução [Monteiro 1992]. Em um sistema pipeline, essas fases podem se sobrepor entre diversas instruções, criando um certo nível de paralelismo. Esse processo é exemplificado na figura 2.1, onde, por exemplo, enquanto é feita a decodificação da primeira da instrução, também é simultaneamente feita a busca da segunda instrução da memória.

Em arquiteturas vetoriais existem diversas unidades processadoras, que são formadas por processadores e memórias, e operam de modo sincronizado, podendo realizar a mesma operação. O fetch de instruções é realizado por uma unidade 
especial de controle, que possui um processador de controle e uma memória de controle. Essa unidade distribui as instruções para as unidades processadoras, que, por sua vez, operam com dados locais.

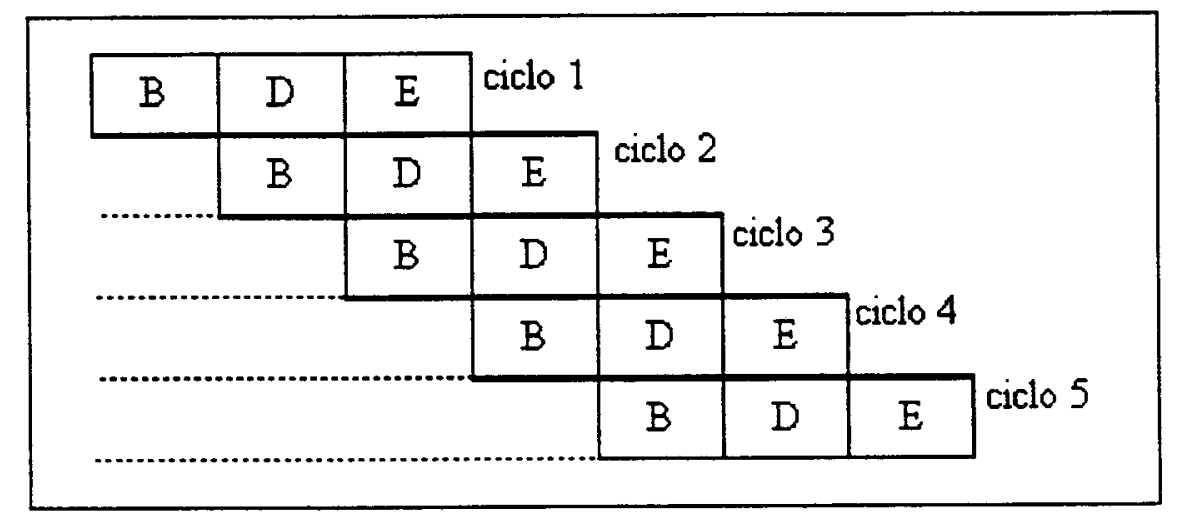

Figura 2.1 - Sistema pipeline. Os ciclos de instrução são divididos em fases de busca (B), decodificação (D) e execução (E), sendo que a execução dos ciclos é sobreposta.

A arquitetura multiprocessador, em alguns casos, pode se assemelhar a uma arquitetura vetorial, porém, opera de modo assíncrono. Nesse caso, diversos processadores podem ter acesso ao mesmo conjunto de memórias distribuidas e cada processador pode ter a sua própria memória local.

Segundo Flynn, uma arquitetura paralela pode ser classificada em função da forma como as instruções e os dados são manipulados. Nesse caso, existem quatro classificações diferentes, que são [Flynn 1966]:

- SISD (Single Instruction Single Data);

- SIMD (Single Instruction Multiple Data);

- MISD (Multiple Instruction Single Data);

- MIMD (Multiple Instruction Multiple Data). 
O sistema SISD representa as arquiteturas seqüenciais convencionais, com um processador e um módulo de memória. Mesmo nesse caso, atualmente, existem processadores que podem operar com um sistema pipeline, criando uma espécie de paralelismo. O sistema SIMD representa a arquitetura vetorial, descrita anteriormente.

O sistema MISD envolve vários processadores manipulando o mesmo conjunto de dados, assim, o resultado obtido por um processador poderia ser utilizado como entrada de um outro processador. Esse é considerado um modelo meramente teórico. O sistema MIMD envolve o uso de diversos processadores executando diversos dados diferentes e de forma independente.

Com a evolução das arquiteturas paralelas tem surgido novos modelos que não se enquadram perfeitamente nas classificações descritas acima. Por exemplo, Duncan sugere, entre outras coisas, que a arquitetura MIMD seja subdividida em MIMD com memória distribuída, MIMD com memória compartilhada e MIMD paradigma [Duncan 1990]

Os sistemas MIMD, com memória distribuída e compartilhada, também podem ser classificados como multicomputador e multiprocessador [Bhuyan 1987], cuja representação é mostrada na figura 2.2 .

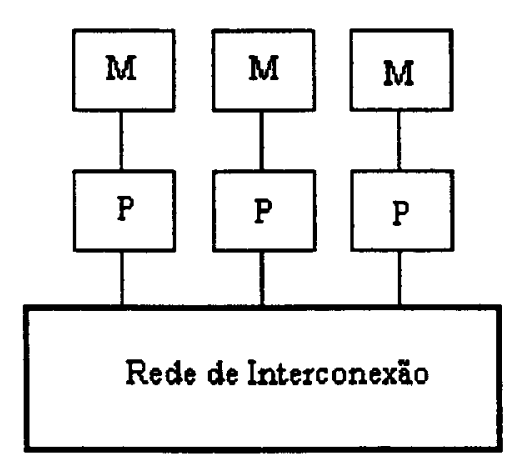

(A)

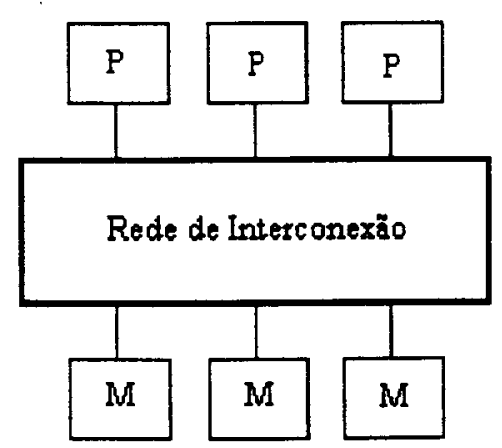

(B)

Figura 2.2 - Representação de sistemas paralelos. A figura (A) mostra o sistema multicomputador e a figura (B) mostra do sistema multiprocessador. 
As arquiteturas MIMD paradigmas englobam sistemas não convencionais como o sistema MIMD/SIMD ou o Dataflow. No primeiro caso, uma parte do sistema MIMD é configurado para operar como um sistema SMD, criando uma arquitetura híbrida.

\section{Arquitetura Dataflow}

A arquitetura Dataflow é destacada nesse item pelo fato de, no capitulo 5 desta tese de doutorado, serem feitos projetos e análises sobre o uso de sistemas fotônicos no desenvolvimento da Chave de Distribuição utilizada nessa arquitetura.

No sistema Dataflow existe um paradigma onde a seqüência de execução das instruções é dependente da existência de operandos. Esse modelo tem vantagens como o fato de ser assíncrono e não necessitar de um controle centralizado de paralelismo. Embora haja uma dependência seqüencial de operandos no programa, a utilização de um grafo para descrever os programas elimina a necessidade de um controle central ou contador de programa, uma vez que as operações são realizadas logo que os operandos estiverem disponíveis [Louri 1990, Lee 1994]

Esse sistema cria uma operação funcional (não procedural) que depende da chegada dos operandos e não de acessos à memória. As desvantagens do sistema são o overhead, a estrutura de dados e a programação. O overhead é ocasionado pela necessidade de se detectar instruções e gerar tokens de resultados. A estrutura de dados encontra dificuldades na manipulação de estruturas como vetores, uma vez que os tokens representam valores escalares. A programação depende de linguagens específicas, como o SISAL, e não é realizada com linguagens mais populares como $\mathrm{C}$ 
ou Pascal. Embora a implementação de uma máquina dataflow não seja simples, a evolução tecnológica tem incentivado novas pesquisas nessa área [Lee, Hurson 1994].

A figura 2.3 mostra o grafo que representa o programa para executar a equação 2.1. Nesse grafo, os nós representam as operações e os arcos representam a dependência de dados.

$$
\mathbf{R}=\frac{[(\mathrm{a}+\mathrm{b}) * \mathrm{c}]}{\mathrm{y}}
$$

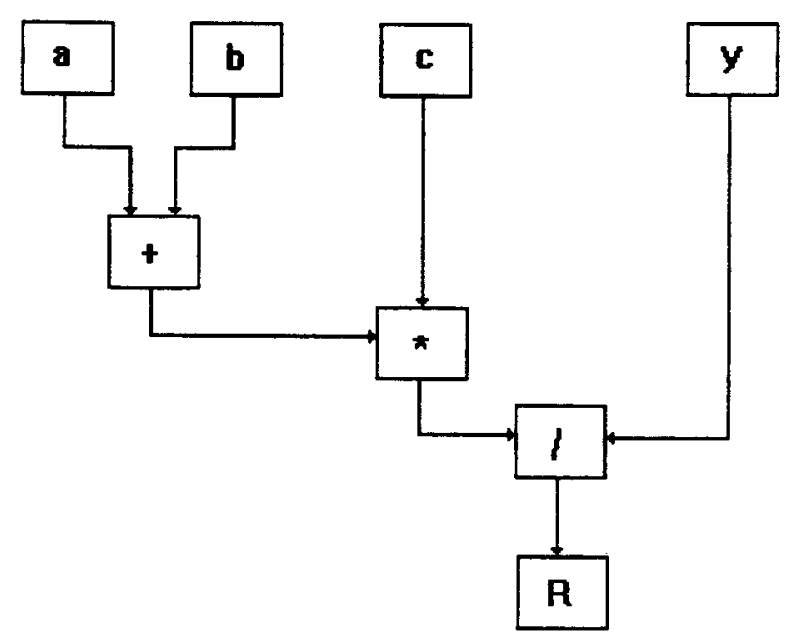

Figura 2.3 - Grafo em Dataflow. Esse grafo representa a estrutura de resolução da equação $R=(A+B){ }^{*} C / Y$, em um sistema dataflow.

A arquitetura Dataflow foi proposta na década de 70 e surgiram várias arquiteturas baseadas nesse conceito de fluxo de dados, como, por exemplo, a MTTDA do MIT, a Sigma-1 no Japão e a MDFM da Universidade de Manchester. Cada um destes sistemas possui características positivas e negativas, que foram comparativamente descritas por Magna - 1997.

A figura 2.4 mostra a organização básica da arquitetura MDFM (Manchester DataFlow Machine), que possui duas redes de interconexão, que são chamados de 
Chave de Distribuição e Chave de Coleta. Caso a Chave de Distribuição não tenha uma vazão apropriada, ocorrerá um aumento do número de pacote enfileirados na memória, caso a Chave de Coleta não tenha vazão apropriada os dados serão armazenados em uma unidade especial chamada de Fila de Fichas, aliviando as Unidades-Processadoras.

Alguns trabalhos foram recentemente desenvolvidos com base na arquitetura MDFM, como o sistema SAW (Simulador da Arquitetura Wolf) [Cavenaghi 1997], a análise de desempenho de redes convencionais de interconexão em arquiteturas a fluxo de dados [Martini 1994] e o sistema SEED (Sistema de Escalonamento e Execução Dataflow) [Magna 1997].

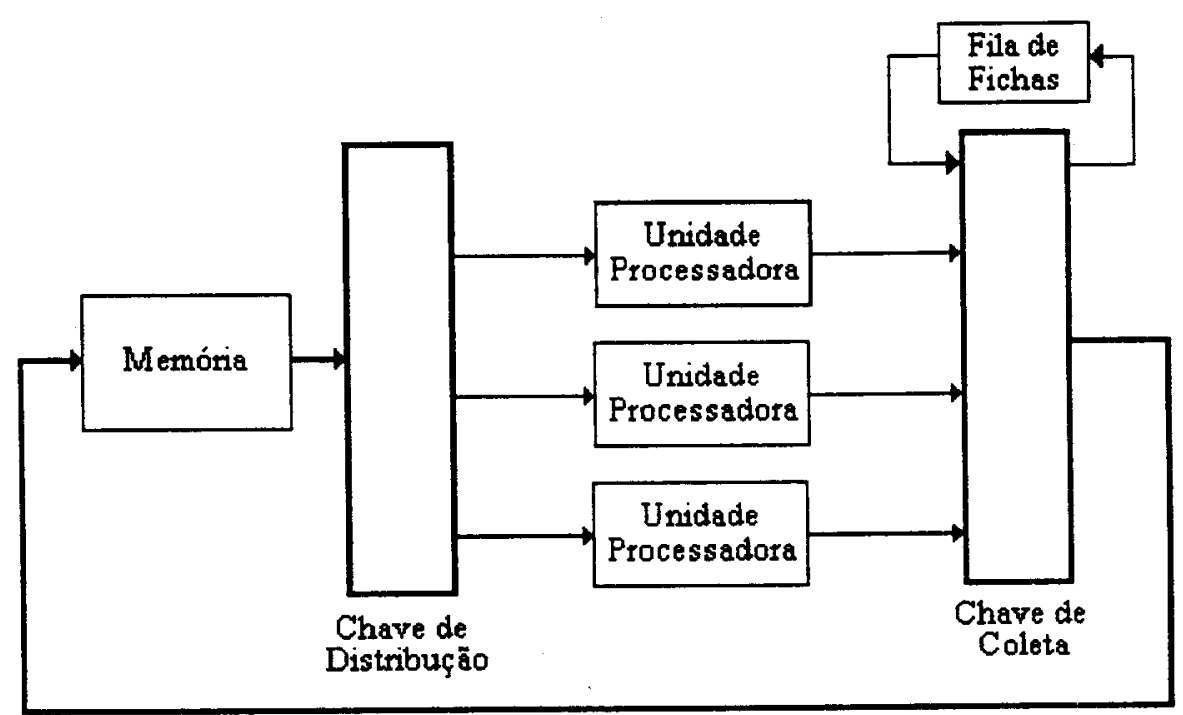

Figura 2.4 - Organização básica da arquitetura Manchester DataFlow Machine. Essa arquitetura necessita de duas redes de interconexão, que são chamadas de Chave de Distribuição e de Chave de Coleta. 


\section{Sistemas Ópticos em Dataflow}

O sistema de interconexão óptica para arquitetura dataflow, apresentado por McAulay, visa superar os limites impostos pelo interfaceamento eletrônico através da implementação de sistema de processamento eletrônico e diodos laser, montado em uma base transparente para chaveamento óptico. Esse sistema é baseado em um circuito integrado com alta escala de integração e diodos laser integrados sobre um substrato transparente para chaveamento [MacAulay 1993]

Cada unidade processadora é composta de diversos processadores arranjados de forma matricial e montados em um sistema de três camadas, compostas por um vidro, ar e um espelho. A luz emitida passa pelo vidro e sofre uma reflexão quando entra na camada de ar, sendo, posteriormente, refletido pelo espelho. Cada processador tem um conjunto de transmissão e recepção óptica, podendo comunicarse com qualquer outro processador em menos de $300 \mathrm{ps,} \mathrm{em} \mathrm{um} \mathrm{sistema} \mathrm{10 \times 10.} \mathrm{Um}$ conjunto de cabos ópticos liga a unidade processadora à unidade de memória, que é construída similarmente.

O modelo de arquitetura óptica dataflow, apresentado por Lauri, usa uma interconexão em espaço livre. Embora o artigo mencione o modelo crossbar como o ideal para uma interconexão, ele menciona as dificuldades de sua implementação, a nível óptico, e propõe uma interconexão em espaço livre, com estrutura em anel, que permite conexão direta entre dois nós. Cada nó do grafo é representado por uma linha em um plano 2-D e é composto por uma unidade processadora, que executa as operações e o controle de seqüência do fluxo de dados, uma unidade de comunicação, que é responsável pelo protocolo de passagem de mensagem, e uma unidade de 
interconexão, que representa uma camada fisica de comunicação para a transferência de mensagens entre os processadores [Louri 1990].

A utilização de uma unidade processadora e uma unidade de comunicação permite que o processamento e a comunicação sejam realizadas simultaneamente. A unidade de comunicação verifica o destino da mensagem e a unidade de interconexão envia a informação em uma estrutura do tipo anel, com uma via de comunicação entre nós adjacentes, e uma segunda via que permite a comunicação entre nós não adjacentes.

Os modelos ópticos associados à arquitetura dataflow, que foram estudados, não são baseados em interconexões ópticas do tipo WDM e propõem sistemas mais complexos, envolvendo não apenas a interconexão óptica, mas, também o uso de óptica integrada. Isto exige o desenvolvimento de circuitos integrados especiais e sistemas microópticos específicos para essas arquiteturas, o que não é tão simples. $O$ uso do sistema WDM é atualmente mais conveniente, pelo ponto de vista prático e comercial, pois, esse sistema é mais genérico para várias aplicações e, portanto, tem maiores opções comerciais.

\section{Redes de interconexão}

Uma rede interconexão pode ser definida como um conjunto de conexões e chaves, que permitem a comunicação entre processadores e memórias em uma arquitetura paralela [Bhuyan 1987]. A rede é uma questão fundamental no desenvolvimento dessas arquiteturas [Bhuyan et al 1989, Pountain 1992], que exigem um grande esforço de comunicação durante o processamento. 
A eficiência da interconexão está diretamente relacionada com o número de conexões por nó (grau), e com o número de pontos intermediários por onde a mensagem deve passar para trafegar entre o transmissor e o receptor (diâmetro), que devem ser os menores possiveis [Pountain 1992]. A tabela 2.1 mostra as características consideradas ideais para uma rede de interconexão.

Tabela 2.1 - Características ideais de uma rede de interconexão

\begin{tabular}{|c|c|}
\hline Caracteristica & Valor esperado \\
\hline Grau & Mínimo \\
\hline Diâmetro & Mínimo \\
\hline Conectividade & Máxima \\
\hline Latência & Mínima \\
\hline Vazão & Máxima \\
\hline
\end{tabular}

A latência é o tempo exigido para a transmissão de uma informação do transmissor para o receptor final. Esse valor depende da taxa de transmissão e dos estágios intermediários pelos quais a informação tem que passar entre o nó inicial e o final. A conectividade é o número de nós com os quais um determinado nó pode ter comunicação direta e a vazão representa o número de informações que conseguem trafegar na rede, por unidade de tempo.

Uma rede de interconexão pode ser classificada quanto ao modo de temporização, ao modo de chaveamento de comunicação e ao modo de controle [Bhuyan et al 1989]. 
O modo de temporização divide o sistema em síncrono ou assíncrono. Os sistemas sincronos necessitam de um clock central que faz o referencial de temporização. No modo assíncrono, os dispositivos da rede operam independentemente do clock global.

O modo de chaveamento de comunicação divide a rede em chaveamento por circuito e chaveamento por pacotes. No sistema por circuito, é estabelecido um caminho, entre o transmissor e o receptor, que será usado durante toda a transferência dos dados. No sistema por pacote, a mensagem é dividida em pacotes que são transmitidos por estágios intermediários da rede

O modo de controle é classificado em centralizado ou distribuído. No primeiro caso um controle central recebe as requisições e faz o gerenciamento da transmissão, enquanto que, no segundo caso, as requisições são manipuladas individualmente.

O desempenho ideal de uma rede de interconexão pode exigir implementações que, a nivel eletrônico, poderiam apresentar um alto custo ou até mesmo inviabilizar o projeto prático. Assim, uma solução é o uso de sistemas ópticos de comunicações, que, entre outras coisas, são imunes à interferência eletromagnética, possuem alta banda passante, são transparentes ao formato dos dados e são transparentes à taxa de transmissão.

O ideal é que a comunicação entre dois nós da rede de interconexão seja realizada sem conversões eletro/ópticas intermediárias, fazendo a rede operar como uma rede transparente. A eletrônica não permite implementações com o mesmo desempenho da óptica e o uso de sistemas eletrônicos intermediários tende a prejudicar sensivelmente o desempenho do sistema, diminuindo a velocidade máxima de transmissão, aumentando a latência e tornando o sistema mais sujeito a erros de transmissão. 
As redes de interconexão podem ser classificadas em três tipos básicos, que são a shared-bus, a crossbar e a MIN. A arquitetura shared-bus é mostrada na figura 2.5, e é composta por um único canal de comunicação compartilhado por todos os nós da rede. Esse canal único impõe um alto nivel de contenção e torna essa arquitetura a menos eficiente dos três modelos apresentados.

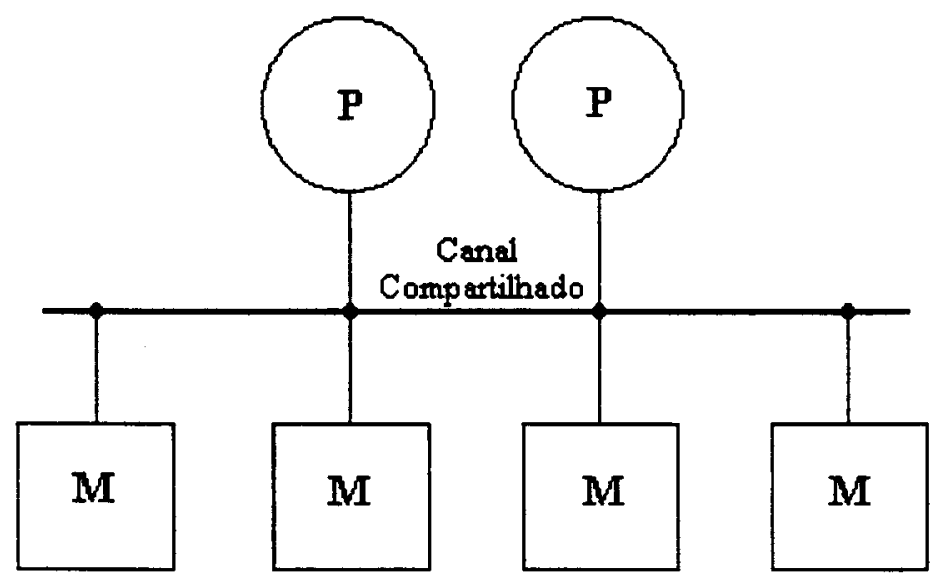

Figura 2.5 - Rede de interconexão shared-bus. Os processadores (P) e memórias (M) do sistema têm um processo de comunicação baseado em um único canal compartilhado.

A arquitetura crossbar, cuja estrutura lógica é mostrada na figura 2.6 , é a mais eficiente das três arquiteturas apresentadas e é a que tem maior custo de implementação. Essa arquitetura faz ligações diretas entre todas as portas de entrada e saída da rede, permitindo que diversas permutações de dados sejam realizadas de modo independente e simultâneo, sem latência e com um baixo nível de contenção

Evidentemente deve haver um sistema de controle para evitar que mais de um processador requisite o mesmo canal ou a mesma memória ao mesmo tempo. A probabilidade de um determinado canal estar disponível para um determinado processador e a probabilidade de que uma memória seja simultaneamente requisitada 
por um determinado número de processadores são dois bons indicadores, na análise de desempenho de uma rede de interconexão [Youn; Chen 1993].

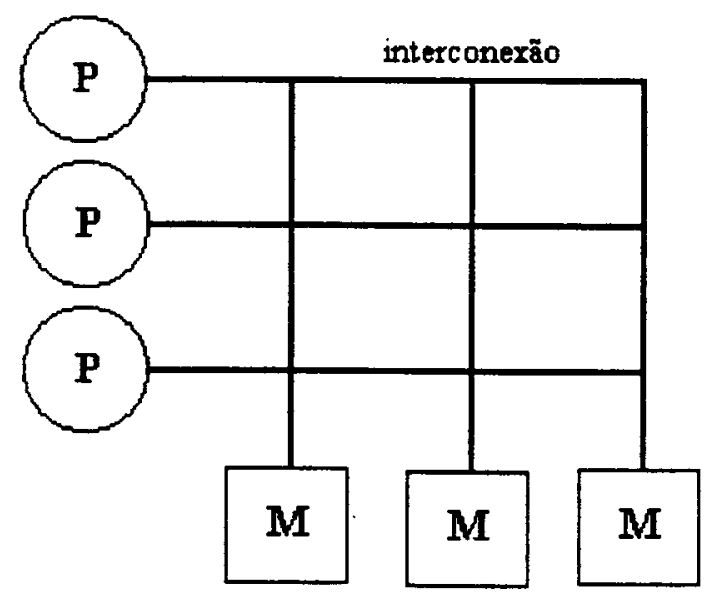

Figura 2.6 - Estrutura lógica da rede crossbar. Há uma ligação direta entre todos os dispositivos do sistema o que aumenta sensivelmente a sua eficiência, porém, aumenta o número de conexões e o custo de implementação.

A arquitetura do tipo MIN (Multistage Interconnection Network) representa um conjunto de diferentes interconexões, onde a informação é transmitida entre dois nós através de pontos intermediários. Sua eficiência é menor que o crossbar, mas tem um menor custo de implementação. Entre as redes MIN de interconexão podem-se mencionar arquiteturas como: anel, malha, árvore, hipercubo e omega. Em todas essas redes, a transmissão entre dois nós pode exigir estágios intermediários. Opticamente, isso exigiria conversões eletro-ópticas intermediárias, contrariando o princípio de transparência óptica. A figura 2.7 exemplifica duas destas redes. 


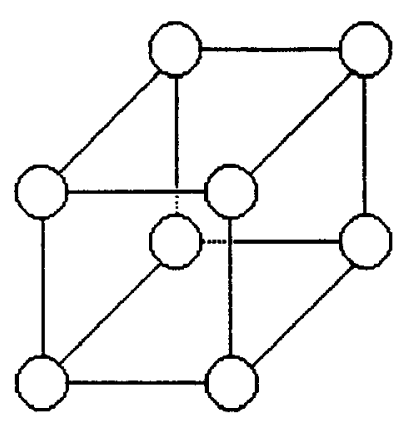

(A)

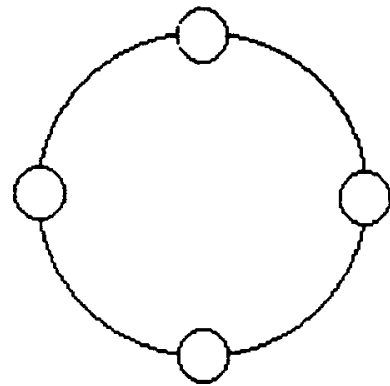

(B)

Figura 2.7 - Exemplificação do sistema de rede MIN através da arquitetura hipercubo (A) e da arquitetura anel (B).

Apesar da vantagem da interconexão crossbar em uma arquitetura paralela, existem limitações fisicas que restringem a sua implementação eletrônica, como o número de componentes exigidos, o sistema de controle e o tempo de atraso nos componentes. Todos esses problemas crescem consideravelmente à medida que o número de nós do sistema aumenta, uma vez que grandes sistemas são configurados a partir de pequenos sistemas crossbar implementados em circuitos integrados específicos [Sawchuk et al 1987]. Para a implementação de um sistema NXN são necessárias $\mathrm{N}^{2}$ conexões, o que torna o sistema altamente complexo para a interconexão de centenas de processadores e memórias.

Em qualquer rede de interconexão deve haver alguma forma de controle, para evitar que dois ou mais nós transmitam simultaneamente pelo mesmo canal, o que provocaria uma colisão. Assim, é necessário que haja um programa de gerenciamento, impondo uma disciplina de acesso ao meio fisico.

Um protocolo de acesso ao meio deve ser analisado em função da sua capacidade de vazão, capacidade de priorização, retardo na transmissão e estabilidade [Soares 1995]. 
Esses protocolos podem ser divididos em cinco categorias básicas, que são [Zakir Jr 1988]:

- Protocolos com alocação fixa;

- Protocolos com alocação aleatória;

- Protocolos com alocação por reserva;

- Protocolos com alocação por enquete;

- Protocolos com alocação mista.

Existem vários protocolos de controle de acesso ao meio fisico, porém, entre os mais comuns, podem-se mencionar o TDM, Aloha, CSMA e o CSMA/CD [Tanembaum 1988].

Uma solução para os problemas causados pelos dispositivos eletrônicos é a utilização do sistema de comunicação óptica WDM (Wovelength Division Multiplexing), onde diversos canais ópticos são multiplexados e transportados por uma única fibra. Além disso, a comunicação direta, entre dois nós da rede, pode ser realizada de modo totalmente transparente.

Apesar das vantagens do sistema WDM, a sua utilização fica limitada ao número de canais disponiveis no acoplador e às características operacionais dos transmissores e receptores ópticos [Aly; Dowd 1993, Borella et al 1994].

Em determinadas situações seria necessário um número muito grande de canais no acoplador, fugindo aos modelos comerciais. Assim, alguns estudos visam solucionar esse problema, organizando os nós em grupos [Ghose 1994] ou usando diversos acopladores [Chiarulli et al 1994]. Essas tecnologias apresentam inconvenientes, como um aumento de contenção ou aumento do grau de um nó, mas, conseguem contornar limitações de escalabilidade. 
O transmissores e receptores, que podem ser fixos ou sintonizáveis, influenciam diretamente a velocidade de operações na rede, a sua arquitetura e sua capacidade de reconfiguração dinâmica [Borella et al 1994]. Isso exige que esses componentes sejam analisados em função do número de canais que podem sintonizar e do tempo de sintonia, que infelizmente são características opostas [Brackett 1990].

Os sistemas de sintonia passiva, como os laser sintonizados mecanicamente ou os filtros Fabry-Perot, podem operar com centenas de comprimentos de onda, mas, tem um tempo de sintonização na ordem de milisegundos. Os sistemas de sintonia ativa, que podem usar injeção de corrente para a sintonização de um determinado comprimento de onda, têm uma sintonização na ordem de nanosegundos, mas, operam com poucos canais [Brackett 1990, Mukherjee 1992-a, Pan; Liang 1995].

\section{Redes de Interconexão WDM}

Segundo Mukherjee, um sistema WDM pode ser classificado quanto ao modo de comunicação. Essa classificação divide as redes WDM em redes single-hop, onde a comunicação entre dois nós é feita sem a utilização de nós intermediários, e redes multi-hop, onde a comunicação entre dois nós é feita com o auxilio de nós intermediários [Mukherjee 1992-a, Mukherjee 1992-b].

A segunda classificação dos sistemas WDM é relativa à caracterização de sintonia dos dispositivos transmissores e receptores, que podem ser classificados em sintonizáveis ou fixos. 
Essa classificação divide o sistema em quatro grupos distintos, que são descritos a seguir [Mukherjee 1992-a]:

- FT-FR (Transmissores e receptores fixos): Esta estrutura, normalmente, é usada em sistemas multi-hop, pois, a comunicação é sempre fixa entre dois pontos específicos;

- TT-FR (Transmissor Sintonizável e Receptor Fixo): Esta estrutura tem transmissores que podem sintonizar um comprimento de onda específico, enquanto que os receptores sempre recebem dados através de um comprimento de onda fixo. Isto permite que qualquer transmissor envie dados a qualquer receptor;

- FT-TR (Transmissor Fixo e Receptor Sintonizável): Neste sistema os transmissores são fixos e os receptores realizam o controle de sintonização, escolhendo o transmissor do qual receberão informações. O sistema impede a ocorrência de colisões e o broadcast pode ser facilmente realizado;

- TT-TR (Transmissor Sintonizável e Receptor Sintonizável): Este sistema é o mais flexivel e todos os dispositivos são sintonizáveis. Isto permite um grande número de arranjos no processo de comunicação, mas, também pode exigir controles mais complexos.

A classificação, relativa à forma de sintonização, permite que a rede óptica seja caracterizada pela notação $C C-F T^{i} T T^{j}-F^{m}{ }^{m} R^{n}$. Nesse caso, um nó tem $i$ transmissores fixos, $j$ transmissores sintonizáveis, $m$ receptores fixos, $n$ receptores sintonizáveis. A sigla $C C$ determina que a rede possui canal compartilhado e exclusivo de controle $(C C)$, que determina as coordenadas da comunicação através dos canais de dados 
Os dispositivos sintonizáveis dão mais versatilidade à rede de comunicação, no entanto, impõem restrições relativas ao custo e ao tempo de sintonização. Os sistemas totalmente fixos obrigam a implementação de redes multi-hop, enquanto que, em sistemas onde haja um dispositivo sintonizável e um dispositivo fixo, poderá haver a implementação de uma arquitetura single-hop, porém, o número de nós fica limitado ao número de canais do acoplador WDM, criando um problema de escalabilidade.

A topologia fisica do tipo sigle-hop pode ser formada por um acoplador WDM, conforme mostra a figura 2.8. No entanto, essa mesma topologia pode ser utilizada para a implementação de diversos modelos virtuais de redes multi-hop [Mukherjee 1992-b]. Redes como a ShuffleNet, Bruijn Graph, Manhattan Street Network, etc. podem ser virtualmente implementadas na mesma topologia estrela, bastando que os transmissores e receptores sejam ajustados conforme a configuração da rede [Vetter; Du 1993, Borella 1994].

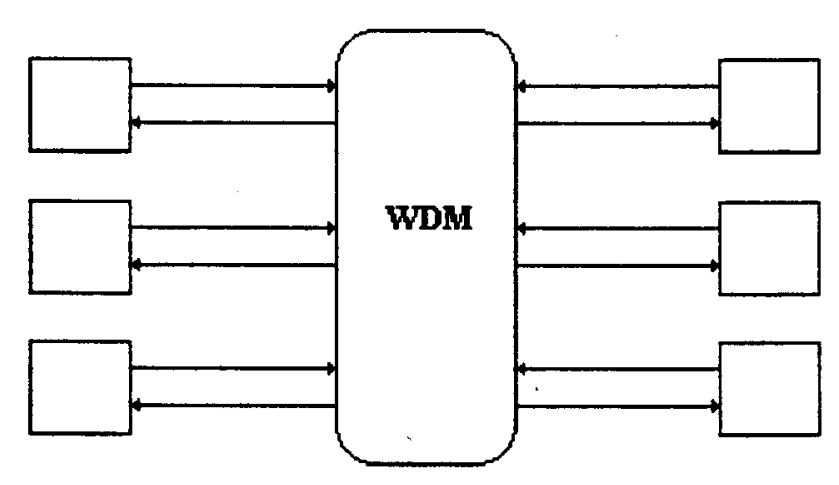

Figura 2.8 - Um sistema de multiplexação óptica WDM single-hop 3x3. Nesse caso, qualquer nó pode enviar ou receber dados diretamente de qualquer nó da rede, sem que a informação passe por nós intermediários.

A implementação de topologias virtuais do tipo multi-hop pode ser útil para contornar o problema do tempo de sintonização, permitindo que o sistema opere totalmente com transmissores e receptores fixos. 
A figura 2.9 mostra uma rede de interconexão ShuffleNet com oito nós em um sistema $2 \times 2$, ou seja, cada nó tem dois transmissores e dois receptores operando com comprimentos de onda fixos. Essa rede poderia ser implementada na topologia estrela descrita na figura 2.8 , bastando que os comprimentos de onda fossem ajustados conforme as exigências da rede ShuffleNet.

Em muitos casos, as topologias virtuais são implementadas com dispositivos sintonizáveis, porém, de baixa velocidade. Isso se deve ao fato destes dispositivos serem sintonizados somente durante a configuração da rede e permanecerem inalterados durante a operação do sistema

Esse ajuste de sintonia permite que seja possível realizar uma reconfiguração dinâmica da topologia virtual utilizada. Isso permite uma otimização do sistema de comunicação, que pode, rapidamente, selecionar rotas alternativas em casos de falhas ou congestionamento [Vetter; Du 1993, Borella 1994].

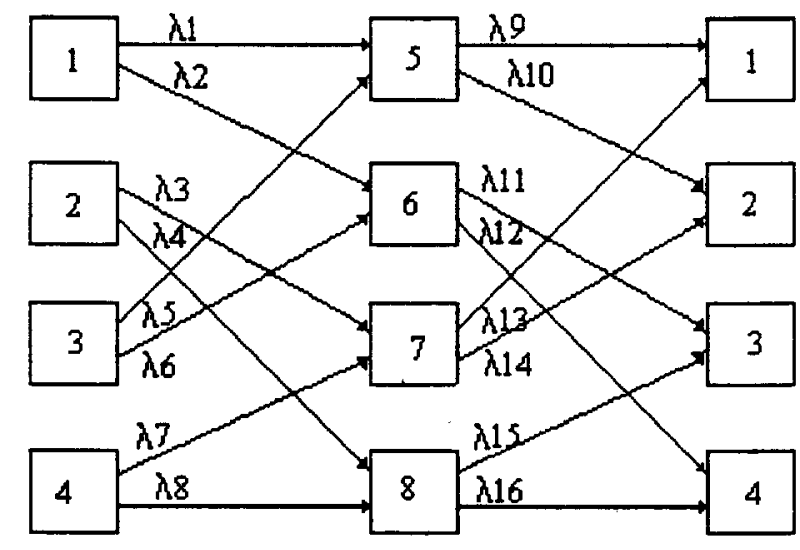

Figura 2.9 - Rede de interconexão ShuffleNet. Essa rede é uma arquitetura MIN e uma determinada informação pode passar por diversos nós intermediários até chegar ao seu destino.

A reconfiguração dinâmica pode ser realizada com o sistema de comunicação temporariamente parado, o que pode causar problemas em algumas aplicações. A 
reconfiguração, realizada com sistema funcionando, pode ser feita em uma parte de cada vez, assim, apenas uma parte do sistema estaria inativo de cada vez. Isto pode ocasionar perdas de informações, mas, existem algoritmos especificos que visam diminuir o tempo de reconfiguração [Borella et al 1994].

\section{Modelos de redes ópticas}

\subsection{LAMBDANET}

A rede LAMBDANET [Goodmam 1990] é um sistema com um transmissor fixo e $\mathrm{N}$ receptores fixos, formando uma configuração $\mathrm{FT}-\mathrm{FR}^{\mathrm{N}}$, conforme mostra a figura 2.10 .

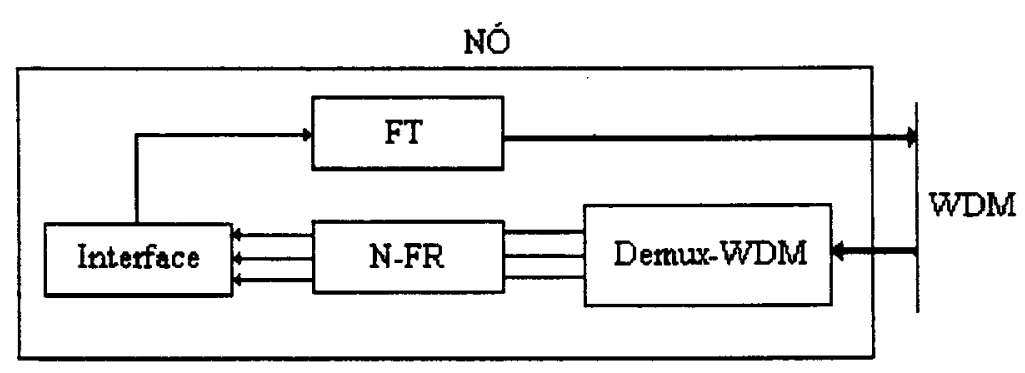

Figura 2.10 - Configuração de um nó da rede LAMBDANET. Existe um transmissor fixo e um sistema de multiplexagem com $N$ receptores fixos, onde $N$ é o numero de nós do sistema.

O transmissor fixo limita o tamanho da rede em função do número de canais do WDM, porém, o sistema admite que todos os nós transmitam sem interferência. Esse sistema operou com WDM-Denso e chegou a transmitir informações com uma 
taxa de $2 \mathrm{~Gb} / \mathrm{s}$ com 18 canais de comunicação. O seu inconveniente é o uso de $\mathrm{N}$ receptores em cada nó, o que lhe dá um alto grau e aumenta sensivelmente o custo de implementação.

\subsection{FOX}

O sistema FOX (Fast Optical Crossconnect) é um modelo experimental de interconexão óptica que investiga o potencial de utilização de transmissores, com sintonização rápida, em arquiteturas paralelas. Esse sistema é formado por dois acopladores, conforme mostra a figura 2.11 , que fazem a comunicação em sentidos opostos [Arthus et al 1988].

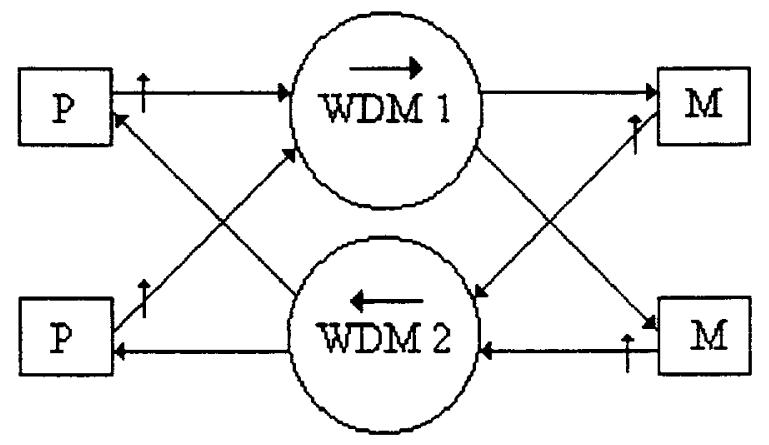

Figura 2.11 - Representação da arquitetura FOX. Cada nó do sistema tem um transmissor sintonizável e um receptor fixo. $O$ WDMI faz a comunicação entre os processadores $(P)$ e as memórias $(M)$, enquanto o WDM2 faz a comunicação no sentido oposto.

A rede FOX apresenta um baixo grau, com apenas um transmissor sintonizável e um receptor fixo por nó. Como os receptores são fixos, é necessário um algoritmo para controle de colisão e o número máximo de nós fica limitado ao número de canais. O algoritmo de contenção utilizado é "binary exponential backoff', que tem 
bom desempenho quando o acesso à memória não é intenso. O sistema é composto por $N$ processadores e $N$ memórias, com $4 \leq N \leq 256$, e a transmissão de pacotes, com tempo entre $100 \mathrm{~ns}$ e $1 \mu \mathrm{s}$, pode ser realizada com transmissores, cujo tempo de sintonia é na ordem de $20 \mathrm{~ns}$.

Uma alternativa visando a diminuição do overhead da rede FOX foi feita através da implementação da rede HIPASS (Hybrid Packet Switching System), [Arthurs et al 1988-b], que usa um sistema de transmissores e receptores fixos. Os receptores informam, em um broadcast, se estão livres para recepção e um algoritmo "tree-polling" de controle de contenção. Na interface de comunicação há um buffer eletrônico que armazena sinais de entrada para verificação do header e sintonização dos transceptores. Esse sistema diminuiu o overhead, mas, é dependente de um processo eletrônico.

\subsection{RAINBOW}

É um sistema da IBM, apresentado em 1990 por Dono et al, que usa uma configuração FT-TR, com 32 nós operando a uma taxa de $200 \mathrm{Mb} / \mathrm{s}$. O nó transmissor envia continuamente uma requisição com o endereço do nó receptor $\mathrm{e}$ mantém o seu receptor sintonizado no referido canal. Quando o receptor enviar uma resposta, será estabelecida uma conexão e a comunicação será feita por chaveamento de circuito, sem a ocorrência de colisões. Um nó dessa rede, enquanto fica monitorando uma resposta do receptor, não pode ser utilizado na recepção de pacotes, o que afeta o seu desempenho. 


\subsection{TDMA-C}

O sistema TDMA-C (Time Division Multiple Acess with a Control channel), [Bogineni; Dowd 1992], é um sistema TT-TR-FR. O receptor fixo monitora um canal de controle, onde cada nó tem um slot de tempo e transmite o endereço do receptor e o número do canal de transmissão. Através dos slots, os nós atualizam duas tabelas de controle, uma indica o estado dos receptores e a outra indica o estado dos canais de comunicação.

Os nós receptores também devem monitorar o canal de controle, assim, um transmissor envia suas informações no seu slot e sintoniza o seu transmissor, sendo que o receptor, ao identificar um slot com o seu endereço, sintoniza o seu receptor no canal especificado e a transmissão pode ser feita. Além do canal de controle ter que ser monitorado pelo transmissor e pelo receptor, o sistema também depende do tempo de sintonia do transmissor e do receptor.

\subsection{POPS}

O sistema POPS (Partioned Optical Passive Star), apresentado por Chiarulli et al 1994, é formado por uma topologia composta por diversos acopladores WDM, e tem a vantagem de permitir um alto nivel de escalabilidade em um sistema single-hop. Nessa rede, existem $\mathrm{N}$ grupos de nós, com $\mathrm{N}$ WDM cada. Assim, o nó $i$ de cada conjunto sempre envia dados ao WDM- $i$ de todos os conjuntos. Isto permite que um nó envie dados diretamente a qualquer receptor, porém, exige que o mesmo tenha $\mathrm{N}$ transmissores. 
Embora o sistema permita a escalabilidade, existe um custo para isso, pois, a mesma depende do aumento do número de grupos ou do aumento do número de nós em cada grupo. O primeiro caso exige um aumento do número de transmissores em cada nó. O segundo caso necessita de acopladores WDM com mais canais, o que exige acopladores mais sofisticados e fontes de luz sem pulsos largos.

\subsection{OPTIMUL}

O sistema OPTIMUL (OPTically Interconnected MULtiporocessor) é uma rede WDM, que divide o sistema em grupos de nós, conforme mostra a figura 2.12 [Ghose 1994].

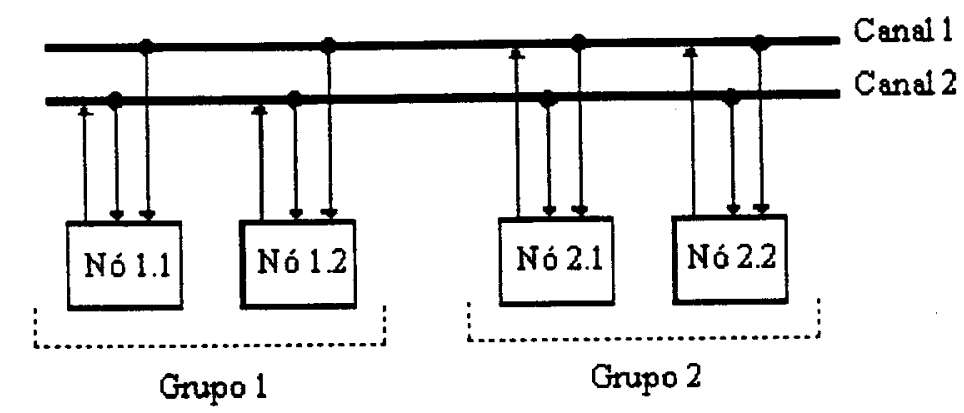

Figura 2.12 - Estrutura da rede OPTIMUL. Os nós de um grupo transmitem para o mesmo canal, mas podem receber de todos eles.

Cada nó de um grupo tem um transmissor fixo e $\mathrm{N}$ receptores fixos, formando um sistema FT-FR ${ }^{\mathrm{N}}$. Todos os nós de um grupo usam o mesmo canal transmissor, mas, podem receber dados de qualquer canal, através dos $\mathrm{N}$ receptores fixos.

Os resultados do trabalho mostraram que 100 nós podem ser acomodados em apenas 5 canais de comunicação WDM e, para coordenar o acesso de um grupo ao 
canal de transmissão, é feito um simples controle randômico, que admite que uma requisição seja feita em 20 ns

Na OPTIMUL, cada nó possui um processador, uma memória local, uma memória cache e o sistema de interfaceamento eletro/óptico. Também existe uma preocupação relativa ao compartilhamento de memória, pois, cada processador pode ter acesso à memória de qualquer outro nó e fazer uma cópia da posição acessada. Um broadcast permite que todas as cópias sejam sempre atualizadas e que a coerência seja mantida. Para simplificar o algoritmo é admitido apenas uma requisição pendente de memória.

No modelo ideal de um sistema, com memória compartilhada, todos os processadores podem se comunicar simultaneamente com a mesma, realizando operações de leitura e escrita, em um único passo. Em termos práticos, esse modelo é implementado de um modo alternativo, com a divisão da memória em módulos e com o uso de uma rede de interconexão, que permite a troca de dados entre processadores e memórias [Waterson; Jemkis 1994].

\subsection{DCCN}

Na rede DCCN (Distributed Channel Controller Network) os nós são mostrados como estações de trabalho, cujos receptores são ajustados para receberem informações em uma freqüência específica e os transmissores são sintonizáveis conforme a necessidade de transmissão, configurando um sistema TT-TR [Janoska; Todd 1994]. 
Para cada canal de comunicação existe um canal especifico de controle e cada um deles pode suportar até $\mathrm{N}$ estações. Assim, cada estação tem uma sistema de controle, que, além do aceso ao sistema óptico, possui um barramento elétrico paralelo, que é usado para transmissão de informações pouco requeridas, como troca de configurações, alocações e clock.

\subsection{SLOTTED-ALOHA/PA}

A rede Slotted-Aloha/PA (Polite Access) [Sudhaker et al 1994] é um sistema TT-TR com $\mathrm{N}$ canais de dados e um canal de controle, que é monitorado por todos os receptores ociosos. O transmissor envia ao canal de controle, através de um protocolo Aloha, um quadro indicando a origem, o destinatário e o canal de dados que deseja transmitir. Se o receptor estiver ocioso e não ocorrer uma colisão no canal de controle, então o receptor receberá o quadro.

Após o quadro de controle o transmissor envia os dados que só serão recebidos se o receptor estiver sintonizado e não ocorrerem colisões. Nesse processo, só haverá comunicação se não houver colisões no acesso ao canal de controle e durante a transmissão de dados. 


\section{Conclusões do Capítulo}

Este capítulo aborda diretamente o conceito de redes ópticas de interconexão e pode ser considerado o mais importante da revisão. Como conclusões do capítulo podem-se mencionar:

- O alto grau de dificuldade de implementação de algumas redes com sistemas elétricos pode ser sensivelmente atenuado com o uso de sistemas ópticos;

- Existe todo um formalismo teórico de classificação das redes ópticas de comunicação;

- A tecnologia óptica está suficientemente madura para permitir a implementação de sistemas de alto desempenho, operando na faixa de $\mathrm{Gb} / \mathrm{s}$ e aproveitando a possibilidade de transparência ao formato de dados e transparência da taxa de transmissão;

- Com um formalismo teórico desenvolvido e com diversos modelos de redes ópticas implementados satisfatoriamente, pode-se concluir que a utilização de redes ópticas é uma alternativa real, vantajosa e viável, sendo que o seu uso tende a viabilizar o desenvolvimento de diversas novas pesquisas. 


\section{Capítulo 3}

\section{Simulação e Desempenho de Redes}

Este capítulo apresenta um conjunto de conceitos relativos às técnicas de simulação, à teoria de filas e também apresenta uma descrição dos parâmetros básicos utilizados na análise de desempenho de uma rede de comunicação de dados. Esses conceitos estão associados ao processo de simulação de redes ópticas que foi implementado e à análise dos resultados obtidos, que são descritos nos capítulos quatro e cinco.

\section{Simulação}

Um processo de simulação pode ser definido como um conjunto de experiências baseadas em uma série de cálculos e rotinas pré-determinadas, que descrevem o comportamento de um sistema real ao longo de um determinado periodo de tempo [Kobayashi 1978]. Isso permite que, a partir da criação de um modelo do sistema real e do fornecimento de alguns parâmetros de entrada, se analise o comportamento de diversos outros parâmetros envolvidos no funcionamento do sistema.

A simulação é uma técnica freqüentemente usada quando as soluções analiticas não são viáveis ou em casos onde a implementação de um sistema real apresenta um alto custo ou deve ser feita com a menor margem possivel de erros. $\mathrm{O}$ 
seu uso também pode trazer vantagens como a flexibilidade do projeto ou a aceleraçâo tecnológica.

A flexibilidade do projeto permite que determinadas caracteristicas do sistema sejam alteradas e testadas antes da sua montagem real, podendo aumentar as chances de sucesso e permitindo uma conseqüente diminuição de custos e tempo. Essa flexibilidade também permite simular e analisar o comportamento do sistema em condições consideradas críticas, que, a nivel real, poderiam comprometer o seu funcionamento.

O atual ambiente de aceleração tecnológica também estimula a simulação, pois permite o desenvolvimento de projetos que são baseados em dispositivos cuja tecnologia ainda se encontra em fase de amadurecimento. Essa vantagem tem sido amplamente utilizada no desenvolvimento de projetos de redes de comunicações ópticas, onde determinadas características como, por exemplo, a velocidade de sintonização dos transmissores ópticos é atribuida com um valor superior aos modelos comerciais e assim analisada sua influência no desempenho geral da rede.

No desenvolvimento de um sistema óptico computacional, em determinados casos, podem ser necessários alguns anos entre o projeto de um sistema óptico, sua implementação e seus testes finais. Desta forma, a simulação pode ser observada como uma ligação entre um projeto conceitual e o seu protótipo [Louri 1994]

\subsection{Modelo de simulação}

Um modelo de simulação é uma representação de um sistema real através de um conjunto de suas características e, portanto, é considerado uma abstração do 
mesmo [Naylor 1971]. A abstração permite representar uma parte do sistema através de um modelo mais simples e viabiliza a implementação do processo de simulação.

$\mathrm{O}$ próprio conceito de abstração torna-se relativo, pois, o ato de abstrair consiste-se na separação de uma ou mais partes de um todo, assim, o nivel de abstração do sistema real torna-se uma questão chave no desenvolvimento do processo de simulação. Normalmente, um sistema real não é tão simples que possa ser representado sem abstrações, sendo necessário que se determine qual o nível necessário de abstração [Kobayashi 1978].

Um aumento do nivel de abstração tende a exigir um volume cada vez maior de dados para assegurar que a mesma seja próxima da realidade e permita uma simulação com resultados satisfatórios [Naylor 1971].

A necessidade de manipulação de um grande volume de dados pode exigir um grande esforço de processamento de informações. Em determinados casos, essa exigência pode inviabilizar o processo de simulação e, em outros casos, os resultados finais poderiam não justificar o esforço de simulação requerido. Evidentemente que um nível baixo de abstração pode inviabilizar a obtenção de resultados satisfatórios.

A abstração exige que seja feita uma seleção criteriosa das características do sistema que serão utilizadas na simulação, no entanto, a falta de regras específicas e a impossibilidade de se considerar todas as características de um sistema, tornam a modelagem uma forma de arte e não de ciência [Sauer; Chandy 1981].

Como não há regras para se fazer a abstração de um sistema real [MacDougall 1989], cabe ao projetista chegar a uma relação satisfatória entre o nivel de abstração necessário e a viabilidade de implementação do sistema de simulação, formando uma relação de equilíbrio que pode ser chamada de "relação abstração- viabilidade". Essa relação procura encontrar um nivel de 
abstração que, além da viabilidade de implementação, garanta determinados níveis de exatidão nas respostas da simulação.

Um modelo de simulação não pode ser classificado de forma única [Naylor 1971], porém, uma classificação usual é a chamada classificação do modelo do sistema, que descreve o seu comportamento em função de um modelo matemático, que pode ser [Naylor 1971, Davies 1989]:

- Modelo Determinístico: é um sistema que não opera com variáveis randômicas, sendo que os dados de entrada são fixos;

- Modelo Estocástico: é um sistema que opera com variáveis randômicas, tendo características operacionais em função de uma probabilidade;

- Modelo Estático: é um sistema que trabalha de modo independente do tempo e que normalmente tem características determinísticas, podendo ter soluções matemáticas diretas;

- Modelo Dinâmico: é um sistema onde há interações variáveis com tempo, havendo uma relação entre o evento em atividade com os eventos anteriores e posteriores.

\subsection{Etapas da simulação}

A fase de planejamento de um sistema de simulação pode ser dividida em várias etapas [MacDougall 1989], que não podem ser definidas de modo muito distinto, pois estão diretamente relacionadas. O desenvolvimento de uma dessas etapas pode exigir revisões em etapas desenvolvidas anteriormente ou, em determinados casos, algumas dessas etapas podem ser desenvolvidas 
simultaneamente. Essas etapas de simulação podem ser basicamente resumidas em três tipos, que são: a análise e modelagem do sistema real, a validação de dados e a avaliação do modelo. Essas três etapas são descritas nos itens a seguir.

\subsubsection{A análise e modelagem do sistema real}

A análise do sistema real é feita a partir de um levantamento de informações a respeito do seu funcionamento e da maneira como operam suas diversas partes. A partir dessas informações, é feita a modelagem, criando-se um modelo que represente o seu comportamento.

Essa é uma fase de aprendizado para o projetista, onde são observados os fatores fundamentais a serem utilizados no processo de simulação, levando-se em consideração como as diferentes partes do sistema interagem entre si, quais são as variáveis envolvidas no sistema, quais os dados que devem ser analisados na simulação, quais as condições iniciais do seu funcionamento, quais as restrições do sistema, etc

Além do modelo do sistema, que mostra o seu tipo, é necessário que se analise o comportamento do sistema em relação ao modo como os eventos ocorrem em função do tempo, criando um modelo de distribuição.

Um modelo de distribuição pode ser desenvolvido a partir da análise do sistema real ou pode ser desenvolvido através da adaptação de um sistema presumivelmente semelhante. Isto dá ao projetista um determinado grau de liberdade para propor características fundamentais aos parâmetros de funcionamento do sistema [Naylor 1971]. 
Em casos onde haja poucos dados e a sua distribuição não seja conhecida, é possivel propor um determinado modelo e analisar o comportamento do sistema em função do mesmo [MacDougall 1989]. Isso pode exigir uma série de ajustes e diversas execuções do processo de simulação, até que se atinja um modelo considerado satisfatório.

Existem diversos modelos de distribuição, entre os quais se pode mencionar a distribuição geométrica, a distribuição binomial, a distribuição exponencial, a distribuição de Poisson e a distribuição uniforme [Naylor 1971 e Kobayashi 1978].

\subsubsection{Distribuição geométrica}

A distribuição geométrica é baseada no sistema de Bernoulli, onde os eventos são analisados de forma independente e um determinado evento tem uma probabilidade $p$ de ocorrer com sucesso e uma probabilidade $q$ de não ocorrer sucesso. Nessa distribuição, são repetidos diversos experimentos até que se obtenha sucesso no experimento número $\boldsymbol{x}$, o que é expresso pela equação 3.1 [Naylor 1971, Held 1994].

$\mathrm{P}(\mathrm{x})=p q^{\mathrm{x}}$

Onde:

$\mathrm{P}(\mathrm{x})$ é a probabilidade de sucesso na tentativa número $\mathrm{x}$.

$p$ é a probabilidade de sucesso na ocorrência de um evento isoladamente. $q$ é a probabilidade de não haver sucesso, ou seja: $p=1-q$. 


\subsubsection{Distribuição Binomial}

Se for realizada uma seqüência de $\boldsymbol{n}$ ensaios de Bernoulli, a probabilidade de que um evento ocorra $x$ vezes será dada através de uma distribuição binomial, que é expressa por:

$$
P(x)=\left(\begin{array}{l}
n \\
x
\end{array}\right) p^{x} q^{n-x}
$$

Onde:

$$
\left(\begin{array}{l}
n \\
x
\end{array}\right)=\frac{n !}{x !(n-x) !}
$$

\subsubsection{Distribuição Exponencial}

$\mathrm{Na}$ distribuição exponencial, o tempo entre dois eventos é exponencialmente distribuído e o sistema é considerado "sem memória", ou seja, a ocorrência de um evento não depende dos eventos anteriores e, além disto, há apenas uma pequena probabilidade de ocorrência de um evento em um pequeno intervalo de tempo.

Esse sistema é dependente da taxa de ocorrência de um determinado evento. Essa taxa pode ser representada pela variável $\lambda$, assim, o tempo médio entre dois eventos é 1/ג [Naylor 1971]. Assim, a função de densidade de probabilidade, que descreve a taxa de ocorrência de eventos, será expressa por $f(x)$ na equação 3.3 e a função de distribuição acumulativa $\mathrm{F}(\mathrm{x})$ será expressa por 3.4 . 


$$
\begin{aligned}
& f(x)=\lambda e^{-\lambda x} \\
& F(x)=1-e^{-\lambda x}
\end{aligned}
$$

A figura 3.1 mostra o formato dos gráficos das funções $f(x)$ e $F(X)$.
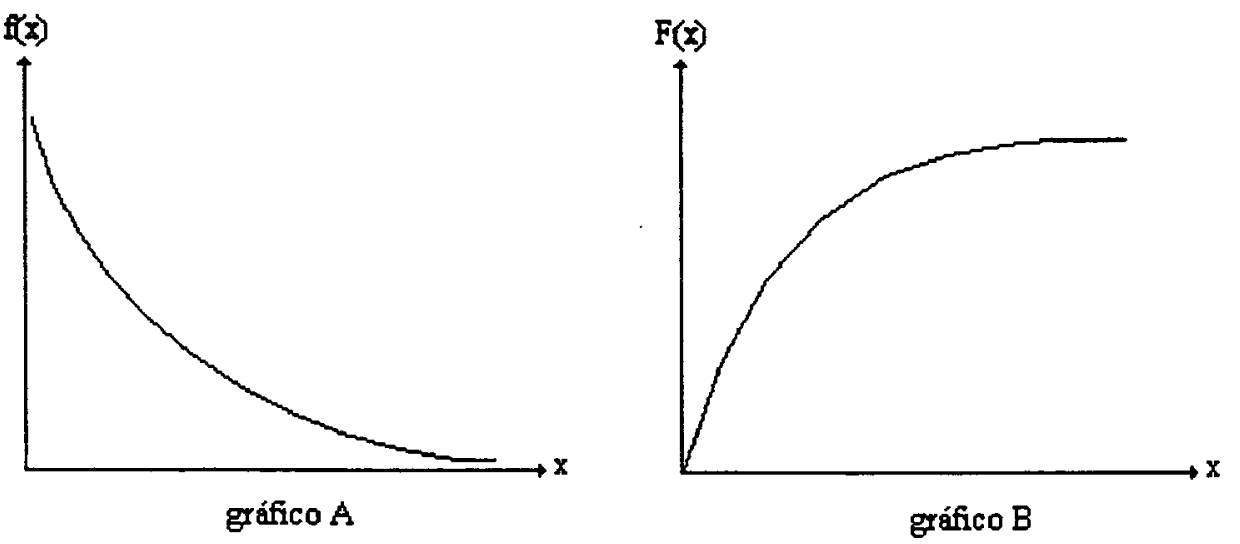

Figura 3.1 - Gráfico da função exponencial. O gráfico-A representa a função de densidade de probabilidade $f(x)$ e o gráfico-B representa a função de distribuição acumulativa $F(x)$. Estes gráficos são respectivamente baseados nas equações $3.3 e$ 3.4, onde $\lambda$ é uma constante que representa a taxa de ocorrência de um determinado evento.

\subsubsection{Distribuição de Poisson}

Considerando-se que o intervalo de tempo entre dois eventos forma uma distribuição exponencial, pode-se considerar que os eventos formam um processo de Poisson [Sauer; Chandy 1981, Kobayashi 1978]. processo descreve a probabilidade de ocorrência de $x$ eventos, quando o número de ensaios de Bernoulli tende ao infinito [Naylor 1971]. Neste caso, a ocorrência de um determinado evento, 
em um intervalo de tempo $t$, depende exclusivamente do valor de $t$, sem nenhuma dependência de ocorrências anteriores [Sauer; Chandy 1981, Held 1994].

Neste caso, a probabilidade de ocorrência de $x$ eventos durante o período de tempo $t$, quando a taxa de geração de eventos, por unidade de tempo for $\lambda$, é dada pela equação 3.5 [Kobayashi 1978, Held 1994]:

$$
P(x)=\frac{e^{-\lambda t}(\lambda t)^{x}}{x !}
$$

A partir da equação 3.5 , pode-se concluir que a probabilidade de ocorrência de $x$ eventos por unidade de tempo é:

$$
P(x)=\frac{e^{-\lambda} \lambda^{x}}{x !}
$$

\subsubsection{Distribuição Uniforme}

A distribuição uniforme é conceitualmente simples e prevê a ocorrência de eventos somente em um determinado intervalo de tempo, sendo que os mesmos são igualmente distribuidos nesse intervalo. Matematicamente, a distribuição uniforme é dada pela expressão 3.7 e representada pela figura 3.2

$$
\begin{array}{ll}
f(x)=1 /(b-a) & \text { se } a<x<b \\
f(x)=0 & \text { se } a>=x>=b
\end{array}
$$




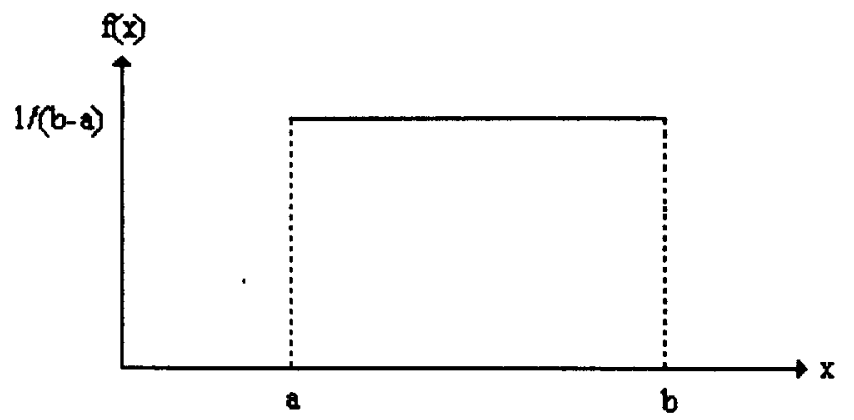

Figura 3.2 - Gráfico de representação da distribuição uniforme. Os valores a e b são os limites do intervalo onde os valores de $x$ se distribuem uniformemente.

\subsubsection{Validação de dados}

Para a análise e modelagem do sistema é necessário que se colete um determinado número de dados, permitindo um levantamento do modelo do sistema e do modelo de distribuição. Assim, na fase de validação de dados, é feito um levantamento mais detalhado a respeito dos dados que são manipulados no sistema, permitindo melhorias na modelagem desenvolvida anteriormente ou até mesmo o desenvolvimento de um novo modelo.

Essa etapa permite que os dados sejam analisados em relação aos seus valores extremos, à sua quantidade, à sua margem de erro, à exatidão e à precisão do sistema Todas essas informações permitirão que o programa de simulação seja desenvolvido de forma mais otimizada e com maior probabilidade de operar sem erros. $\mathrm{Na}$ simulação, esses dados serão utilizados a partir de valores previamente fixados em tabelas ou gerados a partir de um modelo de distribuição matemática [Naylor 1971]. 


\subsubsection{Avaliação do modelo}

A avaliação de um modelo é feita através de alguns ensaios de simulação onde são verificados o comportamento das variáveis, a ausência ou excesso de parâmetros, erros e a exatidão do modelo criado. Juntamente com a avaliação do modelo criado, é feita uma avaliação dos resultados da simulação desse modelo.

A avaliação dos resultados da simulação pode ser feita através do uso de valores de entrada predeterminados, que resultem em valores de saída, previamente conhecidos.

Em alguns casos, não há valores previamente conhecidos ou os mesmos podem não ter quantidade e consistência suficientes para garantirem uma avaliação do processo de simulação. Nesses casos, a análise pode ser feita através do uso de modelos matemáticos que permitam previsões a respeito do comportamento esperado do sistema

\subsection{Análise de tempo em simulação}

Num processo de simulação, existem dois parâmetros fundamentais, em relação ao tempo. O primeiro deles é o modo como os eventos se comportam em relação ao tempo, o segundo é a determinação de quanto tempo de operação do sistema real deve ser simulado.

Uma atividade é uma rotina de trabalho e um evento é a troca de estado para uma atividade, determinando o seu início ou fim. Dessa forma, uma atividade pode ser classificada em dois estados distintos, que são ativa ou inativa. Com relação ao modo 
como os eventos se comportam em função do tempo, a simulação pode ser classificada em simulação discreta ou simulação contimua.

Na simulação discreta, o tempo varia em função de um incremento fixo e os eventos ocorrem em instantes discretos do mesmo. A simulação contínua é usada em modelos cujas características variam continuamente no tempo, sendo freqüentemente utilizada na simulação de problemas na área de física ou engenharia [Davies 1989].

O tempo de operação do sistema real, que é utilizado na simulação, influencia o próprio tempo de execução do programa de simulação e pode influenciar o próprio nível de exatidão das respostas obtidas. Esse tempo é chamado de tempo de observação e o seu limite pode ser determinado através de um processo de interações fixas ou de um processo de erro relativo.

No processo de interações fixas, a simulação é executada até que seja executado um determinado número de atividades predeterminadas. No processo de erro relativo, a simulação é executada até que determinadas características do sistema atinjam um determinado limite [Denning 1991-b].

No processo de erro relativo, pode-se assegurar um determinado nível de exatidão para as variáveis do sistema simulado, no entanto, o projetista deve assegurar que esse nível tenha um limite de conversão.

\subsection{Análise de medições}

Após a execução do programa de simulação, é feita uma análise dos parâmetros de saída. Um único levantamento desses valores pode induzir a uma 
análise tendenciosa. Assim, a simulação pode ser executada várias vezes, a fim de se obter o valor médio dos resultados, garantindo-se um melhor nivel de exatidão.

Em sistemas discretos, que são o alvo deste trabalho, o valor médio é obtido pela equação 3.8 .

$\mathrm{M}=\frac{1}{\mathrm{n}} \sum_{\mathrm{i}=1}^{\mathrm{n}} \mathrm{Xi}$

Onde:

$n$ é o número de amostras.

$X i$ é o valor individual de cada uma das amostras

Além do valor médio das variáveis analisadas, é necessário que se calcule o desvio padrão destes valores, que representa a variação destes valores em torno da média. Nos sistemas discretos, que são utilizados neste trabalho, o desvio padrão pode ser calculado por:

$$
\sigma=\sqrt{\frac{1}{(n-1)} \sum_{i=1}^{n}(X i-M)^{2}}
$$

Para exemplificação do conceito de desvio padrão podemos adotar a análise de um sistema onde as amostras computadas, no cálculo da média, formam uma distribuição normal. Neste caso, a média aritmética (M) é o valor mais provável de ocorrência e o desvio padrão $(\sigma)$ é considerado o intervalo onde estariam distribuídas cerca de $68,3 \%$ das amostras utilizadas no cálculo da média, conforme é exemplificado na figura 3.3 [Castro 1967]. 


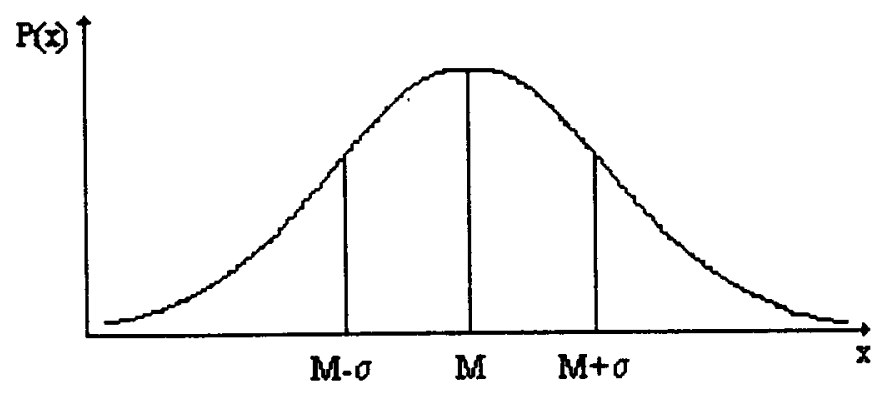

Figura 3.3 - Representação de um sistema com distribuição "normal" das amostras. A média aritmética (M) representa o valor mais provável de ocorrência e o intervalo $M \pm \sigma$, onde $\sigma \dot{e}$ o desvio padrão, representa a distribuição de $68,3 \%$ das amostras.

O cálculo da média é importante para uma análise criteriosa dos dados obtidos na simulação e para uma análise dos dados coletados no sistema real. Esse cálculo pode ser eficiente na representação de muitos problemas, porém, pode ser feita uma análise em função da distribuição de probabilidades, onde é feita uma relação entre os valores obtidos em diversas medições e a freqüência com que cada valor se repete, conforme exemplificado na figura 3.4.

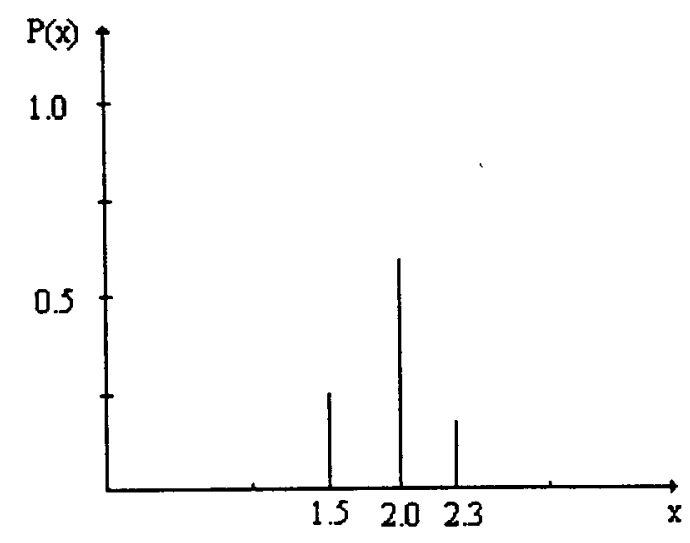

Figura 3.4 - Distribuição de probabilidades das amostras medidas em um sistema. $O$ eixo $X$ representa os valores medidos na amostragem e o eixo $P(x)$ representa a freqüência com que cada valor apareceu na amostragem. 
A partir do levantamento da distribuição de probabilidades, onde $\mathrm{P}(\mathrm{x})$ sempre fica no intervalo entre 0 e 1 e o somatório de todos os $\mathrm{P}(\mathrm{x})$ é sempre 1 , pode-se calcular o valor médio esperado, que é expresso por:

$$
E[X]=\sum_{i=1}^{n} X i P(X i)
$$

Onde:

Xi é o valor da amostra $i$

$\mathrm{P}(\mathrm{Xi})$ é a freqüência de ocorrência da amostra $\mathrm{Xi}$

O desvio padrão relativo ao levantamento da distribuição de probabilidades é calculado por:

$$
\sigma x=\sqrt{\sum_{i=1}^{\mathrm{n}}(\mathrm{Xi}-\mathrm{E}[\mathrm{X}])^{2} \mathrm{P}(\mathrm{Xi})}
$$

Conforme levantamento representado na figura 3.4, pode-se calcular o valor médio esperado e o desvio padrão:

$$
\begin{aligned}
& \mathrm{E}[\mathrm{X}]=1.5 * 0.25+2.0 * 0.6+2.3 * 0.15=1.92 \\
& \sigma x=\sqrt{(1.5-1.92)^{2} * 0.25+(2.0-1.92)^{2} * 0.6+(2.3-1.92)^{2} * 0.15}=0.26
\end{aligned}
$$

Freqüentemente o desvio padrão é mostrado de forma relativa ao valor da média, sendo chamado de coeficiente de variação. Quanto menor for esse valor, menor será a distribuição das amostras em relação à média, ou seja, o sistema terá um 
comportamento mais homogêneo. $\mathrm{O}$ coeficiente de variação pode ser calculado pelas equações 3.12 e 3.12 .

$$
\begin{aligned}
& C x=\sigma / M \\
& C x=\sigma x / E[X]
\end{aligned}
$$

\section{Teoria de filas}

\subsection{Processos de filas}

Um processo de fila é formado por três componentes fundamentais, que são um produtor, a fila e um servidor. Esse processo é mostrado na figura 3.5 e pode ser utilizado para representar o sistema de geração e de fluxo de informações em um sistema computacional.

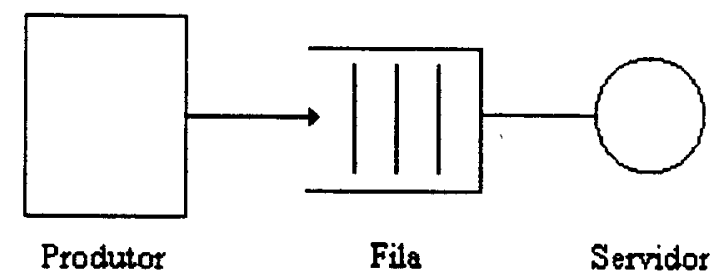

Figura 3.5 - Um processo de fila simples ou monocanal. O sistema é composto por um produtor, uma fila e um servidor.

O produtor é o componente de onde os elementos da fila se originam. A fila é o ponto onde os mesmos são agrupados, segundo uma ordem, e o servidor é o 
componente para onde os elementos da fila são direcionados. Dessa forma, a fila torna-se apenas um dos componentes do processo de fila.

O tamanho da fila depende do volume de elementos que o produtor fornece em um periodo de tempo e do número de elementos que o servidor consegue receber, no mesmo período [Kobayashi 1978]. O sistema de fila pode ter três estados diferentes, que são o estado ocupado, onde o servidor está atendendo um elemento, o estado de espera ocupada, onde o servidor está atendendo um elemento e existem outros aguardando na fila, e o estado inativo, onde a fila e o servidor não têm nenhum elemento [Davies 1989].

Um processo de fila pode ser analisado em função de cinco características básicas, que são [Castro 1967]:

- Modelo de Chegada: É o modelo que descreve o tempo entre a chegada de dois pacotes sucessivos à rede;

- Modelo de serviço: Esse modelo descreve o tempo necessário para o atendimento de um determinado elemento da fila;

- Capacidade do Sistema: É o número máximo de elementos que podem ser atendidos pelo sistema. Neste caso, são computados os elementos em fila e os elementos que estão sendo atendidos pelo servidor. Os sistemas teóricos podem operar com uma capacidade infinita. No entanto, os sistemas práticos são limitados e pode ocorrer o impedimento, onde um elemento gerado não entra na fila pelo fato da mesma estar lotada;

- Modelo de atendimento: É o modelo que representa a ordem pela qual os elementos da fila são encaminhados ao servidor. 
O modelo de atendimento possui uma classificação própria, segundo a qual, a fila é manipulada. Essa classificação pode ser descrita como:

- Primeiro a Entrar, Primeiro a Sair: esse sistema também é chamado de FIFO (First In First Out) e a ordem de atendimento é feita seqüencialmente, conforme a ordem de chegada do elemento na fila;

- Ultimo a Entrar, Primeiro a Sair: esse sistema também é chamado de LIFO (Last In First Out) e é usado em sistemas normalmente de armazenamentos, como o sistema de pilha usado por processadores;

- Aleatória: neste caso o elemento a ser atendido é aleatoriamente escolhido;

- Prioritário: os elementos são classificados segundo uma ordem predefinida de atendimento, sendo que os elementos de maior prioridade são atendidos antes dos demais, independentemente da sua ordem de chegada na fila.

Como existem várias formas de se organizar um fila, foi desenvolvida uma notação padrão para isto, que é chamada de notação de Kendall e que tem a seguinte forma [Bronson 1985, MacDougall 1989]:

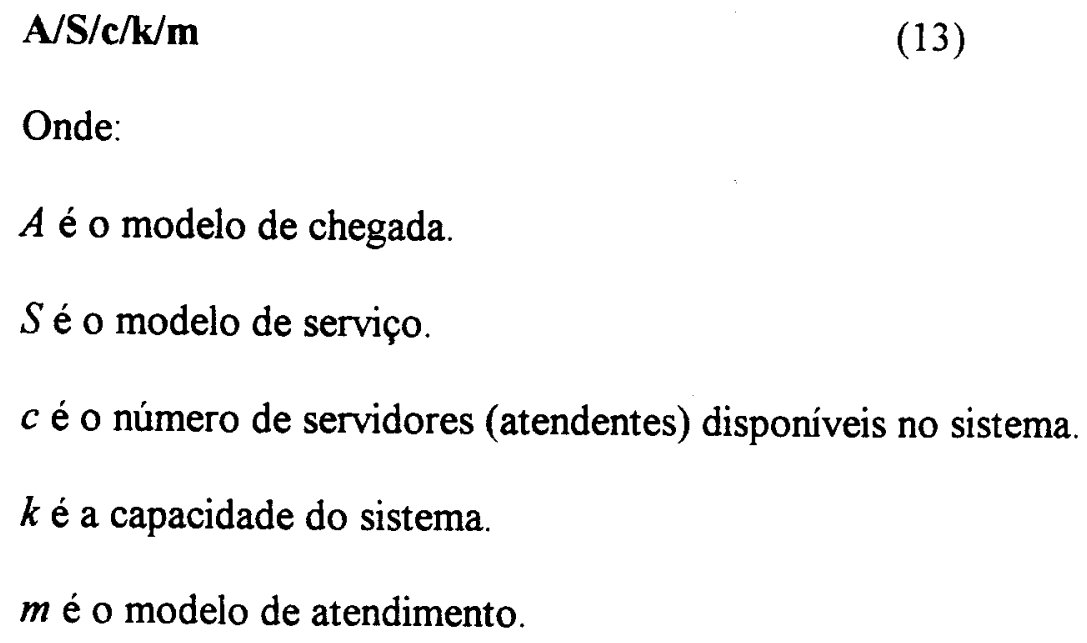

Onde:

$A$ é o modelo de chegada.

$S$ é o modelo de serviço.

$c$ é o número de servidores (atendentes) disponíveis no sistema.

$k$ é a capacidade do sistema.

$m$ é o modelo de atendimento. 
Nessa notação, o modelo de chegada $(A)$ e o modelo de serviço $(S)$ operam segundo um modelo matemático que, entre diversos outros, pode ser:

- $D$ : Representa que o modelo tem uma distribuição determinística;

- $M$ : Representa que o sistema tem uma distribuição exponencial;

- $G$ : Representa que o sistema tem uma distribuição aleatória.

Uma exemplificação dessa notação pode ser M/D/3/10/FIFO, onde o modelo de entrada é exponencial e o modelo de serviço é determinístico; existem três servidores e o sistema comporta até 10 elementos, que são manipulados, segundo um modelo FIFO.

Caso as variáveis $k$ e $m$ sejam omitidas, o sistema assumirá valores predeterminados para as mesmas, que são $k$ infinito e $m$ do tipo FIFO. Assim, um modelo M/M/1 terá modelo de entrada exponencial, um modelo de serviço exponencial, um único servidor e uma capacidade infinita de atendimento através do modelo FIFO.

\subsection{Sistemas de filas}

Um sistema de filas é composto por um conjunto de produtores, servidores e um modelo que caracterize o atendimento. Essa variedade de elementos, no sistema, permite a existência de diversos arranjos para o mesmo, utilizando-se de diversas filas ou produtores conectados em série ou em paralelo

Na figura 3.6, há um sistema em série, que é composto por um único produtor e dois arranjos de fila-servidor relacionados em série. Esse modelo é freqüentemente 
utilizado na modelagem de linhas de produção industrial, onde os produtos seguem uma ordem de operação.

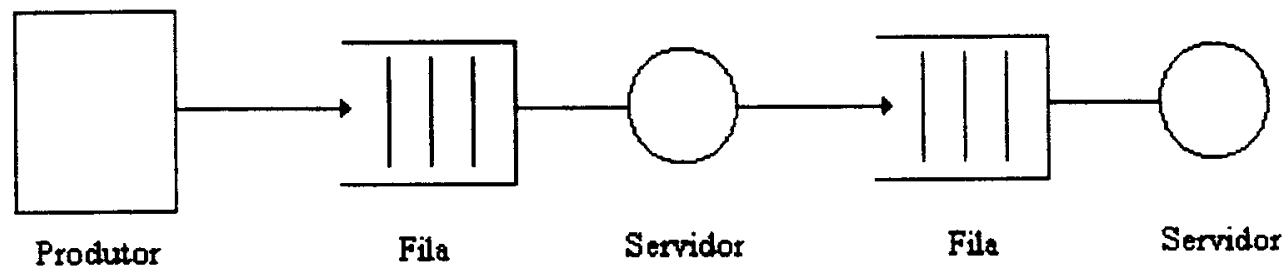

Figura 3.6 - Um sistema de filas em série. O sistema é composto por um único produtor e uma seqüência de pares fila-servidor, relacionados em série.

Na figura 3.7 , temos um sistema de fila com servidores paralelos, que é formado por um produtor, uma fila e um conjunto de $N$ servidores. Esse modelo é freqüentemente empregado em agências bancárias.

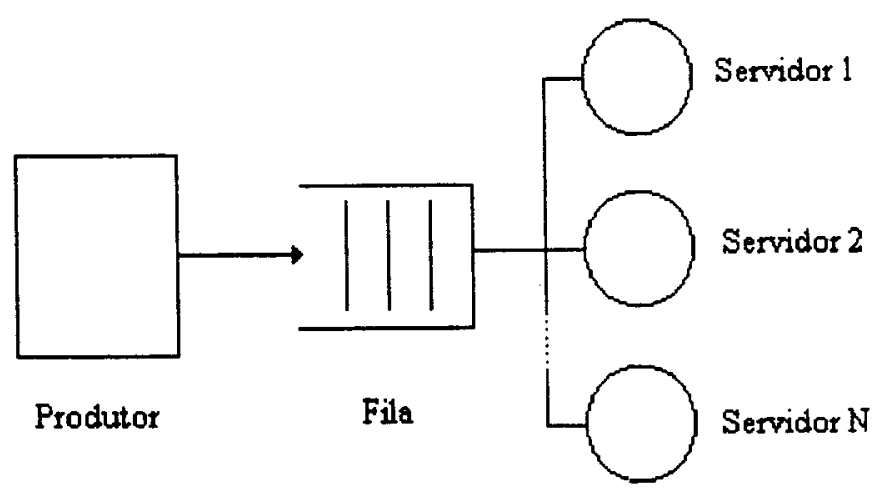

Figura 3.7 - Um sistema de filas com servidores paralelos. O sistema é composto por um produtor, uma fila e $N$ servidores.

Outro sistema de filas é o chamado Concorrente, que é formado por diversos subsistemas produtor-fila, porém, com um único servidor, conforme mostra a figura 
3.8. Nesse sistema, há uma espécie de concorrência entre os produtores, pois todos tentam enviar elementos ao mesmo servidor. Como conseqüência disto, o tamanho da fila tende a crescer à medida que cresce o número de subsistemas produtor-fila. Esse sistema também exige algum tipo de mecanismo que faça o gerenciamento de fluxo entre as diversas filas e o único servidor.

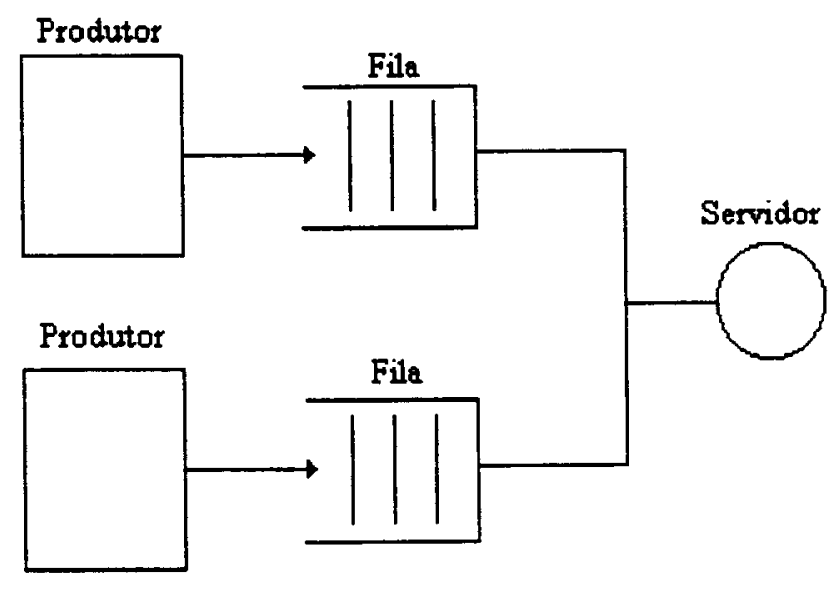

Figura 3.8 - Um sistema de filas Concorrentes. Existem diversos pares produtor-servidor, porém, existe um único servidor.

\section{Análise de desempenho de redes}

A análise de desempenho de uma rede, através do processo de simulação, pode ser feito através do levantamento dos valores médios de algumas variáveis que representem determinadas caracteristicas da rede ao longo do tempo. A quantidade de parâmetros a serem analisados, no processo de simulação, pode variar em função das particularidades de cada caso. 
Os parâmetros manipulados no processo de simulação podem ser divididos em parâmetros de entrada, que seriam determinados pelo projetista da simulação, e parâmetros de saída, que seriam obtidos como uma resposta do sistema de simulação.

Para a execução do processo de simulação, inicialmente, determina-se o tempo de observação e o modelo dos dados de entrada. A partir dai pode-se fazer uma análise dos parâmetros selecionados.

$\mathrm{Na}$ simulação de uma rede de comunicação de dados, existem alguns parâmetros básicos que são verificados na análise do seu desempenho. Estes parâmetros são:

- O tempo de observação (T);

- A taxa de geração de pacotes (Ar);

- O número de pacotes gerados $(\mathrm{A})$;

- O número de pacotes transmitidos (C);

- A vazão da rede (X);

- O equilibrio de fluxo (FB);

- O tamanho médio da fila (Lq);

- O tempo médio de ocupação da fila (Wi);

- A utilização do sistema (U);

- O tempo de ocupação do servidor (B). 


\subsection{Tempo de Observação}

O tempo de observação (T) é o tempo relativo à operação do sistema real e o seu valor é determinado pelo projetista do sistema, conforme critérios discutidos no item 1.6.

\subsection{Número de Pacotes Gerados.}

O número de pacotes gerados (A) é um parâmetro básico de entrada, que depende das características do produtor do sistema e é medido ao longo do período de tempo T. Esse parâmetro representa o número de pacotes que todos os possiveis produtores existentes, em um sistema, geraram durante o processo de simulação, sendo, portanto, uma característica intrínseca do sistema.

\subsection{Taxa de geração de pacotes}

A taxa de geração de pacotes (Ar) é a quantidade de pacotes que o produtor fornece à rede por unidade de tempo. Assim, essa variável é dependente dos valores de A e T, sendo expressa por:

$$
\mathrm{Ar}=\mathrm{A} / \mathrm{T}
$$


Em um sistema real, a taxa de geração de pacotes pode ser medida através do monitoramento da rede [Held 1994] ou através de um levantamento preciso do seu modelo de comportamento.

A taxa de geração de pacotes irá influenciar o resultado das diferentes características analisadas na rede, pois, quanto maior for essa taxa, maior deve ser a capacidade da rede em transmitir informações.

\subsection{Número de pacotes transmitidos}

O número de pacotes transmitidos $(C)$ é o número de pacotes que a rede transmitiu durante o período de observação $(\mathrm{T})$. Esse valor é medido durante a simulação da rede, que deve transmitir o maior número de pacotes possivel. Essa informação, quando analisada isoladamente, pode ser relativamente vaga, assim ela normalmente é analisada de uma forma relativa, como é mostrado no próximo item.

\subsection{Vazão}

A vazão do sistema $(\mathrm{X})$ é um valor relativo, que representa o número de pacotes que a rede transmite por unidade de tempo, sendo expressa pela equação:

$$
\mathrm{X}=\mathrm{C} / \mathrm{T}
$$

O valor desejado para a vazão é sempre o maior possível, a fim de se evitar um aumento no tamanho das filas, permitir uma diminuição no tempo que cada pacote 
permanece no sistema e aumentar a capacidade de transmissão. Embora essa característica seja desejada, existem implicações práticas, a nível de hardware e software, que limitam esse valor.

A vazão pode ser diretamente associada a um conceito mais amplo e mensurada de forma relativa. Isto é feito através da relação entre o número de pacotes gerados e o número de pacotes efetivamente transmitidos em um período de tempo. A vazão da rede é expressa por:

$$
\mathrm{X}=(\mathrm{C} / \mathrm{T}) /(\mathrm{A} / \mathrm{T})=\mathrm{C} / \mathrm{A}
$$

Na equação expressão 3.15 , o valor da vazão $(\mathrm{X})$ é medido em informações por segundo, enquanto que, na expressão 3.16, esse valor é uma grandeza percentual.

\subsection{Equilíbrio de fluxo}

Se o sistema for observado por um periodo de tempo relativamente longo, o volume de informações de entrada pode se aproximar do volume de informações transmitidas pelo sistema. Essa condição é chamada de equilibrio de fluxo (FB) e implica em uma estabilização das características do sistema [MacDougall 1989, Denning 1991-a]. Essa condição pode ser expressa por:

$$
\mathrm{Ar}=\mathrm{X}
$$




\subsection{Tempo médio de serviço}

O tempo médio de serviço (Ts) é o tempo médio que cada elemento permanece no servidor. O tempo médio desejado é o menor possivel, pois esse parâmetro influencia todo o comportamento da rede.

Em um sistema de fila simples, composto por um produtor, uma fila e um servidor, o tempo médio de serviço será a própria taxa de transmissão com a qual o servidor opera. Por exemplo, se, nesse sistema, os pacotes tivessem 256 Bytes e a taxa de transmissão fosse de 9600 bps, teríamos, então, um tempo de serviço (Ts) de $256 * 8 / 9600$, ou seja, 0,213 segundos. Nesse caso temos:

$\mathrm{Ts}=\mathrm{tx}$

Onde:

tx é o tempo de transmissão de um pacote

Em alguns casos, a rede não é formada por um sistema tão simples como o exposto no parágrafo anterior e o servidor pode estar impedido de transmitir o pacote para outras partes da rede. Neste caso, o pacote fica em um buffer até que possa ser transmitido. Isto cria uma situação conflitante, pois o pacote está no servidor, mas, não está sendo transmitido, o que aumenta o tempo médio de serviço. Dessa forma, o tempo médio de serviço pode ser expresso por: 


$$
\mathrm{Ts}=\mathrm{te}+\mathrm{tx}
$$

Onde:

te é o tempo que o pacote permaneceu no servidor antes de ser transmitido

Supondo que a rede trabalha com pacotes de tamanho fixo e com taxa de transmissão fixa, o valor de $t x$ será constante, no entanto, o valor de te dependerá das características da rede. Assim, o valor de Ts pode ser recalculado a partir do valor médio de tempo que o servidor usou para cada pacote, conforme mostra a equação 3.20 .

$$
\mathrm{Ts}=\frac{1}{\mathrm{C}} \sum_{\mathrm{i}=1}^{\mathrm{c}} \mathrm{Tsi}
$$

Onde:

Tsi é o valor do tempo médio de serviço para cada pacote que foi transmitido

O valor de Ts é importante na previsão de comportamento de uma rede, pois, esse valor, juntamente com o valor da taxa de pacotes gerados $(A r)$, permitem o emprego de fórmulas matemáticas para o cálculo de diversas características da rede

Essas previsões permitem que o próprio programa de simulação seja desenvolvido de forma mais consistente. Por exemplo, a área de memória, reservada para simular a colocação dos pacotes em fila, pode ser dimensionada de forma mais precisa, evitando dimensionamentos errados e comprometedores ao desempenho do programa. 


\subsection{Tempo de ocupação do servidor}

O tempo de ocupação do servidor (B), durante o periodo de tempo $T$, é computado pelo somatório de todos os Tí e sua principal aplicação é como um referencial para o cálculo da taxa de utilização do servidor.

$$
\mathrm{B}=\sum_{\mathrm{i}=1}^{\mathrm{c}} \mathrm{Ti}
$$

\subsection{Taxa de utilização do servidor}

A taxa de utilização do servidor (U) é um valor relativo que mostra o tempo de utilização do servidor ao longo do periodo de tempo $\mathrm{T}$. Dessa forma, está se analisando a carga operacional do servidor. $\mathrm{O}$ ideal é que a rede consiga transmitir $\mathrm{O}$ maior número possível de informações sem aumentos consideráveis da taxa de utilização, que é expressa por:

$$
\mathrm{U}=\mathrm{B} / \mathrm{T}
$$

A taxa de utilização do sistema também pode ser calculada através de uma relação entre a taxa de geração de pacotes e o tempo médio de serviço:

$$
\mathrm{U}=\mathrm{Ar} / \mathrm{Ts}
$$


A taxa de não utilização do servidor (Po), ou seja, a parte de $\mathrm{T}$ em que a rede estava ociosa, pode ser determinada por:

$$
\text { Po }=1-U
$$

\subsection{Tempo médio de permanência no sistema}

O tempo médio de permanência no sistema (W) é o tempo médio que cada pacote transmitido permaneceu no sistema, incluindo o tempo em fila e o tempo de serviço. Esse valor deve ser o menor possível é expresso por:

$$
\mathrm{W}=\mathrm{Wi} / \mathrm{C}
$$

Onde:

Wi é a soma dos tempos que cada um dos pacotes transmitidos permaneceram no sistema.

$\mathrm{O}$ cálculo de $\mathrm{W}$ em função de $\mathrm{Wi}$ exige que o tempo que cada pacote permaneceu no sistema seja observado durante a simulação. Um segundo método para levantamento do valor de W, e que não exige análise durante a simulação, é dado pela equação 3.26 , onde $W$ é calculado em função da taxa de geração de pacotes e do tempo médio de serviço.

$$
W=\frac{1}{T s-A r}
$$




\subsection{Tempo médio de permanência em fila}

Sabendo-se o tempo médio que um pacote fica no sistema (W) e o tempo médio de serviço (Ts), pode-se facilmente calcular o tempo médio que os pacotes transmitidos permaneceram na fila (Wq). Esse cálculo é dado por:

$$
\mathrm{Wq}=\mathrm{W}-\mathrm{Ts}
$$

O valor do tempo médio em fila também pode ser diretamente calculado em função da taxa de utilização do servidor (U) e do tempo médio de permanência no sistema (W), conforme equação 3.28 .

$$
\mathrm{Wq}=\mathrm{UW}=\frac{\mathrm{Ar}}{\mathrm{Ts}(\mathrm{Ts}-\mathrm{Ar})}
$$

\subsection{Tamanho médio da fila}

$\mathrm{O}$ tamanho médio esperado para uma fila $(\mathrm{Lq})$ deve ser o menor possivel. Isto evita gastos excessivos de hardware e facilita o programa de controle. Além disto, um crescimento exagerado da fila indica que a vazão da rede não está operando em niveis satisfatórios.

Alguns sistemas de simulação consideram as filas como modelos infinitos, permitindo, assim, que seja feita uma análise mais precisa do tamanho real que seria necessário na fase de implementação real da rede. 
O número médio de pacotes, em fila, é determinado pela chamada “Little 's Law" [Denning 1991-a], que é expressa por:

$$
\mathrm{Lq}=\frac{\mathrm{WqC}}{\mathrm{T}}
$$

Baseando-se nas equações de cálculo do valor $\mathrm{W}$, pode-se facilmente concluir que o número médio de pacotes no sistema $(\mathrm{L})$ é:

$$
\mathrm{L}=\mathrm{Wi} / \mathrm{T}
$$

$\mathrm{O}$ número médio de pacotes no sistema (L) é a soma do número médio de pacotes em fila (Lq) e o número médio de pacotes no servidor.

As equações acima mostram o cálculo de comprimento da fila, em função do tempo médio que cada pacote permanece no sistema (W), porém, é possível calcular o tamanho médio da fila em função da taxa de geração de pacotes (Ar) e do tempo médio de serviço (Ts), conforme equação abaixo.

$$
\mathrm{Lq}=\mathrm{UL}=\frac{\mathrm{Ar}^{2}}{\mathrm{Ts}(\mathrm{Ts}-\mathrm{Ar})}
$$

Partindo do mesmo princípio da equação 3.32 , pode-se obter o número médio de pacotes no sistema através da equação:

$$
L=\frac{A r}{(T s-A r)}
$$




\section{Conclusões do Capítulo}

Como conclusões do capítulo podem-se mencionar:

- Um sistema de simulação exige que seja criado um modelo que represente o sistema real através de um conjunto de características;

- O uso de simulação pode permitir que diversos parâmetros do sistema simulado sejam previamente analisados e que um determinado projeto físico possa ser implementado com menor margem de erros e maior economia de tempo e custos;

- A simulação depende da análise e modelagem do sistema real, da validação dos dados e da avaliação do modelo;

- Um processo de fila, formado por um produtor, uma fila e um servidor, pode ser utilizado na representação de um sistema de comunicação de dados;

- O desempenho de uma rede de comunicação pode ser verificado através da simulação, analisando-se alguns parâmetros como o tamanho das filas, a vazão do sistema, a utilização do sistema, etc. 


\section{CAPÍTULO 4}

\section{Proposta e Investigação da Rede SCF}

Este capítulo apresenta a proposta e organização de uma rede óptica de comunicação, que é chamada de SCF (Sistema Circular com Filas). Também é apresentado o algoritmo de controle da rede, o sistema de simulação desenvolvido e a descrição e a análise de desempenho da rede

\section{A Arquitetura da rede}

A rede óptica SCF, proposta neste trabalho, é uma arquitetura $\mathrm{NxN}$, baseada no sistema WDM single-hop, usando um canal especifico para controle de transmissão e canais específicos para transmissão de dados. $O$ acesso de cada nó ao canal de controle $(C C)$ é feito através de um transmissor fixo e um receptor fixo, enquanto que o acesso a um canal de dados é feito com um transmissor sintonizável e um receptor fixo. Isto forma uma rede óptica single-hop, com configuração do tipo CC-TT ${ }^{1} \mathrm{FT}^{1} \mathrm{FR}^{2}$. A figura 4.1 mostra a organização lógica desse sistema.

O canal de controle tem um único comprimento de onda fixo, definido como $\lambda 0$, enquanto que, para a transmissão de dados, existem vários canais e cada um dos $\mathrm{N}$ nós receptores tem um canal específico de operação, que é definido como $\lambda i$, onde $i$ é o número do nó. Assim, para a transmissão de dados, o nó transmissor tem que 
sintonizar o seu transmissor óptico no comprimento de onda específico do nó receptor.

Cada nó a rede recebe dados através de um comprimento de onda fixo, o que limita a escalabilidade do sistema em função do número de canais do WDM, porém, evita a dependência do sistema em relação ao tempo de sintonização dos receptores ópticos

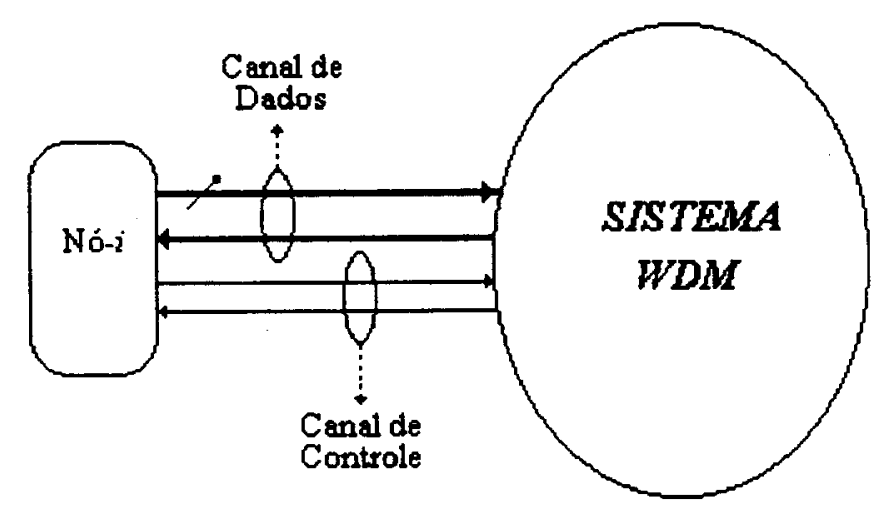

Figura 4.1 - Arquitetura da rede proposta. Cada nó tem um receptor fixo e um transmissor fixo para acesso ao canal de controle, e um transmissor sitonizável e um receptor fixo para acesso ao canal de dados, formando um sistema de comunicação single-hop CC-TT'FT'FR'.

O sistema de comunicação dessa rede é bidirecional. As informações são organizadas em pacotes de dados com um tamanho fixo e compostos por um cabeçalho com o endereço do nó receptor e por um número fixo de bytes de dados.

O período de tempo utilizado para a transmissão de pacotes de dados é chamado de ciclo de transmissão de dados. Durante esse ciclo nunca ocorrerão colisões, pois existe um algoritmo de controle que impede a ocorrência desse problema. A execução desse algoritmo de controle é executada em um ciclo chamado ciclo de controle, que é realizado antes do ciclo de transmissão de dados. Assim, se dois ou mais nós quiserem transmitir para o mesmo receptor, apenas um nó poderá 
transmitir, enquanto que os demais armazenarão os pacotes em filas, causando uma contenção.

O ciclo de controle e o ciclo de transmissão de dados formam um ciclo maior, chamado de ciclo de comunicação, conforme mostra a figura 4.2.

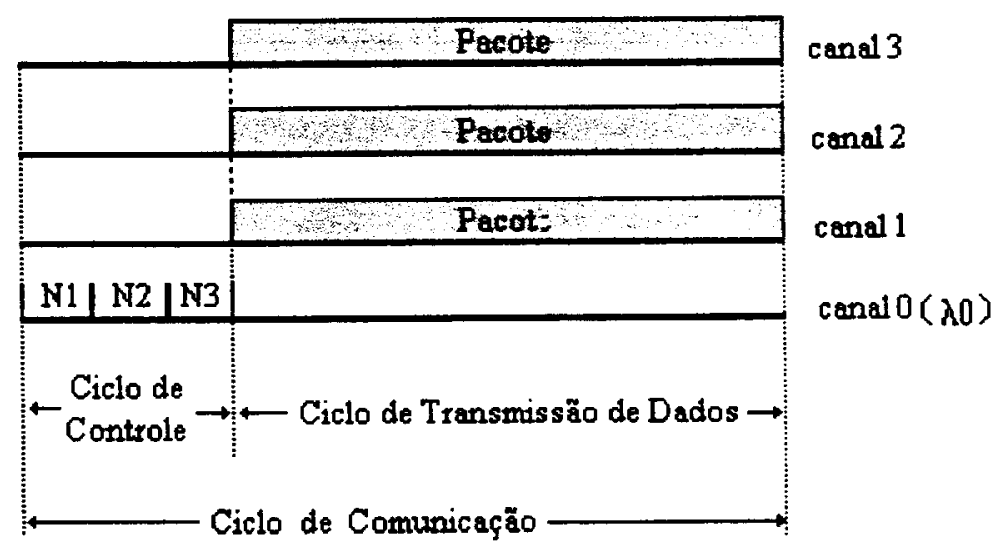

Figura 4.2 - Ciclo de Comunicação. Esse ciclo é formado por dois ciclos menores, que são o ciclo de controle e o ciclo de transmissão de dado, sendo que o processo de controle executado no ciclo de controle impede que haja colisões no ciclo de transmissão de dados.

A arbitragem realizada no ciclo de controle é baseada no sistema TDM (time division multiplexing), onde cada nó tem um periodo de tempo exclusivo para acesso ao canal de controle. Esse periodo de tempo é chamado de slot e é usado para fazer uma transmissão em broadcast, onde um transmissor pode requisitar, com exclusividade, um receptor para o próximo ciclo de transmissão de dados.

Para o controle descentralizado da comunicação, cada nó transmissor possui uma tabela de alocação, que é "inicializada" no início de cada ciclo de controle e "atualizada" durante o mesmo. Durante o Ciclo de Controle, a tabela de alocação é preenchida com o número dos receptores requisitados para o próximo ciclo de comunicação. 
Quando um nó transmissor tem o seu slot de tempo para acesso ao canal de controle, ele primeiramente verifica, na sua tabela de alocação, se o nó para o qual deseja transmitir já foi requisitado.

Caso o receptor ainda não tenha sido requisitado, então o transmissor faz um broadcast, informando o número do receptor a todos os demais nós transmissores. Assim, todos os nós transmissores receberão simultaneamente essa informação e atualizarão suas respectivas tabelas de alocação.

Caso o receptor desejado já tenha sido requisitado, então o nó em operação irá manter o pacote de dados na fila e tentará transmiti-lo nos próximos ciclos de comunicação, impedindo a ocorrência de colisões.

A figura 4.3 mostra o algoritmo da operação de controle realizada no Ciclo de Controle do algoritmo proposto.

\begin{tabular}{|} 
I Inicio do algoritmo do ciclo de controle \\
2 A tabela de alocação e "inicializada" \\
3 Se for o seu slot de acesso ao canal de controle (CC), então: \\
3.1 Se tiver pacotes em fila, então: \\
3.1.1 Verifica o nó destinatário do primeiro pacote da fila \\
$\quad 3.1 .2$ Consulta a tabela de alocação \\
$\quad 3.1 .3$ Se o destinatário ainda não foi requisitado, então \\
transmite o seu endereço em broadcast. \\
4 Se não for o seu slot de acesso ao canal de controle, então: \\
4.1 Recebe o número enviado no broadcast do CC \\
4.2 Atualiza tabela de alocação. \\
5 Se ainda não terminou o ciclo de controle, então retorna ao passo 3 \\
6 Fim do algoritmo do ciclo de controle
\end{tabular}

Figura 4.3 - Algoritmo de gerenciamento do Ciclo de Controle 
O algoritmo do Ciclo de Transmissão de dados é mais simples, já que, cada nó transmissor, simplesmente sintoniza no comprimento de onda referente ao receptor desejado e, em seguida, faz a transmissão do pacote de dados.

Para otimização do sistema, cada nó é idealizado para ter duas unidades independentes de comunicação. Uma das unidades faz o acesso ao canal de dados, sendo encarregada unicamente de transmitir os pacotes de dados, enquanto que a segunda unidade faz o gerenciamento do sistema através do canal de controle. Isto permite uma sobreposição dos Ciclos de Comunicação, pois, enquanto uma unidade realiza o Ciclo de Transmissão de dados, a outra faz, de forma simultânea, o Ciclo de Controle relativo à próxima transmissão de dados, conforme mostra a figura 4.4.

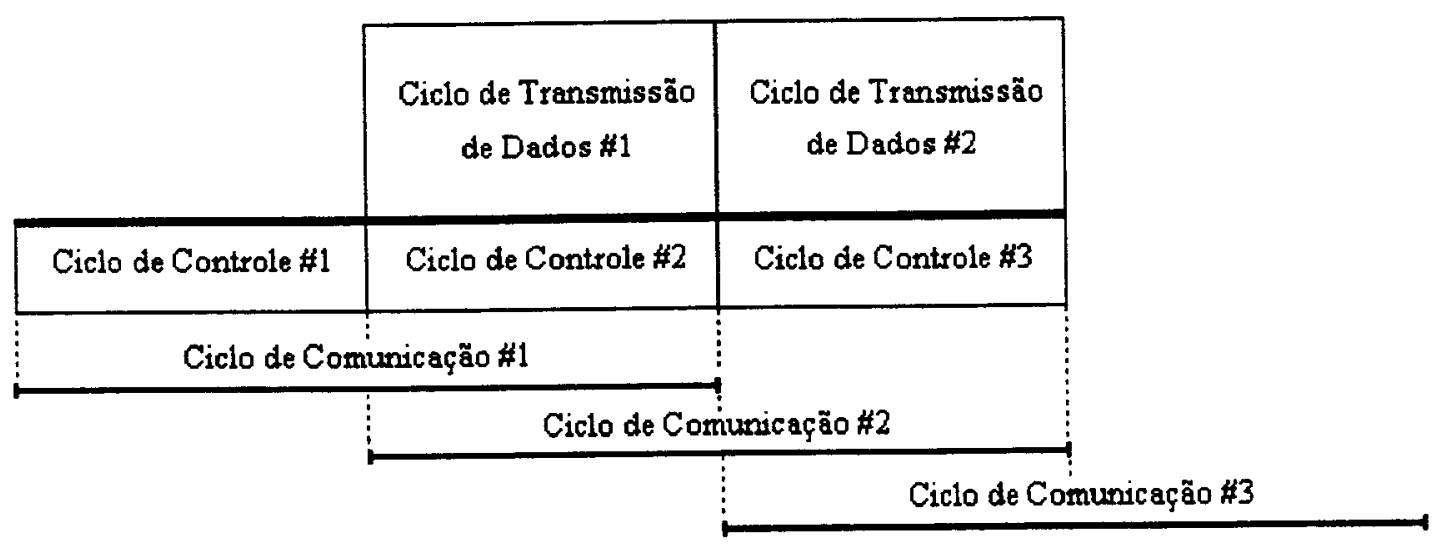

Figura 4.4 - Sobreposição dos ciclos de comunicação. Enquanto uma unidade do nó faz a transmissão de pacotes no ciclo de transmissão de dados, a outra unidade realiza o ciclo de controle do próximo ciclo de transmissão de dados.

Essa sobreposição agiliza a operação do sistema, mas, também cria uma restrição; pois, o tempo gasto com o Ciclo de Controle deve ser menor ou igual ao tempo gasto com o Ciclo de Transmissão do pacote de dados. Caso contrário, o Ciclo de Transmissão de dados terminará antes que o Ciclo de Controle e haverá um tempo ocioso entre dois Ciclos de Transmissão, diminuindo o desempenho da rede. Como o número de nós do sistema determina o comprimento do Ciclo de Controle, acaba 
havendo uma relação direta entre o número de nós da rede e o tamanho do pacote de dados utilizado na Ciclo de Transmissão

Para exemplificação prática dessa relação, pode-se mencionar que alguns sistemas paralelos atingem um bom nivel de desempenho com um número relativamente pequeno de nós, como é o caso do sistema Dataflow Monsson, onde, para diversas aplicações desenvolvidas com a linguagem Id, um "speedup" maior que 7 foi conseguido com apenas 8 processadores [Hicks et al 1993]. A análise desse sistema, na arquitetura óptica proposta, exigiria a utilização de pacotes de dados com mais de 8 bytes, o que é perfeitamente viável.

Em relação ao tamanho de pacotes, tem-se diversos valores, como o das redes ATM, que operam com 53 bytes [Soares 1995], o que limitaria o sistema óptico apresentado em 53 nós. Porém, existem pacotes que podem atingir até 1.518 bytes, como os padrões Ethernet e IEEE 802.3 [Held 1994], aumentando significativamente o número máximo de nós da rede óptica.

Como existem sistemas que operam eficientemente com poucos processadores e existem sistemas que usam pacotes de dados relativamente grandes, a restrição estabelecida pela relação entre tamanho da rede e tamanho do pacote de dados pode, em muitos casos, ser perfeitamente contornável.

As vantagens da rede óptica de comunicação apresentada neste trabalho são:

- Inexistência de Colisões;

- Independência de receptores sintonizáveis;

- Opticamente transparente;

- Baixo grau;

- Baixo Diâmetro; 
As restrições do sistema óptico de comunicação apresentado neste trabalho são:

- Dependência do número de canais do WDM devido ao uso de dispositivos receptores fixos;

- Relação entre o tamanho do pacote de dados e o número de nós da rede.

\section{Controle de acesso ao canal de controle}

Cada nó tem um periodo de tempo fixo para acesso ao canal de controle, sendo que a ordem de acesso ao canal de controle é fundamental para o desempenho da rede.

Se houvesse uma ordem fixa de prioridade para acesso ao canal de controle, o último nó teria menor prioridade $\mathrm{e}$, portanto, teria uma maior probabilidade de não conseguir transmitir os pacotes, tendo um conseqüente aumento do tamanho de fila. Isto seria útil em sistemas onde alguns nós tivessem um volume de dados superior aos demais, porém, seria ineficiente em sistemas homogêneos, onde não houvesse uma diferença significativa no volume de dados entre os diversos nós transmissores.

Este trabalho é concentrado no gerenciamento de sistemas onde os nós tenham um volume homogêneo de dados. Um algoritmo usual para o gerenciamento de sistemas com essa caracteristica é o algoritmo Round Robin, onde não há nós prioritários e a cada ciclo de operação ocorre uma alternância na ordem de acesso a um determinado meio. Desta forma, o nó de maior prioridade em um determinado ciclo será o nó de menor prioridade no ciclo seguinte, conforme exemplifica a figura 4.5 [Tanenbaum 1992, Sauer 1981]. 


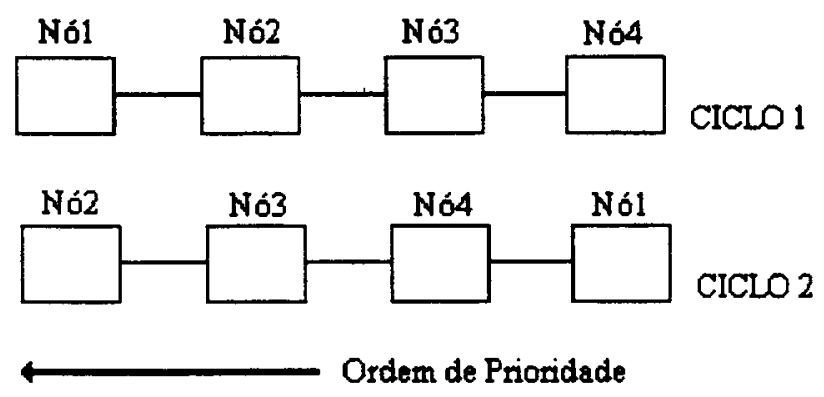

Figura 4.5 - Algoritmo Round Robin. Nesse algoritmo a ordem de prioridade é rotativa, assim, no ciclo numero 1 , o nó número 1 tem maior prioridade, sendo que, no segundo ciclo, ocorre uma rotação na ordem de prioridades e o nó 1 passa a ser o de menor prioridade.

No sistema proposto, o Ciclo de Controle é utilizado para um gerenciamento da transmissão, evitando colisões, o que obriga a conseqüente ocorrência de contenções. Supondo uma rede NxN, onde a probabilidade $(p)$ de um determinado nó ser requisitado para recepção de dados seja de $1 / \mathbb{N}$, então, a probabilidade de um nó transmissor sofrer contenção $(P c i)$ dependerá do fato de um ou mais nós transmissores, com maior prioridade, também terem requisitado o mesmo receptor no mesmo ciclo. O valor de Pci é expresso pela equação 4.1.

$$
\operatorname{Pci}=p \sum_{\mathrm{J}=1}^{\mathrm{Ni}-1}\left[\left(\begin{array}{l}
\mathrm{Ni}-1 \\
\mathrm{~J}
\end{array}\right) \mathrm{p}^{\mathrm{J}} \mathrm{q}^{(\mathrm{Ni-1)- \textrm {J }}}\right]
$$

Onde:

$q=1-p$

Ni é o número do nó, $i=1,2,3, \ldots, \mathrm{N}$

A figura 4.6 mostra a probabilidade de contenção para cada um dos $\mathrm{N}$ nós de uma rede $8 \times 8$, baseando-se na equação 4.1 . Esse cálculo mostra a probabilidade de 
contenção para um único ciclo, onde a probabilidade de um determinado receptor ser requisitado por um nó específico é de $1 / \mathrm{N}$ ou $1 / 8$.

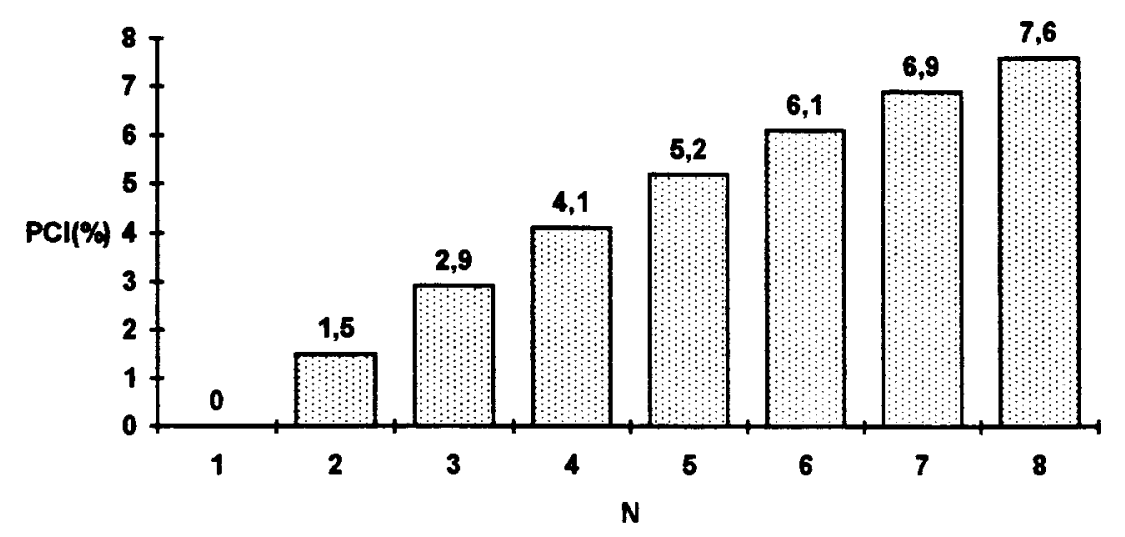

Figura 4.6 - Probabilidade de contenção (Pci). Essa probabilidade é calculada para cada um dos $N$ nós de uma rede 8x8. O cálculo é feito para um único ciclo onde a probabilidade de um determinado receptor ser requisitado por um determinado transmissor é de 1/8.

No algoritmo Round Robin existe uma rotação na ordem de prioridade, assim, após um determinado número de ciclos, todos os nós terão passado por todos os diferentes valores de probabilidade de contenção mostrados na figura 4.6. Isto cria um sistema homogêneo, onde todos os nós terão a mesma probabilidade média de contenção.

No algoritmo proposto, cada nó transmissor possui uma fila que é manipulada segundo uma estrutura FIFO e, a cada ciclo de controle, o nó verifica a possibilidade de poder transmitir o primeiro pacote dessa fila. Como isto nem sempre é possivel, ocorrerá um crescimento da fila.

Esse problema pode ser atenuado se o nó transmissor não limitar a comunicação em função exclusiva do primeiro pacote da fila. Isto pode ser feito 
através de uma pesquisa na fila, onde é feita uma busca do primeiro pacote de dados, que seja destinado a um receptor que ainda não tenha sido requisitado naquele ciclo.

Esse processo tende a aumentar a utilização da rede, mas, poderia exigir um grande esforço computacional na realização da pesquisa. Para otimizar a utilização dessa técnica, minimizando o esforço computacional requerido, propomos um sistema onde a fila de dados é dividida em $\mathrm{N}$ partes.

Essa divisão pode ser feita com a utilização de $\mathrm{N}$ módulos fisicos de memória, ou com a divisão de uma única memória fisica em $\mathrm{N}$ partes lógicas. Cada uma dessas partes, fisicas ou lógicas, é chamada de sub-fila, assim, a sub-fila $i$ é uma memória que armazena pacotes exclusivamente destinados ao receptor Ni. A figura 4.7 (A) mostra uma fila de dados e a figura 4.7 (B) mostra a divisão dessa fila em $\mathrm{N}$ sub-filas

Essa técnica induziu à criação do nome SCF (Sistema Circular com Filas), pois a cada ciclo de simulação ocorre uma alternância circular na ordem de prioridade dos nós, sendo que cada um deles é subdividio em $\mathrm{N}$ filas de armazenamento.

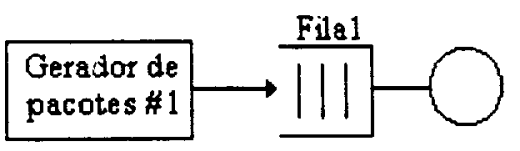

(A)

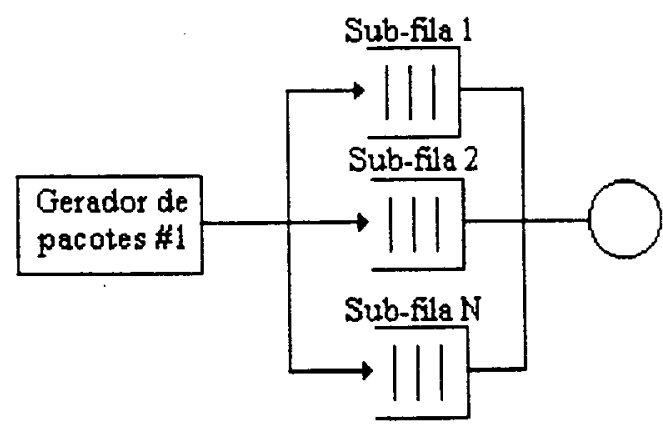

(B)

Figura 4.7 - Organização de memória do sistema. A figura (A) mostra a estrutura de um dos $N$ nós transmissores do sistema, onde existe uma memória para armazenar a fila de pacotes a serem transmitidos. A figura (B) mostra que a fila de cada um dos $N$ geradores é subdividida em $N$ sub-filas menores. 
Quando um nó tem acesso ao canal de controle, durante o seu slot de tempo no Ciclo de Controle, ele procura uma sub-fila com pacotes para serem transmitidos e verifica se o receptor está livre na tabela de alocação. Quando as duas condições forem satisfeitas, o número do receptor requisitado será enviado em broadcast. Isto exige que a cada Ciclo de Comunicação, cada nó do sistema realize um número de comparações, que pode variar de 1 a N. Essas comparações aumentam o tempo gasto no ciclo de controle, mas, o seu "custo" ainda fica dependente da relação entre o tempo gasto no Ciclo de Controle e o tempo gasto na transmissão de um pacote de dados com um determinado tamanho.

A figura 4.8 mostra a implementação do algoritmo de gerenciamento proposto para a rede óptica de comunicação apresentada neste trabalho.

1 Inicio do algoritmo de controle - SCF

2 último $=0$

$3 i=$ último

4 paraj $=1$ até $N$, faça:

$4.1 i=i+1$

4.2 se $i>N$ então $i=1$

4.3 o nó i pesquisa em sua tabela de alocação

4.4 O nó i tem acesso o canal de controle (broadcast)

5 último $=$ último +1

6 se $($ último $=N)$ então último $=0$

7 retorna para o passo 3

8 Fim do algoritmo de controle - SCF

Figura 4.8 - Algoritmo de controle da rede proposta 
As variáveis utilizadas no algoritmo, mostrado na figura 4.8 , são descritas a seguir:

$i$ é o número do nó que está tendo acesso ao canal de controle;

último é o número do que teve maior prioridade no ciclo anterior ao atual;

$N c$ é o número de ciclos de comunicação que serão utilizados;

$N$ é referente ao tamanho da rede $\mathrm{NxN}$.

\section{Estruturação lógica do sistema}

A análise do processo operacional da rede de comunicação proposta levou à estruturação de uma modelo lógico baseado em três módulos, cujo controle é feito pelo algoritmo de gerenciamento proposto no item 2 deste capitulo. Esses módulos são:

- Módulo produtor de pacotes;

- Módulo chave de transmissão;

- Módulo consumidor de pacotes.

A divisão do sistema em módulos distintos facilita a análise do sistema, a implementação física e a simulação.

\subsection{Módulo produtor de pacotes}

O Módulo produtor de pacotes é o responsável pela geração dos pacotes que serão transmitidos pela rede de interconexão, sendo que a frequiência com que os pacotes são gerados é chamada taxa de geração de pacotes (Ar). 
No processo de simulação, os pacotes são gerados sempre no inicio de um ciclo de simulação e são imediatamente colocados em uma das $\mathrm{N}$ sub-filas.

A figura 4.9 mostra a estrutura desse módulo, que é implementado com uma configuração de $\mathrm{N}$ geradores individuais de pacotes, sendo um para cada nó transmissor. No programa de simulação, esse sistema é implementado com o uso de ponteiros, sem um limite de tamanho pré fixado e, conforme já foi mencionado, a fila de cada um dos $\mathrm{N}$ geradores individuais é dividida em $\mathrm{N}$ sub-filas.

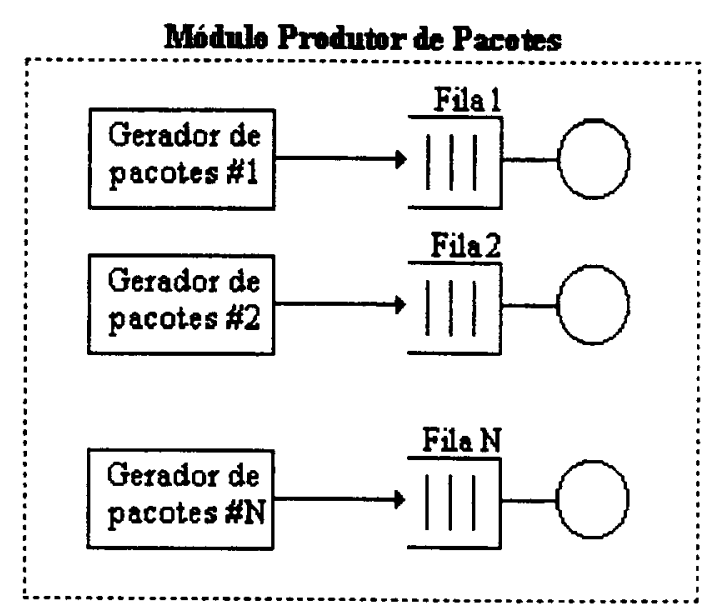

Figura 4.9 - Estrutura do Módulo Produtor de Pacotes. O sistema possui $N$ geradores de pacotes, sendo um para cada nó transmissor. Cada gerador possui uma fila para armazenamento de dados, que é dividida em $N$ sub-filas.

A taxa de geração de pacotes (Ar) foi matematicamente representada por um modelo estocástico ou probabilístico. Assim, se, por exemplo, houver uma probabilidade de geração de pacotes $(\mathrm{Pp})$ de $25 \%$, a cada ciclo de simulação existirá $25 \%$ de probabilidade de ser gerado um novo pacote no sistema. Isto equivale a um Ar média de 0,25 pacotes por ciclo de simulação.

A opção por esse tipo de sistema foi feita pelo fato do mesmo oferecer uma boa média em função do tempo e oferecer determinados níveis de rajadas (burst). Ou 
seja, é possível prever o número de pacotes que serão gerados, mas não é possivel determinar com exatidão o tempo entre o surgimento de dois pacotes consecutivos

No exemplo acima, com uma probabilidade de geração de pacotes de $25 \%$ surgirá, em média, um pacote a cada 4 ciclos de transmissão, mas, nada impede que surjam dois pacotes em seguida ou que, em alguns ciclos seguidos, não surja nenhum pacote. Esse modelo com rajadas pode expor o sistema a condições mais críticas do que quando a geração de pacotes ocorre em intervalos precisos de tempo, permitindo uma análise do sistema em condições mais extremas de operação.

Se for necessária a geração de um pacote a cada ciclo de simulação, basta que o valor de Pp seja fixado em $100 \%$. Nesse caso particular, o modelo probabilístico se transformaria automaticamente um modelo de distribuição uniforme

\subsection{Módulo chave de transmissão}

Cada um dos $\mathrm{N}$ transmissores da rede de comunicação possui um buffer capaz de armazenar somente o pacote que será transmitido. O pacote de dados enviado para o buffer de transmissão é originário do módulo produtor de pacotes, sendo que a figura 4.10 mostra a interação lógica entre esses módulos.

Quando o buffer de transmissão recebe um pacote, o módulo transmissor analisa o endereço para o qual o pacote deve ser enviado e então sintoniza o transmissor no canal do referido receptor e executa a transmissão. Antes de efetuar a transmissão, o módulo transmissor verifica se o receptor está livre para a recepção de dados. No presente trabalho os receptores foram considerados sempre livres. 


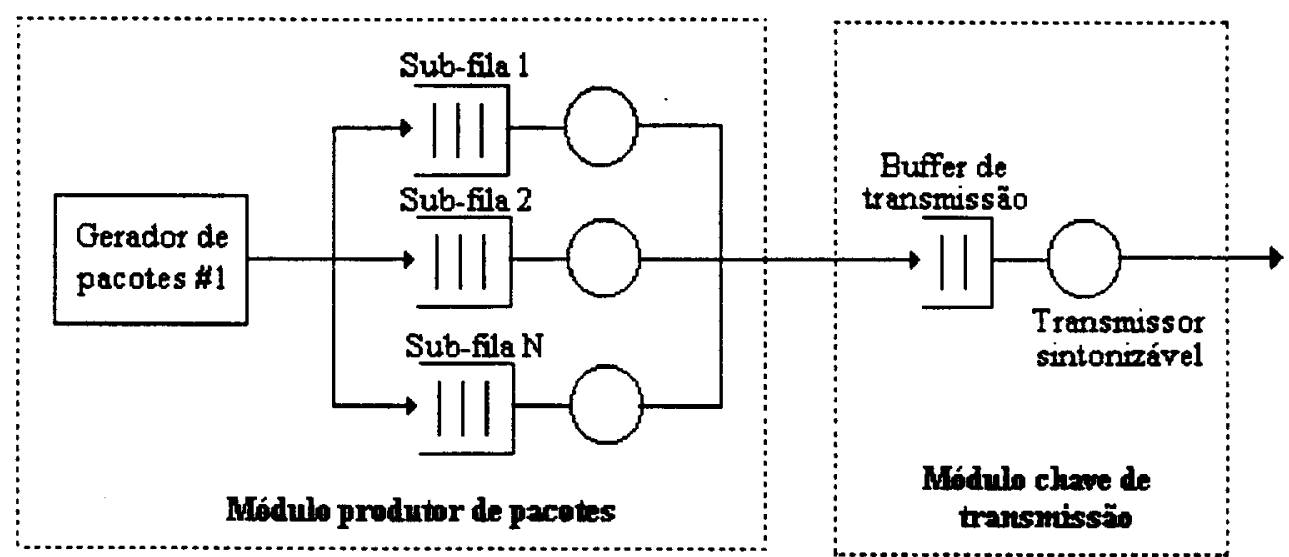

Figura 4.10 - Módulo chave de transmissão. Cada um dos $N$ elementos geradores do módulo produtor de pacotes está ligado diretamente a um dos $N$ transmissores sintonizáveis do módulo transmissor.

\subsection{Módulo consumidor}

O módulo consumidor de pacotes representa a operação dos nós receptores da rede óptica de interconexão. Cada nó receptor tem uma caracteristica fundamental, que é a disponibilidade de um determinado nó estar livre para a recepção de pacotes em um determinado ciclo. Isto se deve ao fato do receptor poder necessitar de um período de tempo para processar um pacote após a sua recepção.

O tempo que um nó receptor demora para processar um pacote de dados é chamado tempo de ocupação e pode variar em função do tipo de dados do pacote, da velocidade de processamento do nó receptor e da sua própria estrutura fisica.

Se o tempo de ocupação for zero, então o consumidor é considerado um consumidor ideal, ou seja, a probabilidade do mesmo estar livre em um determinado ciclo de simulação será sempre de $100 \%$. Um consumidor ideal pode ocorrer em sistemas teóricos, em sistemas de distribuição (broadcast) ou em sistemas onde o 
receptor possui um módulo específico para recepção de dados e um segundo módulo específico para o processamento.

\section{Programa de simulação}

O programa de simulação é baseado na análise do modelo produtor-chaveconsumidor descrito anteriormente, e o seu desenvolvimento foi modular, em linguagem C e ambiente operacional LINUX.

O primeiro parâmetro determinado no sistema de simulação foi a forma de contagem de tempo. Nesse programa de simulação, o tempo é medido em função de um ciclo de simulação, que, por sua vez, é dimensionado como sendo a soma do tempo de sintonização do transmissor óptico e do tempo de transmissão de um pacote de dados. Assim, determinando-se o tempo real de um ciclo de simulação, pode-se obter o tempo relativo de todas as operações temporais do sistema.

Como o tempo de cada ciclo de simulação é tempo que cada pacote permaneceu no buffer de transmissão, incluindo o tempo de sintonização e o tempo de transmissão, pode-se afirmar que o tempo de cada ciclo de simulação é igual ao tempo de serviço (Ts) do transmissor óptico.

$\mathrm{Na}$ implementação do programa de simulação, a estrutura produtor-chaveconsumidor foi desenvolvida com a utilização de duas variáveis globais que sinalizam a possibilidade de transferência de pacotes entre o produtor e a chave de transmissão, e entre a chave de transmissão e o consumidor. Essas variáveis são respectivamente chamadas de flagch e flagcons, e a estrutura lógica do sistema é mostrada na figura 4.11. Essas variáveis de controle são atualizadas no início de cada ciclo de simulação 
e, na prática, indicam quais os buffers de transmissão que estão desocupados e quais os receptores que estão livres para recepção.

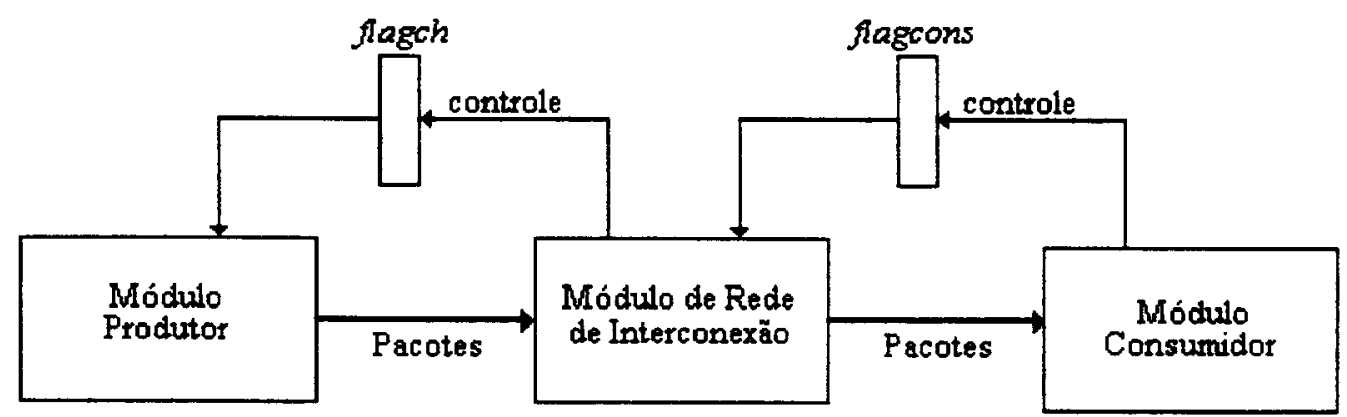

Figura 4.11 - Estrutura lógica do sistema produtor-chave-consumidor. As variáveis flagch e flagcons são variáveis globais e indicam, respectivamente, se a chave e o consumidor estão livres para a recepção de pacotes.

A implementação do programa de simulação foi baseada em quatro subrotinas básicas, que são acionadas a partir de um módulo principal. A figura 4.12 mostra essa estrutura de programação, onde as sub-rotinas são acionadas um determinado número $(\mathrm{Nc})$ de vezes.

$$
\begin{array}{r}
\text { \#define Nc } 100000 \\
\text { For }(i=1 ; i<=N c ; i++)\} \\
\\
\text { transmissão(); } \\
\\
\text { produtor (); } \\
\text { controle (); } \\
\text { consumidor (); } \\
\}
\end{array}
$$

Figura 4.12 - Estrutura do programa de simulação. 
A rotina transmissão representa a operação de transmissão de um pacote de dados armazenado no buffer de transmissão e inclui a verificação dos consumidores livres, a sintonização dos transmissores ópticos e a efetivação da transmissão.

A rotina produtor é responsável pela operação dos $\mathrm{N}$ geradores de pacotes, que são acionados no início de cada ciclo de simulação. Os pacotes são gerados segundo um modelo matemático específico e cada gerador armazena o novo pacote na sub-fila específica

A rotina consumidor analisa o estado dos nós receptores, verificando quais estão livres para a recepção de novos pacotes e atualiza o controle flagcons.

A rotina controle determina qual o pacote que cada um dos $\mathrm{N}$ geradores de pacotes enviará para o seu buffer de transmissão. Essa rotina contém o algoritmo de controle de acesso ao canal de controle, sendo, portanto, a responsável pela operação da rede.

No sistema apresentado neste capítulo, foi utilizado o algoritmo de controle SCF, descrito anteriormente, porém, o uso de outro sistema de controle poderia ser implementado com a troca ou alterações nessa rotina. Essa troca poderia aproveitar todo o processo produtor-chave-consumidor utilizado no programa de simulação, facilitando o teste de novos algoritmos de controle sem a necessidade de desenvolvimento de um novo simulador

\subsection{Operação do programa}

O usuário deve determinar alguns parâmetros de execução do programa de simulação, como a probabilidade de geração de pacotes, o tamanho da rede, o número 
de ciclos de simulação, o número de execuções do programa e o tempo de ocupação do consumidor

O tempo de sintonização, somado ao tempo de transmissão de um pacote, forma o tempo requerido para a execução de um ciclo de simulação. Assim, esses valores não precisam ser especificados, pois formam uma grandeza relativa.

A probabilidade de geração de pacotes $(p t x)$ é um parâmetro que determina a probabilidade de cada gerador de pacotes produzir um novo pacote de dados em um determinado ciclo de simulação. Esse valor pode ser específico para cada um dos geradores ou pode ser comum para todos eles.

O tamanho da rede (ntx) determina o número de nós transmissores $\mathrm{e}$ receptores que serão utilizados no sistema, formando uma configuração $\mathrm{NxN}$.

$\mathrm{O}$ número de ciclos de simulação $(N c)$ determina o tempo de observação do sistema. O tempo de cada ciclo de simulação é igual à soma do tempo de sintonização com o tempo de transmissão.

O número de execuções $(\mathrm{Ne})$ determina quantas vezes o programa de simulação será executado, sendo que, em cada execução, o programa de simulação realiza $N c$ ciclos. Isto permite que seja emitido um relatório com valores médios de desempenho.

O tempo de ocupação do consumidor é o tempo necessário para que cada consumidor processe um pacote de dados após a sua recepção. No caso de um consumidor ideal, esse tempo é zero. 
O programa de simulação emite um relatório onde podem ser analisados os seguintes parâmetros de desempenho da rede:

- Número médio de pacotes gerados;

- Número médio de pacotes transmitidos;

- Porcentagem de pacotes transmitidos, em relação aos gerados (Vazão);

- Tamanho médio de fila em cada nó transmissor;

- Maior tamanho absoluto que cada fila do módulo produtor atingiu em todas as simulações executadas;

- Tempo médio em fila;

- Utilização de cada canal do transmissor óptico;

- Utilização geral do transmissor óptico;

- Fluxo de equilibrio relativo;

- Fluxo de equilibrio absoluto.

Como o programa de simulação pode ser executado diversas vezes, os parâmetros descritos acima são analisados como o valor médio entre todas as execuções e, juntamente com cada valor médio, são apresentados os valores do desvio padrão e do coeficiente de variação.

A vazão do sistema $(\mathrm{X})$ representa a relação percentual entre o número médio de pacotes transmitidos $(\mathrm{C})$ pelo sistema e o número médio de pacotes gerados $(\mathrm{R})$ A vazão do sistema representa a eficiência na transmissão de dados e o valor desejado para essa grandeza é o mais próximo possivel de $100 \%$.

O tamanho médio de fila (Lq), em cada nó transmissor, representa o número médio de pacotes armazenados em um transmissor, somando-se todas as suas 
$\mathrm{N}$ sub-filas. Esse valor é medido em número de pacotes e não em bytes, e pode ser usado no dimensionamento da memória mínima necessária para o sistema operar.

Devido ao modelo de geração de pacotes com rajadas, em alguns momentos, o tamanho da fila pode ser muito superior ao valor de Lq. Para análise desse valor foi verificado o maior tamanho absoluto de fila (La), que representa o maior valor absoluto que uma fila atingiu em todas as execuções do programa de simulação.

$\mathrm{O}$ tempo médio de espera em fila ( $\mathrm{Tw}$ ) determina o tempo médio que cada pacote permaneceu na sub-fila, antes de ser enviado para o buffer de transmissão

A utilização do sistema (U) é um valor percentual que representa o número de ciclos onde houve alguma transmissão, em relação ao número total de ciclos usados na observação do sistema. Enquanto a vazão do sistema representa uma relação entre o fluxo de entrada e o fluxo de saída, a utilização representa o esforço operacional exigido para que se consiga um determinado nível de vazão.

A análise de utilização do sistema pode ser feita em função de dois parâmetros básicos, que são a utilização individual ou a utilização geral. Na utilização individual (Ui) é verificada a utilização de cada um dos $\mathrm{N}$ canais do WDM, enquanto que na utilização geral (Uw) é feita uma análise percentual do número médio de ciclos em que ocorreu pelo menos uma transmissão no WDM

O "flow balance" ou equilibrio de fluxo (FB) representa uma estabilização do sistema, à medida que o número médio de informações de entrada se aproxima do número médio de informações de saída. Essa grandeza é analisada em diversos momentos da simulação, com a finalidade de se determinar a tendência de estabilização do sistema. O fluxo de equilíbrio relativo é uma relação percentual entre o número de pacotes transmitidos e gerados, enquanto que o fluxo absoluto representa o módulo da diferença entre esses dois valores. 


\section{Resultados da simulação}

Até o item 4 deste capítulo, foi apresentado o formalismo teórico da rede SCF. A partir deste item são apresentados os resultados da simulação da rede e a análise do seu desemp ho.

A rede SCF fo mulada com diversos tamanhos e diversas taxas de geração de pacotes, sendo que consumidores foram sempre considerados ideais, estando sempre livres para a recepção de dados no início de cada ciclo.

Foram utilizados quatro tamanhos de redes, com as configurações $8 \times 8,16 \times 16$, $32 \times 32$ e $64 \times 64$, sendo que cada uma dessas configurações foi simulada com as seguintes taxas de geração de pacotes (Ar): 25\%, 50\%, 75\%, 90\%, 95\%, $99 \%$ e $100 \%$. Cada processo de simulação foi executado com 100.000 ciclos de simulação e repetido 10 vezes, permitindo que os resultados de desempenho da rede fossem analisados em função dos valores médios.

\section{Rede 8x8}

Essa seção apresenta os resultados da simulação da rede proposta, com uma configuração de 8 nós transmissores e 8 nós receptores.

\subsection{Análise de fila}

A figura 4.13 mostra os valores de Lq e La para cada um dos $\mathrm{N}$ nós da rede, quando a probabilidade de geração de um pacote $(\mathrm{Pp})$ é de $25 \%$. 


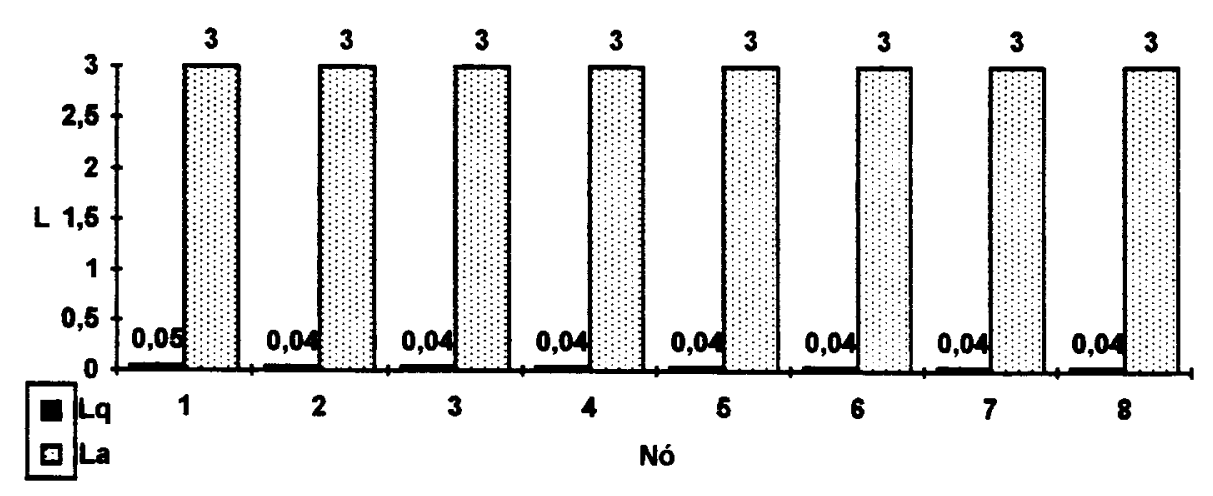

Figura 4.13 - Valores de Lq e La para rede 8x8, com Pp de 25\%

Conforme se pode observar na figura 4.13, cada nó tem um resultado igual ou muito próximo dos demais. Os valores de $\mathrm{Lq}$ e $\mathrm{La}$ também foram analisados em função de diversos outros valores de Pp e, para cada um deles, a diferença dos valores entre os nós foi muito pequena ou nula. Baseando-se nesse fato, conclui-se que não é necessário mostrar o tamanho de fila para cada um dos $\mathrm{N}$ nós da rede, sendo satisfatória a apresentação de um valor médio.

Para a rede $8 \times 8$, com $\mathrm{Pp}$ de $25 \%$, o valor médio de Lq é 0,04 pacote, e o coeficiente de variação $(\mathrm{Cv})$ é de $0,725 \%$, confirmando que os valores de cada nó estão muito próximos da média.

$\mathrm{Na}$ tabela 4.1, pode-se observar os valores de $\mathrm{Lq} \mathrm{e} \mathrm{Cv}$, quando a probabilidade de geração de pacotes $(\mathrm{Pp})$ varia entre $25 \%$ e $100 \%$. O valor de La em função da variação de Pp é mostrada na figura 4.14.

Tabela 4.1. Variação de Lq em função de Pp, em uma rede $8 \times 8$.

\begin{tabular}{|c|c|c|}
\hline $\mathbf{P p}(\%)$ & Lq (pacotes) & Cv (\%) \\
\hline 25 & 0,04 & 0,73 \\
\hline 50 & 0,33 & 0,53 \\
\hline 75 & 1,7 & 0,4 \\
\hline 90 & 6,8 & 0,53 \\
\hline 95 & 15 & 1,5 \\
\hline 99 & 67 & 2,8 \\
\hline 100 & 203 & 4 \\
\hline
\end{tabular}




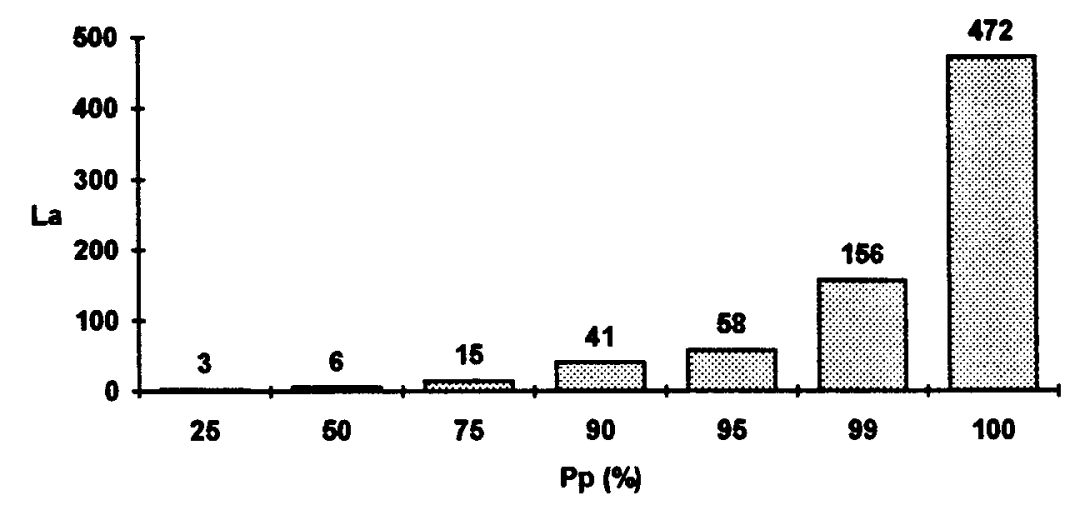

Figura 4.14 - Variação de La em uma rede $8 \times 8$, em função de Pp.

Na tabela 4.1, observa-se que, variando a $\mathrm{Pp}$ de $99 \%$ para $100 \%$, ocorre uma mudança relativamente acentuada no comportamento do sistema. Quando o valor de Pp é de $100 \%$, surge um tamanho médio e um coeficiente com valores relativamente altos para os padrões do sistema, indicando uma maior instabilidade do mesmo. Para uma análise mais detalhada dessa condição operacional, são mostrados na figura 4.15, os valores médios de Lq para cada um dos 8 nós transmissores, quando o valor de Pp é $100 \%$.

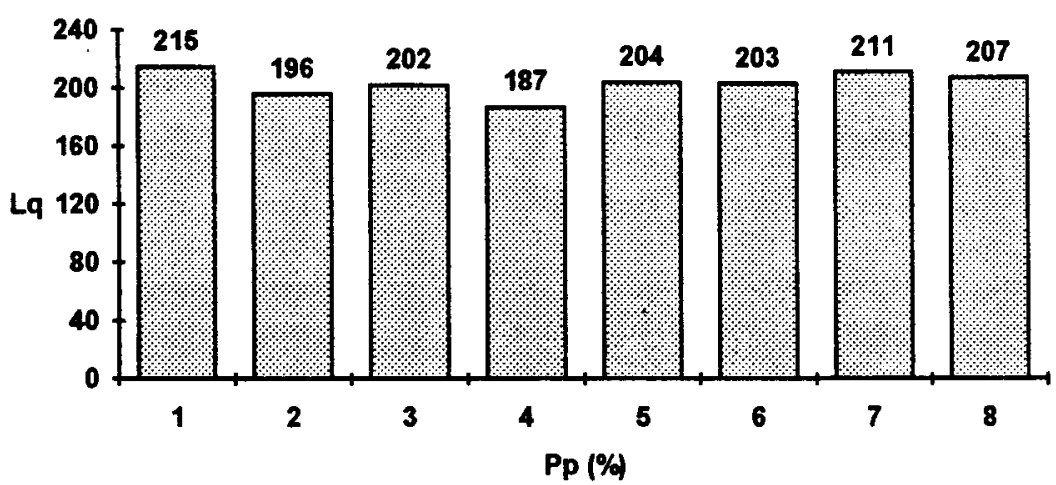

Figura 4.15 - Tamanho de Lq para uma rede 8x8, quando Pp é 100\%.

À medida que Pp se próxima de $100 \%$, ocorre um crescimento relativamente acentuado do tamanho de fila, em comparação com valores menores de Pp. Porém, a análise dos dados permite concluir que o sistema tem um comportamento altamente estável, pois, mesmo no pior caso, o coeficiente de variação foi de $4 \%$. Também no 
pior caso, o tamanho médio de fila foi de 203 pacotes e o maior valor absoluto foi de 472 pacotes, o que, dependendo do tamanho do pacote de dados, pode ser facilmente implementado.

\subsection{Vazão do sistema}

A vazão do sistema $(X)$ é mostrada na figura 4.16. Esse valor apresenta um esperado decréscimo à medida que $\mathrm{Pp}$ aumenta, porém, mesmo para o caso mais crítico, quando Pp é $100 \%$, a vazão valor se mantém acima de $99,60 \%$. Quando a Pp é de $25 \%$, a vazão é de $99,99 \%$ e não atinge $100 \%$ devido ao fato da simulação ser interrompida após 100.000 ciclos de observação, independente de haver ou não pacotes no buffer de transmissão.

Os dados da figura 4.16 mostram que o sistema possui um alto nível de vazão, independentemente do valor de $\mathrm{Pp}$.

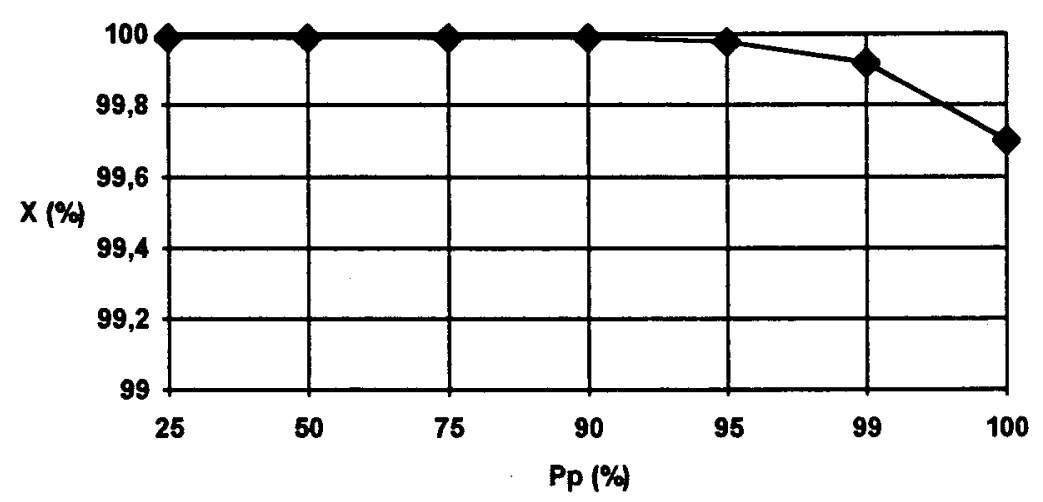

Figura 4.16 - Vazão do sistema (X) para uma rede $8 \times 8$, em função da variação do valor de Pp. 


\subsection{Tempo em fila}

O tempo médio que cada pacote permaneceu em sua sub-fila (Twq) antes de ser enviado para a o buffer de transmissão é mostrado na figura 4.17. A unidade de mediç desse valor é dimensionada em ciclos de simulação.

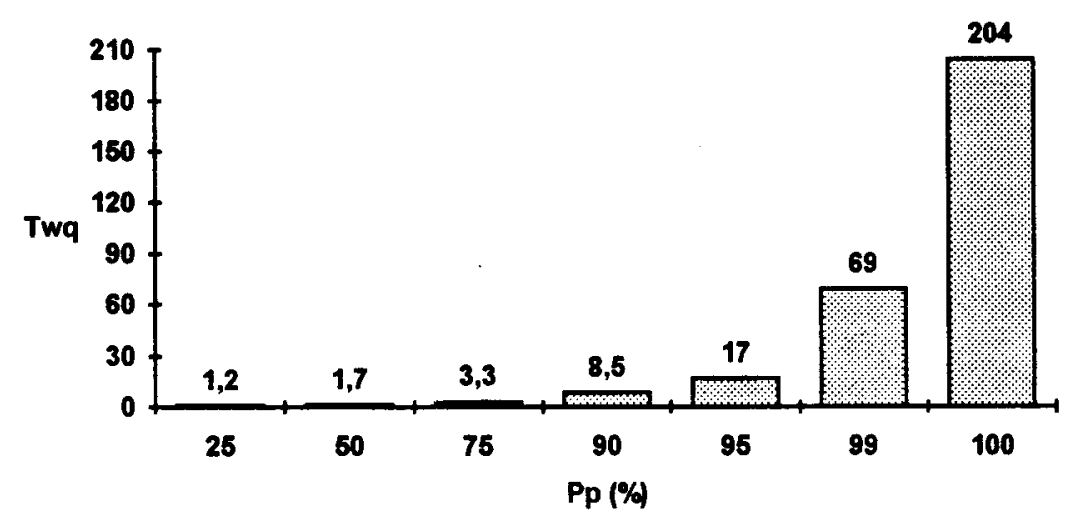

Figura 4.17 - Tempo médio em fila para uma rede $8 x 8$, em função da variação de Pp

O tempo que cada pacote permaneceu na fila antes de ser enviado para o buffer de transmissão está diretamente relacionado com o tamanho da fila. Se esses valores forem comparados com o tamanho médio de fila, poderá ser observado que ambos têm o mesmo comportamento e ordem de grandeza, o que vem a validar o sistema de simulação desenvolvido.

\subsection{Utilização do sistema}

A figura 4.18 mostra a utilização (Ui) de cada um dos 8 canais de transmissão do sistema, quando a $\mathrm{Pp}$ é de $25 \%$. Esse valor é percentual em relação ao número total de ciclos de simulação, sendo que o valor médio dos dados mostrados na figura 4.18 é de $24,93 \%$ e o coeficiente de variação desse valor médio é $0,21 \%$.

A tabela 4.2 mostra os valores médios de utilização de cada canal da rede $8 \times 8$, em função de diferentes valores de Pp. Nessa mesma tabela também pode ser 
observado o valor médio de utilização global (Uw) do WDM. Esses valores médios são acompanhados dos respectivos coeficientes de variação.

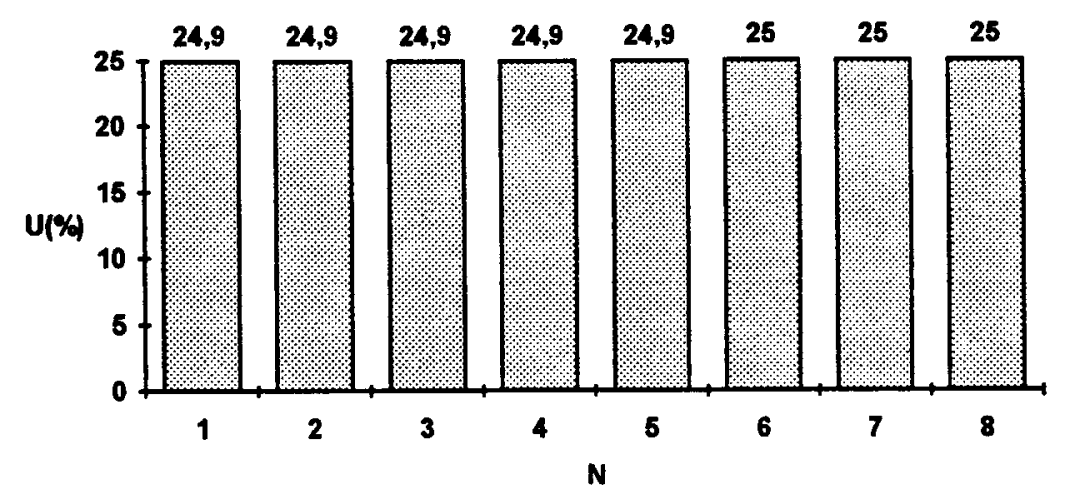

Figura 4.18 - Utilização dos canais da rede 8x8, quando a Pp é de 25\%.

Tabela 4.2 - Valores médios de Ui e Uw em função de Pp, com os respectivos coeficientes de variação ( $C v)$.

\begin{tabular}{|c|c|c|c|c|}
\hline Pp (\%) & Ui (\%) & Cv (\%) & Uw (\%) & Cv (\%) \\
\hline 25 & 24,93 & 0,21 & 92,97 & 0,09 \\
\hline 50 & 49,92 & 0,17 & 99,96 & 0,005 \\
\hline 75 & 74,99 & 0,09 & 100 & 0 \\
\hline 90 & 89,98 & 0,09 & 100 & 0 \\
\hline 95 & 94.99 & 0,07 & 100 & 0 \\
\hline 99 & 98,92 & 0,09 & 100 & 0 \\
\hline 100 & 99,7 & 0,14 & 100 & 0 \\
\hline
\end{tabular}

Os dados da tabela 4.2 mostram primeiramente que o sistema é altamente estável, pois o coeficiente de variação dos valores médios é baixo, comprovando que a maior parte dos valores amostrais estão muito próximos do valor médio. Além disto, os valores de Uw mostram que o sistema tem uma ociosidade muito baixa e o WDM se mantém em operação a maior parte do tempo, mesmo quando a Pp é relativamente pequena. Esse alto nível de utilização demonstra o esforço do sistema 
de enviar o maior número possível de informações por unidade de tempo, o que permite um melhor desempenho da rede.

\subsection{Equilíbrio de fluxo}

A figura 4.19 mostra o gráfico de equilíbrio de fluxo do sistema (FB), ou "flow balance", quando a Pp é de $25 \%$ e quando a Pp é de $100 \%$. Após 100.000 ciclos, esses valores são $99,998 \%$ e $99,69 \%$, respectivamente.

Para 10.000 ciclos os valores do fluxo de equilíbrio já são superiores a $99,0 \%$. Isto vem validar o processo de simulação, pois, o sistema atingiu uma satisfatória condição de equilibrio dentro do tempo de operação proposto para a simulação, que é de 100.000 ciclos.

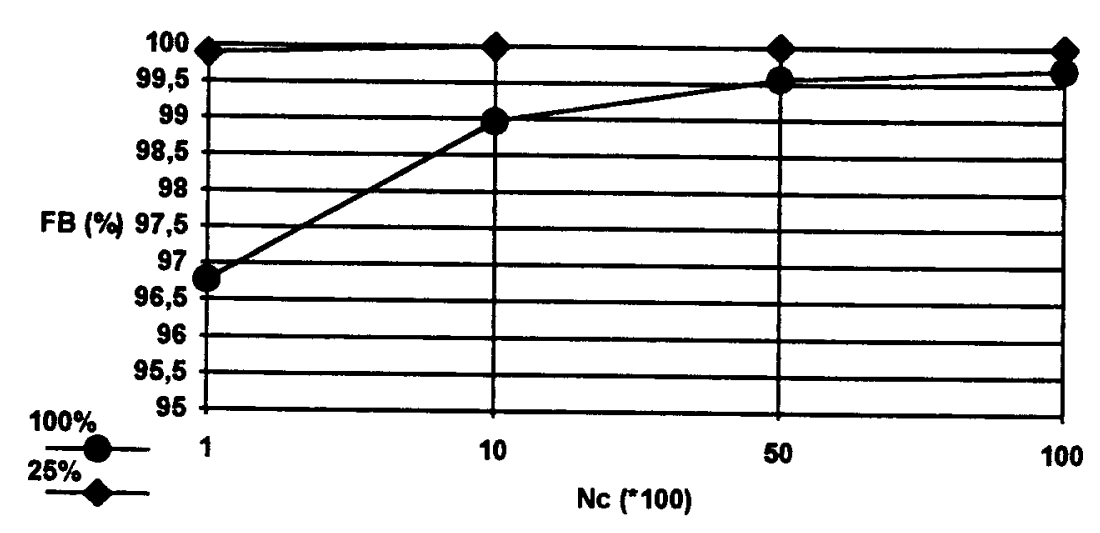

Figura 4.19 - Equilibrio de fluxo do sistema (FB) com Pp de 25\% e 100\% 


\section{Rede 16X16}

Essa seção apresenta os resultados da simulação da rede proposta, com uma configuração de 16 nós transmissores e 16 nós receptores.

\subsection{Análise de fila}

A figura 4.20 mostra os valores de Lq e La para os nós de uma rede 16×16, quando a Pp é de $26 \%$.

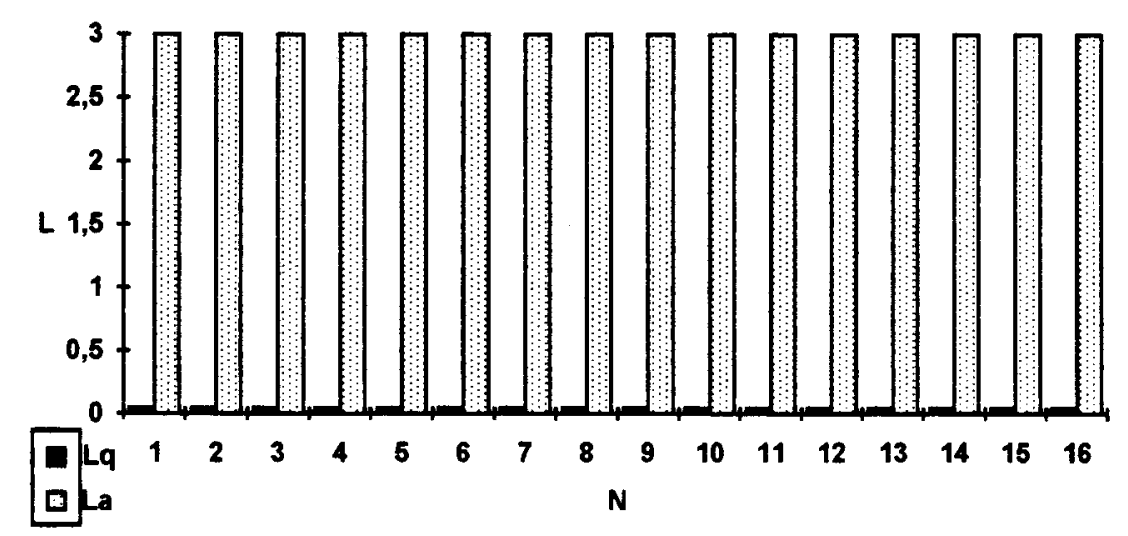

Figura 4.20 - Valores de Lq e La para os $N$ nós de uma rede 16x16, quando o valor de Ppé de 25\%.

Os dados apresentados na figura 4.20 mostram um comportamento altamente estável do sistema, assim, na tabela 4.3, são mostrados os valores médios de Lq, para os $\mathrm{N}$ nós de uma rede $16 \times 16$, quando a Pp varia de $25 \%$ a $100 \%$. 
Tabela 4.3 - Tamanho médio da fila (Lq) e respectivo coeficiente de variação (Cv), em função da variação de $P p$.

\begin{tabular}{|c|c|c|}
\hline Pp (\%) & Lq (pacotes) & Cv (\%) \\
\hline 25 & 0,05 & 0,7 \\
\hline 50 & 0,35 & $0,4 /$ \\
\hline 75 & 1,85 & 0,3 \\
\hline 90 & 7,0 & 0,5 \\
\hline 95 & 16,4 & 1,2 \\
\hline 99 & 83,6 & 3,8 \\
\hline 100 & 219 & 3,6 \\
\hline
\end{tabular}

A figura 4.21 mostra o maior valor absoluto do tamanho de fila (La) em função da variação de $\mathrm{Pp}$.

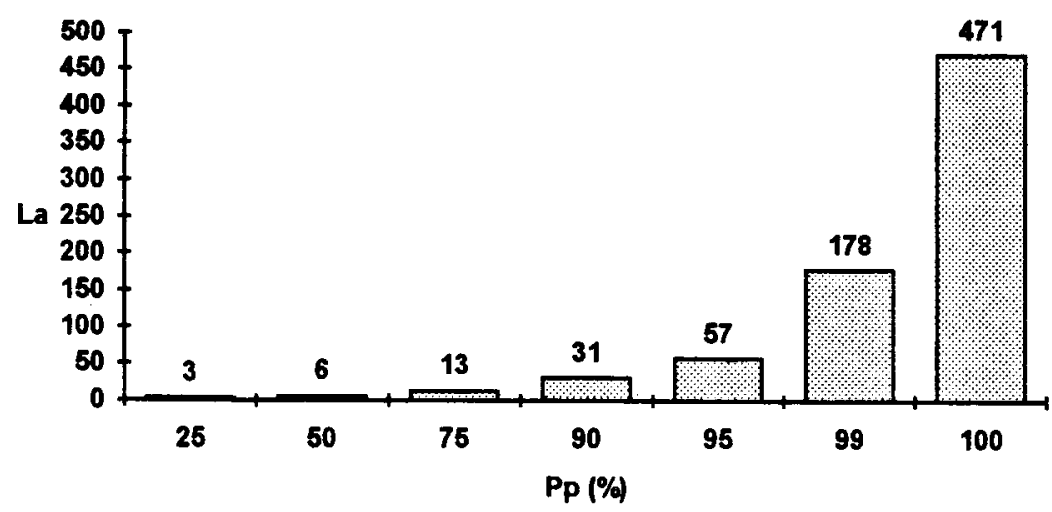

Figura 4.21 - Valores de La em função de Pp, para uma rede $16 \times 16$

Quando o valor de Pp é de $100 \%$, o tamanho médio de fila apresentou um valor méd $r$ de 219 pacotes, com um coeficiente de variação de 3,6\%. Para uma análise m s detalhada dessa condição, a figura 4.22 mostra os valores médios de cada um dos $\mathrm{N}$ nós da rede $16 \times 16$, quando Pp é $100 \%$. 


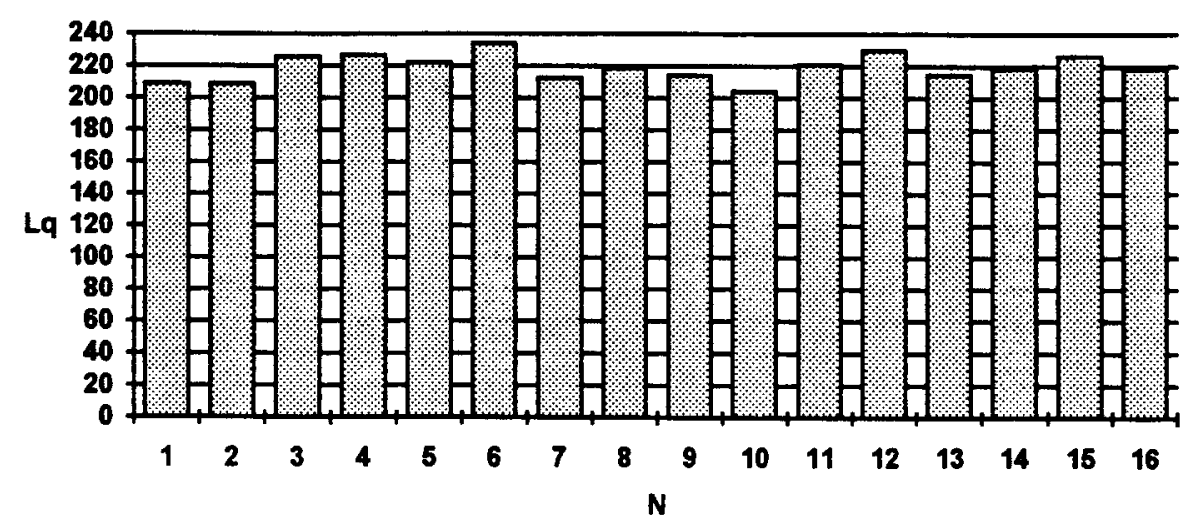

Figura 4.22 - Tamanho médio de fila dos N nós de rede 16x16, quando Pp é100\%

A análise desses dados permite concluir que a rede apresenta um crescimento acentuado do tamanho de fila, à media que $\mathrm{Pp}$ se aproxima de $100 \%$, porém, em qualquer caso, o comportamento pode ser considerado estável e os valores não atingem níveis imensuráveis.

\subsection{Vazão do sistema}

A vazão do sistema (X) é mostrada na figura 4.23 e apresenta um esperado decréscimo à medida que o valor de $\mathrm{Pp}$ se aproxima de $100 \%$, porém, mesmo nesse caso, a vazão apresenta um valor de $99,6 \%$.

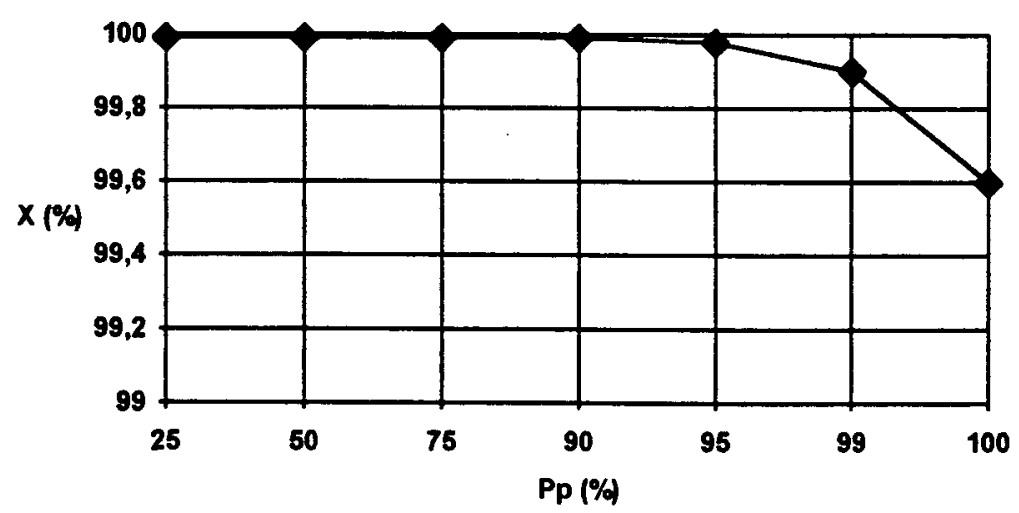

Figura 4.23 - Vazão do sistema $(X)$ em uma rede 16x16, em função da variação do valor de Pp. 
A rede $16 \times 16$ apresentou um alto nivel de vazão do sistema, mesmo quando a Pp se aproxima de $100 \%$, o que é uma característica satisfatória.

\subsection{Tempo em fila}

O tempo médio que cada pacote permaneceu em fila (Twq), antes de ser enviado para o buffer de transmissão, é mostrado na figura 4.24. A unidade de medição desse valor é dada em ciclos de execução.

Esse valor apresenta um esperado crescimento acentuado, à medida que o valor de $\mathrm{Pp}$ se aproxima de $100 \%$. Esses valores são compatíveis com o tamanho médio de fila apresentado, validando o sistema de simulação.

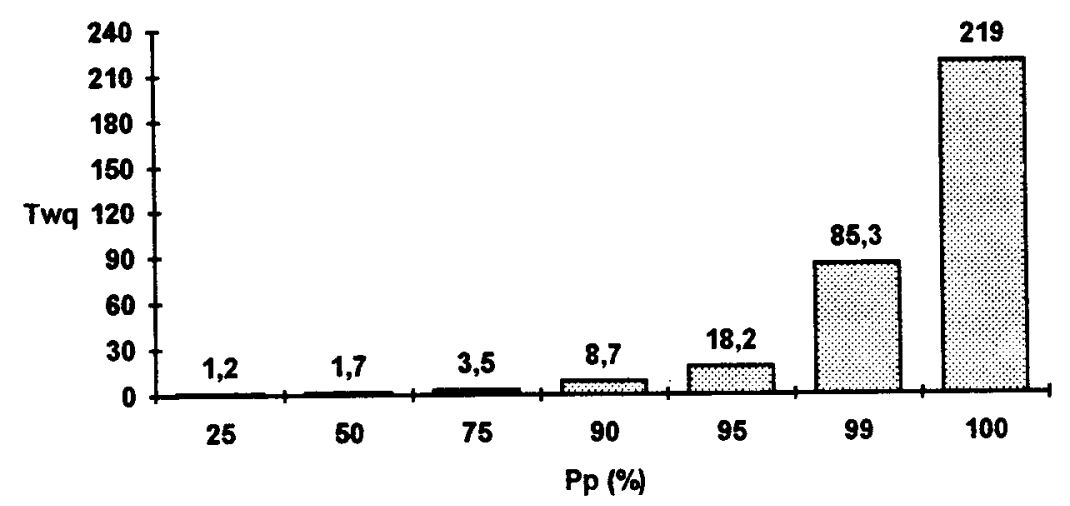

Figura 4.24 - Tempo médio em fila na rede 16x16, em função de Pp.

\subsection{Utilização do sistema}

A figura 4.25 mostra a utilização individual de cada um dos 16 canais do sistema, quando a $\mathrm{Pp}$ é de $25 \%$. Na tabela 4.4 são descritos os valores médios de utilização (Ui) de cada um dos $\mathrm{N}$ canais do WDM e o valor médio de utilização do próprio WDM $(\mathrm{Uw})$. Nessa tabela, os valores médios são apresentados com os respectivos coeficientes de variação $(\mathrm{CV})$. 


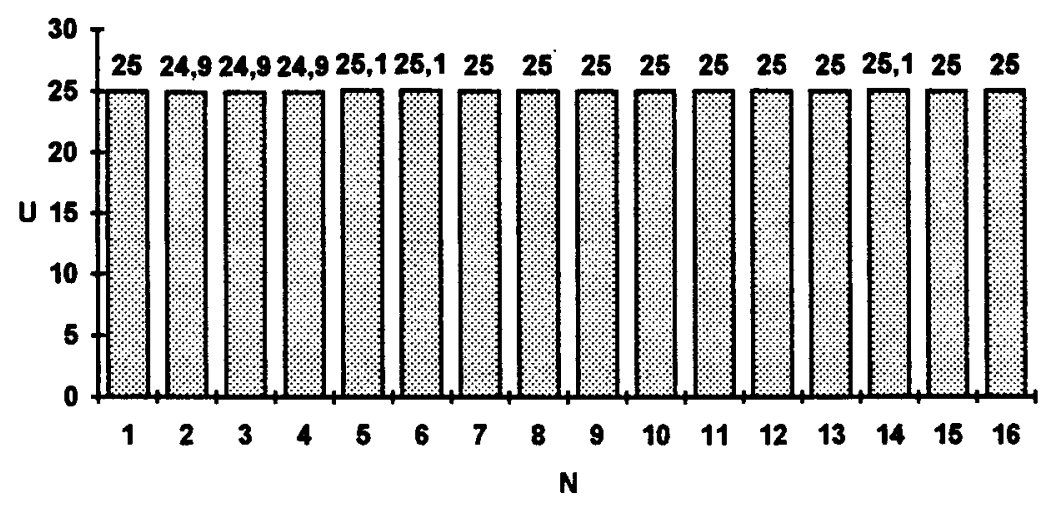

Figura 4.25 - Utilização média de cada um dos 16 canais do WDM em uma rede 16x16, quando a Pp é de 25\%

Tabela 4.4 - Valores médios de Ui e Uw em função de Pp

\begin{tabular}{|c|c|c|c|c|}
\hline Pp (\%) & Ui (\%) & Cv (\%) & Uw (\%) & Cv (\%) \\
\hline 25 & 24,99 & 0,26 & 99,54 & 0,03 \\
\hline 50 & 50,05 & 0,13 & 100 & 0 \\
\hline 75 & 75,00 & 0,1 & 100 & 0 \\
\hline 90 & 89,99 & 0,1 & 100 & 0 \\
\hline 95 & 94,98 & 0,1 & 100 & 0 \\
\hline 99 & 98,9 & 0,1 & 100 & 0 \\
\hline 100 & 99,7 & 0,2 & 100 & 0 \\
\hline
\end{tabular}

Esses valores mostram que a ocupação individual de cada canal do WDM na rede $16 \times 16$, é proporcional ao valor de Pp e a ocupação do sistema WDM (Uw) apresenta um valor muito alto. Assim, o sistema WDM apresenta um nível muito baixo de ociosidade, que, a partir de uma Pp de $25 \%$, é nulo. 


\subsection{Equilíbrio de fluxo}

A figura 4.26 mostra o gráfico de valores do equilíbrio de fluxo do sistema (FB), quando o valor de Pp é de $25 \%$ e $100 \%$. Após 100.000 ciclos, esses valores são $99,99 \%$ e $99,6 \%$, respectivamente.

Com um valor de $\mathrm{Pp}$ de $25 \%$ o sistema atingiu um equilibrio de praticamente $100 \%$ com 10.000 ciclos de simulação. Nesse mesmo ponto, com um valor de Pp de $100 \%$, o equilibrio foi de $99,0 \%$. Esses valores comprovam que o sistema sempre atinge uma condição de equilíbrio dentro dos 100.000 ciclos de simulação utilizados.

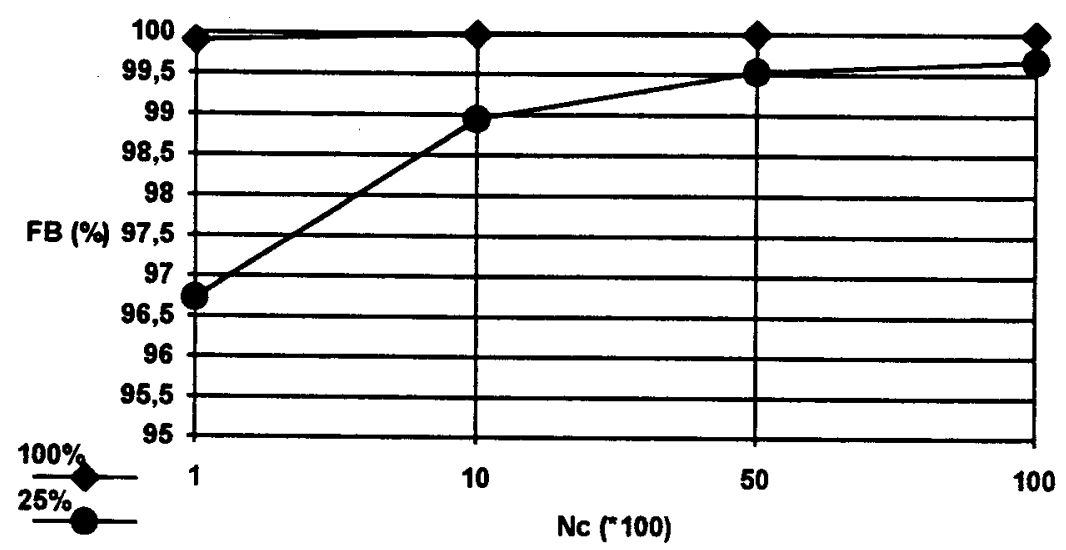

Figura 4.26 - Equilibrio de fluxo do sistema (FB) com Pp de $25 \%$ e $100 \%$ 


\section{Rede 32x32}

Essa seção mostra os resultados obtidos na simulação da rede proposta, com uma configuração de 32 transmissores e 32 receptores

\subsection{Análise de filas}

A figura 4.27 mostra os valores de $\mathrm{Lq}$ e $\mathrm{La}$ para cada um dos $\mathrm{N}$ nós transmissores de uma rede $32 \times 32$, quando a Pp é de $25 \%$.

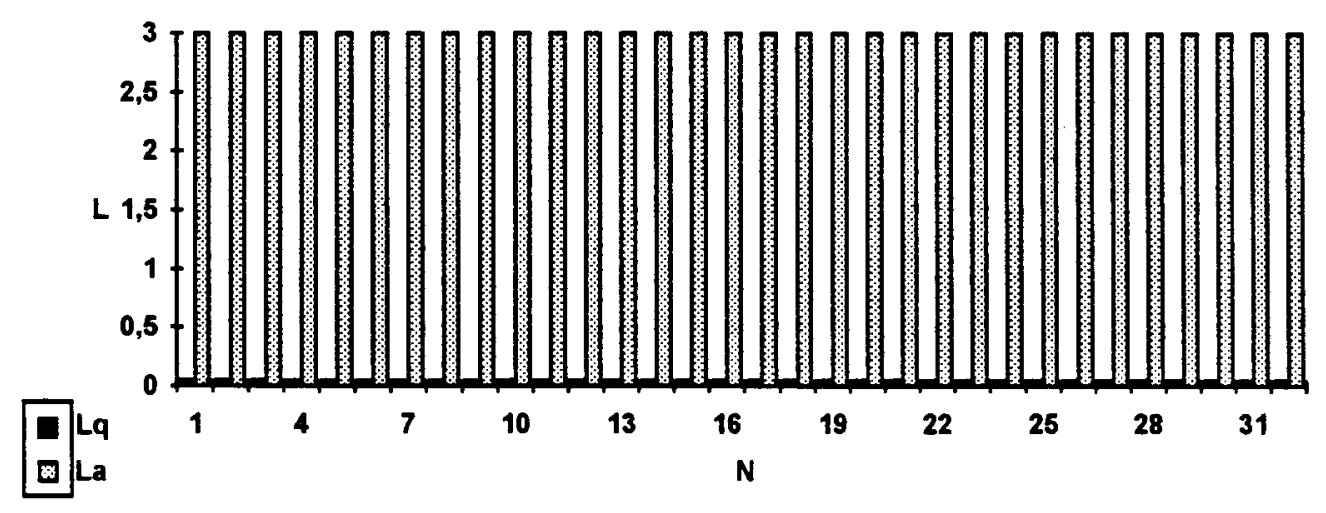

Figura 4.27 - Valores de Lq e La para os $N$ nós de uma rede 32x32, quando o valor de Ppé 25\%.

Os valores de Lq na figura 4.27 são muito próximos, o que induz ao uso de um valor médio para todo o sistema. Assim, a tabela 4.5 mostra os valores médios de Lq; com os respectivos coeficientes de variação $(\mathrm{Cv})$, em função de diversos valores de $\mathrm{Pp}$. A figura 4.28 mostra os valores de $\mathrm{La}$ em função de $\mathrm{Pp}$. 
Tabela 4.5 - Valores médios de Lq. Os valores médios são apresentados com os respectivos coeficientes de variação (Cv), em função da variação de Pp.

\begin{tabular}{|c|c|c|}
\hline Pp (\%) & Lq (pacotes) & Cv (\%) \\
\hline 25 & 0,05 & 0,6 \\
\hline 50 & 0,36 & 0,3 \\
\hline 75 & 1,92 & 0,3 \\
\hline 90 & 7,0 & 0,37 \\
\hline 95 & 15,9 & 0,8 \\
\hline 99 & 82,2 & 4,1 \\
\hline 100 & 231 & 3,9 \\
\hline
\end{tabular}

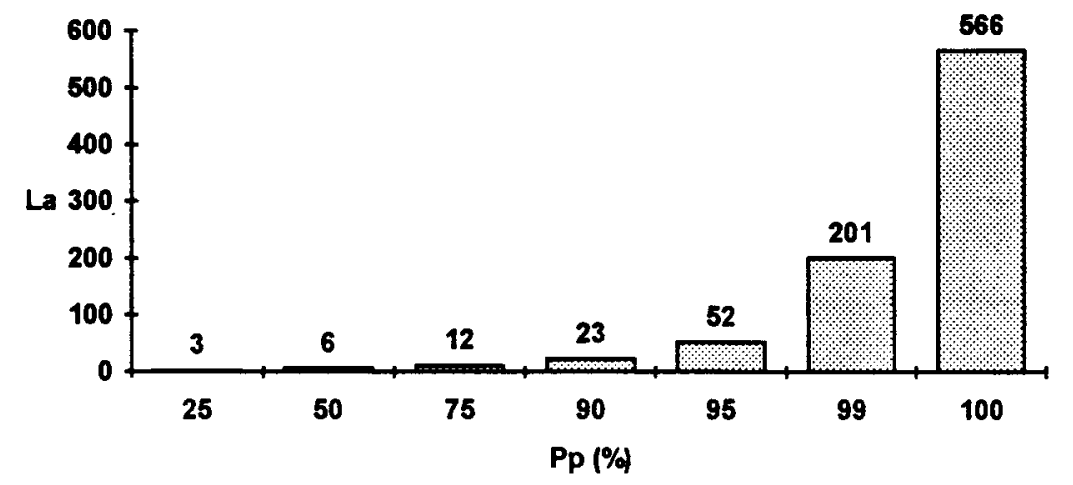

Figura 4.28 - Valores de La para a rede $32 \times 32$ em funçâo de Pp.

Quando o valor de Pp é $100 \%$ ocorre um acentuado crescimento do tamanho de fila e um aumento do coeficiente de variação. Desta forma, para uma analise mais detalhada desse caso, mostramos na figura 4.29 o valor médio de fila para cada um dos $\mathrm{N}$ nós transmissores da rede $32 \times 32$. 


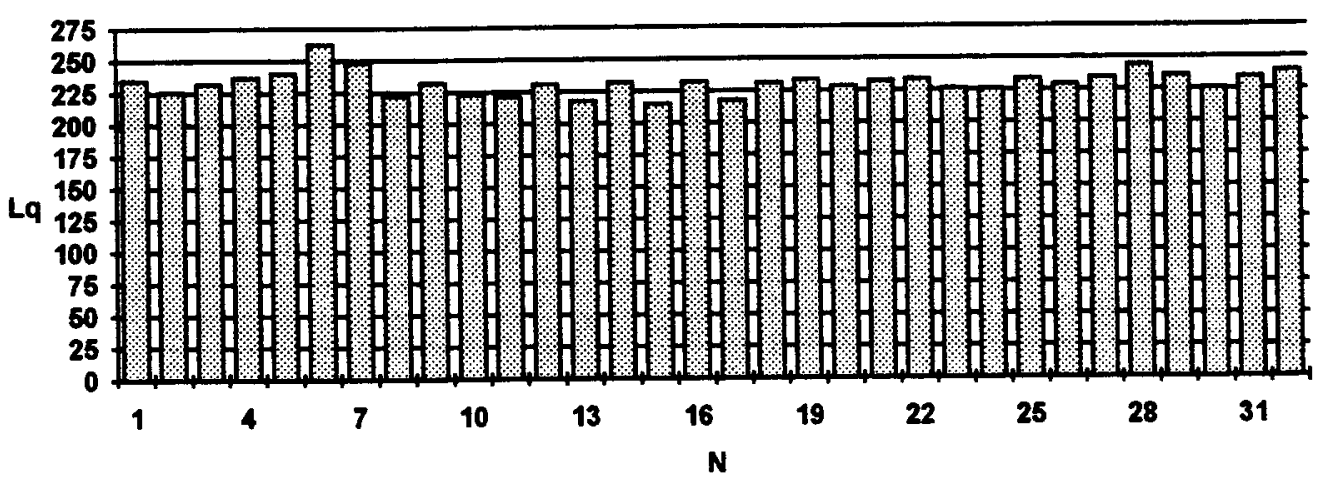

Figura 4.29 - Valor de Lq para os N nós da rede 32×32, quando Pp é 100\%

\subsection{Vazão do sistema}

A vazão do sistema $(X)$ é mostrada na figura 4.30. Esse valor apresenta um esperado acréscimo à medida que o valor de $\mathrm{Pp}$ aumenta, porém, mesmo para um valor de $\mathrm{Pp}$ de $100 \%$, a vazão fica em $99,6 \%$. A análise desses valores permite concluir que a rede $32 \times 32$ tem um alto nivel de vazão, independentemente do valor de $\mathrm{Pp}$.

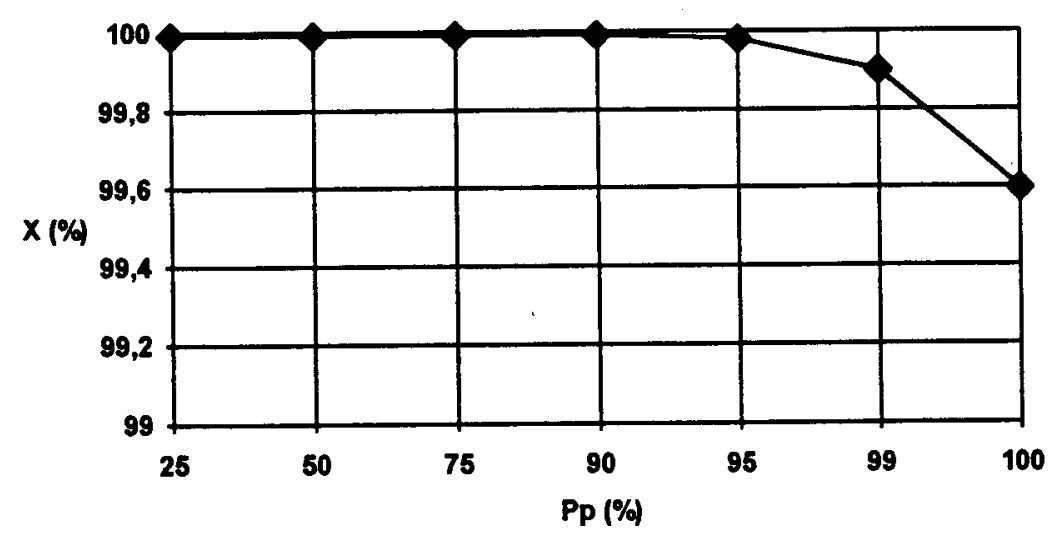

Figura 4.30 - Vazão do sistema $(X) 32 \times 32$, em função da variação de $P p$ 


\subsection{Tempo em fila}

O tempo médio que cada pacote permaneceu em fila (Twq) antes de ser enviado para a o buffer de transmissão, em uma rede $32 \times 32$, é mostrado na figura 4.31. A unidade de medição desse valor é dada em ciclos de execução.

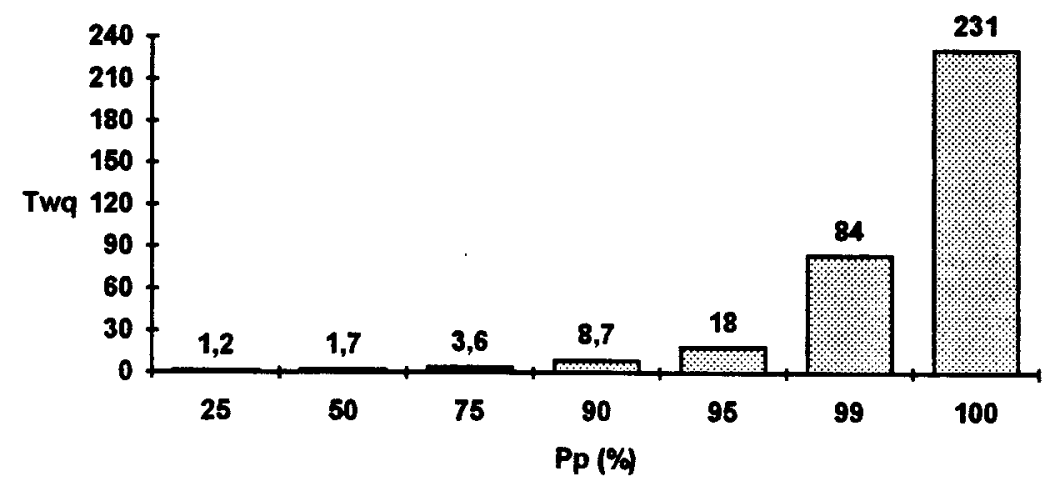

Figura 4.31 - Tempo em fila antes da transmissão, em uma rede 32x32, em função dos valores de $\mathrm{Pp}$.

Esses valores são proporcionais aos valores do tamanho médio de fila, o que valida o sistema de simulação desenvolvido.

\subsection{Utilização do sistema}

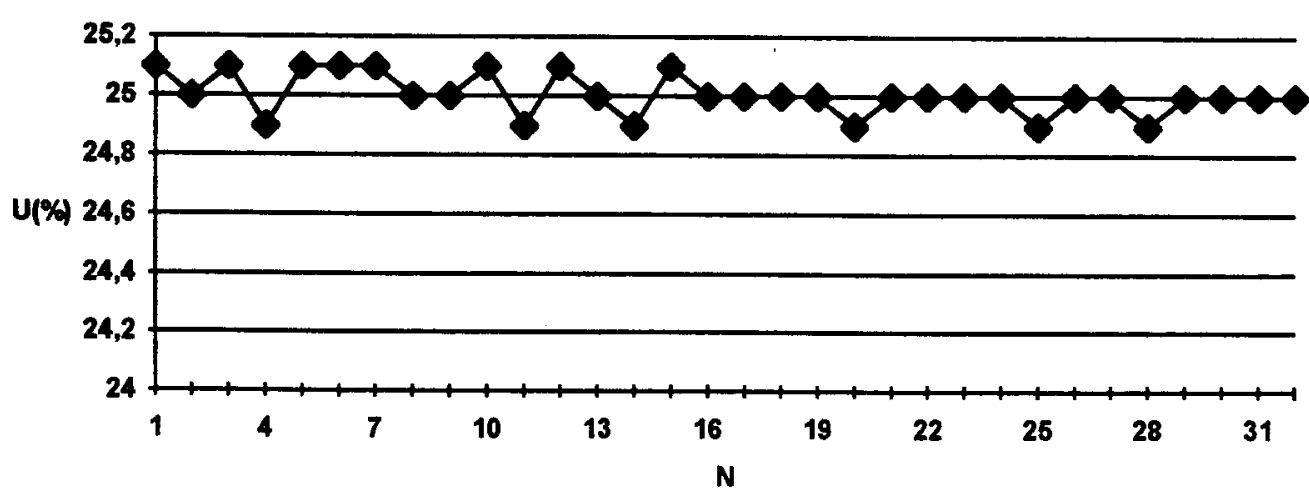

Figura 4.32 - Utilização média de cada um dos $N$ canais WDM de uma rede $32 \times 32$, quando o valor de Ppé $25 \%$. 
A figura 4.32 mostra o valor médio de utilização de cada um dos 32 canais do WDM em uma rede $32 \times 32$, quando a $\mathrm{Pp}$ é $25 \%$. A tabela 4.6 mostra os valores médios de $\mathrm{Ui}$ e $\mathrm{Uw}$, com os respectivos coeficientes de variação $(\mathrm{Cv})$.

Tabela 4.6 - Valores médios de Ui e Uw em função de Pp

\begin{tabular}{|c|c|c|c|c|}
\hline Pp (\%) & Ui (\%) & Cv (\%) & Uw (\%) & Cv (\%) \\
\hline 25 & 25,0 & 0,2 & 100 & 0 \\
\hline 50 & 50,0 & 0,13 & 100 & 0 \\
\hline 75 & 74,99 & 0,13 & 100 & 0 \\
\hline 90 & 89,99 & 0,1 & 100 & 0 \\
\hline 95 & 94,98 & 0,1 & 100 & 0 \\
\hline 99 & 98,9 & 0,18 & 100 & 0 \\
\hline 100 & 99,65 & 0,34 & 100 & 0 \\
\hline
\end{tabular}

Esses valores mostram que a ocupação individual de cada canal do WDM na rede $32 \times 32$ é proporcional ao valor de Pp e a ocupação do sistema WDM (Uw) apresenta um valor de $100 \%$, ou seja, o nível de ociosidade do sistema WDM é nulo.

\subsection{Equilíbrio de fluxo}

A figura 4.33 mostra o gráfico de equilibrio de fluxo (FB), quando a Pp é de $25 \%$ e $100 \%$. Após 100.000 ciclos esses valores são de $100 \%$ e $99,6 \%$, respectivamente, mostrando um alto nível de equilibrio do sistema.

Os valores da figura 4.33 permitem confirmar que o sistema atinge um satisfatório nível de equilíbrio dentro do número dos 100.000 ciclos utilizados na simulação, o que vem a validar o processo de simulação. 


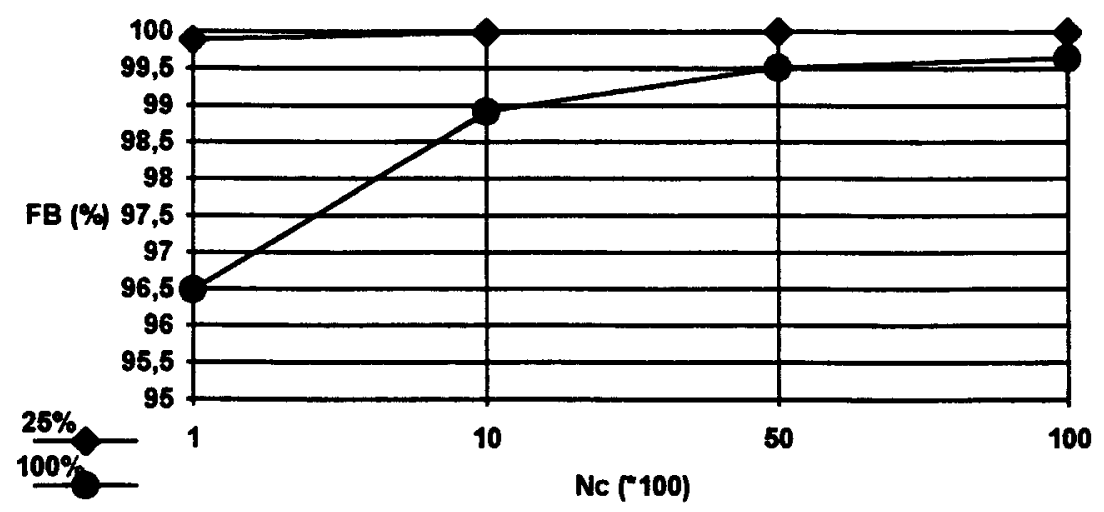

Figura 4.33 - Equilibrio de fluxo do sistema (FB) com Pp de 25\% e 100\%, em uma rede $32 \times 32$.

\section{Rede 64x64}

Essa seção apresenta os resultados da simulação da rede proposta, com uma configuração com 64 transmissores e 64 receptores.

\subsection{Análise de fila}

A figura 4.34 mostra os valores de Lq e La para cada um dos $\mathrm{N}$ nós da rede $64 \times 64$, quando a probabilidade de geração de pacotes é de $25 \%$.

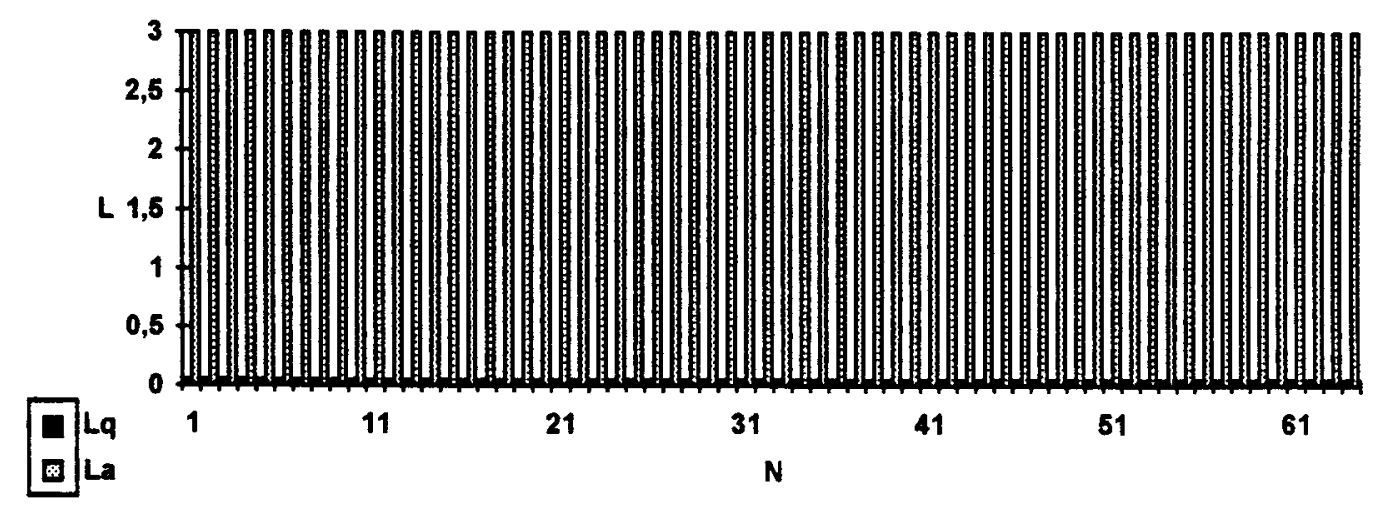

Figura 4.34 - Valores de Lq e La para cada nó de uma rede 64x64, com Pp de 25\%. 
A tabela 4.7 mostra os valores de Lq, com os respectivos coeficientes de variação $(\mathrm{Cv})$, para uma rede $64 \times 64$, em função da variação do valor de $\mathrm{Pp}$. A figura 4.35 mostra o maior tamanho absoluto de fila (La), em função da variação de $\mathrm{Pp}$.

Tabela 4.7 - Valor de Lq em função de Pp, para a rede $64 x 64$.

\begin{tabular}{|c|c|c|}
\hline Pp (\%) & Lq (pacotes) & Cv (\%) \\
\hline 25 & 0,05 & 0,6 \\
\hline 50 & 0,36 & 0,36 \\
\hline 5 & 1,91 & 0,28 \\
\hline 90 & 7,34 & 0,29 \\
\hline 95 & 15,3 & 0,38 \\
\hline 99 & 82,2 & 3,3 \\
\hline 100 & 233,3 & 2,7 \\
\hline
\end{tabular}

Quando a Pp é de 100\%, observa-se o maior tamanho médio fila e um coeficiente de variação de $2,7 \%$, que é um valor relativamente alto em relação aos demais valores. Assim, a figura 4.36 mostra o tamanho médio de fila para cada um dos 64 nós da rede, quando a Pp é de $100 \%$.

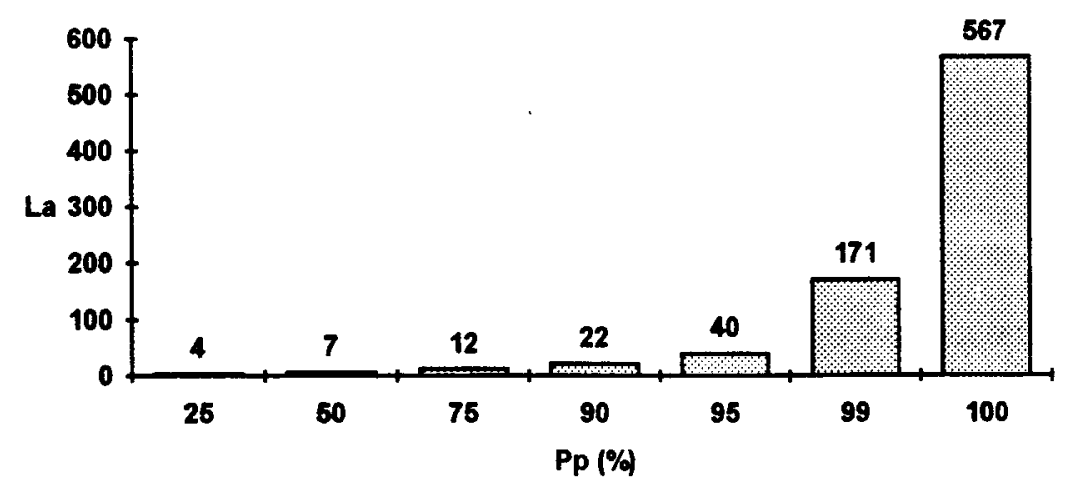

Figura 4.35 - Valor de La em função de Pp, em uma rede $64 x 64$ 


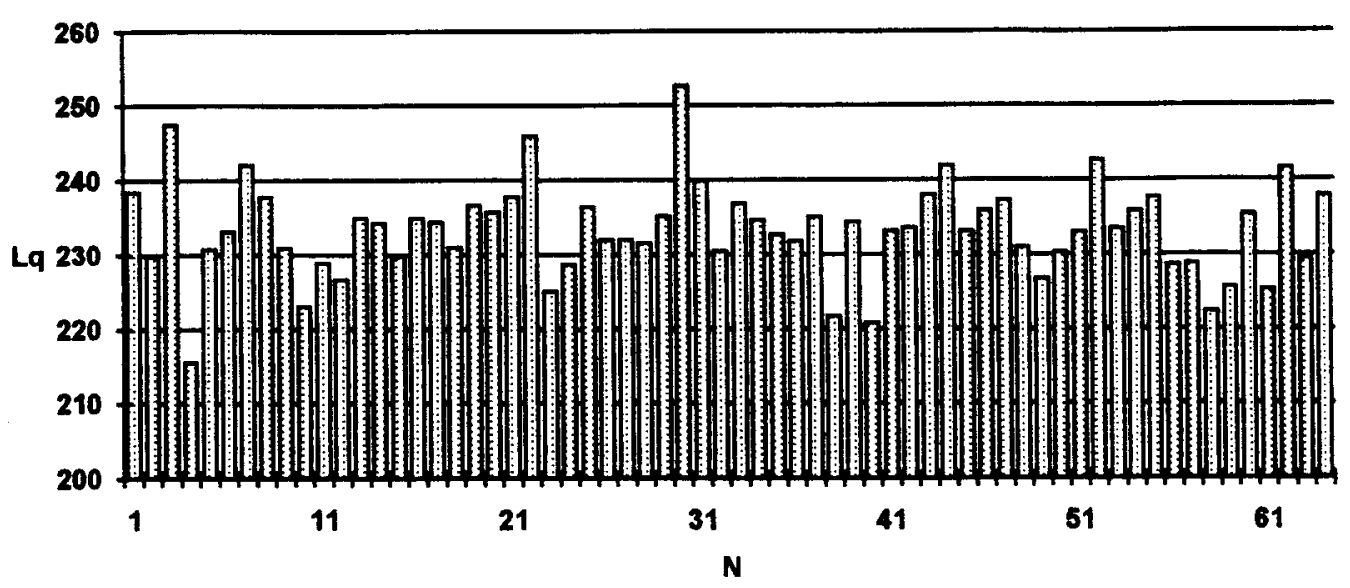

Figura 4.36 - Valor de Lq para cada um dos $N$ nos da rede 64x64, quando o valor de Pp é de $100 \%$.

$\mathrm{O}$ tamanho médio de fila apresenta um crescimento acentuado à medida que o valor de Pp se aproxima de 100\%. Mesmo para o valor mais crítico, o coeficiente de variação foi de apenas $2,7 \%$ e o tamanho médio foi de 233,3 pacotes, o que, dependendo do tamanho do pacotes, exigiria uma memória com tamanho perfeitamente implementável.

\subsection{Vazão do Sistema}

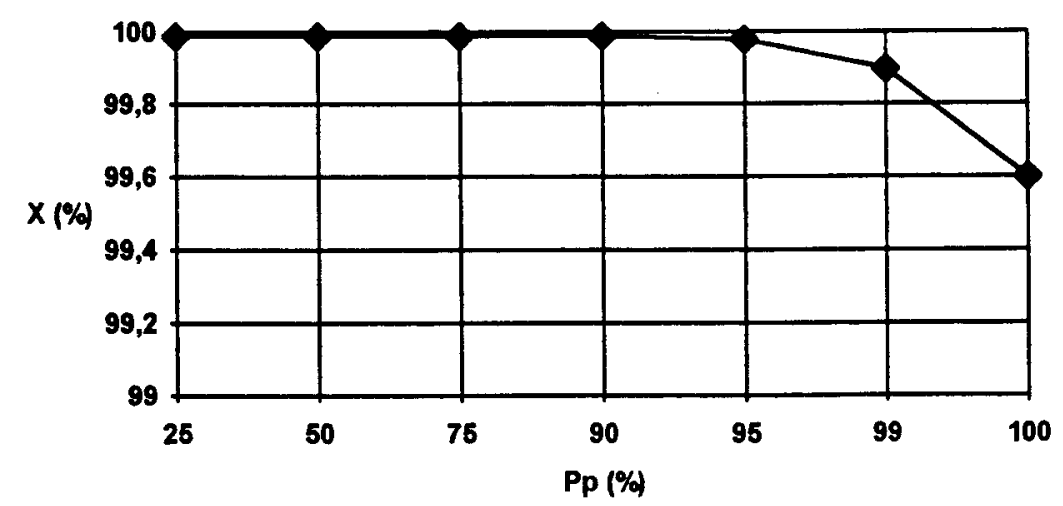

Figura 4.37 - Vazão do sistema em uma rede 64x64, em função do valor de Pp. 
A figura 4.37 mostra a vazão do sistema (X) em função do valor de $\mathrm{Pp}$. $\grave{A}$ medida que o valor de $\mathrm{Pp}$ aumenta, ocorre um esperado decréscimo no valor da vazão. Mesmo para um valor de $P$ p de $100 \%$, a vazão do sistema foi de $99,6 \%$, o que é considerado um valor altamente satisfatório.

\subsection{Tempo em fila}

O tempo médio que cada pacote permaneceu em fila (Twq), antes de ser enviado para a o buffer de transmissão, é mostrado na figura 4.38. A unidade de medição desse valor é dada em ciclos de execução.

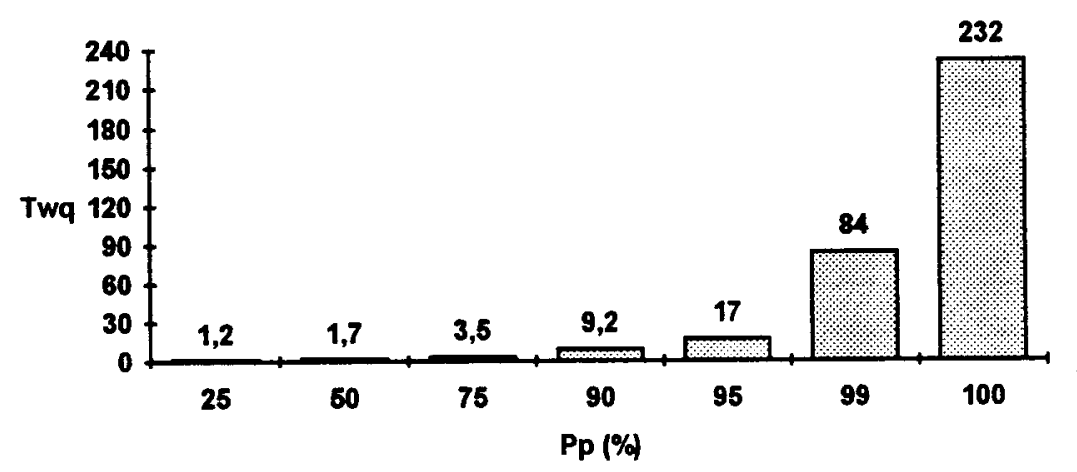

Figura 4.38 - Tempo médio em fila, em função da variação do valor de Pp

Esses valores são proporcionais ao tamanho médio de fila e validam o sistema de simulação desenvolvido.

\subsection{Utilização do sistema}

A tabela 4.8 mostra os valores médios de Ui e Uw, com os respectivos coeficientes de transmissão $(\mathrm{Cv})$. Os valores de Ui são proporcionais aos valores de Pp e os valores de Uw são sempre de $100 \%$, mostrando claramente que o nivel de ociosidade do sistema WDM é zero. 
Tabela 4.8 - Valores de Ui e Uw em função de Pp

\begin{tabular}{|c|c|c|c|c|}
\hline Pp (\%) & Ui (\%) & Cv (\%) & Uw (\%) & Cv (\%) \\
\hline 25 & 25,0 & 0,17 & 100 & 0 \\
\hline 50 & 50,0 & 0,14 & 100 & 0 \\
\hline 75 & 75,0 & 0,07 & 100 & 0 \\
\hline 90 & 90,0 & 0,07 & 100 & 0 \\
\hline 95 & 94,99 & 0,11 & 100 & 0 \\
\hline 99 & 98,9 & 0,21 & 100 & 0 \\
\hline 100 & 99,65 & 0,40 & 100 & 0 \\
\hline
\end{tabular}

\subsection{Equilíbrio de fluxo}

A figura 4.39 mostra o gráfico de equilibrio de fluxo (FB), quando a Pp é de $25 \%$ e 100\%. Após 100.000 ciclos, esses valores são de $99,9 \%$ e $99,6 \%$, respectivamente, mostrando um alto nível de equilíbrio do sistema.

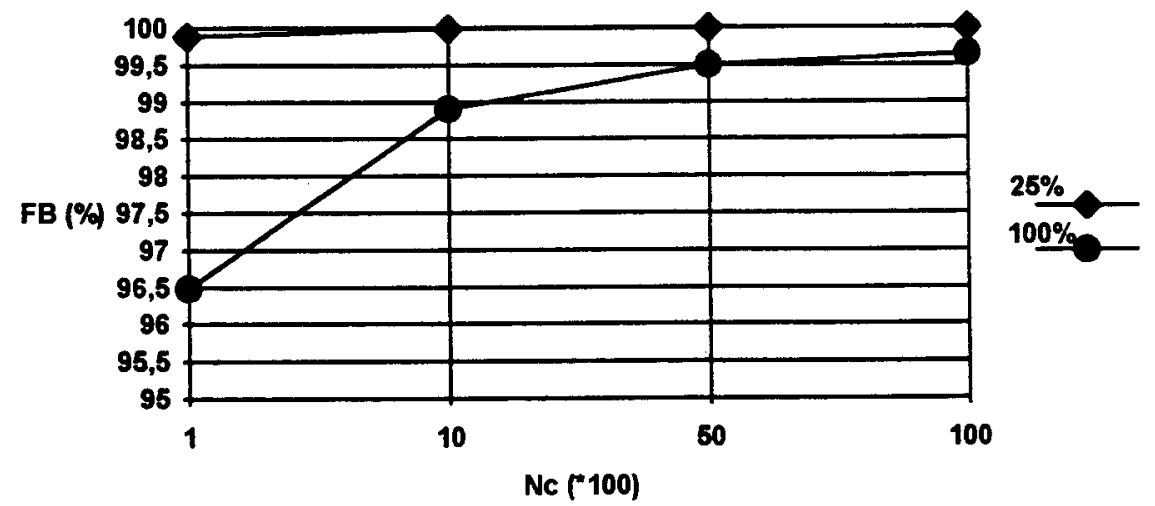

Figura 4.39 - Valores de FB, com Pp de 25\% e 100\%, em uma rede $32 \times 32$.

Com 10.000 ciclos, os valores de FB, mostrados na figura 4.39 , estão na faixa de $99,0 \%$ e $100 \%$, respectivamente. Isto comprova que o sistema apresenta um nível satisfatório de estabilização dentro dos 100.000 ciclos utilizados na simulação. 


\section{Análise de escalabilidade da rede proposta}

Para uma análise da escalabilidade da rede são comparados os valores do tamanho médio de fila (Lq), o maior valor absoluto de fila (La) e a vazão do sistema (X) para redes $8 \times 8,16 \times 16,32 \times 32$ e $64 \times 64$, sempre se utilizando uma probabilidade de produção de pacotes $(\mathrm{Pp})$ de $100 \%$.

$\mathrm{Na}$ figura 4.40, é mostrado o tamanho médio de fila para cada um dos tamanhos de rede utilizados. Nessa figura, observa-se que, quando o tamanho da rede varia de $8 \times 8$ para $64 \times 64$, o tamanho médio de fila varia de 203 para 233 , o que é uma variação muito pequena em comparação com a proporção de variação do tamanho da rede.

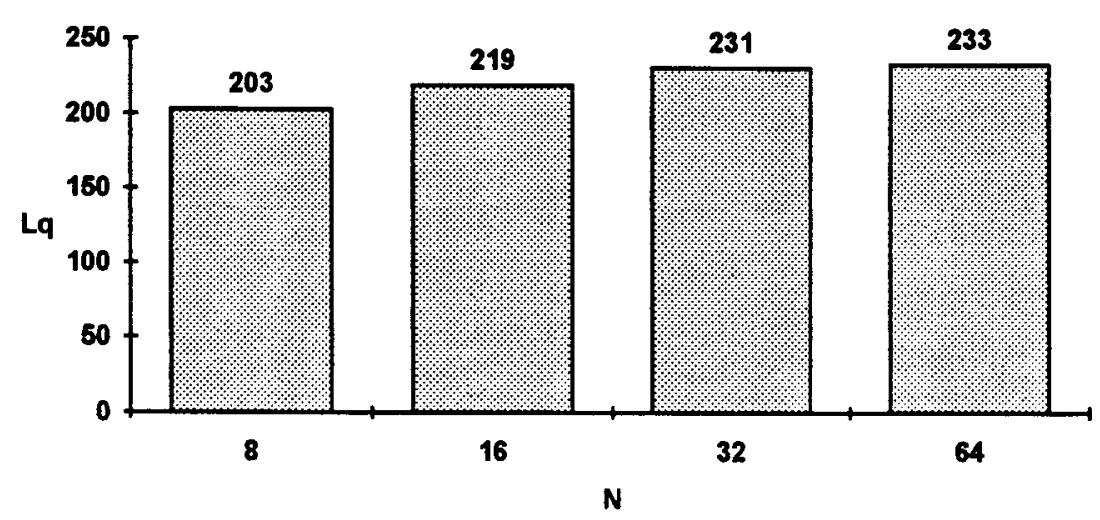

Figura 4.40 - Tamanho médio da fila ( $L q$ ) em função do tamanho da rede $N x N$, quando o valor de Pp é de 100\%

A figura 4.41 mostra o maior valor absoluto de tamanho de fila (La) em função do tamanho da rede, quando a Pp é de $100 \%$. Nesse caso, quando o tamanho da rede varia de $8 \times 8$ para $64 \times 64$, o maior valor absoluto varia de 472 para 567 , ou seja, o tamanho da rede cresce 8 vezes e o valor de La cresce apenas 1,2 vezes. 


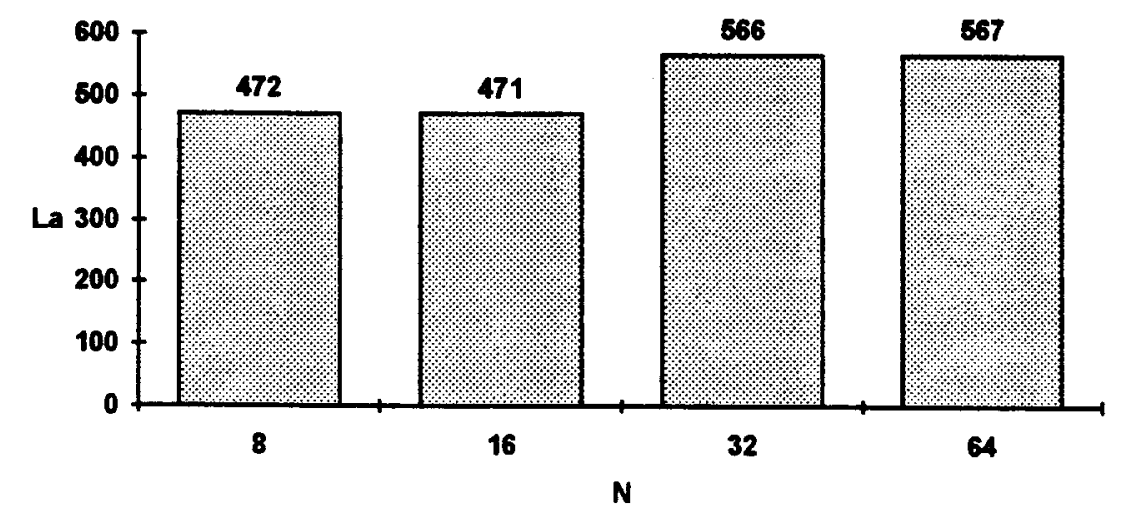

Figura 4.41 - Maior valor absoluto de fila (La) em função da variação do tamanho da rede, quando a Pp é de $100 \%$.

A figura 4.42 mostra a vazão do sistema $(X)$ em função da variação do tamanho de rede, quando a probabilidade de produção de um pacote é de $100 \%$. Para todos os tamanhos de rede utilizados, a vazão apresentou um valor superior a $99,6 \%$ e a sua diferença, em função do tamanho da rede, foi pequena. $O$ valor médio da vazão dos quatro tamanhos de redes analisados é de $99,665 \%$, com um desvio padrão de $0,02 \%$.

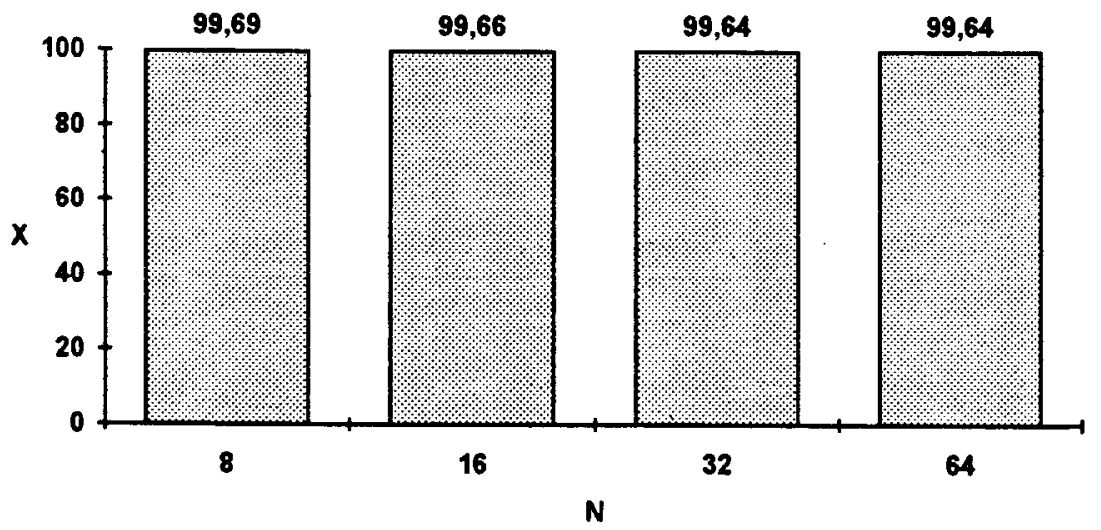

Figura 4.42 - Vazão do sistema $(X)$ em função da variação do tamanho da rede $N x N$, quando a Pp é de 100\%. 


\section{Conclusões do Capítulo}

A rede proposta neste capítulo do trabalho possui uma caracteristica restritiva, que é a necessidade do tempo de controle ser menor que o tempo de transmissão de um pacote. Isto significa que o número de nós da rede $(\mathrm{N})$ deve ser menor ou igual ao número de bytes de um pacote de dados, pois, caso isto não ocorra, haverá uma diminuição no desempenho da rede. Como o canal de controle e os canais de dados operam com a mesma taxa de transmissão, essa restrição se torna independente da taxa de transmissão.

A rede SCF foi simulada com configurações quadradas de 8, 16, 32 e 64 nós, sendo que o seu comportamento, em todas as configurações, foi muito parecido. Isto indica um alto grau de coerência relativa à escalabilidade, pois o comportamento da rede pode ser previsto de forma independente do seu tamanho.

Apesar da rede proposta possuir uma característica restritiva, ela possui várias características extremamente vantajosas, que independem do seu tamanho e da taxa de transmissão utilizada, o que justifica fortemente o seu uso. Essas características são:

- Escalabilidade coerente. Se a relação de tamanhos entre a rede e o pacote de dados for respeitada, o comportamento da rede será previsível, independentemente do seu tamanho;

- Tamanho aceitável de fila. Os tamanhos médios e absolutos das filas da rede podem ser implementados com memórias simples, cujos tamanhos não têm restrições tecnológicas ou de custo;

- Nível de vazão com um valor sempre superior a $99,5 \%$, o que é considerado altamente satisfatório;

- Rápida estabilização. O sistema atinge um nivel satisfatório de fluxo de equilibrio com um número relativamente pequeno de ciclos de execução. Isto indica uma boa estabilização no comportamento da rede;

- Um tempo de espera em fila proporcional ao tamanho da mesma, comprovando a coerência operacional do sistema;

- Alto nível de utilização da rede. Isto mostra que o sistema não fica ocioso e envia dados a maior parte do tempo. 


\section{CAPÍTULO 5}

\section{Chave Óptica de Distribuição}

\section{Apresentação}

Este capítulo apresenta a simulação e a análise do desenvolvimento da chave óptica de distribuição de uma arquitetura Dataflow. Nesse sistema de simulação, foi adotado um tamanho de ficha de dados (pacote) com 50 bytes e os transmissores utilizados sempre tiveram $2,0 \mathrm{~Gb} / \mathrm{s}$ como taxa de transmissão, o que exige um tempo de 200 ns para efetuar a transmissão de uma ficha. $\mathrm{O}$ valor de $2,0 \mathrm{~Gb} / \mathrm{s}$ foi adotado pelo fato de ser um valor típico em sistemas de comunicação óptica [Borella et al 1994], apesar de existirem sistemas comerciais operando com taxas maiores. Cada ficha enviada a uma Unidade-Processadora exige um tempo médio de processamento, que, nessa simulação, foi fixado em $100 \mathrm{~ns}$

Para uma análise mais precisa dos resultados, cada processo de simulação foi executado com 1.000 .000 de ciclos e repetido 10 vezes, sendo que os resultados foram analisados em função dos valores médios.

Este capitulo apresenta três versões de uma chave óptica de distribuição, que foram simuladas com o simulador descrito no capítulo 4. O simulador foi inicialmente adaptado para operar o comportamento de redes $\mathrm{NxM}$ e cada ciclo de simulação passou a representar um período de tempo de $10 \mathrm{~ns}$ 
Nessa versão do simulador, o usuário entra com os seguintes parâmetros:

- Dimensões do sistema (NxM);

- Tempo de sintonização do transmissor óptico;

- Tempo de processamento de um pacote;

- Valor da Ar desejada;

- Número de ciclos de simulação.

Nesse sistema, foi mantida a estrutura produtor-chave-consumidor e os controles flagch e flagcons, descritos no capitulo 4. A principal alteração do simulador é feita na rotina controle, que controla a transmissão de dados da rede óptica conforme as características do processo de gerenciamento.

\section{Chave óptica de distribuição 1xN}

A figura 5.1 mostra a primeira proposta de uma chave óptica de distribuição, que é composta por um transmissor sintonizável e um acoplador divisor (splitter) que divide o sinal entre os $\mathrm{N}$ receptores ou Unidades-Processadoras (UPs). Segundo a classificação de Mukerjee, isto forma um sistema single-hop TT-FR ${ }^{\mathrm{N}}$.

Nesse sistema, o Módulo de Memória de Dados (MMD) envia pacotes para a chave de distribuição, que se encarrega de enviá-los para as Unidades-Processadoras. Na simulação dessa chave, foram utilizadas 8 Unidades-Processadoras e um único transmissor ónuco, com velocidade de transmissão de $2,0 \mathrm{~Gb} / \mathrm{s}$ e tempo de sintonia de 1 ns.

A chave de distribuição foi desenhada com uma área de memória, chamada de Buffer, que é capaz de armazenar somente a ficha que está sendo transmitida. 
Enquanto ocorre uma transmissão, a MMD não envia fichas para a chave de distribuição e as novas fichas produzidas durante a transmissão, são armazenadas em uma fila da MMD.

Para a simulação dessa chave, a rotina controle foi adaptada para realizar um controle que é relativamente simples, pois, só há um transmissor e não haverá colisões. No início de cada ciclo de simulação, os controles flagch e flagcons são atualizados e, assim que o Buffer de transmissão receber uma ficha, o transmissor sintonizará o canal da primeira Unidade-Processadora livre e transmitirá a ficha.

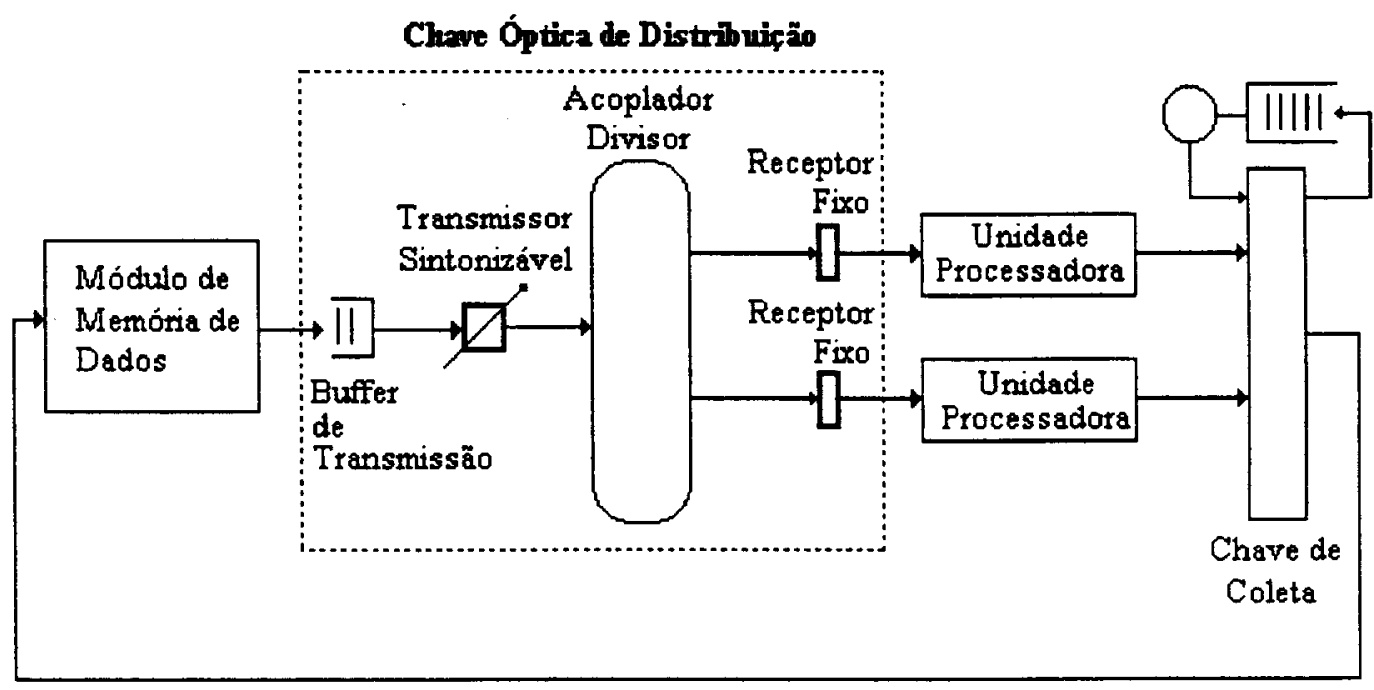

Figura 5.1 - Modelo do sistema Dataflow com uma chave óptica de distribuição. O transmissor é sitonizável e distribui o sinal através de um acoplador divisor, para $N$ Unidades-Processadoras.

O desempenho do processo de comunicação depende de três fatores distintos de tempo, que são o tempo de sintonização do transmissor óptico, o tempo de transmissão de uma ficha e o tempo que a Unidade-Processadora necessita para processar uma ficha. O tempo de sintonização afeta diretamente a banda passante do sistema de transmissão e o tempo de processamento determina a possibilidade da 
Unidade-Processadora estar disponivel para receber novas fichas em um determinado ciclo de execução.

$\mathrm{Na}$ operação da chave óptica de distribuição proposta nesta seção, o transmissor sintoniza o comprimento de onda relativo ao canal óptico de uma Unidade-Processadora e efetua a transmissão de uma ficha para a referida UP. Após a recepção, a UP inicia o processamento da ficha recebida e simultaneamente o transmissor inicia a sintonização e transmissão de uma outra ficha para uma segunda Unidade-Processadora. A figura 5.2 descreve esse processo, onde se pode analisar poderá não influenciar o desempenho do sistema, desde que ele seja menor ou igual à soma do tempo de sintonização e do tempo de transmissão

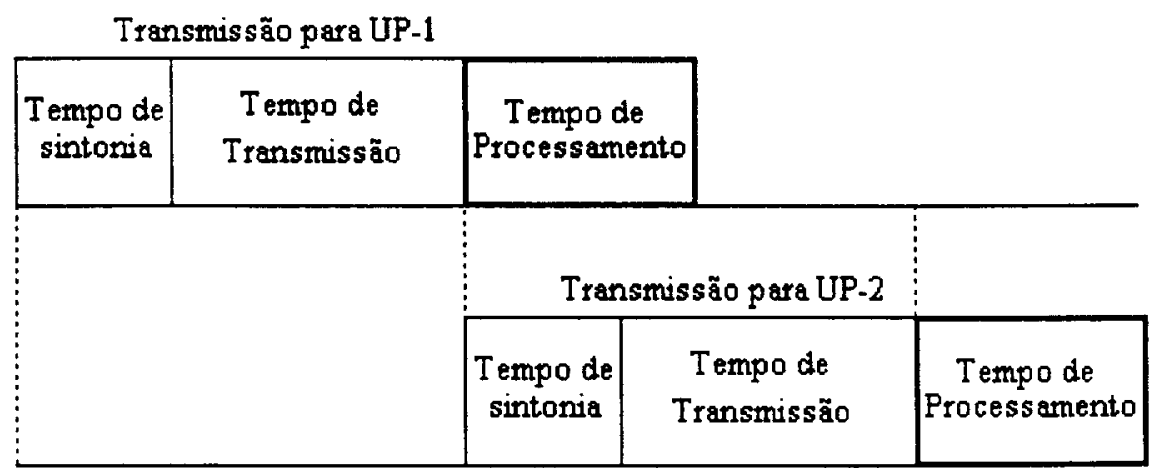

Figura 5.2 - Representação do processo de comunicação. Enquanto uma UnidadeProcessadora faz o processamento de uma ficha recebida, o transmissor simultaneamente envia uma segunda ficha para uma outra Unidade-Processadora.

A chave óptica $1 \times N$ foi inicialmente simulada em um sistema $1 \times 8$ e o seu desempenho foi analisado em função de diferentes valores para a taxa de geração de ficha (Ar), usando-se sempre um período de observação de 1.000 .000 de ciclos de execução. A taxa de geração de fichas representa o número médio de bits por segundo que o MMD tenta enviar para a chave óptica de distribuição. $O$ envio desses dados para a chave de distribuição depende do fato da mesma estar ociosa, sendo que, 
se a chave estiver ocupada, então os dados ficarão armazenados em uma fila do MMD. Como a taxa de transmissão do transmissor óptico é de $2,0 \mathrm{~Gb} / \mathrm{s}$, a simulação foi feita com uma Ar variando entre $1,0 \mathrm{~Gb} / \mathrm{s}$ e $2,0 \mathrm{~Gb} / \mathrm{s}$.

\subsection{Vazão do sistema}

A vazão do sistema de transmissão $(\mathrm{X})$ representa a relação entre o número de fichas que a $M M D$ gerou $(R)$ e o número de fichas que a chave efetivamente transmitiu (C), sendo expressa de forma percentual e dada pela expressão: $X=R / C$.

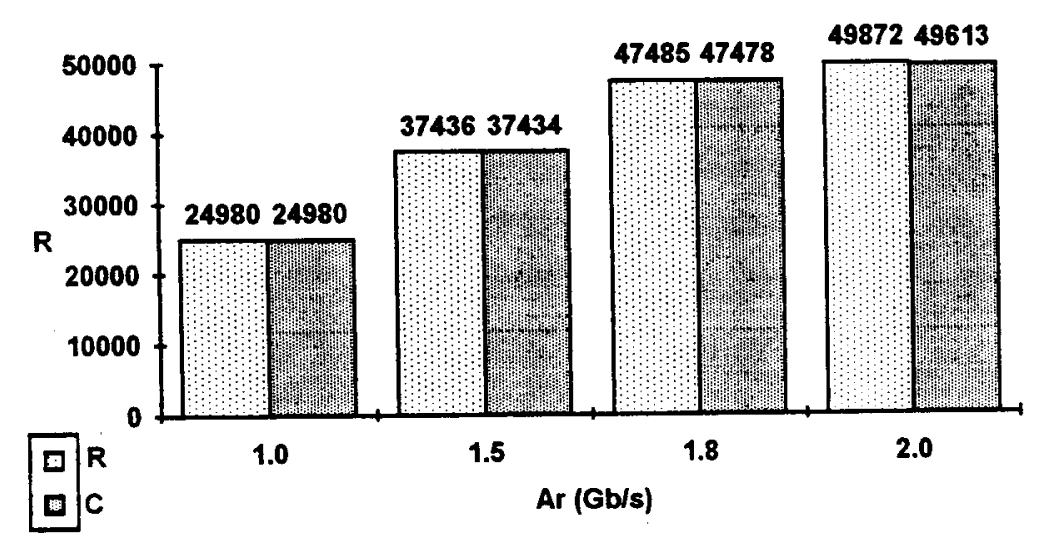

Figura 5.3 - Número de pacotes gerados $(R)$ e número de pacotes transmitidos (C) pela chave óptica de distribuição, em função de diferentes valores de Ar.

Tabela 5.1 - Vazão do sistema (X), em função da Ar.

\begin{tabular}{|c|c|}
\hline $\mathbf{A r}(\mathbf{G b} / \mathbf{s})$ & $\mathbf{X}$ (\%) \\
\hline 1,0 & 100 \\
\hline 1,5 & 99,99 \\
\hline 1,8 & 99,98 \\
\hline 2,0 & 99,48 \\
\hline
\end{tabular}


A figura 5.3 mostra os valores de R e C, medidos em função de uma variação do valor de Ar, sendo que os valores da vazão, relativos a esses números, são mostrados na tabela 5.1. O valor da vazão do sistema apresenta uma previsível queda à medida que a $\mathrm{Ar}$ se aproxima de $2,0 \mathrm{~Gb} / \mathrm{s}$. Porém, mesmo para esse valor, que é considerado um valor crítico, a vazão do sistema se mantém em valores próximos a $100 \%$. Isto mostra a alta capacidade de vazão oferecida pela rede $1 \times 8$, quando a $\mathrm{Ar}$ se mantém em valores de até $2,0 \mathrm{~Gb} / \mathrm{s}$.

\subsection{Balanceamento da transmissão.}

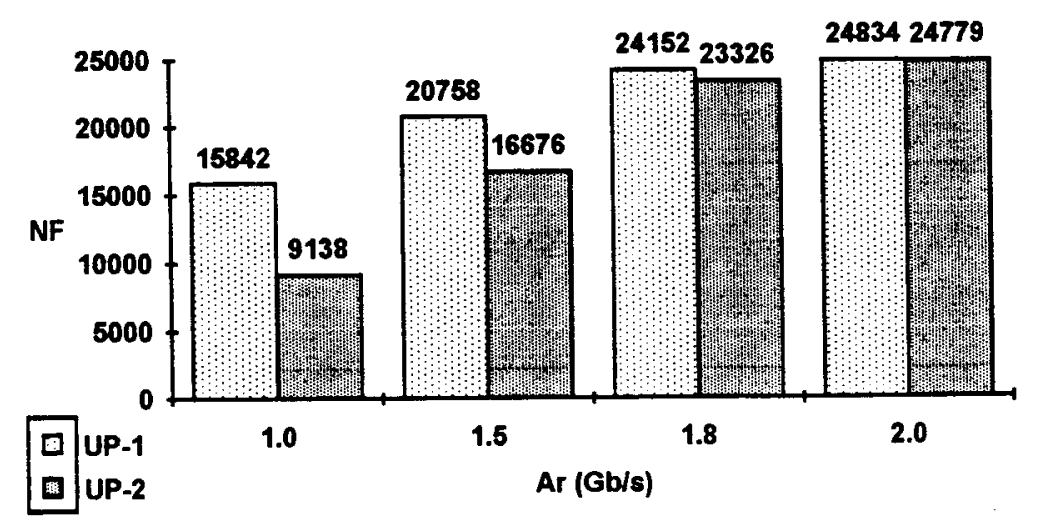

Figura 5.4 - Nümero de fichas (NF) que as Unidades-Processadoras 1 e 2 receberam durante a simulação, em função da variação da Ar. Todas as demais UnidadesProcessadoras permaneceram ociosas.

O balanceamento da transmissão representa o número de fichas que cada uma das oito Unidades-Processadoras recebeu, permitindo analisar a carga operacional de cada unidade. Como o tempo de processamento é menor que a soma do tempo de sintonização e do tempo de transmissão, o transmissor envia dados para somente dois 
receptores. Essa caracteristica previsível pode ser analisada na figura 5.4, onde se observa que somente as duas primeiras Unidades-Processadoras receberam fichas, enquanto que as outras seis Unidades-Processadoras permaneceram ociosas durante todo o processo de simulação, sem receber nenhuma ficha. Esse fato compromete seriamente o grau de paralelismo oferecido por essa chave.

Observa-se que, à mediada que a Ar se aproxima de $2,0 \mathrm{~Gb} / \mathrm{s}$, ocorre um maior equilibrio entre o número de fichas que cada uma das duas únicas UPs ativas recebeu.

\subsection{Análise de fila}

Um outro parâmetro analisado durante o processo de simulação foi o número de fichas que ficam armazenadas na fila do MMD, durante o processo de simulação, pois quando uma ficha é produzida, ela é colocada na fila até que possa ser transmitida.

A figura 5.5 mostra o tamanho médio de fila de fichas $(\mathrm{Lq})$, onde se observa que o seu crescimento não é acentuado para uma Ar de até $1,8 \mathrm{~GB} / \mathrm{s}$, porém cresce desproporcionalmente quando a Ar atinge $2,0 \mathrm{~Gb} / \mathrm{s}$. O maior valor médio foi de 154 fichas, o que não exige uma memória com alta capacidade de armazenamento, pois cada ficha utilizada tem 50 bytes e, assim, uma memória de apenas 7700 bytes seria suficiente para atender as exigências desse valor médio. 


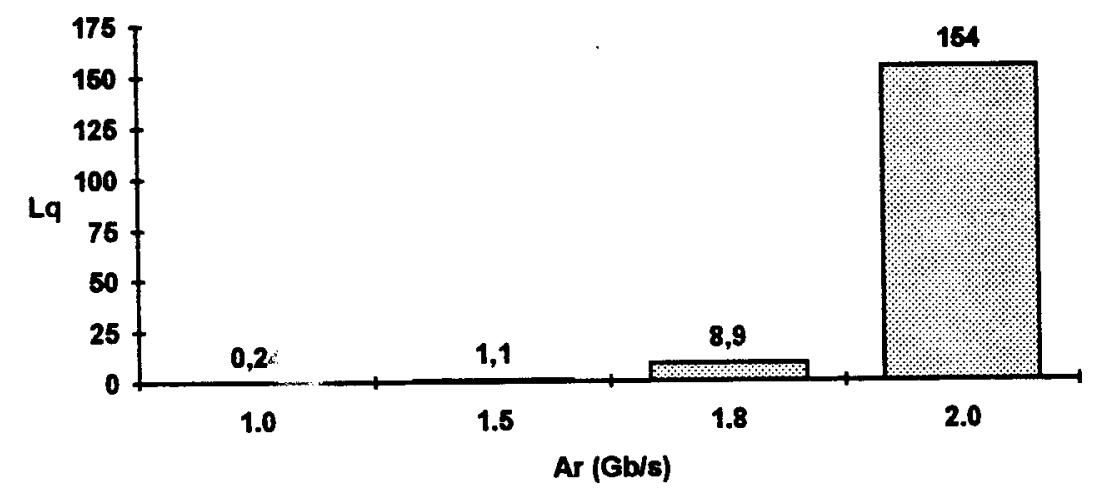

Figura 5.5 - Tamanho médio da fila de fichas (Lq), em função da variação da Ar.

A tabela 5.2 mostra o coeficiente de variação $(\mathrm{Cv})$ dos tamanhos médios de fila, que são apresentados na figura 5.5. Pode-se observar que o coeficiente de variação dos valores médios aumenta à medida que a $\mathrm{Ar}$ cresce, e que, para uma $\mathrm{Ar}$ de até $1,8 \mathrm{~Gb} / \mathrm{s}$, o seu valor se manteve em niveis que mostram um comportamento estável do sistema. Para uma $\mathrm{Ar}$ de 2,0 Gb/s o coeficiente de variação apresenta um crescimento acentuado, mostrando um comportamento mais instável do sistema.

Tabela 5.2 - Coeficiente de variação (Cv) do tamanho médio de fila, em função da variação do valor de $A r$

\begin{tabular}{|c|c|}
\hline $\mathbf{A r}(\mathbf{G b} / \mathbf{s})$ & $\mathbf{C v}(\%)$ \\
\hline 1,0 & 2,4 \\
\hline 1,5 & 3,9 \\
\hline 1,8 & 10,8 \\
\hline 2,0 & 70,5 \\
\hline
\end{tabular}

O modelo matemático de geração de pacotes foi um modelo estocástico, o que permite um bom valor médio e força o aparecimento de rajadas (burst) no sistema, 
conforme mencionado no capitulo 4. Essas rajadas podem forçar o geração acentuada de fichas em determinados instantes.

Analisando-se o coeficiente de variação, pode-se concluir que esses valores acentuados aparecem poucas vezes durante a simulação do sistema, quando a $\mathrm{Ar}$ é de até $1,8 \mathrm{~Gb} / \mathrm{s}$, porém, não se pode ignorar sua ocorrência. Para análise desses valores extremos, foi medido o maior valor absoluto (La) que a fila apresentou em todos os ciclos de todas as simulações.

Uma fila com tamanho de La poderia armazenar $100 \%$ das fichas que the fossem enviadas. Para uma $\mathrm{Ar}$ de até $1,8 \mathrm{~Gb} / \mathrm{s}$, essa fila seria pouco utilizada em sua totalidade, podendo induzir a um super dimensionamento do sistema. Para uma Ar de 2,0 Gb/s, o tamanho médio da fila apresenta um alto coeficiente de variação e o uso do tamanho médio no dimensionamento da fila poderia induzir a um tamanho insuficiente para atender a demanda do sistema. O valor de La também poderia criar um super dimensionamento do sistema. A figura 5.6 mostra os maiores de $\mathrm{La}$ em função da variação da $\mathrm{Ar}$.

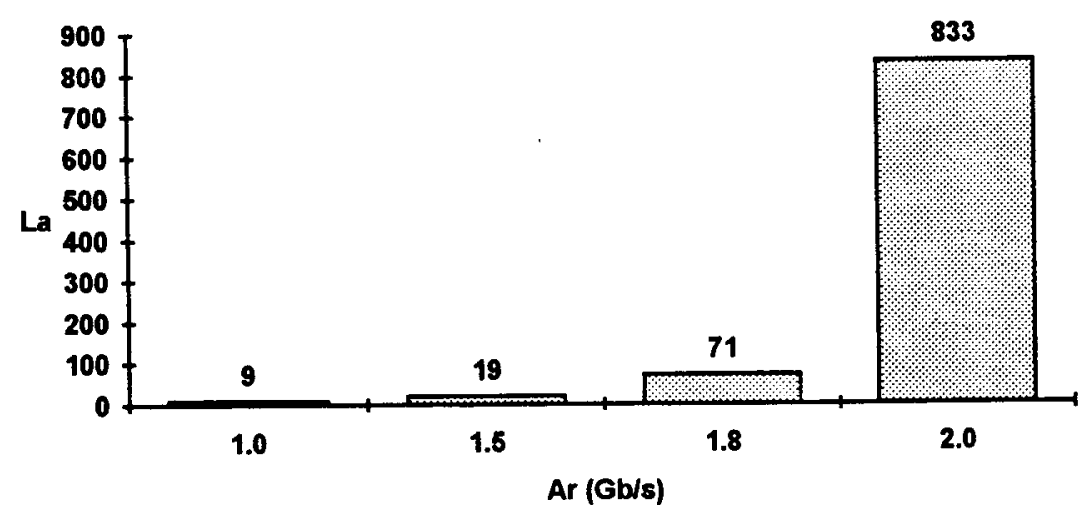

Figura 5.6 - Maior valor absoluto da fila de fichas (La), em função da Ar. 
Observe que, para uma Ar de 1,8 Gb/s, seria necessária uma memória de 3550 bytes, enquanto que para uma $\operatorname{Ar}$ de $2,0 \mathrm{~Gb} / \mathrm{s}$, seria necessária uma memória de 41650 bytes, ou, aproximadamente, $41 \mathrm{KBytes}$. Desta forma, o conceito de super dimensionamento de memória, quando se usa o valor de La no seu dimensionamento, torna-se um conceito muito relativo. Isto se deve ao fato de, mesmo no caso mais extremo, que é de $41 \mathrm{KBytes,} \mathrm{a} \mathrm{implementação} \mathrm{fisica} \mathrm{da} \mathrm{memória} \mathrm{ser} \mathrm{um} \mathrm{problema}$ complexo.

\subsection{Equilíbrio de fluxo}

O equilibrio do sistema é obtido à medida que o valor de $\mathrm{Ar}$ se aproxima de $\mathrm{C}$, fazendo $X \cong 100 \%$. A figura 5.7 mostra a variação da vazão do sistema em função do número de ciclos executados, quando a $\mathrm{Ar}$ de $1,0 \mathrm{~Gb} / \mathrm{s}$ e $2,0 \mathrm{~Gb} / \mathrm{s}$, permitindo uma análise do equilíbrio do sistema.

Quando a Ar é de $1,0 \mathrm{~Gb} / \mathrm{s}$, se observa que com 1.000 ciclos de execução, a vazão é de $97,11 \%$ e que, com 10.000 ciclos, ela atinge um valor de $99,7 \%$. Quando a Ar é de $2,0 \mathrm{~Gb} / \mathrm{s}$, se observa que, com 1.000 ciclos de execução, a vazão é de $93,2 \%$; com 100.000 ciclos ela atinge um valor de $98,8 \%$ e com 1.000 .000 de ciclos ela é de $99,48 \%$. Os valores da figura 5.7 mostram que o sistema atinge uma satisfatória condição de equilibrio, dentro do intervalo de tempo utilizado na simulação.

Quando a $\operatorname{Ar}$ é de $1,5 \mathrm{~Gb} / \mathrm{s}$ a vazão do sistema apresentou um valor de $99,89 \%$ com 20.000 ciclos de execução e, com uma $\mathrm{Ar}$ de $1,8 \mathrm{~Gb} / \mathrm{s}$, a vazão do sistema apresentou um valor de $99,80 \%$ com 75.000 ciclos de execução. Isto confirma que o sistema atinge uma condição satisfatória de equilíbrio dentro do 
intervalo de tempo utilizado na simulação.

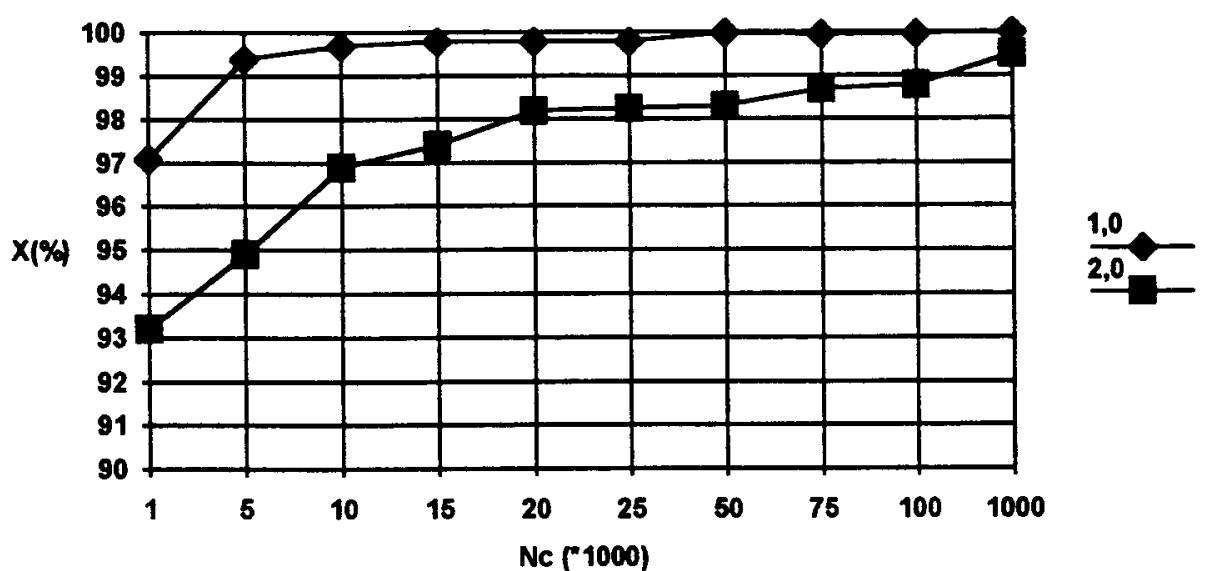

Figura 5.7 - Análise de equilibrio dos sistema, através dos valores da vazão do sistema em relação ao número de ciclos de simulação executados. Foram usados dois valores de $\mathrm{Ar}$, que são $1,0 \mathrm{~Gb} / \mathrm{s}$ e 2,0 Gb/s.

\section{Chave 4x8, com sintonização variável}

A chave apresentada com um único transmissor mostrou um comportamento insatisfatório em relação ao balanceamento de transmissão, limitando o processamento a apenas dois processadores, o que compromete seriamente o grau de paralelismo do sistema. A fim de solucionar esse problema, foi feito o projeto de uma segunda chave óptica de distribuição, usando quatro transmissores sintonizáveis, conforme mostra a figura 5.8, o que permite o envio de fichas para oito Unidades-Processadoras. 


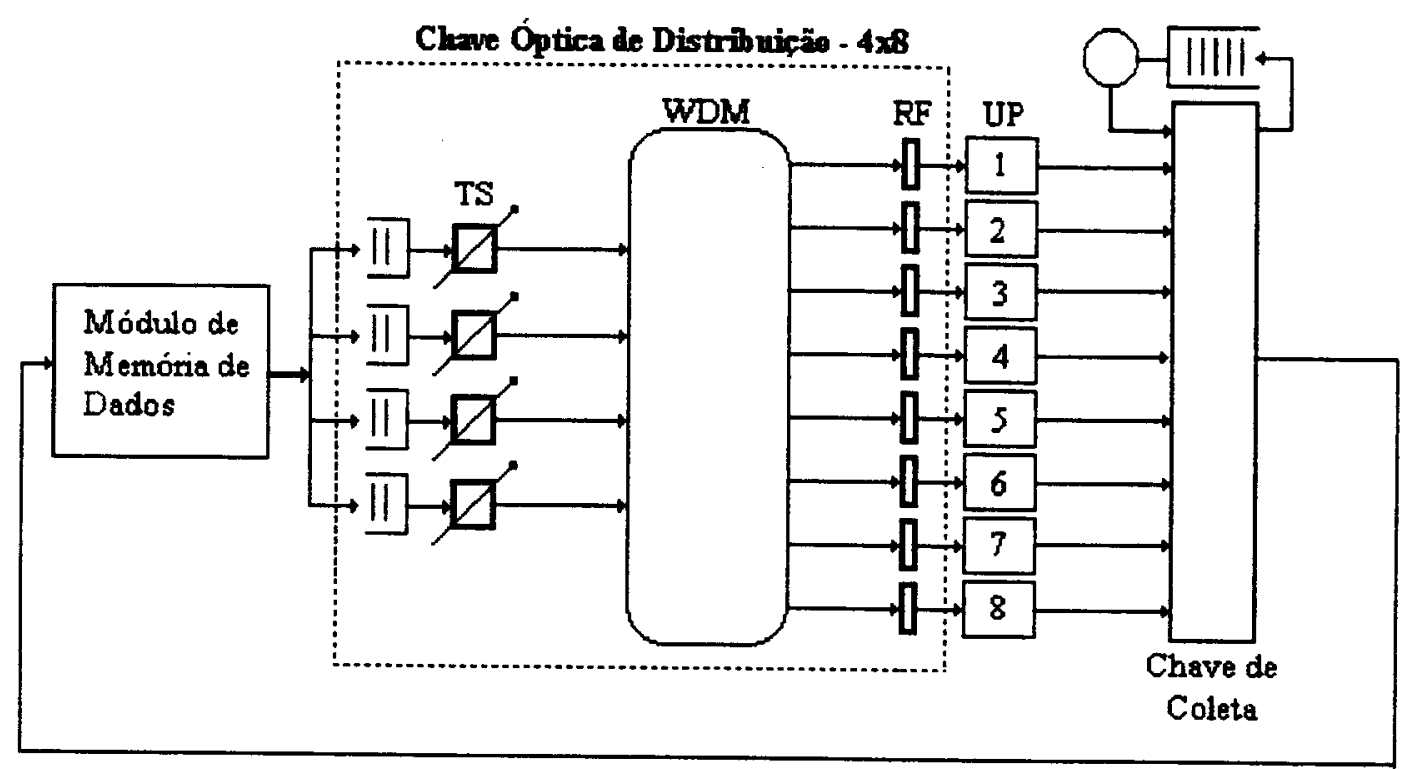

Figura 5.8 - Chave ótica de distribuição $4 x 8$, utilizando quatro transmissores sintonizáveis e oito receptores fixos

A simulação dessa chave exigiu que a rotina controle, do simulador, fosse alterada. Essa alteração foi relativamente simples, pois as características do sistema limitam um transmissor a só conseguir enviar dados para dois receptores e isto acaba facilitando o gerenciamento do sistema. Nesse caso, os controles flagch e flagcons são atualizados no início de cada ciclo de simulação, assim, o módulo produtor de pacotes envia pacotes para todos os buffers de transmissão vazios.

Como esse sistema Dataflow é livre de contexto, ou seja, um pacote pode ser enviado para qualquer processador, é feita uma associação fixa entre cada transmissor e dois processadores. Nesse caso, por exemplo, os receptores $i$ e $j$ só recebem pacotes oriundos do transmissor $k$, o que facilita o gerenciamento e impede a ocorrência de colisões.

O dimensionamento $4 \times 8$ foi adotado pelo fato de existirem trabalhos mostrando a eficiência do uso de oito Unidades-Processadoras em arquiteturas a fluxo de dados, como o sistema Monsoon [Hicks et al 1993] ou o sistema SEED (Sistema 
de Escalonamento e Execução Dataflow) [Magna 1997].

Cada transmissor de $2,0 \mathrm{~Gb} / \mathrm{s}$ gasta $200 \mathrm{~ns}$ para transmitir uma ficha de dados com 400 bits, no entanto, a sintonização faz com que o transmissor fique de posse da ficha por mais de $200 \mathrm{ns,} \mathrm{ou} \mathrm{seja,} \mathrm{o} \mathrm{número} \mathrm{de} \mathrm{informações} \mathrm{que} \mathrm{cada} \mathrm{transmissor}$ consegue transmitir por segundo diminui em função do tempo de sintonização. Suponha-se que o tempo de sintonização fosse de $10 \mathrm{ns,} \mathrm{o} \mathrm{transmissor} \mathrm{precisaria} \mathrm{de}$ 210 ns para efetivamente transmitir uma ficha de dados com 400 bits. Isto significa que ele só poderia transmitir $1,9 \mathrm{~Gb} / \mathrm{s}$. O tempo de sintonização adicionado ao tempo de transmissão indica quanto tempo cada ficha permaneceu no transmissor e é chamando de tempo de serviço.

Para análise de desempenho da rede, foi adotada uma Ar fixa e verificado o seu comportamento em função de diferentes valores do tempo de sintonização. A taxa de geração de fichas foi fixada em $5,3 \mathrm{~Gb} / \mathrm{s}$. Esse valor é originário da análise do número de fichas que passavam pela chave de distribuição durante o tempo de execução de alguns programas no simulador SAW. Esse simulador foi desenvolvido no IFSC-USP e simula a arquitetura WOLF a fluxo de dados (Dataflow), utilizando um modelo teórico de chave de distribuição de alta velocidade [Cavenaghi 1997].

Os programas analisados no simulador foram o DMRAN, o SIMPLE e o GAUSS. O programa DMRAN realiza cálculos matemáticos em sistemas de dinâmica molecular com alto grau de paralelismo. O programa SIMPLE realiza cálculos na área de hidrodinâmica e o programa GAUSS é utilizado na resolução de sistemas lineares.

A Ar para esses programas girou em torno de $5,0 \mathrm{~Gb} / \mathrm{s}$ e o maior valor encontrado foi de $5,3 \mathrm{~Gb} / \mathrm{s}$, o que determinou a utilização desse valor na simulação da chave óptica de distribuição apresentada nesta seção. Esse é um valor médio, uma vez que o modelo real do trafego, na chave de distribuição do sistema SAW, pode 
apresentar rajadas e, em determinados momentos, apresentar valores isolados acima dessa média.

Com a Ar fixada em $5,3 \mathrm{~Gb} / \mathrm{s}$ e seguindo um padrão probabilistico com rajadas, a chave óptica de distribuição foi simulada com o tempo de sintonização dos transmissores, variando entre 1 ns e 100 ns. Embora não se possa afirmar que o padrão de rajadas existente na chave do SAW e na chave simulada, neste trabalho, sejam iguais, a taxa média de geração de pacotes apresenta o mesmo valor em ambos os sistemas.

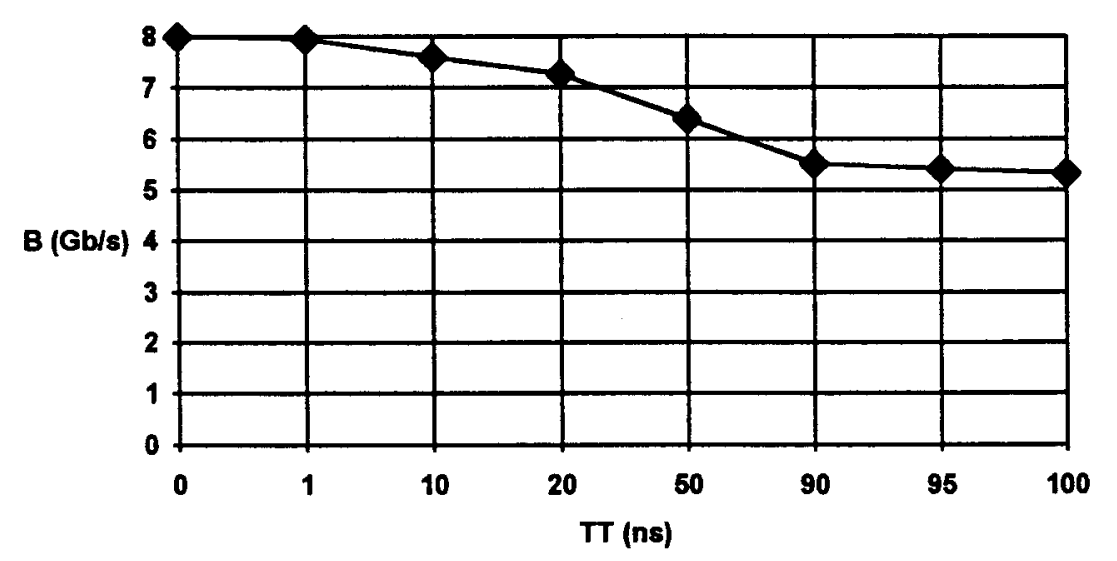

Figura 5.9 - Variação da banda passante (B) de um sistema com quatro transmissores de 2,0 Gb/s cada e fichas de dados com 400 bits, em função do tempo de sintonização (TT).

A figura 5.9 mostra a variação da banda passante (B) do sistema com quatro transmissores de 2,0 Gb/s cada, em função do tempo de sintonização (TT). Observase que o tempo máximo aceitável de sintonização é de $100 \mathrm{ns,} \mathrm{pois,} \mathrm{com} \mathrm{esse} \mathrm{valor,} \mathrm{a}$ banda passante do sistema cai para $5,33 \mathrm{~Gb} / \mathrm{s}$, que é um valor ligeiramente superior ao valor da Ar utilizada. 


\subsection{Vazão do sistema}

A vazão do sistema, em função das variações do tempo de sintonização pode ser analisada na tabela 5.3. A taxa de geração de pacotes foi de $5,3 \mathrm{~Gb} / \mathrm{s}$ em todas as simulações, assim, o número médio de fichas geradas em 1.000 .000 de ciclos de cada simulação foi de 132.512 fichas e o coeficiente de variação desse valor médio foi de $0,05 \%$.

Quando o tempo de sintonização cresce de 1 ns para 100 ns, a vazão do sistema apresenta um decréscimo de $99,99 \%$ para $99,95 \%$, o que é um decréscimo muito pequeno e mostra a tolerância do sistema em relação a esse parâmetro. Esse fato é muito significativo, pois, mostra que a vazão do sistema não sofreu profundas alterações, quando o tempo de sintonia aumentou em cem vezes.

Um dos problemas relativos às chaves ópticas com transmissores sintonizáveis é o tempo necessário para sintonizar um canal especifico. Esse tempo pode ser relativamente longo em comparação com o tempo de transmissão dos pacotes e interferir de forma extremamente negativa no desempenho do sistema. Outro fator crítico é que o número de canais sintonizáveis e a velocidade de sintonização são características concorrentes, ou seja, quanto mais rápida a sintonização, menor tende a ser a faixa de canais que o transmissor consegue transmitir. E quanto maior 0 número de canais, maior é o tempo de sintonização [Borella et al 1994].

Além do sistema poder operar eficientemente com transmissores que tenham uma sintonização lenta, na ordem de até $100 \mathrm{ns,} \mathrm{pode-se} \mathrm{observar} \mathrm{que} \mathrm{cada}$ transmissor transmite para apenas dois receptores. Assim, a chave óptica de distribuição $4 \times 8$ pode operar com dispositivos que tenham uma sintonização lenta e 
que tenham apenas dois canais de transmissão. Essas características são inerentes aos transmissores ópticos mais simples, permitindo a implementação de uma chave óptica com menor custo e menor exigência operacional.

Tabela 5.3 - Vazão do Sistema $(X)$ em função do tempo de sintonização (TT)

\begin{tabular}{|c|c|}
\hline TT (ns) & $\mathbf{X}$ (\%) \\
\hline 1 & 99,99 \\
\hline 10 & 99,99 \\
\hline 20 & 99,99 \\
\hline 50 & 99,99 \\
\hline 90 & 99,98 \\
\hline 95 & 99,98 \\
\hline 100 & 99,95 \\
\hline
\end{tabular}

\subsection{Análise de fila}

A figura 5.10 mostra o tamanho médio da fila de fichas (Lq) em função da variação do tempo de sintonização (TT). A partir de um tempo de sintonização de $90 \mathrm{~ns}$, o tamanho da fila começa a apresentar um crescimento acentuado, porém, mesmo para o maior tempo de sintonia utilizado, que é de $100 \mathrm{ns,} \mathrm{a} \mathrm{fila} \mathrm{apresentou}$ um tamanho médio de 56,6 pacotes, o que equivale a uma memória de armazenamento com 2830 bytes. 


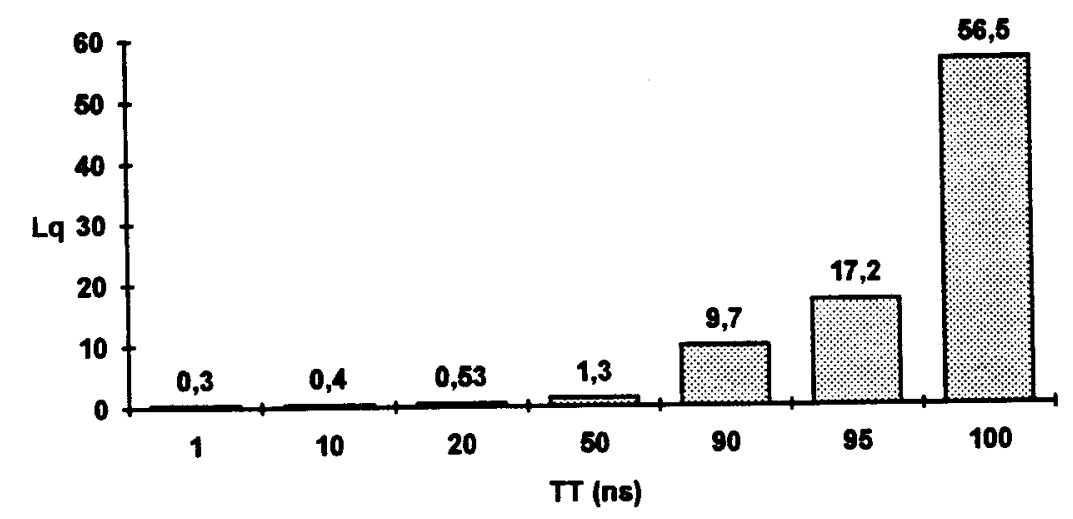

Figura 5.10 - Tamanho médio da fila de fichas $(L q)$ em função da variação do tempo de sintonização dos transmissores (TT).

Para uma análise mais crítica, foi medido o maior valor absoluto do tamanho da fila de fichas (La) entre todas as simulações. Esses valores são mostrados na figura 5.11 .

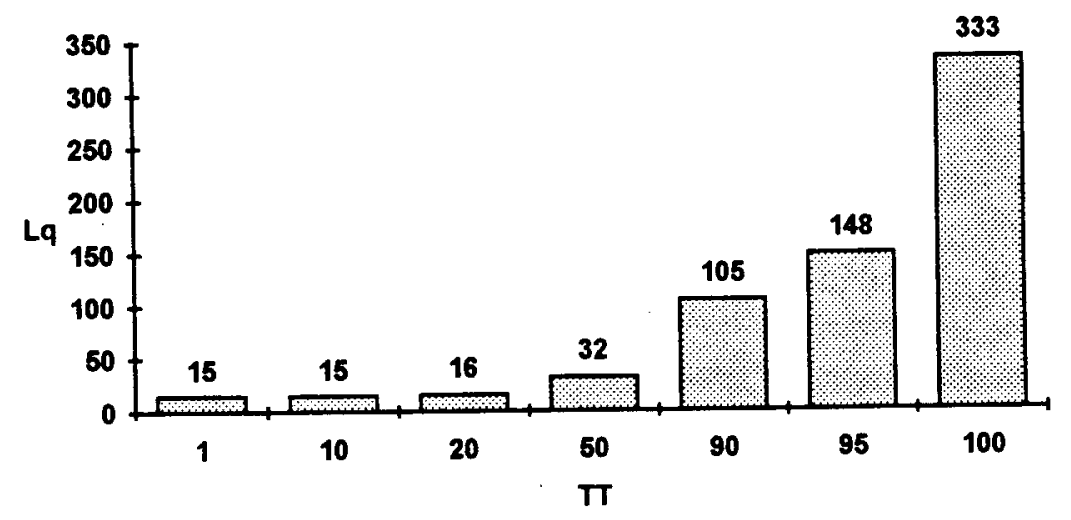

Figura 5.11 - Maior número absoluto de fichas de filas (La) em função da variação do tempo de sintonização do transmissor óptico (TT).

O valor médio de 56,6 pacotes apresentou um coeficiente de variação de $23 \%$. Assim, uma memória com 16.650 bytes, que é o valor equivalente aos 333 pacotes de La, poderia melhorar o desempenho do sistema e ser implementado sem maiores problemas de tecnologia e custo. Para os valores de Lq, relativos aos demais valores 
de TT, houve um coeficiente de variação menor. Para um TT de 95 ns, o coeficiente de variação cai para $11,5 \%$, enquanto que, para $1 \mathrm{ns,} \mathrm{o} \mathrm{coeficiente} \mathrm{de} \mathrm{variação} \mathrm{é}$ de $1,5 \%$. Isto mostra que o sistema apresenta um comportamento mais estável à medida que o valor de TT diminui, porém, mesmo para o pior caso analisado, não haverá problema prático de implementação de memória.

No pior caso, que é um tempo de sintonização de $100 \mathrm{ns,} \mathrm{a} \mathrm{fila} \mathrm{apresentou} \mathrm{um}$ valor máximo absoluto de 333 fichas, o que equivale a uma memória de 16.650 bytes. Esse tamanho pode ser considerado relativamente pequeno, o que permite uma fácil implementação, baixo custo e maior versatilidade no gerenciamento e recuperação das informações armazenadas.

\subsection{Balanceamento de transmissão}

Para analisar como a chave $4 \times 8$ distribui as fichas entre as UnidadesProcessadoras e como o tempo de sintonização afeta essa distribuição, foi feito um levantamento que é mostrado nas figuras $5.12,5.13,5.14,5.15,5.16,5.17,5.18$ Esses valores representam o número de fichas processadas por cada UnidadeProcessadora, quando o tempo de sintonia é $1 \mathrm{~ns}, 10 \mathrm{~ns}, 20 \mathrm{~ns}, 50 \mathrm{~ns}, 90 \mathrm{~ns}, 95 \mathrm{~ns}$ e 100 ns. O valor máximo de 100 ns foi adotado para que a banda passante do sistema não fosse inferior a $5,3 \mathrm{~Gb} / \mathrm{s}$.

$\mathrm{Na}$ análise das figuras, pode-se observar que todos os processadores receberam fichas durante o processo de simulação. Outra característica analisada é que a distribuição não é homogênea entre todos os processadores, havendo alguns com maior número de fichas recebidas, porem, o alto grau de vazão do sistema 
demonstra que isto não afeta o grau de paralelismo usado nesse sistema.

Outro fator a ser analisado é que o tempo de sintonização, variando de 1 ns a 100 ns, não muda sensivelmente a tendência de distribuição de fichas entre as Unidades-Processadoras. Os primeiros nós sempre recebem mais fichas que os demais, porém, à medida que o tempo de sintonização aumenta, ocorre uma diminuição do número de fichas recebidas pelos primeiros nós e ocorre um incremento do número de fichas recebidas pelos nós intermediários. Com isto pode-se concluir que o tempo de sintonização de até 100 ns não afeta negativamente a distribuição de carga de processamento entre as oito Unidades-Processadoras. Esse fato confirma a viabilidade de se utilizar transmissores com baixa velocidade de sintonização na implementação dessa chave óptica.

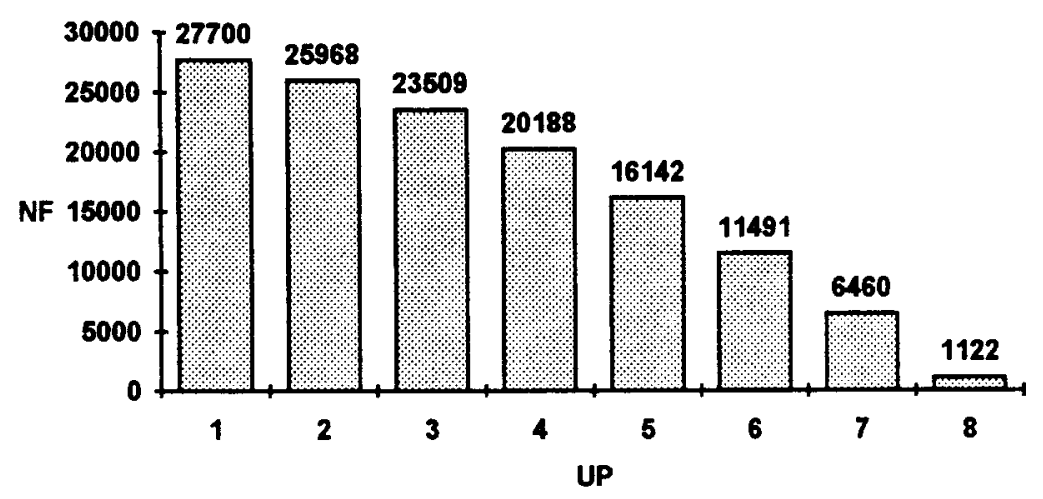

Figura 5.12 - Número de fichas processadas (NF) por Unidade-Processadora (UP), com um tempo de sintonização de $1 \mathrm{~ns}$. 


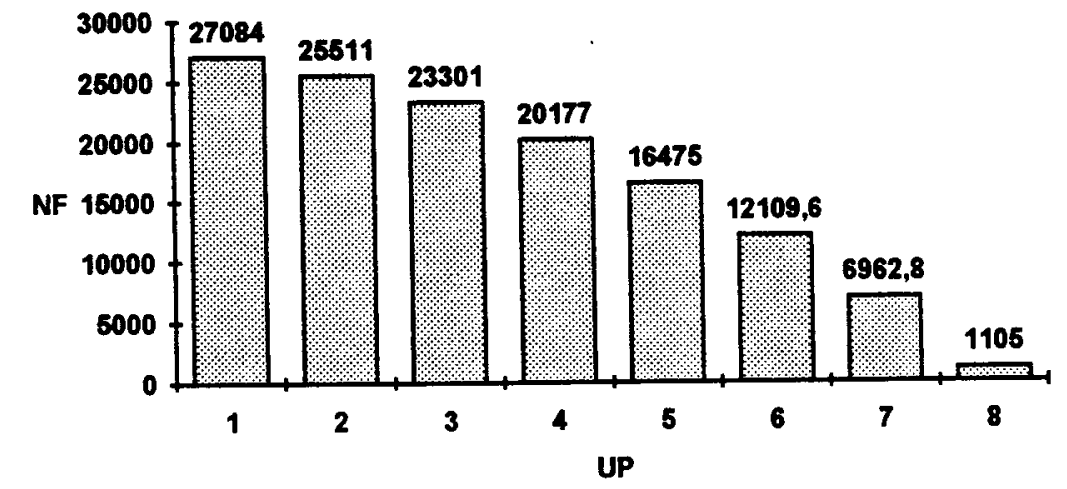

Figura 5.13 -. Número de fichas processadas (NF) por Unidade-Processadora (UP), com um tempo de sintonização de $10 \mathrm{~ns}$

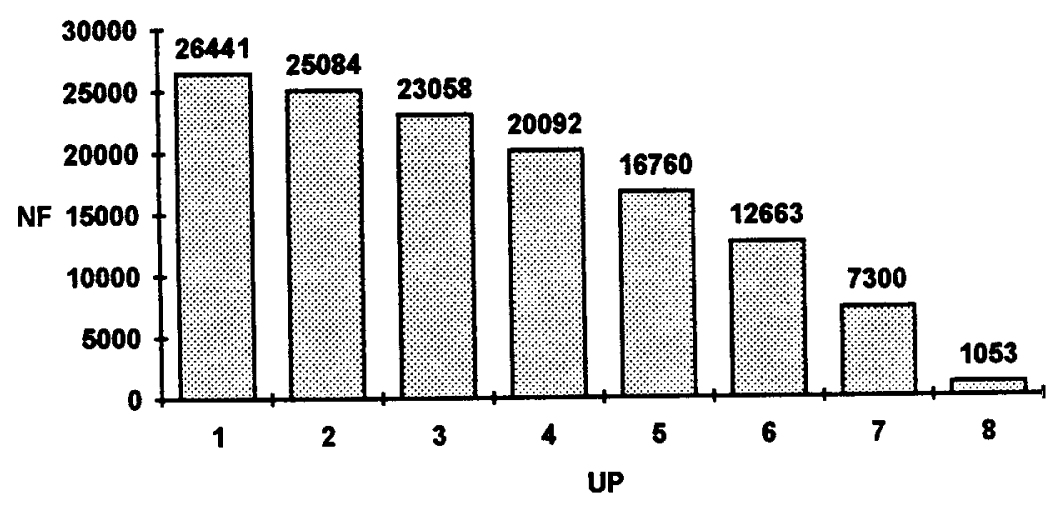

Figura 5.14 - Número de fichas processadas (NF) por Unidade-Processadora (UP), com um tempo de sintonização de $20 \mathrm{~ns}$

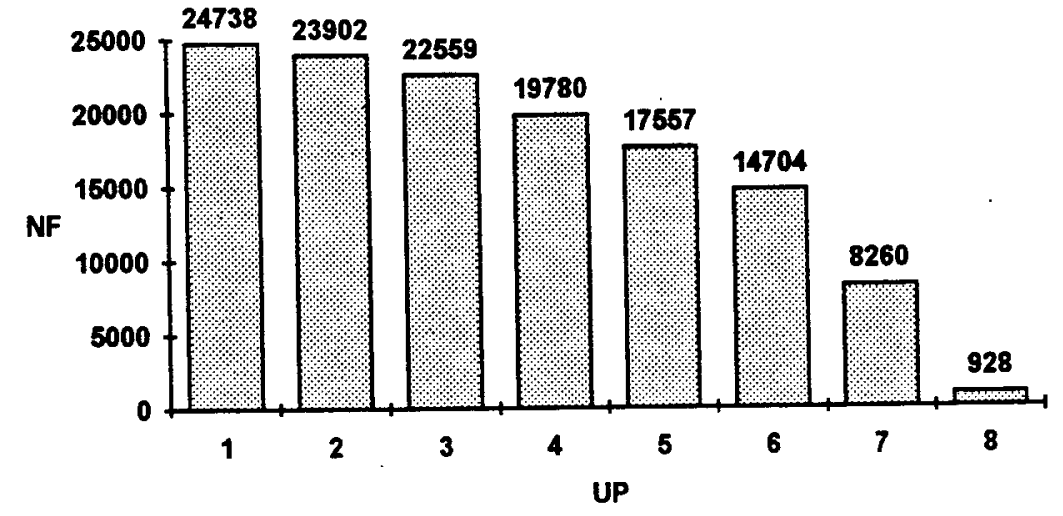

Figura 5.15 - Número de fichas processadas (NF) por Unidade-Processadora (UP), com um tempo de sintonização de $50 \mathrm{~ns}$. 


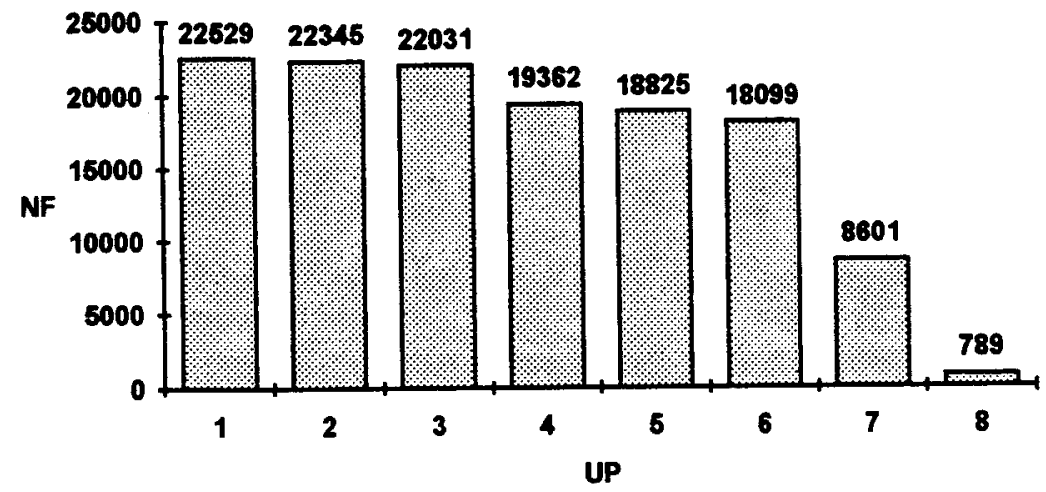

Figura 5.16 - Número de fichas processadas (NF) por Unidade-Processadora (UP), com um tempo de sintonização de $90 \mathrm{~ns}$.

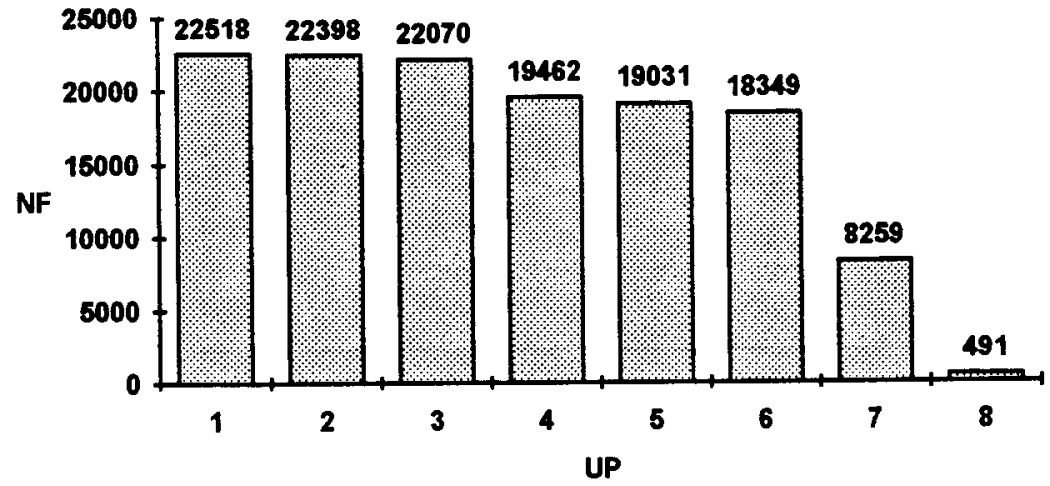

Figura 5.17 - Número de fichas processadas (NF) por Unidade-Processadora (UP), com um tempo de sintonização de $95 \mathrm{~ns}$.

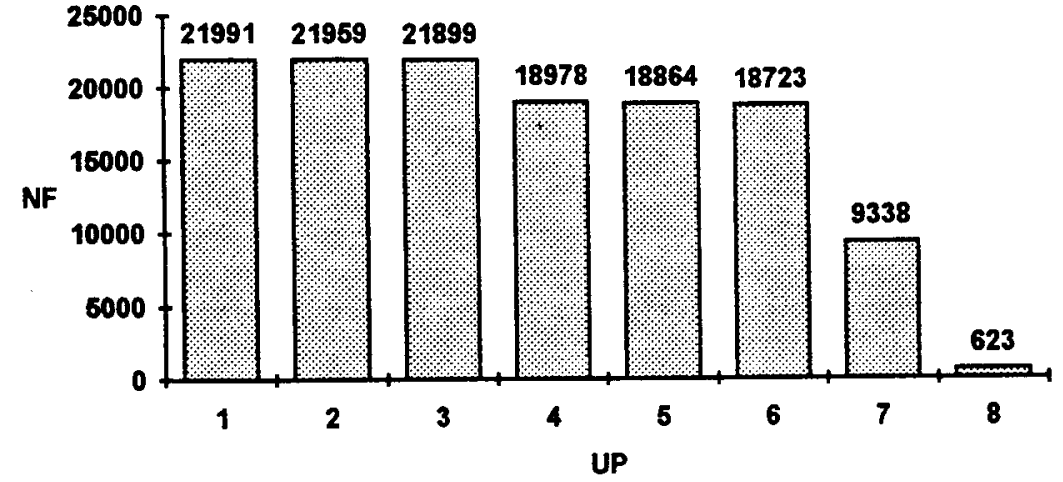

Figura 5.18 - Número de fichas processadas (NF) por Unidade-Processadora (UP), com um tempo de sintonização de $100 \mathrm{~ns}$. 


\subsection{Equilíbrio de fluxo}

A tabela 5.19 mostra o equilíbrio de fluxo do sistema, quando o mesmo opera com um valor de TT de 1 ns e com um valor de TT de 100 ns. Na figura, pode-se observar que, com apenas 1.000 ciclos de simulação, o sistema já apresentava um equilíbrio de fluxo superior a $90,0 \%$ e que, com 20.000 ciclos, esses valores já estavam na faixa de $99,0 \%$. Isto mostra que o sistema atinge uma condição de equilíbrio dentro do número de ciclos utilizados na simulação, que foi de 1.000 .000 .

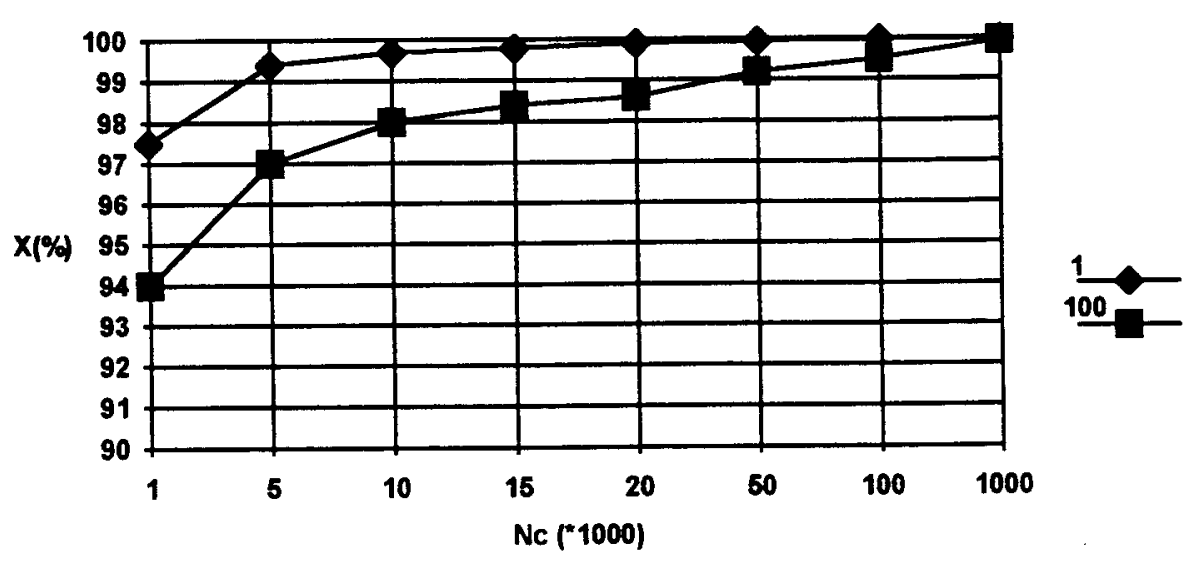

Figura 5.19 - Fluxo de equilibrio. Os valores da vazão $(X)$ representam a tendência de estabilização do sistema, quando o tempo de sintonização do transmissor é de I ns e de $100 \mathrm{~ns}$.

\section{Chave óptica de distribuição 8x8, com sintonização fixa}

Em situações, como em um sistema Dataflow livre de contexto, o chaveamento pode ser dispensável. Assim, apesar da chave óptica de distribuição $4 \times 8$, com sintonização variável, ter apresentado um desempenho satisfatório, foi projetada 
uma terceira chave óptica de distribuição, operando apenas com transmissores de sintonização fixa.

A figura 5.20 mostra esse sistema, que é classificado como single-hop $\mathrm{FT}^{8}-\mathrm{FR}^{8}$ e idealizado para operar com oito transmissores de $2,0 \mathrm{~Gb} / \mathrm{s}$ cada um. Isto evita o tempo exigido para a sintonização entre diferentes canais e permite a implementação fisica de uma chave óptica com uma tecnologia mais simples.

Nesse caso, a rotina controle, do simulador, foi adaptada para efetuar um controle que é muito simples. No início de cada ciclo de simulação, os controles flagch e flagcons são atualizados e o módulo produtor envia fichas de dados para todos os buffers vazios. O transmissor, quando recebe uma ficha, espera o seu receptor ficar livre e então faz a transmissão, sem nenhuma sintonização e sem nenhuma possibilidade de colisão.

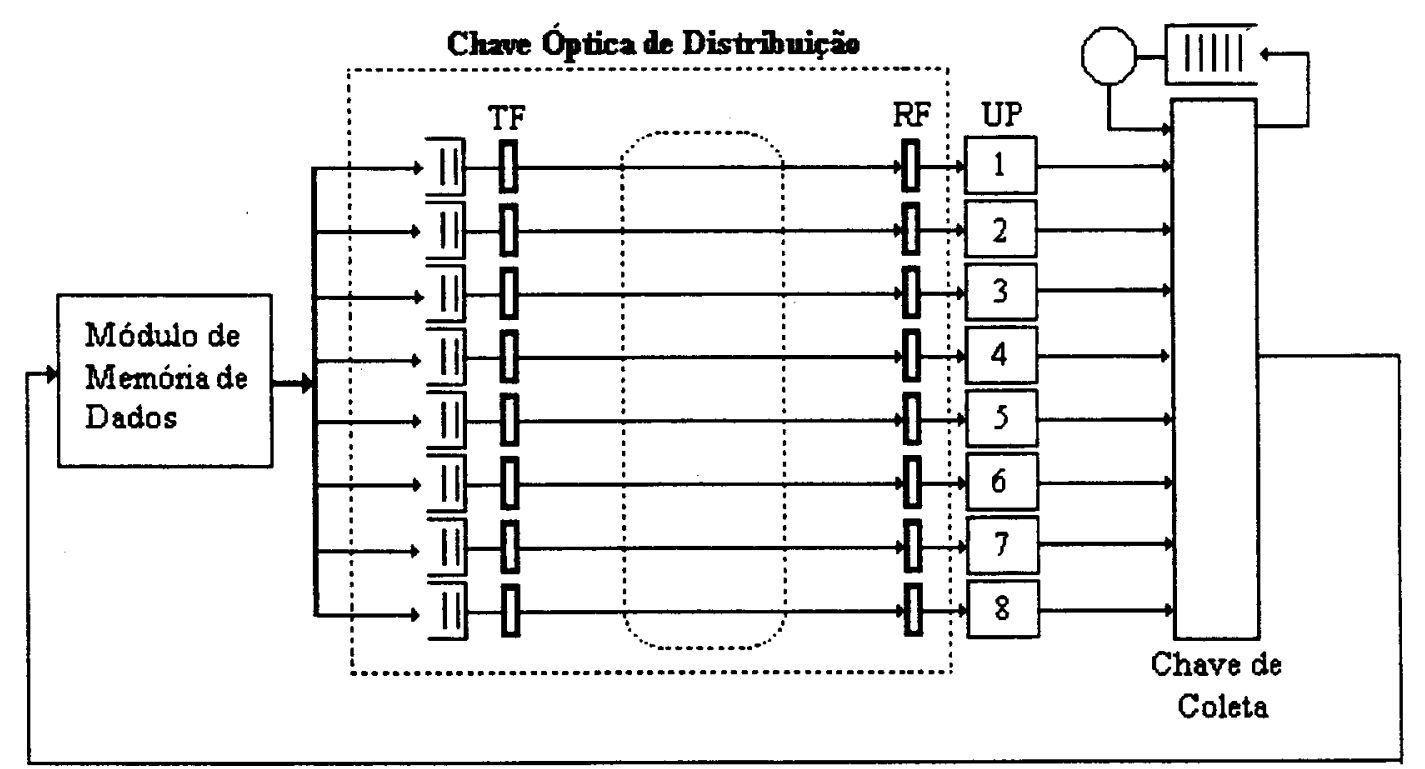

Figura 5.20 - Chave óptica de Distribuição com um sistema $8 x 8$, usando transmissores e receptores fixos. 
Como cada um dos transmissores usa uma taxa de transmissão de $2,0 \mathrm{~Gb} / \mathrm{s}$, o sistema teria uma banda passante teórica de $8,0 \mathrm{~Gb} / \mathrm{s}$, porém, o receptor precisa de um período de tempo para processar uma ficha recebida. Somente após esse processamento é que o receptor pode receber uma segunda ficha.

No sistema simulado, foi fixado um tempo de processamento de 100 ns por ficha. Isto significa que uma determinada Unidade-Processadora poderia receber, no máximo, uma ficha a cada 300 ns, o que limita a banda passante de cada sistema individual de comunicação a uma taxa de $1,33 \mathrm{~Gb} / \mathrm{s}$ e permite que o sistema com oito transmissores tenha uma banda passante de comunicação de $10,66 \mathrm{~Gb} / \mathrm{s}$.

Em relação à chave com quatro transmissores sintonizáveis, o sistema com oito transmissores fixos tem a vantagem de poder ser implementada com dispositivos mais simples, porém, o aumento do número de transmissores não aumenta proporcionalmente a banda passante do sistema. Em um sistema com quatro transmissores sintonizáveis de $2,0 \mathrm{~Gb} / \mathrm{s}$ e tempo de sintonização de $100 \mathrm{~ns}$, o sistema teria uma banda passante de $8 \mathrm{~Gb} / \mathrm{s}$, enquanto que, em um sistema com oito transmissores fixos, a banda passante do sistema seria de $10,66 \mathrm{~Gb} / \mathrm{s}$

Em um sistema com transmissores fixos, à medida que a velocidade de processamento de uma ficha aumenta, a banda passante também aumenta, assim, em um modelo teórico, onde o tempo de processamento fosse zero, a banda passante de comunicação, em um sistema com oito transmissores fixos de $2,0 \mathrm{~Gb} / \mathrm{s}$ cada, seria de $16 \mathrm{~Gb} / \mathrm{s}$. A figura 5.21 mostra a banda passante de comunicação (B) de um sistema com oito transmissores, em função da variação do tempo de processamento (Tp). 


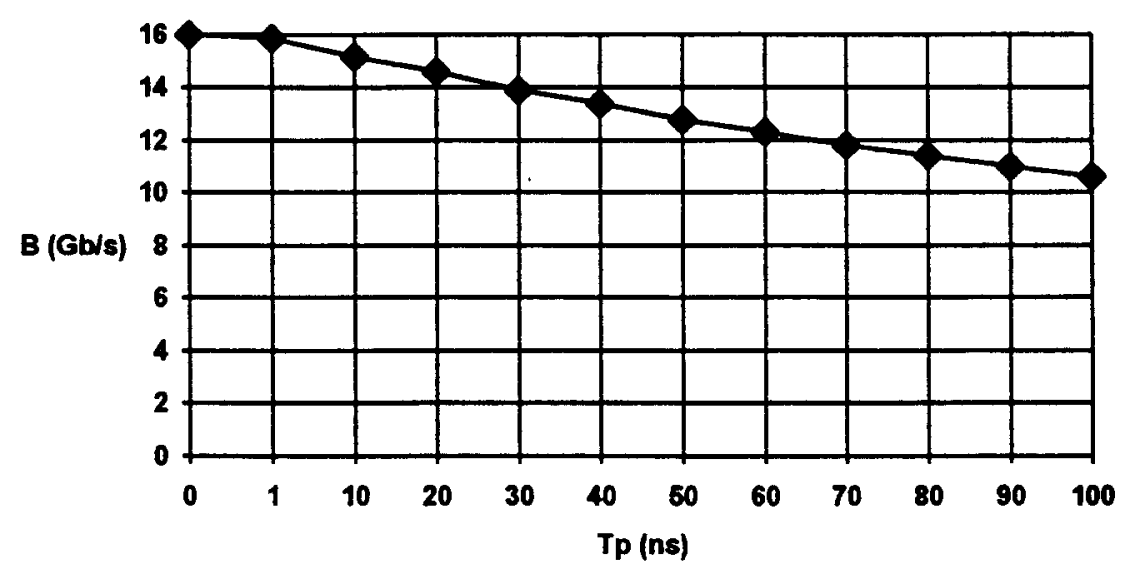

Figura 5.21 - Variação da banda passante de comunicação (B) em função do tempo de processamento (Tp) de uma ficha de dados. O sistema é projetado com oito transmissores fixos e com taxa de transmissão de 2,0 Gb/s cada um.

A banda passante de comunicação do sistema fica limitada em $10,66 \mathrm{~Gb} / \mathrm{s}$, pois, o tempo de processamento de uma ficha é 100 ns. Assim, o processo de simulação foi executado com uma taxa de geração de dados (Ar) variando entre $5,3 \mathrm{~Gb} / \mathrm{s}$ e $10,66 \mathrm{~Gb} / \mathrm{s}$. Esses valores foram adotados pelo fato de serem, respectivamente, um valor típico analisado no ambiente WOLF e o valor da banda passante máxima dessa chave de distribuição.

\subsection{Vazão do sistema}

A tabela 5.4 mostra a vazão do sistema, que apresentou valores sempre superiores a $99,90 \%$. Esses valores são considerados altos e mostram que o sistema tem uma boa vazão, mesmo quando o valor de $\operatorname{Ar}$ se aproxima do valor da banda passante do sistema. Isto significa que a maioria absoluta dos pacotes enviados à rede são transmitidos.

Quando a Ar é menor que a banda passante do sistema, a vazão é superior a 
$99,99 \%$. Esse valor pode ser considerado $100 \%$, pois, o sistema de simulação executa exatamente 1.000 .000 de ciclos de simulação e, nesse momento, pode haver pacotes que foram gerados e que ainda não foram transmitidos ou ainda estão em transmissão. Esse pacotes entram no cômputo do número médio de pacotes gerados pelo sistema, mas, como não foram efetivamente transmitidos, não entram no cômputo do número médio de pacotes transmitidos.

Tabela 5.4 - Vazão do Sistema $(X)$ em função da variação da toxa de geração de pacotes (Ar)

\begin{tabular}{|c|c|}
\hline $\mathbf{A r}(\mathbf{G b} / \mathbf{s})$ & $\mathbf{X}(\%)$ \\
\hline 5,3 & 99,99 \\
\hline 8,0 & 99,99 \\
\hline 10,5 & 99,99 \\
\hline 10,66 & 99,91 \\
\hline
\end{tabular}

\subsection{Análise de fila}

A figura 5.22 mostra o tamanho médio da fila de fichas em função da variação da Ar. A fila apresenta um crescimento desproporcional quando a Ar varia de 10,0 $\mathrm{Gb} / \mathrm{s}$ para $10,66 \mathrm{~Gb} / \mathrm{s}$, porém, mesmo na condição mais crítica, seria necessária uma memória de 10.400 bytes para armazenar as 208 fichas de 50 bytes cada.

Para uma Ar de 10,0 Gb/s, o tamanho médio de fila (Lq) teve um coeficiente de variação de $6,4 \%$, e, para uma $\mathrm{Ar}$ de $10,66 \mathrm{~Gb} / \mathrm{s}$, o coeficiente de variação foi de $42,8 \%$. Isto mostra que o comportamento do sistema tende a se tornar mais instável, 
à medida que a Ar se aproxima da sua banda passante.

Para análise do comportamento do sistema em função dos valores críticos de Ar, foi feita a medição do maior valor absoluto que a fila de fichas atingiu em 10 processos de simulação executados para cada valor de Ar. A figura 5.23 mostra os valores absolutos (La) do tamanho de fila.

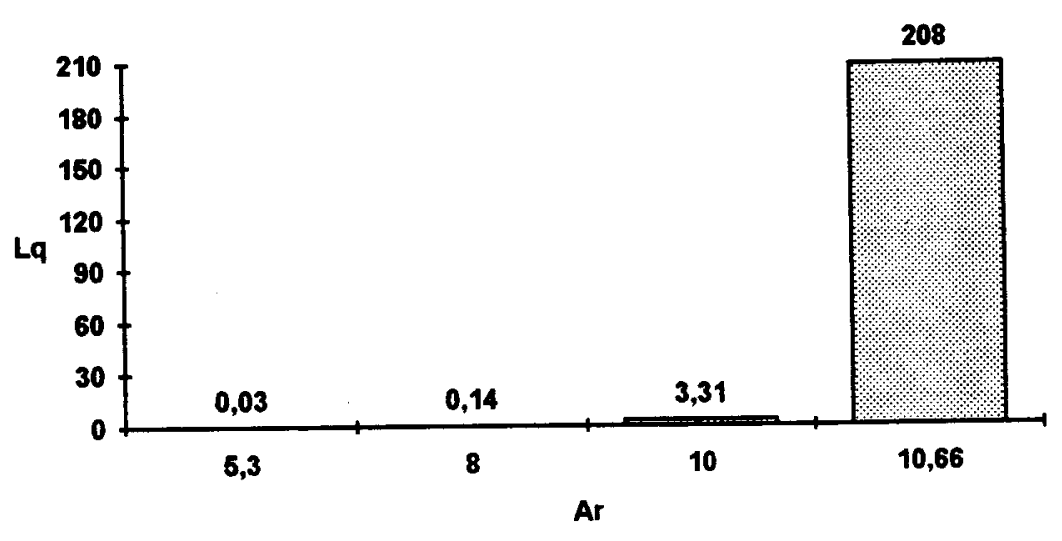

Figura 5.22 - Tamanho médio da fila de fichas (Lq) em função de Ar.

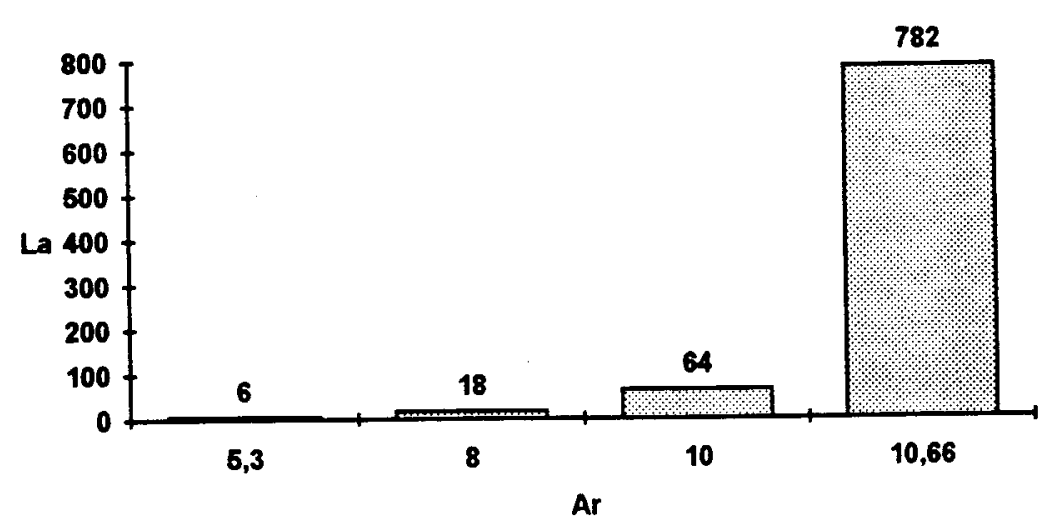

Figura 5.23 - Maior valor absoluto do tamanho de fila (La) em função de Ar

No parâmetro mais crítico, que é uma $\operatorname{Ar}$ de $10,66 \mathrm{~Gb} / \mathrm{s}$, o maior valor absoluto de fila foi de 782 fichas, o que exige uma memória de 39.100 bytes. Uma memória com essa dimensão poderia ser facilmente implementada e gerenciada, o que 
comprova a viabilidade operacional da chave óptica proposta, mesmo quando operando em condições críticas.

Tabela 5.5 - Tamanho médio de fila (Lq) e maior tamanho absoluto de fila (La). Esses valores são relativos às duas chaves demonstradas, quando a Ar é de 5,3 Gb/s.

\begin{tabular}{|c|c|c|}
\hline & Lq & La \\
\hline Chave 4x8 $\left(\mathbf{T T}^{4}-\right.$ FR $\left.^{8}\right)$ & 0,3 & 15 \\
\hline Chave 8x8 $\left(\mathbf{F T}^{8}-\right.$ FR $\left.^{8}\right)$ & 0,03 & 6 \\
\hline
\end{tabular}

Usando uma Ar de $5,3 \mathrm{~Gb} / \mathrm{s}$, pode-se comparar a chave $8 \times 8$ de sintonização fixa, com a chave $4 \times 8$ de sintonização variável. A tabela 5.5 mostra a comparação do tamanho médio de fila (Lq) e do maior tamanho absoluto de fila (La) para as duas chaves, com Ar de 5,3 Gb/s. No caso da chave sintonizável foram analisados os tamanhos de fila, quando o tempo de sintonização é de $1 \mathrm{~ns}$, que é o melhor caso. Pode-se analisar que a chave $8 \times 8$ apresenta tamanhos de filas relativamente menores que a chave óptica $4 \times 8$, porém, em ambos os casos, a implementação fisica de memórias com as dimensões apresentadas seria facilmente conseguida.

\subsection{Balanceamento da Transmissão}

O número de pacotes que cada Unidade-Processadora recebeu é mostrado nas figuras $5.24,5.25,5.26,5.27$ e 5.28 . Todas as Unidades-Processadoras recebem fichas, o que comprova a capacidade de paralelismo da chave.

Para os valores de Ar utilizados, sempre as primeiras Unidades-Processadoras 
recebem mais pacotes que as demais, porém, à medida que aumenta a $\mathrm{Ar}$, a distribuição de fichas, entre os processadores, tende a se tornar mais equilibrada e os últimos processadores passam a receber mais fichas de dados.

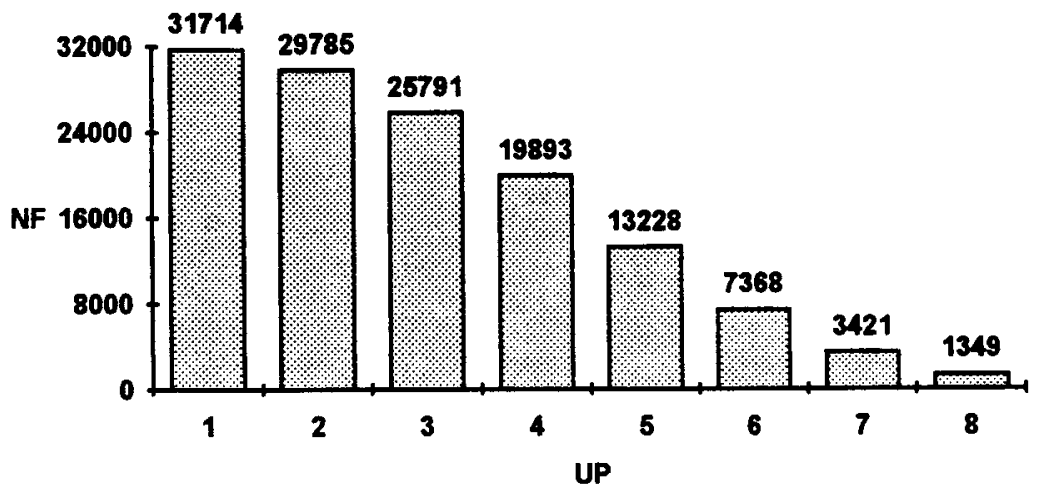

Figura 5.24 - Número de fichas recebidas (NF) por Unidade-Processadora (UP), com uma Ar de $5.3 \mathrm{~Gb} / \mathrm{s}$.

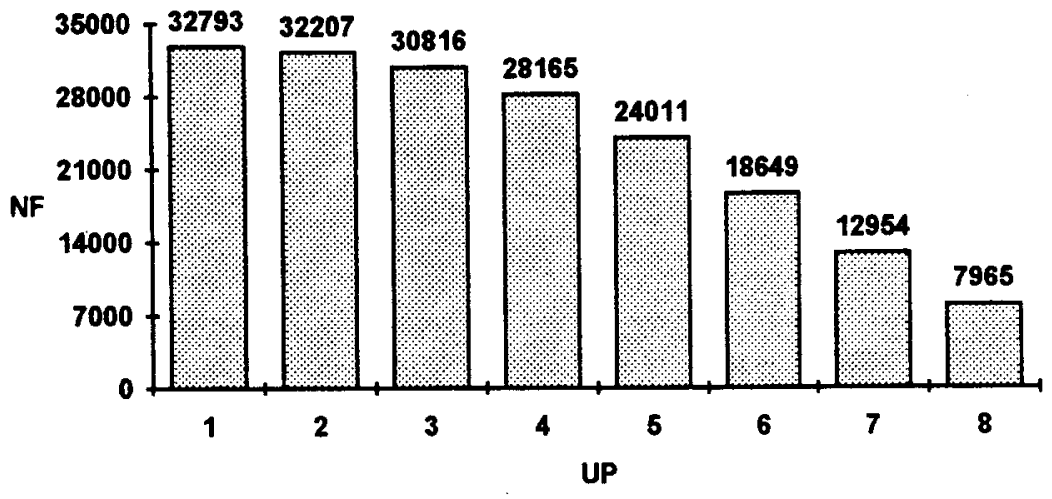

Figura 5.25 - Número de fichas recebidas (NF) por Unidade-Processadora (UP), com uma Ar de 7,5 Gb/s. 


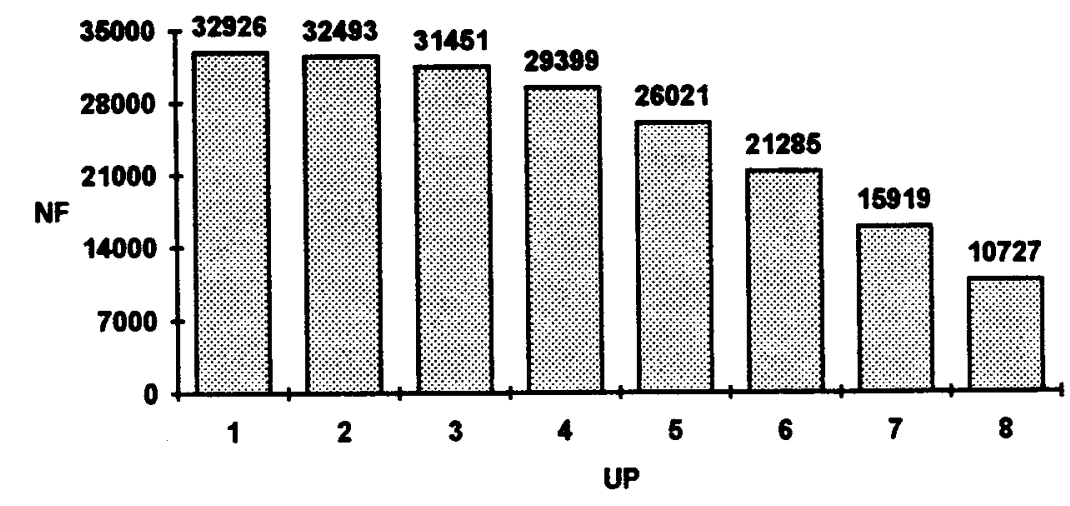

Figura 5.26 - Número de fichas recebidas (NF) por Unidade-Processadora (UP), com uma Ar de 8,0 Gb/s.

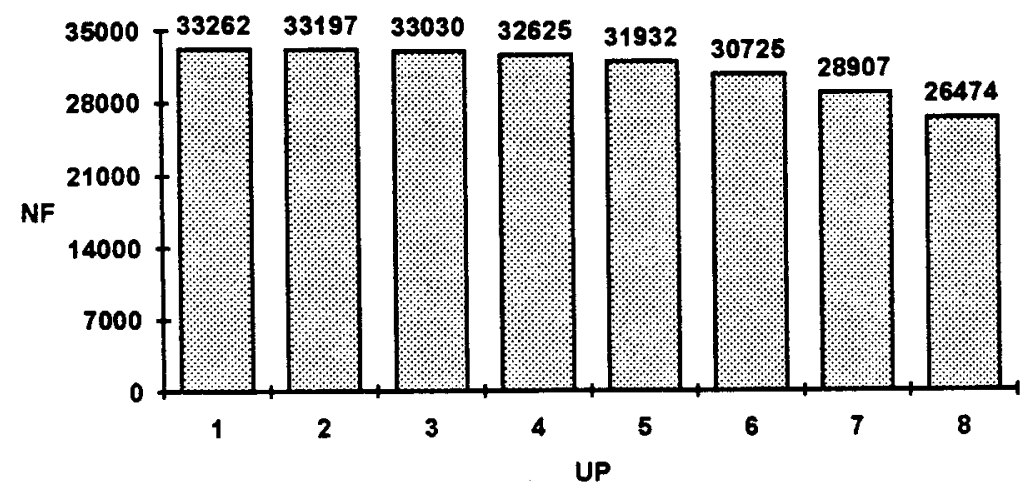

Figura 5.27 - Número de fichas recebidas (NF) por Unidade-Processadora (UP), com uma Ar de 10,0 Gb/s.

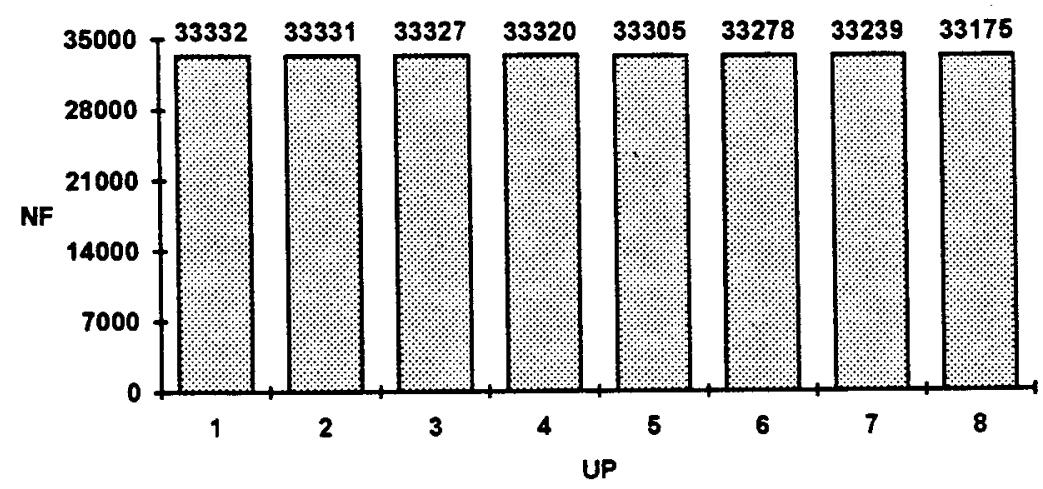

Figura 5.28 - Número de fichas recebidas (NF) por Unidade-Processadora (UP), com uma Ar de $10,66 \mathrm{~Gb} / \mathrm{s}$. 
Conforme mencionado acima, quando a $\mathrm{Ar}$ cresce, as últimas Unidades-Processadoras passam a receber mais fichas de dados. Quando a Ar é de $5,3 \mathrm{~Gb} / \mathrm{s}$, a Unidade-Processadora número 1 (primeira) recebeu 31.714 fichas, enquanto a Unidade-Processadora número oito (última) recebeu apenas 1.349 fichas de dados.

Para uma análise mais detalhada do balanceamento da transmissão, que influi diretamente no grau de paralelismo do sistema, foi feita uma análise comparativa entre a diferença (Dp) do número de fichas recebidas pela Unidade-Processadora número 1 e pela Unidade-Processadora número 8, com diferentes taxas de Ar. A figura número 5.29 mostra os valores dessas diferenças e pode-se verificar claramente que, à medida que a Ar cresce, a diferença diminui sensivelmente, mostrando uma distribuição mais homogênea de fichas entre as diversas Unidades-Processadoras.

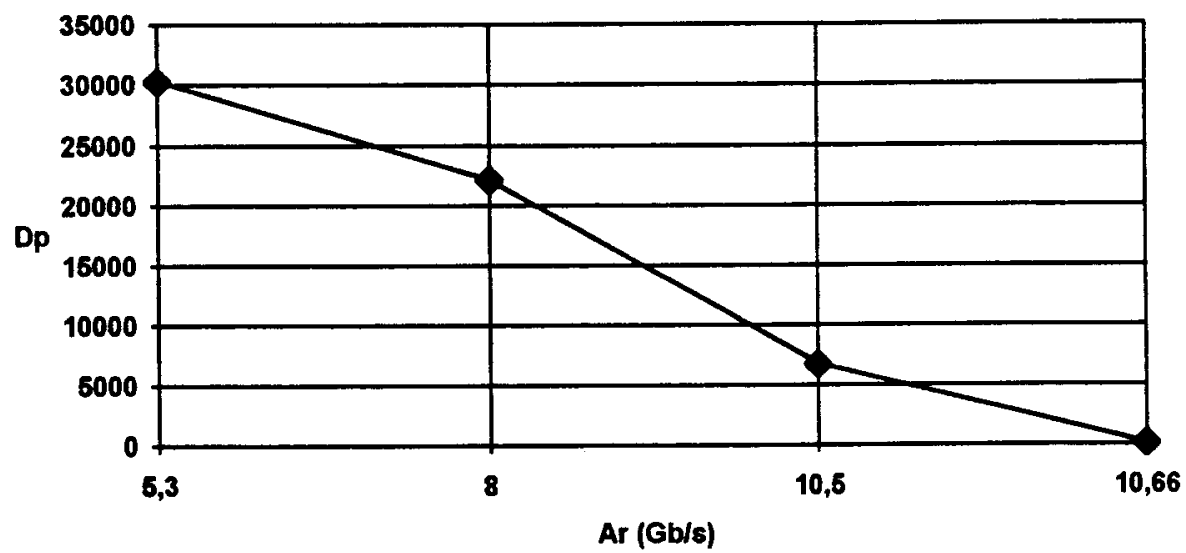

Figura 5.29 - Diferença entre o número de fichas (Dp) que a Unidade-Processadora número 1 e a Unidade-Processadora número 8 receberam. Esse valor foi medido em função de diferentes valores de AR. 


\subsection{Equilíbrio de fluxo}

O equilíbrio do sistema é atingido à medida que a vazão do sistema se aproxima de $100 \%$. Após 1.000 .000 de ciclos de simulação, o sistema se mostrou estável, com uma vazão superior a $99,90 \%$, mas, é preciso verificar em que ponto do tempo de simulação o sistema atingiu um valor estável e próximo de $100 \%$.

A figura 5.30 mostra o equilíbrio do sistema para uma Ar de $5,3 \mathrm{~Gb} / \mathrm{s}$, e para uma $\operatorname{Ar}$ de 10,6 Gb/s. Para uma Ar de 5,3 Gb/s, o sistema atinge uma vazão superior a $99,50 \%$ com 5.000 ciclos de comunicação, e para uma Ar de $10,6 \mathrm{~Gb} / \mathrm{s}$, o sistema atinge uma vazão superior a 99,50\%, após 10.000 ciclos de comunicação. Com mais de 1.000 .000 de ciclos, os dois sistemas atingem uma vazão de $99,99 \%$. Isto mostra que o sistema atinge uma condição satisfatória de equilibrio dentro do número de ciclos de simulação utilizados no processo de simulação.

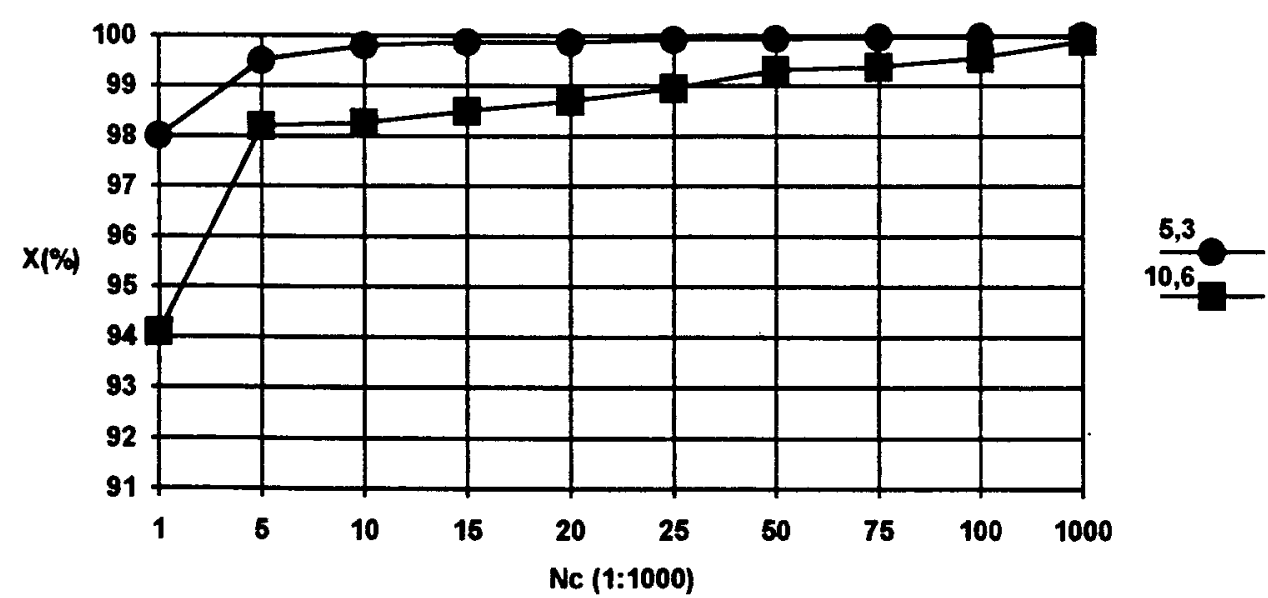

Figura 5.30 - Variação da vazão do sistema $(X)$ em função do mimero de ciclos de transmissão simulados (Nc). Foram usados dois valores de Ar, que são 5,3 Gb/s e $10,6 \mathrm{~Gb} / \mathrm{s}$ 


\section{Conclusões do Capítulo}

O uso de uma chave óptica de distribuição com um único transmissor de $2,0 \mathrm{~Gb} / \mathrm{s}$ mostrou-se ineficiente, pois, o mesmo não consegue fornecer fichas de dados para mais de duas Unidades-Processadoras, comprometendo fortemente o grau de paralelismo do sistema.

O uso de uma chave óptica com quatro transmissores sintonizáveis permite a transmissão de fichas para até oito Unidades-Processadoras, que é um número satisfatório para diversas arquiteturas do tipo Dataflow. O sistema foi simulado com uma $\mathrm{Ar}$ de 5,3 Gb/s e com um tempo de sintonização variando entre $1 \mathrm{~ns}$ e $100 \mathrm{~ns}$. Quanto menor o tempo de sintonização, melhor o desempenho do sistema, porém, em todos os casos, o sistema mostrou um desempenho altamente satisfatório, com uma alta taxa de vazão e tamanho de fila facilmente implementável. Isto mostra uma boa tolerância do sistema em relação ao tempo de sintonização. Nesse sistema, o tempo de processamento pode ser igual ao tempo de sintonização acrescido do tempo de transmissão, o que dispensa o uso de Unidades-Processadoras extremamente rápidas.

O uso de uma chave óptica de distribuição com oito transmissores fixos, sem tempo de sintonização, mostrou um desempenho altamente satisfatório, com uma alta taxa de vazão e tamanho de fila facilmente implementável. Nessa chave, cada transmissor só transmite para um único receptor, assim, enquanto o receptor processa uma ficha, o transmissor pode ficar ocioso aguardando a liberação do receptor. Dessa forma, o tempo de processamento acaba influindo diretamente na capacidade de comunicação do sistema. Esse problema poderia ser solucionado com o desenvolvimento de uma Unidade-Processadora que tivesse um sistema de recepção, 
que pudesse operar de forma paralela com o sistema de processamento

Apesar dessa chave estar fortemente dependente do tempo de processamento e exigir um maior número de transmissores, ela teve um desempenho melhor que os outros dois modelos apresentados. Isto pode ser analisado mesmo quando a chave $4 \times 8$ sintonizável opera com um tempo de sintonização de $1 \mathrm{~ns}$.

A chave $4 \times 8$ com transmissores sintonizáveis é dependente do tempo de sintonização, mas, opera satisfatoriamente com transmissores de apenas dois canais e tempo de sintonização variando entre $1 \mathrm{~ns}$ e $100 \mathrm{~ns}$. No sistema simulado, o ternpo de processamento não é um fator crítico, pois ele é menor que a soma do tempo de sintonização e do tempo de transmissão.

O desempenho da chave $8 \times 8$ fixa é mais dependente do tempo de processamento de uma ficha na UP, porém, dentro dos padrões testados, operou satisfatoriamente. $O$ uso de sistemas de transmissão e recepção fixa permite a implementação de dispositivos com uma tecnologia ainda mais simples

Esses dados demonstram que uma chave óptica de distribuição, em arquitetura Dataflow, pode ser implementada com dispositivos considerados relativamente simples e o seu desempenho é altamente satisfatório.

Outro fator a ser considerado com os dados deste capitulo é que o simulador de sistemas ópticos desenvolvido, e apresentado no capítulo 4 , foi facilmente adaptado para a simulação de três outros sistemas ópticos. A pouca necessidade de alterações e os dados obtidos viabilizam o uso desse programa como uma ferramenta de simulação de redes ópticas de comunicação. 


\section{Capítulo 6}

\section{Conclusões Finais}

Este capítulo apresenta uma sintese geral das conclusões parciais que são apresentadas nos capitulos 2,4 e 5 desta tese.

\subsection{Conclusões sobre o uso de redes ópticas}

Conforme foi mostrado no capítulo dois, as dificuldades de implementação de redes de interconexões com sistemas elétricos podem ser sensivelmente atenuadas com o uso de sistemas ópticos, que já atingiram um satisfatório grau de maturidade tecnológica e já possuem todo um formalismo teórico de classificação.

O aprimoramento dos sistemas ópticos de comunicações tem requerido o estudo de novas arquiteturas e protocolos com características particulares, o que permite vislumbrar, a curto prazo, o desenvolvimento de inúmeras novas pesquisas nessa área.

\subsection{Conclusões sobre a rede SCF}

Na rede SCF (Sistema Circular com Filas), proposta no capítulo 4, é necessário que o tempo de controle seja menor que o tempo de transmissão de um 
pacote. Se essa condição for satisfeita, a rede terá um desempenho altamente satisfatório, independentemente do seu tamanho e da taxa de transmissão utilizada.

A rede foi simulada como um sistema de ordem $\mathrm{NxN}$ e com consumidores ideais. Como caracteristicas de desempenho da rede, podem-se mencionar:

- Sistema com boa escalabilidade;

- Ausência de colisões;

- Tamanho de filas relativamente pequenos;

- Alto nível de vazão;

- Estabilização rápida;

- Tempo em fila proporcional ao tamanho da mesma;

- Alto nível de utilização da rede.

\subsection{Conclusões sobre a chave óptica de distribuição para Dataflow}

O capítulo 5 apresentou a proposta, simulação e análise de três chaves ópticas de distribuição, utilizadas em uma arquitetura Dataflow. Essas três chaves são descritas a seguir:

1. A primeira chave óptica proposta usa um único transmissor de $2,0 \mathrm{~Gb} / \mathrm{s}$ e mostrou-se ineficiente, pois a mesma não consegue fornecer fichas de dados para mais de duas Unidades-Processadoras, comprometendo fortemente o grau de paralelismo do sistema [Martins; Garcia Neto 1997].

2. A segunda chave óptica proposta possui quatro transmissores sintonizáveis e permite a transmissão de fichas para até oito Unidades-Processadoras, o 
que é considerado um número satisfatório para Dataflow. $\mathrm{O}$ comportamento da chave foi altamente satisfatório, mesmo quando $o$ tempo de sintonização dos transmissores varia de $1 \mathrm{~ns}$ a $100 \mathrm{~ns}$.

3. A terceira chave óptica proposta possui oito transmissores fixos e também mostrou um desempenho altamente satisfatório. Essa chave tem um transmissor para cada Unidade-Processadora, porém, não necessita de sintonização.

A análise dos resultados obtidos na simulação das duas ultimas chaves ópticas, propostas para a arquitetura Dataflow, permite concluir que é vantajosa a utilização de sistemas ópticos em arquiteturas paralelas e que o uso de componentes simples pode permitir o desenvolvimento de sistemas de alto desempenho.

\subsection{Conclusões sobre o simulador desenvolvido}

O simulador que foi desenvolvido especificamente para a rede SCF, e é apresentado no capítulo 4, foi facilmente adaptado para a simulação de três outros sistemas de redes ópticas. Esse programa foi implementado em módulos independentes que permitem a alteração de partes individuais do sistema, como o modelo de geração de pacotes, o controle de acesso ou o comportamento do sistema receptor.

A pouca necessidade de alterações viabiliza o uso desse programa como uma ferramenta de simulação de redes ópticas de comunicações 


\section{Capitulo 7}

\section{Trabalhos Futuros}

Este trabalho de doutorado tem o potencial de ser usado como base de outros trabalhos relacionados com o projeto e simulação de redes ópticas de interconexão. Esses trabalhos podem ser agrupados em três áreas básicas, que são a continuidade dos estudos da rede SCF, a continuidade dos estudos de redes ópticas em Dataflow e a simulação de redes ópticas. Essas três áreas são descritas a seguir.

\subsection{Continuidade dos estudos da rede SCF}

\subsubsection{Análise da rede SCF com diferentes modelos de geração de pacotes}

A rede SCF foi simulada com um modelo probabilístico de geração de pacotes, que é considerado eficiente para essa aplicação, porém, existem outros modelos matemáticos que poderiam ser testados para que posteriormente fosse feita uma analise comparativa entre os mesmos. 


\subsubsection{Projeto físico da rede SCF}

A rede proposta neste trabalho foi idealizada a partir de um modelo lógico de arquitetura, necessitando assim de um projeto fisico de engenharia. Neste trabalho devem ser analisados, entre outras coisas, os transmissores ópticos, os acopladores, os receptores ópticos, o tamanho e organização de memórias, técnicas de interfaceamento e os circuitos de controle exigidos.

\subsection{Continuidade dos estudos de redes ópticas em Dataflow}

\subsubsection{Incorporação das chaves ópticas de distribuição aos sistemas SAW e SEED}

Nesse caso a rotina que simula o controle de operação da chave óptica de distribuição deve ser transformado em uma rotina e incorporado ao simulador SAW ou ao simulador SEED. A partir daí o desempenho da arquitetura Dataflow seria analisado em função da chave óptica de distribuição 


\subsubsection{Desenvolvimento de uma chave óptica de coleta para a arquitetura Dataflow}

Conforme mostrado no capitulo 2, a arquitetura Dataflow, além da chave de distribuição, também necessita de uma segunda rede de interconexão que é chamada de chave de coleta, que permite of fluxo de dados entre as Unidades-Processadoras e o Módulo de Memória. Quanto menor for o número de Módulos de Memória, maior será o esforço exigido da chave, o que pode até mesmo inviabilizar a sua eficiência, assim, o desenvolvimento dessa chave pode exigir ajustes no próprio sistema Dataflow utilizado.

\subsubsection{Incorporação da chave óptica de coleta aos sistemas SAW e SEED}

Após o projeto, simulação e análise da chave óptica de coleta proposta no item 7.2.2, a mesma poderá ser incorporada a um sistema de simulação de arquitetura Dataflow, como o SAW e o SEED. Isto permitirá o estudo de sistemas Dataflow com chave de distribuição e chave de coleta totalmente ópticas.

\subsubsection{Projeto físico das chaves ópticas para Dataflow}

A exemplo do que foi proposto no item 7.1.2, as chaves ópticas de distribuição e coleta para a arquitetura Dataflow também necessitam de um projeto fisico de engenharia, analisando as características exigidas dos seus componentes e o seu modo operacional. 


\subsubsection{Análise de outras redes ópticas em Dataflow}

No item 7.2 foi proposta a simulação genérica de diversos modelos de redes opticas, que podem ser incorporadas aos ambientes SAW e SEED. Esses ambientes podem ter o seu comportamento analisado em função de diversas redes ópticas, permitindo uma análise comparativa entre as mesmas.

Um trabalho semelhante a essa proposta foi apresentado como dissertação de mestrado no IFSC-USP, porém no mesmo foram utilizadas exclusivamente redes elétricas de interconexão [Martini 1994]. A própria comparação entre os dois trabalhos seria interessante para a verificação de desempenho dos sistemas elétricos e ópticos em redes de interconexão aplicadas num sistema específico.

\subsection{Simulação de redes ópticas}

O simulador desenvolvido neste trabalho de doutorado simulou o sistema SCF e, com poucas alterações, foi adaptado para simular os três modelos de chaves ópticas de distribuição propostas no capitulo 5 .

Isto permite supor a possibilidade de utilização do simulador para uma análise de desempenho de diversos outros modelos de redes ópticas. Existem muitos modelos de redes WDM que poderiam ser simulados e comparados e, a partir desses dados, poderiam ser propostos novos modelos de redes ou mesmo alterações visando uma melhoria dos modelos já existentes.

Tendo em vista o grande número de possibilidades de sistemas a serem testados, pode-se esperar que essa área de projetos futuros seja muito promissora. 


\subsubsection{Simulação e análise de redes ópticas single-hop}

As redes single-hop permitem a comunicação óptica direta entre o transmissor e o receptor, sem nós intermediários, satisfazendo o conceito de rede transparente. Nesta proposta de trabalho futuro, diversos modelos de redes single-hop serão simulados e o seu desempenho comparado em função de parâmetros como a taxa de geração de dados, velocidade de sintonização e o número de canais WDM.

\subsubsection{Simulação e análise de redes ópticas multi-hop}

As redes multi-hop fazem a comunicação utilizando-se de nós intermediários. Isto contraria o princípio de redes transparentes, porém evita a necessidade de dispositivos sintonizáveis e permite implementações virtuais. Uma proposta é a simulação e análise de diversos modelos de arquiteturas virtuais WDM. Uma outra alternativa de trabalho futuro com as redes single-hop é o estudo de reconfigurações dinâmicas.

\subsubsection{Simulação de redes WDM de grupos}

Os multiplexadores WDM possuem um número limitado de canais, o que limita a sua escalabilidade. Uma proposta de trabalho futuro é um estudo, simulação e análise de arquiteturas que agrupam os nós em conjuntos e dividem os canais WDM entre os conjuntos, o que pode permitir um aumento da escalabilidade. Outra forma 
alternativa de aumento de escalabilidade é o uso de mais de um WDM. Essas técnicas exigem um projeto de arquiteturas e protocolos específicos.

Originariamente, o próprio sistema óptico para Dataflow utilizado nesta tese de doutorado foi idealizado com a técnica de grupos [Cavenaghi et al 1996], o que foi posteriormente descartado quando verificou-se que determinados sistemas Dataflow podem operar eficientemente com cerca de oito Unidades-Processadoras. 


\section{Bibliografia}

AE, Tadashi. Optical Interconnection For Parallel Data Processing. Optoeletronics Devices and Technologies, V. 9, N. 1, P. 15-28, Março, 1994.

ALLOCCA, John A.; STUART, Allen. Transducers - Theory \& Applications. Reston Publishing Company, INC. Reston, Virginia, EUA, 1984.

ALY, Khaled A.; DOWD, Patrick W. Multi-Domain WDM Network Structures For Large-Scale Reconfigurable Partionable Parallel Computer Architecture. Proceedings of the SPIE, V. 1784, P. 181-192, 1993.

ARTHURS, E.; COOPER, J.M.; GOODMAN, M.S.; KOBRINSKI H.; TUR, M.; VECCHI M.P.; Multiwavelength Optical Crossconnect For Parallel-Processing Computers. Electronics Letters, V.21, N.2, P. 119-120, 21 de Janeiro de 1988.

ARTHURS, E.; COOPER, J.M.; GOODMAN, M.S.; KOBRINSKI H.; VECCHI M.P.; HYPASS: An optoeletronic hybrid packet-switching system. IEEE Journal on Selected areas in Communications, V. 6, P. 1500-1510, 1988-b

AUERBACH, J.; PANKAJ, R. Use os Delegated Tuning and Forwarding in Wavelength Division Multiple Acess Network. IEEE Transaction on Communications, V. 43, N. 1, Janeiro, 1995.

BHUYAN, Laxmi N.; "Interconnection Networks for Parallel and Distributed Processing". IEEE Computer - P. 9-12, Junho, 1987

BHUYAN Laxmi N.; YANG, Qing; AGRAWAL, Dharma.P.; Performance of Multiprocessor Interconnection Networks. IEEE Computer, V.22, N.2, P. 25-37, Fevereiro de 1989

BLUMENTHAL, Daniel J.; SHELL, Michael; VAUGHN, M. D. Physical Limitations to Scalability of WDM All-Optical Networks. Optics \& Photonics News. V. 8, n. 2, P. 17-22, Fevereiro de 1997.

BOGINENI, K.; DOWD, P.W. A collisionless multiple acess protocol for wavelength division multiplexed star-coupled configuration: Architecture an performance analysis. IEEE J. Ligthwave Tecnhology, V. 10, n. 11, 1992.

BORELLA, Michael; MUKERJEE, Biswanath.; JIA, F.; RAMAMURTHY, S.; BANERJEE, D.; INESS, J. Optical Interconnects For Multiprocessor Architectures Using Wavelength-Division Multiplexing. Proceedings of the Twenty-Seventh Annual Hawaii Internationsl Conference on System Sciences, P. 499-508, 1994.

BORGO, C. A.; CELASCHI, S. Isoladores Ópticos: Principios e Aplicações. Revista Telebrás. V. 19, n. 63, Julho de 1996. 
BRACKETT, Charles.A.; Dense Wavelength Division Multiplexing Networks: Priciples and Apllications. IEEE Joumal on Selected areas in Communications. V.8, n.6, P. 948-964, Agosto de 1990.

BRONSON, Richard. Pesquisa operacional. São Paulo, McGraw-Hill - 1985

BUTZER, D. C.; CLYMER, B. D.; ANDERSON, B. L. Highly Efficient Interconnection For Use With a Multistage Optical Switching Network With Orthogonally Polarized Data and Address Information. Applied Optics, V. 34, N. 11, P. 1788-1800, 10 de abril de 1995.

CASTRO, Lauro Sodré Viveiros. Pontos de Estatística. Rio de Janeiro, Editôra Científica, 1967. Cap. 9, p.121-130.

CAVENAGHI, M.A.; SPOLON R.; MARTINS, João E. M. Perea; DOMINGUES, S.G; GARCIA NETO, A. Using PVM in the Simulation of a Hybrid Dataflow Architecture. Third Euroipean Parallel Virtual Machine - EuroPVM'96 Proceedings, P. 343-346. 7-9 de outubro de 1996. Munique, Alemanha.

CAVENAGHI, Marcos Antônio. Implementação e estudo da arquitetura a fluxo de dados WOLF. Tese de doutorado. IFSC-USP, São Carlos/SP, 1997.

CHIARULLI, Donald M., et al. Multiprocessor Interconnection Networks Using Partioned Optical Passive Star (POPS) Topologies and Distributed Control. International Workshop On Massively Parallel Processing Using Optical Interconnections, 1. Proceedings. P. 70-80, 1994.

DAVIES, Ruth M.; O'KEEFE, Robert, M. Simulation modeling with pascal. Hertfordshine-UK, Prentice Hall International, 1989.

DENNING, Peter J. Queueing in network of computers. American Scientist, v.79, p.206-209, Maio-Junho de 1991-a.

DENNING, Peter J. In the queue: Mean values. American Scientist, v.79, p.402-403, Setembro-Outubro de 1991-b

DUNCAN, Ralph. A Survey of Parallel Computer Architectures. IEEE Computer, P. 5-16, Fevereiro de 1990.

EDWARDS, Terry. Fiber-optic systems - Network Apllications. John Wiley \& Sons - 1989

ERDOGAN, Turan; MIZRAHI, Victor. Fiber Phase Gratings Reflect Advances in Lightwave Technology. Laser Focus World, V.30, No 2, P. 73-80, Fevereiro de 1994

ESCOBAR, E. Hector. All-Optical Switching Systems Near Practical Use. Laser Focus World, V. 30, No 10, P. 135-141, Outubro de 1994. 
FLYNN, M.J. Very High Speed Computing Systems. Proc. IEEE. V. 54, P. 19011909, Dezembro de 1966.

GHOSE, Kanad; SINGHVI, N. K.; HORSELL, R. K. The Role of WDM Optical Interconnections in a Distributed Shared Memory Multiprocessor. Proceedings of the SPIE, V. 1849, P. 184-195, 1993.

GHOSE, Kanad. Performance Potential Of An Optical Fiber Bus Using Wavelength Division Multiplexing. Proceedings of the SPIE, V. 1849, P. 172-183, 1993.

GHOSE, Kanad. OPTIMUL: A Hybrid Multiprocessor for Distributed and Shared Memory Multiprocessing With WDM Optical Fiber Interconnections. 6th International Parallel Architectures and Languages Europe Conference (PARLE), Proceedings P. 238-249, Atenas/Grécia, Julho de 1994.

GIOZZA, W.P.; EVANDRO, C.; WALDMAM H. Fibras Oticas -Tecnologia e Projeto de Sistemas. Makron Books-Embratel - São Paulo/SP, 1991.

GREEN Jr., Paul E. Toward Customer-Useable All-Optical Networks. IEEE Communications Magazine, V. 32, N. 12, P. 44-49, Dezembro de 1994.

GUHA, Aloke, et al. Optical Interconnections for Massively Parallel Archiotectures. Applied Optics, V. 29, N. 8, P. 1077-1092, 10 de março de 1990.

GUIZANI, M. Picosecond Multistage Interconnection Network Architecture for Optical Computing.Applied Optics. V. 33, N. 8, P. 1587-1599, 10 de março de 1994.

GUIZANI, M.; ANDIJANI A. Simulation of an Optical Architeture for High Speed Multistage Interconnection Networks. Simulation, 64:1, P. 27-33, Janeiro de 1995.

HALLIDAY, David; RESNICK, Robert. Física - V.4. Livros Técnicos e Científicos Editora, Rio de Janeiro, 1980.

Hwang, Kai; Briggs, Fayé A. Computer Architecture and Parallel Processing. McGraw-Hill. 1985.

HECHT, Jeff. Entendendo Fibras Óticas. Tradução de Roberto R. Tavares. Berkeley Brasil Editora, Rio de Janeiro/RJ, 1993.

HELD, Gilbert. Local area network performance - Issues and answers. New York USA, John Willey \& Sons, 1994.

HICKS, James; CHIOU, Derek; ANG, Boon Seong; ARVING. Performance Studies of Id on the Monsoon Dataflow System. Journal of Parallel and Distributed Computing, 18, P. 273-300, 1993.

HIGGINS, Thomas V. Creating Laser Light. Laser Focus World, V. 30, Nº 6, P. 127133, Junho de 1994. 
HIGGINS, Thomas V. The Smaller, Cheaper, Faster World Of The Laser Diode. Laser Focus World, V. 31, No 4, P. 65-76, Abril de 1995.

HIRABAYASHI, Katsuhiko; TSUDA, H.; KUROKAWA, T. Tunable Liquid-Crystal Fabry-Perot Interferometer Filter for Wavelength-Division Multiplexing Communication Systems. IEEE Journal of Lightwave Technology. V. 11, N. 12, Dezembro de 1993.

HUSBANDS, Charles R.; METCALF, Bruce D. A Portable Fiber Optic Local Area Network. IEEE Journal on Selectes Areas in Communications. N. 6, P.882-889, Novembro de 1985.

IIDA, Masonori; ASAKURA, Hiroyuki. A Computer Controlled Narrow Bandpass Optical Tunable Filter Using a Fourier Diffraction Grating in the Range of 1.3-1.5 $\mu \mathrm{m}$. IEEE Journal of Lightwave Technology. V. 13, N. 12, Dezembro de 1995.

ISSACS, Alan; PITT, Valerie. Física. Edições Melhoramentos - Editora da USP - São Paulo, 1979.

JAJSZCZKY, Andrzej; MONFTAH, H. T. Tree-Type Photonic Switching Networks. IEEE Network, V. 9, N. 1, P.10-16, Janeiro/Fevereiro de 1995.

JANOSKA, M. W.; TODD, T. D. A Simplified Optical Star Network Using Distributed Channel Controllers. IEEE Journal of Lightwave Technology, V. 12, N. 11, Novembro de 1994.

KAO, K. Charles. Optical Fiber Systems: Technology, Design, and Applications. McGraw-hill - International Editions, 1986.

KAZOVSKY, Leonid G.; FONG, T.; HOFMEISTER, T. Optical Local Area Network Technologies. IEEE Communications Magazine. V. 32, n. 12, Dezembro de 1994.

KOBAYASHI, Hisashi. Modeling and Analysis - An introduction to system performance evaluation methodology. Addison - Wesley Publishing Company, 1978.

KOSTRYUKOV, V. A.; TORCHIGIN, V. P. Optical Multiprocessor Data-Flow Computer System. Optoeletronics, Instrumentation and Data Processing. N. 2, P. 3-10, 1992.

LACROIX, Yves; Vella, Paul. How to optimize the performance of fiberoptic amplifiers. Laser Focus World. V. 31, n. 1, Janeiro de 1995.

LEE, Ben; HURSON, A. R. Dataflow Architectures and Multithreading. IEEE Computer. V. 27, N. 8, P.27-39, Agosto de 1994.

LI, Tingye. Advances in Optical Fiber Communications: An Historical Perspective. IEEE Journal on Selectes Areas in Communications. V.1, N. 3, P.356-372, Abril de 1983. 
LOURAL, Claudio de Almeida; FURTADO, Mario Tosi. Interconexões Ópticas: Conceitos e Aplicações. Revista Telebrás - Edição Tecnologia V. 18, N.61, P.94-129, Setembro de 1994.

LOURAL, Claudio de Almeida. Fotônica: Uma Tecnologia Estratégica Para As Telecomunicações. Revista Telebrás, V.18, N.62, P. 91-99, Dezembro de 1994.

LOURI, Ahmed. A Preliminary Version of an Optical Data-Flow Architecture. Proceedings od the Hawaii International Conference on System Sciences, $23 \mathrm{rd}, \mathrm{P}$. 121-130, 1990.

LOURI, Ahmed; Na, Jongwhoa. Modeling ad simulating methodology for digital optical computing systems. Applied Optics, v.33, n.8, p.1549-1558, 10 de março de 1994.

MACEDO, Horácio. Dicionário de Física, Nova Fronteira, , Rio de Janeiro/RJ,1976.

MAGNA, Patrícia. Proposta e Simulação de uma Arquitetura a Fluxo de Dados de Segunda Geração. Tese de Doutorado, IFSC-USP - São Carlos/SP, 1997.

MARTINI, J. Angelo. Estudo do Desempenho de Redes de Interconexão Para a Arquitetura a Fluxo de Dados Proto-WOLF. Dissertação de mestrado, IFSC-USP São Carlos/SP, 1994

MARTINS, João E. M. Perea, GARCiA NeTO, A. An Optical Distributing Network for Dataflow Computer Architecture. Symposium on Lasers and Their Applications, Proceedings. P. 232-235, 3-5 de dezembro de 1997. Campinas-SPBrasil.

McAULAY, Alastair D. Optical Interconnection Slab Based Static Dataflow Computer. Optical Computing Topical Meeting, V. 7, P. 1890-183, Março de 1993.

MacDOUGALL, M. H. Simulating Computer Systems - Techniques and Tools MIT Press, 1989.

MIKI, Tetsuya. The Potential of Photonic Networks. IEEE Communications Magazine, V. 32, No 12, Dezembro de 1994.

MONTEIRO, Mário A. Introdução à Organização de Computadores. Livros Técnicos e Científicos Editora. Rio de Jeneiro, 1992.

MORIOKA, T.; MORI, K.; KAWANISH, S.; SARUWATARI, M. Multi-WDMChannel, Gbit/s Pulse Generation from a Single Laser Source Utilizing LD-Pumped Supercontinuum in Optical Fibers. IEEE Photonics Technology Letters. V.6, N.3, P.365-368, Março de 1994.

MUKHERJEE, B. WDM-Based Local Networks. Part I: Single-Hop Systems. IEEE Network., V. 6, N. 3, P. 12-26, Maio de 1992. 
MUKHERJEE, B. WDM-Based Local Networks. Part II: Multihop Systems. IEEE Network, V. 6, N. 4, P. 20-32, Julho de 1992.

NAYLOR, Thomas H. et al. Técnicas de simulação em computadores. Rio de Janeiro, Vozes, 1971.

NELSON, W. H.; CHOUDHURY, A.N.M.M., LACOURSE, Joanne S. Optical Switching Expands Communications-Network Capacity. Laser Focus World, V.30, N 6, P. S17-S-20, Junho de 1994.

NOSU, Kiyoshi; TOBA, H.; INOUE, K.; ODA K. 100 Channel Optical FDM Techology and its Applications to Optical FDM Channel-Based Networks. IEEE Journal of Lightwave Technology. V. 11, N. 5/6, maio/junho de 1993.

ONDRIS-CRAWFORD, Renate; GRAWFORD, Gregory p. ; DOANE, J. William. The Phase of the Future. The Physics Teacher, v. 30, n.6, p. 332-339, Setembro, 1992.

PAN, J.J.; LIANG, Frank. Optoeletronic Components Make WDM Networks Practical. Laser Focus World, V. 30, No 1, P. 111-115, Janeiro de 1995

PARTRIDGE, Craig. Gigabit Networking - Addison-Wesley Publishing company, Inc - EUA, 1994.

PERSONICK, Stewart D. Review of Fundamentals of Optical Fiber Systems. IEEE Journal on Selectes Areas in Communications. V.1, N. 3, P.373-380, Abril de 1983.

POUNTAIN, Dick; BRYAN, John. All Systems Go. Byte, V.17, N.8, P. 112-136, Agosto de 1992.

REFI, James J. Novel Fiber Designs Fulfill Information Superhighway Needs. Laser Focus World, V.30, N 6, P. S5-S7, Junho de 1994

ROBINSON, S.M.; SPANDINGER, N. Optical Couplers Route Signals CostEffectively. Laser Focus World, V. 30, No 6, P. S29-S34, Junho de 1994.

SARUWATORI, Masatoshi. All-Optical Signal Processing in Ultrahigh-Speed Optical Transmission. IEEE Communication Magazine. Setembro de 1994.

SAWCHUK, A. A.; JENKINS, B. K.; RAGHAVENDRA, C.S.; VARMA, A. Optical Crossbar Networks. IEEE Computer, P. 50-60, Junho de 1987.

SAUER, Charles H.; CHANDY, K. Mani. Computer sytems performance modeling. Prentice-Hall, New Jersey - USA, 1981.

SCHOLL, Frederick; CODEN, Michael H. Passive Optical Star Systems for Fiber Optic Local Area Networks. IEEE Journal on Selectes Areas in Communications. V.6, N.6, P. 913-923, Julho de 1988. 
SOARES, Luis F. Gomes; LEMOS, G.; COLCHER, S. Redes de Computadores: Das LANs, MANs e WANs às Redes ATM. Editora Campus, Rio de Janeiro/RJ, 1995.

SOOLE, Juliam B. D.; ZAH, Chung-En. Multiwavelength Semiconductor Laser Advance Rapidly. Laser Focus World, V. 30, No 6, P. S9-S15, Junho de 1994.

SPIRIT, Dave M.; ELLIS, Andrew D.; BARNSLEY, Pete E. Optical Time Division

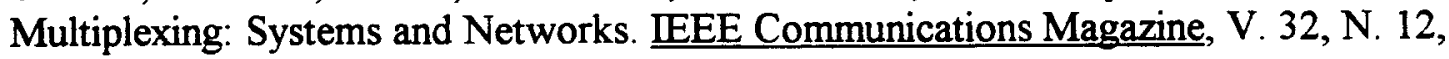
P. 56-62, Dezembro de 1994.

SUDHAKER, G.N.M.; KAVEHRAD, M.; GEORGANAS, N.D. Acess Protocol for Passive Star Networks. Computer Network and ISND Systems. V. 26, N. 6-8, 1994.

TABINI, Ricardo; NUNES, Denizard. Fibras Ópticas. Editora Érica, São Paulo, 1990.

TANEMBAUM, Andrew S. Computer Network. Prentice-Hall International. EUA, 1988

TANEMBAUM, Andrew S. Modern Operating Systems. Prentice-Hall International Editions. USA, 1992.

VETTER, Ronald J.; DU, David H. C. Distributed Computing With High-Speed Optical Networks. IEEE Computer, P. 8-18, Fevereiro de 1993.

YOUN, Hee Young; CHEN, Calvin Ching-Yuen. A Comprehensive Performance Evaluation of Crossbar Networks. IEEE Transactions on Parallel and Distributed Systems. V. 4, N.5, Maio de 1993

WAGNER, Stuart S.; KOBRINSKI, Haim. WDM Applications in Broadband Telecommunications Networks. IEEE Communications Magazine. P.22-30, Março de 1989

WATERSON, C.; JENKINS, B. K. Shared-Memory Optical/Electronic Computer: Architecture and Control. Applied Optics, V. 33, N. 8, P. 1559-1574, 10 de março de 1994.

WILLNER, Alan Eli. Mining the Optical Bandwidth for a Terabit per second. IEEE Spectrum. V. 34, N. 4, Abril de 1997.

ZAKIR Jr, José. Rede Locais - O Estudo de Seus Elementos. Livros Técnicos e Científicos Ltda. Rio de Janeiro, 1988. 